Treatment of severe ankle sprain: a pragmatic randomised controlled trial comparing the clinical effectiveness and cost-effectiveness of three types of mechanical ankle support with tubular bandage. The CAST trial

MW Cooke, JL Marsh, M Clark, R Nakash, RM Jarvis, JL Hutton, A Szczepura, S Wilson and SE Lamb, on behalf of the CAST trial group $\equiv$

Health Technology Assessment NIHR HTA Programme www.hta.ac.uk 


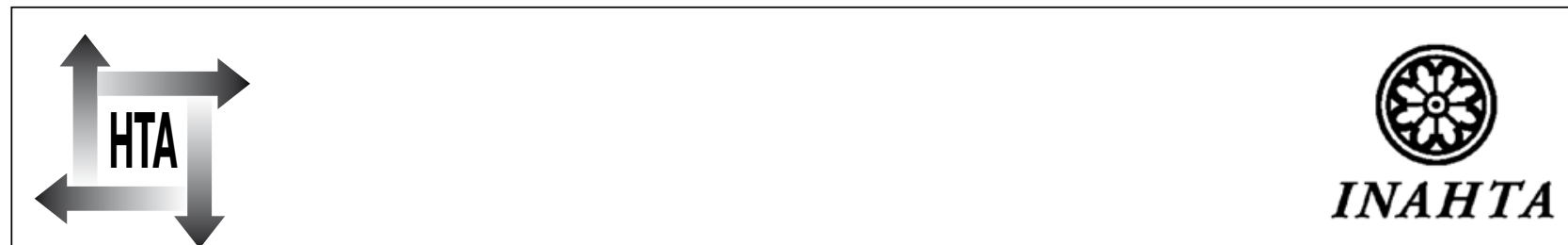

How to obtain copies of this and other HTA Programme reports.

An electronic version of this publication, in Adobe Acrobat format, is available for downloading free of charge for personal use from the HTA website (www.hta.ac.uk). A fully searchable CD-ROM is also available (see below).

Printed copies of HTA monographs cost $£ 20$ each (post and packing free in the UK) to both public and private sector purchasers from our Despatch Agents.

Non-UK purchasers will have to pay a small fee for post and packing. For European countries the cost is $\notin 2$ per monograph and for the rest of the world $£ 3$ per monograph.

You can order HTA monographs from our Despatch Agents:

- fax (with credit card or official purchase order)

- post (with credit card or official purchase order or cheque)

- phone during office hours (credit card only).

Additionally the HTA website allows you either to pay securely by credit card or to print out your order and then post or fax it.

\section{Contact details are as follows:}

HTA Despatch Email: orders@hta.ac.uk

c/o Direct Mail Works Ltd Tel: 02392492000

4 Oakwood Business Centre Fax: 02392478555

Downley, HAVANT PO9 2NP, UK $\quad$ Fax from outside the UK: +442392478 555

$\mathrm{NHS}$ libraries can subscribe free of charge. Public libraries can subscribe at a very reduced cost of $£ 100$ for each volume (normally comprising 30-40 titles). The commercial subscription rate is $£ 300$ per volume. Please see our website for details. Subscriptions can be purchased only for the current or forthcoming volume.

\section{Payment methods}

Paying by cheque

If you pay by cheque, the cheque must be in pounds sterling, made payable to Direct Mail Works Ltd and drawn on a bank with a UK address.

Paying by credit card

The following cards are accepted by phone, fax, post or via the website ordering pages: Delta, Eurocard, Mastercard, Solo, Switch and Visa. We advise against sending credit card details in a plain email.

Paying by official purchase order

You can post or fax these, but they must be from public bodies (i.e. NHS or universities) within the UK. We cannot at present accept purchase orders from commercial companies or from outside the UK.

\section{How do I get a copy of HTA on CD?}

Please use the form on the HTA website (www.hta.ac.uk/htacd.htm). Or contact Direct Mail Works (see contact details above) by email, post, fax or phone. HTA on CD is currently free of charge worldwide.

The website also provides information about the HTA Programme and lists the membership of the various committees. 


\title{
Treatment of severe ankle sprain: a pragmatic randomised controlled trial comparing the clinical effectiveness and cost-effectiveness of three types of mechanical ankle support with tubular bandage. The CAST trial
}

\author{
MW Cooke, , ${ }^{*}$ JL Marsh, ${ }^{2}$ M Clark, ${ }^{\prime}$ \\ R Nakash,' RM Jarvis, ' JL Hutton, ${ }^{2}$ \\ A Szczepura,' S Wilson ${ }^{3}$ and SE Lamb,' \\ on behalf of the CAST trial group
}

'Warwick Medical School, University of Warwick, UK

${ }^{2}$ Department of Statistics, University of Warwick, UK

${ }^{3}$ The Medical School, University of Birmingham, UK

*Corresponding author

Declared competing interests of authors: none

Published February 2009

DOI: $10.3310 /$ htal 3130

This report should be referenced as follows:

Cooke MW, Marsh JL, Clark M, Nakash R, Jarvis RM, Hutton JL, et al., on behalf of the CAST trial group. Treatment of severe ankle sprain: a pragmatic randomised controlled trial comparing the clinical effectiveness and cost-effectiveness of three types of mechanical ankle support with tubular bandage. The CAST trial. Health Technol Assess 2009; I3( I 3).

Health Technology Assessment is indexed and abstracted in Index Medicus/MEDLINE, Excerpta Medica/EMBASE, Science Citation Index Expanded $\left(\right.$ SciSearch $\left.{ }^{\circledR}\right)$ and Current Contents ${ }^{\circledR} /$ Clinical Medicine. 


\section{NIHR Health Technology Assessment Programme}

$\mathrm{T}$ he Health Technology Assessment (HTA) Programme, part of the National Institute for Health Research (NIHR), was set up in 1993. It produces high-quality research information on the effectiveness, costs and broader impact of health technologies for those who use, manage and provide care in the NHS. 'Health technologies' are broadly defined as all interventions used to promote health, prevent and treat disease, and improve rehabilitation and long-term care.

The research findings from the HTA Programme directly influence decision-making bodies such as the National Institute for Health and Clinical Excellence (NICE) and the National Screening Committee (NSC). HTA findings also help to improve the quality of clinical practice in the NHS indirectly in that they form a key component of the 'National Knowledge Service'.

The HTA Programme is needs led in that it fills gaps in the evidence needed by the NHS. There are three routes to the start of projects.

First is the commissioned route. Suggestions for research are actively sought from people working in the NHS, from the public and consumer groups and from professional bodies such as royal colleges and NHS trusts. These suggestions are carefully prioritised by panels of independent experts (including NHS service users). The HTA Programme then commissions the research by competitive tender.

Second, the HTA Programme provides grants for clinical trials for researchers who identify research questions. These are assessed for importance to patients and the NHS, and scientific rigour.

Third, through its Technology Assessment Report (TAR) call-off contract, the HTA Programme commissions bespoke reports, principally for NICE, but also for other policy-makers. TARs bring together evidence on the value of specific technologies.

Some HTA research projects, including TARs, may take only months, others need several years. They can cost from as little as $£ 40,000$ to over $£ 1$ million, and may involve synthesising existing evidence, undertaking a trial, or other research collecting new data to answer a research problem.

The final reports from HTA projects are peer reviewed by a number of independent expert referees before publication in the widely read journal series Health Technology Assessment.

\section{Criteria for inclusion in the HTA journal series}

Reports are published in the HTA journal series if (1) they have resulted from work for the HTA

Programme, and (2) they are of a sufficiently high scientific quality as assessed by the referees and editors.

Reviews in Health Technology Assessment are termed 'systematic' when the account of the search, appraisal and synthesis methods (to minimise biases and random errors) would, in theory, permit the replication of the review by others.

The research reported in this issue of the journal was commissioned by the HTA Programme as project number 01/14/10. The contractual start date was in November 2002. The draft report began editorial review in July 2006 and was accepted for publication in July 2007. As the funder, by devising a commissioning brief, the HTA Programme specified the research question and study design. The authors have been wholly responsible for all data collection, analysis and interpretation, and for writing up their work. The HTA editors and publisher have tried to ensure the accuracy of the authors' report and would like to thank the referees for their constructive comments on the draft document. However, they do not accept liability for damages or losses arising from material published in this report.

The views expressed in this publication are those of the authors and not necessarily those of the HTA Programme or the Department of Health.

Editor-in-Chief:

Series Editors:
Professor Tom Walley

Dr Aileen Clarke, Dr Peter Davidson, Dr Chris Hyde, Dr John Powell, Dr Rob Riemsma and Professor Ken Stein

This monograph may be freely reproduced for the purposes of private research and study and may be included in professional journals provided that suitable acknowledgement is made and the reproduction is not associated with any form of advertising.

Applications for commercial reproduction should be addressed to: NCCHTA, Alpha House, Enterprise Road, Southampton Science Park, Chilworth, Southampton SOI6 7NS, UK.

Published by Prepress Projects Ltd, Perth, Scotland (www.prepress-projects.co.uk), on behalf of NCCHTA.

Printed on acid-free paper in the UK by the Charlesworth Group. 


\title{
Abstract
}

\section{Treatment of severe ankle sprain: a pragmatic randomised controlled trial comparing the clinical effectiveness and cost-effectiveness of three types of mechanical ankle support with tubular bandage. The CAST trial}

\author{
MW Cooke, ${ }^{\prime *} J L$ Marsh, ${ }^{2}$ M Clark,' R Nakash,' RM Jarvis,' JL Hutton, ${ }^{2}$ \\ A Szczepura,' S Wilson ${ }^{3}$ and SE Lamb,' on behalf of the CAST trial group
}

\begin{abstract}
'Warwick Medical School, University of Warwick, UK ${ }^{2}$ Department of Statistics, University of Warwick, UK

${ }^{3}$ The Medical School, University of Birmingham, UK
\end{abstract}

*Corresponding author

Objective: To estimate the clinical effectiveness and cost-effectiveness of three methods of ankle support compared with double layer tubular compression bandage.

Design: A randomised controlled trial, designed to reflect practice in UK hospital emergency departments. Setting: Eight emergency departments in England. Participants: Aged I6 or over with acute severe ankle sprain, unable to weight bear, no fracture.

Interventions: 584 participants were randomised to one of four treatment arms: tubular bandage, below knee cast, Aircast ${ }^{\circledR}$ ankle brace or Bledsoe ${ }^{\circledR}$ boot, all applied 2-3 days after presentation to allow swelling to resolve.

Main outcome measures: Response to treatment was assessed using the Foot and Ankle Outcome Score and generic measures (Functional Limitations Profile, SF- 12 and EQ-5D).

Results: When adjusted for age, sex and baseline scores, the below knee cast offered a small but statistically significant benefit at 4 weeks in terms of pain (FAOS pain difference 5.1; 95\% Cl 0.4-9.8), foot- and ankle-related quality of life (QoL) (FAOS QoL difference 5.9; $95 \% \mathrm{Cl} \mathrm{0.I-I} \mathrm{I.8)} \mathrm{and} \mathrm{the} \mathrm{physical} \mathrm{component} \mathrm{of}$ the SF-I 2 (SF-I 2 score difference 2.2; 95\% Cl 0.0-4.4). Neither the Aircast brace nor the Bledsoe boot was statistically or clinically better. At 12 weeks the below knee cast was significantly better than tubular bandage in terms of pain (FAOS pain difference $5.1 ; 95 \% \mathrm{Cl}$
$0.3-10.0)$, activities of daily living (FAOS ADL difference $3.5 ; 95 \% \mathrm{Cl} 0.4-6.6$ ), sports (FAOS sports difference 8.7; 95\% Cl I.6-15.7) and QoL (FAOS QoL difference 8.7; $95 \% \mathrm{Cl} 2.4-15.0$ ), and the Aircast brace was better only in terms of ankle-related QoL and mental health. The Bledsoe boot conferred no significant advantage over tubular bandage. By 9 months there were no significant differences. Based on mean direct healthcare costs per participant, the Bledsoe boot was the most expensive $(£ 215)$ and tubular bandage the least so ( $£ \mid .44)$. Inclusion of indirect costs (sick leave) raised overall costs substantially and removed any significant differences between the therapies. Cost-utility analysis demonstrated that the Aircast brace $[£ 30$ I per qualityadjusted life-year (QALY)] and below knee cast ( $£ 339$ per QALY) were more cost-effective than the Bledsoe boot ( $£ 2116$ per QALY). However, inclusion of indirect costs produced different rank orders, depending on the assumptions made, and results should be treated with caution.

Conclusions: The below knee cast and the Aircast brace offered cost-effective alternatives to tubular bandage for acute severe ankle sprain, the former having the advantage in terms of overall recovery at 3 months. As there were no differences in long-term outcome, practitioners should consider likely compliance and acceptability to patients when choosing a brace. Trial registration: Current Controlled Trials ISRCTN37807450. 



\section{Contents}

List of abbreviations

Executive summary

vii

ix

I Introduction

Background

Classification of ankle sprains

Review of treatment of ankle sprains

Context of the CAST trial

Rationale for the CAST trial

2 Methods

Trial design

Method of application

Objectives

Participants

Trial procedure

Pilot study

3 Results

Sample characteristics

Randomisation

Baseline injury characteristics

Data collection and completeness of follow-up

Adverse events and serious adverse events

Recovery and estimates of treatment effectiveness

Self-reported benefit

Analysis of treatment uptake

Sensitivity analysis

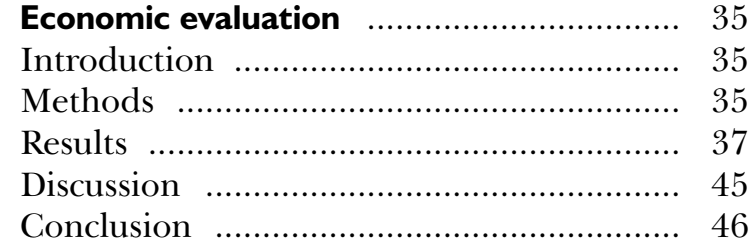

5 Acceptability of a deposit system ........... 47

Introduction ............................................ 47

Method ........................................... 47

Participants ...................................... 47

Results ................................................. 47

Conclusion ….......................................... 48
6 Discussion ............... 49

Main findings of the trial ........................ 49

External validity and generalisability of the findings ...................................... 49

Internal validity and limitations of the trial

Clinical findings .................................... 51

Cost and economic analysis ................... 52

7 Conclusions ........................................ 55

Implications for health care .................. 55

8 Recommendations for future research .... 57

Acknowledgements ............................... 59

References ......................................... 61

Appendix I Search strategy for literature reviews …........................................ 67

Appendix 2 Ankle injury proforma ........ 69



Appendix 4 Patient information sheet ..... 73

Appendix 5 Advice to participants prior to trial clinic

Appendix 6 Consent form

Appendix 7 Pre-randomisation eligibility form

Appendix 8 Background information ...... 83

Appendix 9 Challenges of recruitment .... 87

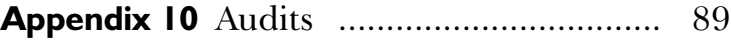

Appendix I I Ankle support instructions to participants

Appendix 12 Resource use questionnaire 
Appendix I3 Results tables

Appendix 14 Methods of derivation of individual costs

Appendix 15 Cost-utility analysis results .. 111
Appendix 16 Scattergrams

Health Technology Assessment reports published to date

Health Technology Assessment

Programme 


\section{List of abbreviations}

\begin{tabular}{|c|c|c|c|}
\hline $\mathrm{ADL}$ & activities of daily living & GCSE & $\begin{array}{l}\text { General Certificate of } \\
\text { Secondary Education }\end{array}$ \\
\hline ANCOVA & analysis of covariance & & \\
\hline APS & Ankle Performance Scale & \multirow{2}{*}{$\begin{array}{l}\text { HRQoL } \\
\text { ICER }\end{array}$} & health-related quality of life \\
\hline BMI & body mass index & & $\begin{array}{l}\text { incremental cost-effectiveness } \\
\text { ratio }\end{array}$ \\
\hline $\mathrm{BNF}$ & British National Formulary & MRI & magnetic resonance imaging \\
\hline CAST & $\begin{array}{l}\text { Collaborative Ankle Support } \\
\text { Trial }\end{array}$ & NICE & $\begin{array}{l}\text { National Institute for Health } \\
\text { and Clinical Excellence }\end{array}$ \\
\hline CEAC & $\begin{array}{l}\text { cost-effectiveness acceptability } \\
\text { curve }\end{array}$ & QALY & quality-adjusted life-year \\
\hline $\mathrm{CI}$ & confidence interval & QoL & quality of life \\
\hline CT & computerised tomography & RCT & randomised controlled trial \\
\hline DMEC & $\begin{array}{l}\text { Data Monitoring And Ethics } \\
\text { Committee }\end{array}$ & $\begin{array}{l}\mathrm{RR} \\
\mathrm{SF}-12\end{array}$ & $\begin{array}{l}\text { relative risk } \\
\text { short form questionnaire with } \\
12 \text { items }\end{array}$ \\
\hline $\begin{array}{l}\text { DVT } \\
\text { EQ-5D }\end{array}$ & $\begin{array}{l}\text { deep vein thrombosis } \\
\text { EuroQol } 5 \text { dimensions }\end{array}$ & SF-36 & $\begin{array}{l}\text { short form questionnaire with } \\
36 \text { items }\end{array}$ \\
\hline FAOS & Foot and Ankle Outcome Score & TSC & Trial Steering Committee \\
\hline FLP & Functional Limitations Profile & VAS & visual analogue scale \\
\hline $\begin{array}{l}\text { All abbrevi } \\
\text { known }(\mathrm{e} . \mathrm{g} \\
\text { figures/tabl } \\
\text { notes at the }\end{array}$ & $\begin{array}{l}\text { ons that have been used in this re } \\
\text { IHS), or it has been used only on } \\
\text { appendices, in which case the ab } \\
\text { nd of the table. }\end{array}$ & $\begin{array}{l}\text { re listed he } \\
\mathrm{t} \text { is a non- } \\
\text { ion is defi }\end{array}$ & $\begin{array}{l}\text { unless the abbreviation is well } \\
\text { dard abbreviation used only in } \\
\text { in the figure legend or in the }\end{array}$ \\
\hline
\end{tabular}





\section{. \\ Executive summary}

\section{Background}

The optimal treatment for severe ankle sprains is unclear. Potential treatments include no intervention, physiotherapy, different types of supports, immobilisation and surgical repair of the ligaments. Recent systematic reviews highlight a lack of good-quality evidence to aid clinical decision-making. There is a need for wellconducted and adequately powered randomised controlled trials of the effectiveness of different clinical approaches.

\section{Objectives}

Objectives were, first, to estimate the clinical effectiveness of three different methods of ankle support [below knee cast, Aircast ${ }^{\circledR}$ ankle brace (DJO Incorporated, Vista, CA) and Bledsoe ${ }^{\circledR}$ boot (Bledsoe Boot Systems, Grand Prairie, TX)] in comparison with double layer tubular compression bandage in terms of recovery of function (primary outcome), recovery of normal occupation (secondary outcome) and avoidance of residual symptoms including recurrent instability, lasting limitation of physical activity and need for further medical, rehabilitation or surgical treatment (secondary outcomes); and, second, to measure the cost-effectiveness of each strategy, including treatment and subsequent health-care costs.

\section{Design}

A pragmatic randomised controlled trial was designed to reflect a model of practice used in the majority of UK hospital emergency departments. It included an integral evaluation of the costeffectiveness of the different therapies. A total of 584 participants were recruited and randomised to one of four treatment arms: tubular bandage, below knee cast (10 days), Aircast brace or Bledsoe boot. Follow-up was by postal questionnaire at 4 weeks, 12 weeks and 9 months, with response rates of $83 \%, 82 \%$ and $76 \%$ respectively.

\section{Participants}

Participants aged 16 or over with acute severe ankle sprain, unable to weight bear, with no fracture, were recruited from eight emergency departments across the UK.

\section{Intervention}

Treatments were applied 2-3 days after presentation to allow time for swelling to resolve. Participants were given written and verbal instructions regarding the use of supports. Instructions were standardised across all centres and derived from a combination of the manufacturer's recommendations, results of a national survey carried out to inform the design of the trial, and current clinical guidelines.

\section{Main outcome measures}

A disease-specific measure [Foot and Ankle Outcome Score (FAOS)] and generic measures [Functional Limitations Profile (FLP), short form questionnaire with 12 items (SF-12) and EuroQol 5 dimensions (EQ-5D)] were used to assess the response to treatment, and information was gathered to assess resource use.

\section{Results}

After adjustment for age, sex and baseline score, the below knee cast offered a small but statistically significant benefit at 4 weeks in terms of pain, footand ankle-related quality of life (QoL), and the physical component score of the SF-12. Neither the Aircast brace nor the Bledsoe boot was statistically significantly or clinically different from tubular bandage.

At 12 weeks, and in comparison with tubular bandage, the below knee cast was statistically significantly better in terms of pain, activities of daily living, return to sports and QoL. Calculation 
of effect sizes suggests that these benefits were small to moderate, depending on the domain of outcome. The Aircast brace was associated with clinically and statistically significant changes in ankle-related QoL and mental health but not in other domains. The Bledsoe boot conferred no significant advantage over tubular bandage.

By 9 months there were no significant differences between the three comparator supports and tubular bandage for any outcome measure.

\section{Economic evaluation results}

Mean direct health-care costs per participant indicated that the Bledsoe boot was the most expensive support ( $£ 215$ including fitting), with tubular bandage the least expensive (£1.44); Aircast (£39.23) was more expensive than the below knee cast (£16.46). Inclusion of indirect costs (sick leave) raised overall costs substantially, resulting in no significant difference between the groups.

Cost-utility analysis, comparing incremental costs with the differential impact on health-related quality of life over 9 months, demonstrated that the Aircast brace [£301 per quality-adjusted lifeyear (QALY)] and below knee cast (£339 per QALY) were more cost-effective than the Bledsoe boot (£2116 per QALY). Cost-effectiveness acceptability curves confirmed that the Bledsoe boot was least cost-effective and that the Aircast brace and below knee cast differences were broadly similar.

Inclusion of indirect costs produced different rank orders depending on the assumptions made; results should be treated with some caution.

\section{Conclusions}

Ankle sprains with an inability to weight bear have a prolonged recovery. The prognosis should be cautious, explaining that the injury, independent of treatment, has a significant risk of some disability in the form of symptoms, limitations of mobility or activities at 9 months.
Such patients, initially treated with 2-3 days of elevation, ice and non-weight-bearing exercise, had a more rapid resolution of symptoms and return to normal activities in the first 3 months when treated with a below knee cast for 10 days than when treated with tubular bandage.

By 9 months all treatments were equally effective. Mental health deteriorated in the early stages of recovery but returned to normal by 12 weeks. The study suggests that choice of treatment may affect speed of recovery but not long-term outcome.

\section{Implications for health care}

Two devices appeared to offer cost-effective alternatives to tubular bandage: the below knee cast and the Aircast brace. The below knee cast resulted in the fastest recovery and higher levels of sporting function and overall quality of recovery by 3 months. There were no differences in long-term outcome and the decision about which brace to apply should incorporate an assessment of likely compliance and acceptability to patients.

\section{Recommendations for research}

1. The role of physiotherapy is not known in these injuries. In view of the poor prognosis in relatively active people, the effects of a regime of physiotherapy during and after the period of functional support or as an alternative to immobilisation should be investigated.

2. There are still no adequately powered studies of less severe ankle sprains.

3. In the UK, anticoagulants are not routinely used in lower limb injury, whereas this is standard practice in most of mainland Europe. More research is needed to determine the riskbenefit of such strategies.

\section{Trial registration}

This trial is registered as ISRCTN37807450. 


\section{Chapter I Introduction}

\section{Background}

Acute ankle sprain is one of the most common conditions seen in UK emergency departments, accounting for between $3 \%$ and $5 \%$ of all UK emergency department attendances ${ }^{1}$ and approximately 5600 injuries each day. ${ }^{2}$ The majority of ankle sprains involve the lateral ligament complex ${ }^{3}$ (Figure 1), accounting for one-quarter of all sports injuries. ${ }^{4}$ The injury is painful and incapacitating and, unless the injury is minor, weight bearing is difficult to tolerate. Lateral ligament sprains are widely viewed as being uncomplicated and self-limiting. However, several studies have shown that, although the acute symptoms resolve, residual symptoms can persist for months or even years after the initial injury. ${ }^{5}$ One long-term follow-up study ${ }^{6}$ showed that, 7 years post injury, 32\% of subjects experienced chronic complaints of pain, swelling or recurrent sprains. Early effective treatment is not only crucial to promote a speedy resolution of acute symptoms but also an important feature in limiting the chronicity of the injury. ${ }^{5}$

\section{Classification of ankle sprains}

Sprains of the lateral ligament complex of the ankle vary in severity. The anterior talofibular ligament (ATFL) is always first to be injured, and in severe sprains the calcaneofibular ligament (CFL) is also disrupted (see Figure 1). A classification of the severity of ankle sprains has been developed by Crichton et al. ${ }^{7}$ (Table 1).
Diagnosis of the grade of sprain in the emergency department is usually guided by the presenting clinical features. Previous trials have described diagnosing the grade of injury using stress radiography, ${ }^{8-10}$ arthrography ${ }^{11,12}$ or both. ${ }^{13,14}$ Such diagnostic methods are rarely used clinically, making their results difficult to generalise into the clinical setting. Other studies have used talar tilt and anterior drawer tests to indicate the severity of the injury. ${ }^{15-17}$ These tests are more easily incorporated into an elective orthopaedic examination, but are difficult to perform accurately in the first few hours following a sprain, when there is gross swelling and the tests themselves induce pain. Evidence shows that it is difficult to gauge the severity of sprain accurately in the acute situation, ${ }^{18}$ and so the degree of severity is usually assessed based on the ability to weight bear and the extent of the pain, swelling and bruising.

Treatment of grade I and minor grade II injuries is generally conservative. Traditional teaching advocates ice, compression and elevation of the affected limb together with anti-inflammatory medication in the early phase, ${ }^{19}$ although there is less consensus on the value of initial rest or early mobilisation. Optimal treatment for severe sprains (grade III), however, remains unclear. Treatments described include no intervention, physiotherapy, different types of brace and supports, immobilisation and surgical repair of the ligaments. Recent systematic reviews highlight a lack of good-quality evidence to aid clinical decision-making in managing these injuries. ${ }^{2,7}$ 
TABLE I Classification of ankle sprains

\begin{tabular}{lllll} 
Grade & Ligament & Joint stability & $\begin{array}{l}\text { Anterior draw } \\
\text { test }\end{array}$ & Symptoms \\
\hline Grade I & Stretched but not torn & Stable & Negative & $\begin{array}{l}\text { Minimal swelling and pain and mechanical } \\
\text { function is hardly affected; can weight bear }\end{array}$ \\
Grade II & Partially torn & Some laxity & Some laxity & $\begin{array}{l}\text { Moderate swelling and pain; partial or non- } \\
\text { weight bearing }\end{array}$ \\
Grade III & $\begin{array}{l}\text { Ligament complex is } \\
\text { completely ruptured }\end{array}$ & Unstable & Positive & $\begin{array}{l}\text { Severe pain, swelling, bruising and loss of } \\
\text { function; unable to weight bear }\end{array}$
\end{tabular}

\section{Review of treatment of ankle sprains}

\section{Current practice}

A recent survey of the management of severe (grades II and III) ankle sprains in UK emergency departments demonstrated the variation in treatment across the country. ${ }^{20}$ The questionnaire was sent to all UK emergency departments seeing more than 50,000 new patients per year and received a $70 \%$ response rate (83 out of 118 ). The most popular treatments reported were ice, elevation, tubular bandage and exercise. Each of these was reported to be used in most cases by over $70 \%$ of respondents. Crutches, early weight bearing and non-steroidal anti-inflammatory drugs were each reported as used in most cases at over half of responding departments. Physiotherapy was usually used only in selected cases. Rest was usually advised for 1-3 days (35\%). Follow-up was only recommended for selected patients. ${ }^{20}$

\section{Current treatment alternatives}

The three main treatments for severe ankle sprain are:

1. surgery

2. immobilisation

3. functional treatment.

\section{Surgery}

A recent Cochrane review ${ }^{21}$ compared immobilisation in a plaster cast for up to 6 weeks with surgical repair. Significantly better results were found in the surgical group in the outcomes of return to sports and objective instability (although the authors questioned the clinical relevance of this). For the majority of outcomes, however, the pooled data failed to demonstrate a clearly superior treatment approach, and there was also mobility after surgery. The authors stressed that, because of the heterogeneity in the results for the primary outcomes (pain, subjective instability and recurrence), the evidence should be interpreted with caution. All of the trials were considered to have methodological flaws and all but one of the trials were conducted more than 15 years ago, reflecting past practice, including more invasive surgical techniques. Recent studies of ankle ligament reconstruction have tended to focus on repair of the ligaments in patients with chronic instability $^{22-24}$ rather than primary repair of an acute injury.

It is widely documented that secondary surgical repair months or even years after the injury can be performed with comparable results to primary repair. ${ }^{25-27}$ The current recommendation for treatment for acute lateral ligament injury is, therefore, conservative treatment. ${ }^{21}$

\section{Immobilisation}

Immobilisation is defined as any therapy that prevents movement of the ankle joint in both flexion/extension and inversion/eversion.

Studies of immobilisation have often used a period of several weeks in a cast. ${ }^{10,14,15} \mathrm{~A}$ recent Cochrane review ${ }^{28,29}$ showed that functional treatment (see next section) appeared to be better than immobilisation for several outcomes including a quicker return to sport and work and increased patient satisfaction. However, only $52 \%$ of included studies fit the criteria for high-quality studies, and most of the differences were found not to be significant after exclusion of the low-quality trials; many trials were poorly reported and there was heterogeneity amongst the functional treatments and duration of treatment evaluated. The current trend in lateral ankle ligament injury treatment is away from immobilisation ${ }^{8,30,31}$ in favour of active mobilisation. ${ }^{32}$ 


\section{Functional treatment}

Functional treatment consists of a programme of early mobilisation that may include some initial external support to the ankle. The support may be in the form of an elasticated bandage, strapping, lace-up boots or an external orthosis, and the use of crutches has also been described as part of a functional treatment strategy. ${ }^{8,33}$ The orthosis may prevent inversion/eversion but will allow some degree of flexion/extension. Immobilisation and functional treatment are not mutually exclusive methods as some regimes have an initial short period of immobilisation followed by functional treatment.

A recent meta-analysis of treatments for ruptures of the lateral ankle ligaments ${ }^{2}$ found that operative treatment leads to better results than functional treatment, and functional treatment leads to better results than cast immobilisation for 6 weeks. However, most of the studies included were of poor quality and the meta-analysis classed all forms of functional treatment together, meaning that it was not possible to draw distinctions between the different methods.

A Cochrane review of different types of functional treatments ${ }^{29}$ concluded that use of an elastic bandage had fewer complications than use of strapping but was associated with a slower return to work and sport and more reported instability than with use of a semi-rigid ankle support. Laceup supports were effective in reducing swelling in the early phase compared with semi-rigid ankle support, elastic bandage and strapping. However, because of the variety of treatments used and the inconsistency of follow-up and outcome measures in the existing evidence, the most effective functional treatment is still unclear.

A recent trial comparing the use of elastic support bandage and the Aircast ${ }^{\oplus}$ (DJO Incorporated, Vista, CA) brace concluded that the Aircast brace produced significant improvement in ankle joint function at 10 days and 1 month compared with standard management with an elastic support bandage..$^{34}$ However, the trial reported results on only 35 patients and was not of high methodological quality.

Current clinical evidence suggests that functional treatment is more beneficial than immobilisation and leads to improved symptoms and functional outcomes at short ( $<6$ weeks), intermediate $(6$ weeks to 1 year) or long term (> 1 year) followup, although effects are less marked at long-term follow-up..$^{35}$

\section{Additional treatments}

These treatments are usually additional to one of the methods outlined above and include:

1. Ice (cryotherapy) - one randomised controlled trial (RCT) found no significant difference in symptoms between cold pack placement and placebo (simulated treatment); one RCT found less oedema with cold pack placement compared with heat or a contrast bath at 3-5 days after injury. ${ }^{36}$

2. Elevation - elevation of the injured limb lowers the pressure in local blood vessels, helping to limit bleeding and improving the drainage of inflammatory exudate through the lymph vessels, reducing oedema. Studies have shown that elevation above the subject's heart level can help to reduce swelling and to increase drainage of the extravascular fluid away from the injured area. ${ }^{35,37}$

3. Physiotherapy:

i. exercise therapy - there is limited evidence that the addition of supervised exercises to a conventional treatment approach results in greater reduction in swelling and a faster return to work ${ }^{38}$

ii. diathermy - one systematic review found insufficient evidence on the effects of diathermy compared with placebo on walking ability and reduction in swelling ${ }^{39}$

iii. ultrasound - a Cochrane review has recently concluded that the extent and quality of the available evidence for the effects of ultrasound therapy for acute ankle sprains is limited; the results of four placebo-controlled trials do not support the use of ultrasound in the treatment of ankle sprains and the magnitude of most reported treatment effects appeared to be small and they may be of limited clinical importance; as yet, only a few trials are available and no conclusions can be made regarding an optimal and adequate dosage schedule for ultrasound therapy and whether such a schedule would improve on the reported effectiveness of ultrasound for ankle sprains ${ }^{40}$

iv.laser therapy - an RCT has shown that neither high- nor low-dose laser therapy is effective in the treatment of lateral ankle sprains. ${ }^{41}$

\section{Context of the CAST trial}

Three Cochrane reviews of different treatments for lateral ankle ligament injuries have been 
conducted, ${ }^{21,28,29}$ but none has been updated since 2002. To provide a context for the CAST trial, and to identify any new research since 2002, the search strategies of the Cochrane reviews of immobilisation versus functional treatment ${ }^{28}$ and of different functional treatments ${ }^{29}$ were rerun. Any new studies found were added to the results of the Cochrane review and the meta-analysis was repeated. The search strategy is detailed in Appendix 1.

\section{Update of Cochrane reviews relevant to the CAST trial Study selection Types of studies}

Randomised and quasi-randomised controlled trials comparing either immobilisation with functional treatment or different methods of functional treatment for injuries to the lateral ligament complex of the ankle were considered.

\section{Types of participants}

Studies recruiting adults who had sustained an acute injury to the lateral ligament complex of the ankle were eligible for inclusion. Studies involving children, patients with congenital deformities and patients with degenerative conditions were excluded. Trials that focused on the treatment of chronic instability or post-surgical rehabilitation were also excluded.

\section{Types of intervention}

The first Cochrane review under consideration (immobilisation versus functional treatment $)^{28}$ compared immobilisation (either by plaster cast or special boots) with three other interventions:

1. physiotherapy

2. functional treatment

3. non-intervention.

The relevant comparison for the CAST trial is immobilisation with functional treatment. Studies looking at physiotherapy or no intervention were therefore not included in this rerun of the review.

The second Cochrane review under consideration (different functional treatments) ${ }^{29}$ included trials that compared one type of functional treatment with another but excluded those that compared different types of the same category of functional treatment. Four categories were used:

1. elastic bandage

2. strapping
3. lace-up ankle support

4. semi-rigid ankle support.

\section{Types of outcome measures}

The outcome measures used in the Cochrane reviews that are relevant to the CAST study are:

1. return to pre-injury level of work (yes/no; time to achieve)

2. return to pre-injury level of sport (yes/no; time to achieve)

3. pain (yes/no)

4. subjective instability (e.g. 'giving way') (yes/no)

5. recurrent injury (yes/no).

Follow-up times were grouped according to the Cochrane review:

(a) short term - within 6 weeks of randomisation

(b) intermediate term -6 weeks to 1 year of followup

(c) long term - 1-2 years after treatment.

The literature searches were reviewed by two reviewers (RN and MWC) to identify any new potentially relevant trials from the title and abstract. From the full text two reviewers independently selected trials for inclusion in the review. Any disagreement was resolved by consensus.

\section{Quality assessment}

The method used in the Cochrane reviews to assess study quality was replicated in this review. Studies were assessed for quality without masking. ${ }^{42}$ The quality assessment tool used was a modification of the generic evaluation tool used by the Cochrane Musculoskeletal Injuries Group. The tool covers 11 aspects of internal and external validity and is shown in Table 2. In the Cochrane review the cut-off point for high- and low-quality trials was set at $50 \%$ of the maximum score.

\section{Data extraction}

Data were independently extracted by two reviewers [RN and Simon Gates (SG)]. Extracted data included country of research, treatment interventions, number of participants randomised to treatment and control groups, outcome measures used and method of diagnosis.

\section{Data synthesis}

The data were analysed using the Cochrane review manager software (RevMan version 4.2; Oxford, UK). The analyses carried out in the Cochrane review ${ }^{28,29}$ were repeated, if appropriate, 
TABLE 2 Quality assessment tool

A. Was the assigned treatment adequately concealed prior to allocation?

B. Were the outcomes of patients who withdrew described and included in the analysis (intention to treat)?

C. Were the outcome assessors blinded to treatment status?

D. Were the treatment and control groups comparable at entry?

E. Were the subjects blind to assignment status after allocation?

F. Were the treatment providers blind to assignment status after allocation?

G. Were care programmes, other than the trial options, identical?

$\mathrm{H}$. Were the inclusion and exclusion criteria clearly defined?
$2=$ method did not allow disclosure of assignment

$\mathrm{I}=$ small but possible chance of disclosure of assignment or unclear

$0=$ quasi-randomised or open list/tables

Cochrane code: clearly yes $=A$, not sure $=B$, clearly no $=C$

$2=$ intention to treat analysis based on all cases randomised possible or carried out

$\mathrm{I}=$ states number and reasons for withdrawal but intention to treat analysis not possible

$0=$ not mentioned or states number of withdrawals only

$2=$ effective action taken to blind assessors

$\mathrm{I}=$ small or moderate chance of unblinding of assessors

$0=$ not mentioned or not possible

2 = good comparability of groups, or confounding adjusted for in the analysis

$\mathrm{I}$ = confounding small; mentioned but not adjusted for

$0=$ large potential for confounding or not discussed

$2=$ effective action taken to blind subjects

I = small or moderate chance of unblinding subjects

$0=$ not possible or not mentioned (unless double blind), or possible but not done

2 = effective action taken to blind treatment providers

$\mathrm{I}=$ small or moderate chance of unblinding treatment providers

$0=$ not possible or not mentioned (unless double blind), or possible but not done

2 = care programmes clearly identical

$\mathrm{I}=$ clear but trivial differences

$0=$ not mentioned or clear and important differences in care programmes

2 = clearly defined

$\mathrm{I}=$ inadequately defined

$0=$ not defined including any new studies found as a result of the up-to-date search. In fact, only one new study was added to the comparison of immobilisation versus functional treatment ${ }^{31}$ (see next section), and the only new study comparing different functional treatments ${ }^{34}$ was not deemed of sufficient quality to be included and this analysis was not repeated. Results of similar studies were pooled using fixedeffects models. Individual and pooled statistics were reported as relative risks (RRs) with $95 \%$ confidence intervals (CIs) for dichotomous outcomes and weighted or standardised mean differences and $95 \%$ CI for continuous outcomes. A standard chi-squared test was used to test statistical heterogeneity between trials.

\section{Results of the literature review Trial flow}

A flow chart summarising the study selection process is shown in Figure 2.

\section{Study characteristics}

The Cochrane review ${ }^{28}$ of immobilisation versus functional treatment identified 20 trials $^{10,15,16,31,43-49,51-57}$ enrolling 2120 participants. Of these, seven trials compared immobilisation 


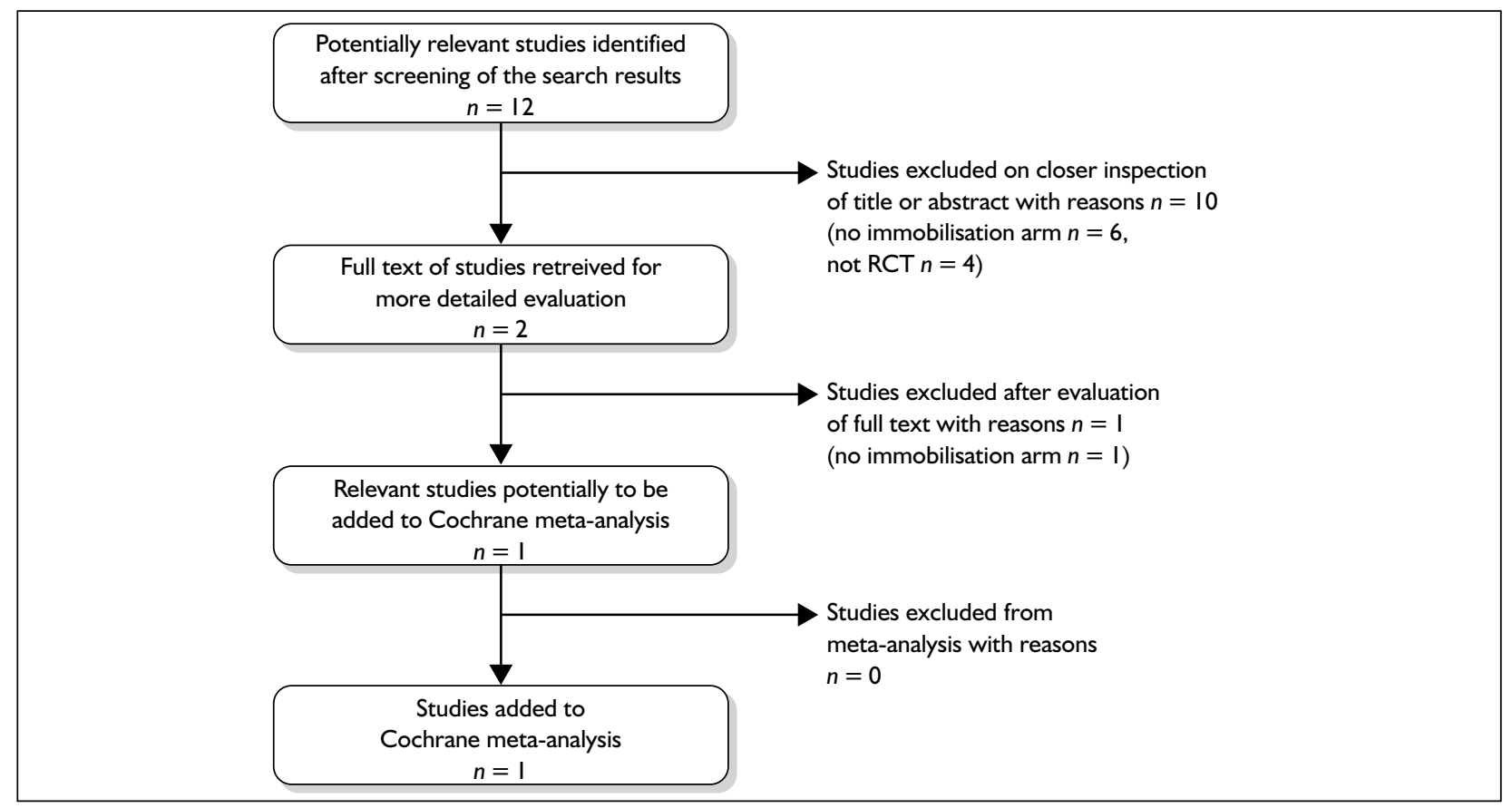

FIGURE 2 Study selection process. RCT, randomised controlled trial.

with the use of an ankle brace,,$^{15,16,47-51}$ five trials compared immobilisation with an elastic bandage, ${ }^{43-45,52,53}$ four trials compared immobilisation with strapping ${ }^{14,51,54,55}$ and five trials compared cast immobilisation with treatment using a softcast or wrap. ${ }^{8,10,46,56,57}$ The rerun of the search strategy identified only one new trial fulfilling the inclusion criteria, ${ }^{31}$ comparing immobilisation with strapping. The trial enrolled 121 participants and used outcomes of pain, subjective instability and recurrent injury.

In the trials reported, participants were likely to be young ( $<50$ years) and trials tended to include a higher percentage of males. Seven of the Cochrane trials were initially deemed to be of high quality (i.e. scoring higher than $50 \%$ on the quality assessment tool). ${ }^{8,10,44,46,48,52,54}$ After additional information was retrieved from the authors, three further trials were categorised as high quality. ${ }^{45,50,56}$ The new study ${ }^{31}$ was assessed for quality using the same tool by two independent reviewers (RN and SG) and was deemed to be of high quality.

The Cochrane review of different functional treatments $^{29}$ identified nine trials ${ }^{33,47,51,58-63}$ enrolling 892 participants; however, none of the trials used the same intervention comparisons. Of these nine trials, four compared elastic bandage and strapping, ${ }^{59,60,62,63}$ four compared elastic bandage with a semi-rigid ankle support, ${ }^{33,47,61,63}$ one compared elastic bandage with strapping, ${ }^{63}$ two compared strapping with semi-rigid ankle support, ${ }^{51,63}$ two compared strapping and lace-up ankle support ${ }^{58,63}$ and one compared semi-rigid with lace-up ankle support. ${ }^{63}$ The new study ${ }^{34}$ compared semi-rigid ankle support with elastic bandage, with a primary outcome of ankle joint function.

The mean validity score of the nine trials reported was 10.8 points (range $5-15$ points, maximum attainable 22 points); following retrieval of additional information from authors the mean validity increased to 10.9 (SD 2.9). An additional study, ${ }^{34}$ which enrolled only 50 participants and reported results for only 35 patients, was deemed to be of insufficient quality for inclusion; it was also assessed for quality using the same tool by two independent reviewers (RJ and SG) (validity 10.5 points). The existing Cochrane review results, therefore, have not been amended.

\section{Quantitative data synthesis}

For the review of immobilisation versus functional treatment, data were extracted for the outcomes of return to pre-injury level of work and sports activities, pain, subjective instability and recurrent injury. The new study identified from the rerun of the Cochrane literature search was added to the studies in the Cochrane review ${ }^{28}$ and the metaanalysis was repeated. 


\section{Meta-analysis: pain}

The new study ${ }^{31}$ was added to the nine studies of the Cochrane review that reported whether the patient was experiencing pain after treatment. This is the only parameter for which the results of the original Cochrane analysis were changed by the addition of the new study (Figure 3). Four studies reported short-term results (6 weeks), ${ }^{8,15,31,47}$ six reported intermediate results ( 6 weeks to 12 months $)^{8,15,31,47,53,56}$ and six reported long-term results (> 12 months). ${ }^{8,10,31,46,55}$ The original Cochrane analysis showed no significant differences at any follow-up time point; addition of the new study altered these results showing that significantly fewer patients reported pain in the functionally treated group at both the short time point (3 months) (RR 1.6, 95\% CI 1.20-2.08) and intermediate time point (12 months) (RR 1.6, 95\% CI 1.08-2.40) compared with the immobilisation group. It is however possible that such change in updated meta-analyses can have occurred by chance.

\section{Rationale for the CAST trial}

The updating of these two Cochrane reviews shows clearly that there is a lack of high-quality

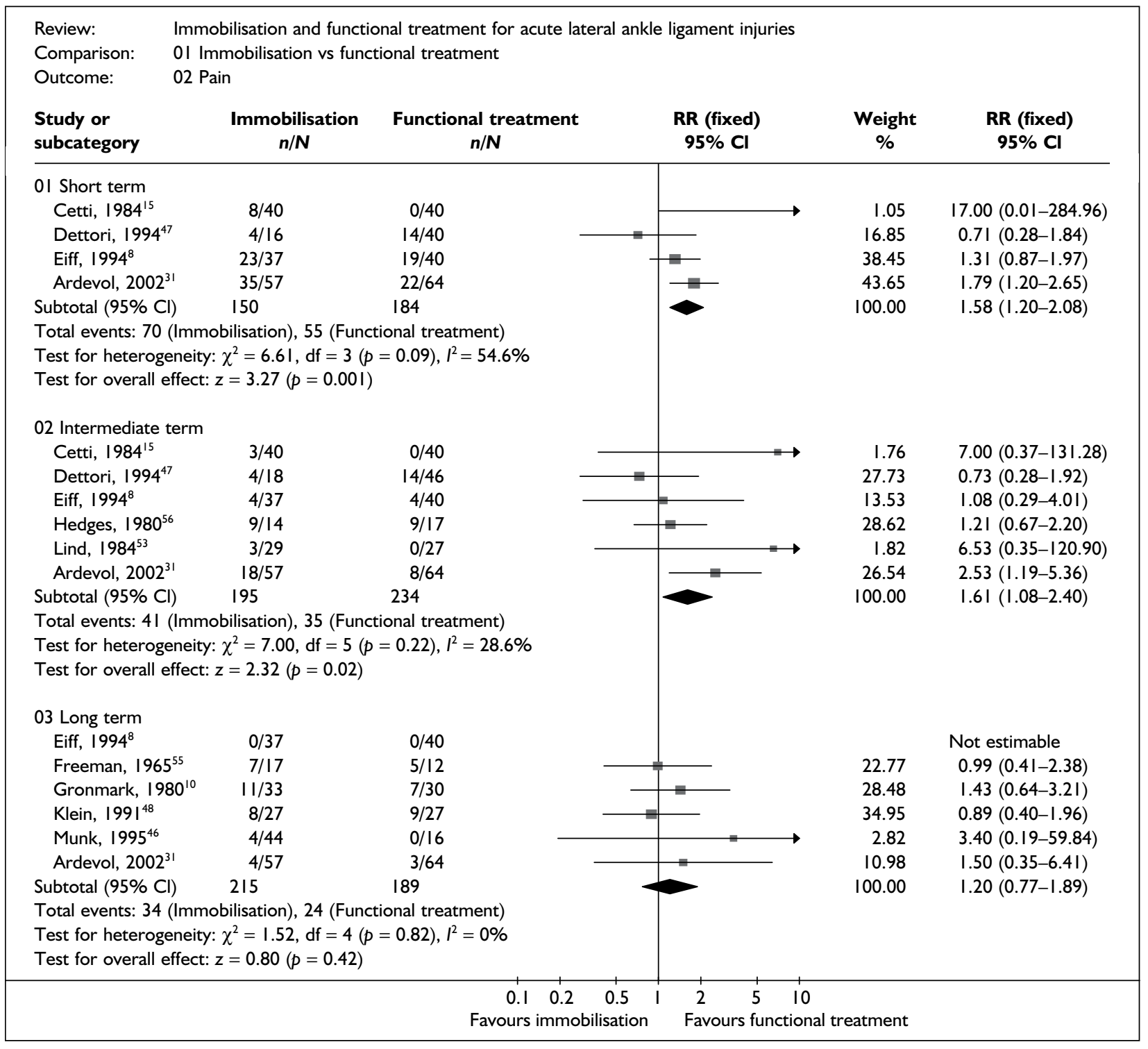

FIGURE 3 Meta-analysis of effects of immobilisation vs functional treatment on pain, including the new study. ${ }^{31}$ 
evidence to support clinical decisions about which type of treatment is best in the management of severe ankle sprains. Present evidence suggests that functional treatment is better than either immobilisation (for longer than 3 weeks) or no treatment. There remains a need for a wellconducted and adequately powered RCT of the clinical effectiveness and cost-effectiveness of different clinical approaches. Our survey of current practice ${ }^{20}$ was used to inform decisions about the design of this trial. We selected three treatments to compare with tubular bandage, which between them represented one method of functional treatment (Aircast brace), one immobilisation method (below knee cast) and one intermediate method [Bledsoe ${ }^{\circledR}$ boot (Bledsoe Boot Systems, Grand Prairie, TX)]. The different methods also allowed varying degrees of ankle movement: full immobilisation (below knee cast), flexion/extension only (Aircast brace) and full range of movement (tubular bandage). In addition, three of the devices allowed the patient to exercise their ankle (tubular bandage, Bledsoe boot, Aircast brace) whereas one allowed no exercise regime (below knee cast).

The trial was designed to be pragmatic in nature and to reflect a model of practice used in the majority of UK hospital emergency departments. It included an analysis of the cost-effectiveness of the different therapies. 


\section{Chapter 2 Methods}

\section{Trial design}

The Collaborative Ankle Support Trial (CAST) was a pragmatic multicentred RCT with blinded assessment of outcome. It was designed to estimate the clinical effectiveness and cost-effectiveness of three different types of mechanical support in the treatment of severe ankle sprains compared with tubular bandage [Tubigrip ${ }^{\circledR}$ (AliMed, Dedham, MA) was used in this study].

People attending selected emergency departments in England who had sustained a sprain of the ankle (ligamentous injury) and were unable to weight bear were identified at the time of presentation. The inability to weight bear was used as a proxy for a diagnosis of a grade II or III ankle sprain as classification is not possible in the acute stage. Potential participants were invited to join the trial and to attend a follow-up clinic 2-3 days following injury where they were randomised to one of four treatment arms: (1) tubular bandage, (2) Bledsoe boot, (3) Aircast ankle brace or (4) below knee cast.

Tubular bandage was chosen as the reference treatment following results of the national survey undertaken immediately before this study showing it to be the most common treatment. ${ }^{20,64}$ The Bledsoe boot, costing £212.68, is many times more expensive than tubular bandage and its clinical effectiveness is yet to be proven. The cast was a conventional below knee walking cast and was applied for 10 days. The Aircast brace (£38.19) was chosen from the range of ankle supports available.

Research physiotherapists recruited and randomised participants at the follow-up clinic and undertook baseline assessments. Appropriately trained health professionals applied interventions to a defined standard. All other treatments were standardised and included ice, elevation, crutches and pain-relieving medications if needed. We felt that withdrawal of these treatments would be inappropriate as they constitute normal and accepted care. Outcomes were measured to reflect short- and longer-term recovery and possible complications. A health economics analysis was included.

\section{Method of application}

A double layer of tubular bandage was applied from the level of the tibial tuberosity to the base of the toes. Sizing of the tubular bandage was undertaken as per the manufacturer's instructions. Patients were instructed to remove the tubular bandage at night.

The Bledsoe boots were sized and applied according to the manufacturer's instructions (supplied with each device; available at www. bledsoebrace.com) with advice to remove at night.

The Aircast splint was sized and applied according to the manufacturer's instructions (supplied with each device; available at www.aircast.com). The below knee cast was applied from the level of the tibial tuberosity to the base of the toes. A layer of Tubinette $^{\circledast}$ (Mölnlycke Health Care, Göteborg, Sweden) and a layer of padding were applied under a complete synthetic non-flexible cast.

\section{Objectives}

The trial had two objectives:

1. to estimate the clinical effectiveness of three different methods of ankle support (below knee cast, Aircast ankle brace and Bledsoe boot) compared with tubular double layer (tubular bandage) in terms of the recovery of function (primary outcome); the recovery of normal occupation, including return to normal work, study, caring or other activities (secondary outcome); and avoidance of residual symptoms including recurrent instability, lasting limitation of physical activity and need for further medical, rehabilitation or surgical treatment (secondary outcomes)

2. to measure the cost-effectiveness of each strategy, including treatment and subsequent health-care costs.

\section{Participants}

Participants were recruited from the emergency departments of eight collaborating hospitals: John 
Radcliffe Hospital, Oxford; Frenchay Hospital, Bristol; Coventry and Warwickshire Hospital, Coventry; Hospital of St Cross, Rugby; Heartlands Hospital, Birmingham; Alexandra Hospital, Redditch; Solihull Hospital, Solihull; and Warwick Hospital, Warwick.

\section{Inclusion criteria}

- $\quad$ Patients attending emergency departments with sprain of the ankle and an inability to weight bear at the time of presentation to the emergency department and their review clinic appointment.

- Age 16 years and older.

- Able to give informed consent.

\section{Exclusion criteria}

- Age less than 16 years (because of the possibility of confusion with epiphyseal injuries).

- Ankle fracture (except flake fractures of less than $2 \mathrm{~mm}$ as these are normally treated as soft-tissue injuries).

- Any other recent fracture.

- Any contraindication to any of the four arms of the trial (this criterion was added following the pilot study).

- Poor skin viability preventing splinting or casting.

- Injury more than 7 days previously.

\section{Trial procedure}

\section{Recruitment}

A standard approach was instituted across all participating hospitals. People who attended emergency departments with an ankle sprain were assessed for injury severity by emergency department medical staff who completed a standard proforma (Appendix 2), which recorded details such as the ability to weight bear, talar tilt and anterior draw test to assess stability. Radiography was used to exclude fracture when this was clinically indicated and as guided by the Ottawa guidelines. ${ }^{65}$ People able to weight bear and those with a fracture were not eligible for the trial and were managed in accordance with normal practice. All those who could not weight bear (proxy for grade II and III injuries) were referred to a follow-up emergency department clinic, which reflected national normal practice reported in the survey undertaken ${ }^{20}$ (Figure 4). Emergency department staff were asked to provide participants with information, a letter inviting them to join the trial (Appendix 3) and a patient information sheet (Appendix 4). Between the time of presentation and the clinic all participants had identical selftreatment consisting of analgesia, ice and elevation combined with an exercise regime as tolerated. Patients were advised to mobilise as tolerated and were provided with crutches as appropriate. Written advice was given to all participants (Appendix 5).

The follow-up clinic was 2-3 days after emergency department attendance. This delay was introduced for three reasons. First, a period of elevation and ice is widely advocated to reduce swelling and one of the treatments (the below knee cast) is contraindicated in the first few days because of the risk of developing a compartment syndrome if swelling increases. Second, it is difficult to accurately assess injury severity at initial presentation. The symptoms associated with grade I sprains resolve rapidly and the time delay allowed additional assessment of injury severity. Last, the delay allowed participants sufficient time to consider their involvement in the trial. If clinic attendance was not possible within 7 days of injury the patient was not eligible.

A record was made of all people who had an ankle sprain and were non-weight bearing at presentation in the emergency department to monitor referral and attendance rates at the follow-up clinic. At the follow-up clinic participants were given a full verbal explanation of the trial by the trial research physiotherapists. Informed consent was obtained from eligible and willing participants (Appendix $6)$. The reasons for declining to participate in the trial were recorded, along with age, sex, ethnicity and severity of injury of all people approached. The research physiotherapist performed a short baseline interview (Appendix 7) to ensure eligibility for randomisation and, after randomisation, the participant completed the baseline questionnaire (Appendix 8). This collected details that included date of birth, age, sex, body mass index (BMI), ethnicity and an assessment of pre-injury abilities including usual levels of mobility, engagement in sporting activity and usual occupation and employment (including hours worked and type of work undertaken), together with a brief examination of weight-bearing status (measured using weighing scales) and pain. Pre-injury quality of life was measured using the EuroQol 5 dimensions (EQ-5D). ${ }^{66}$

\section{Optimising recruitment}

A variety of methods were used to optimise recruitment. The challenges to recruitment in this 


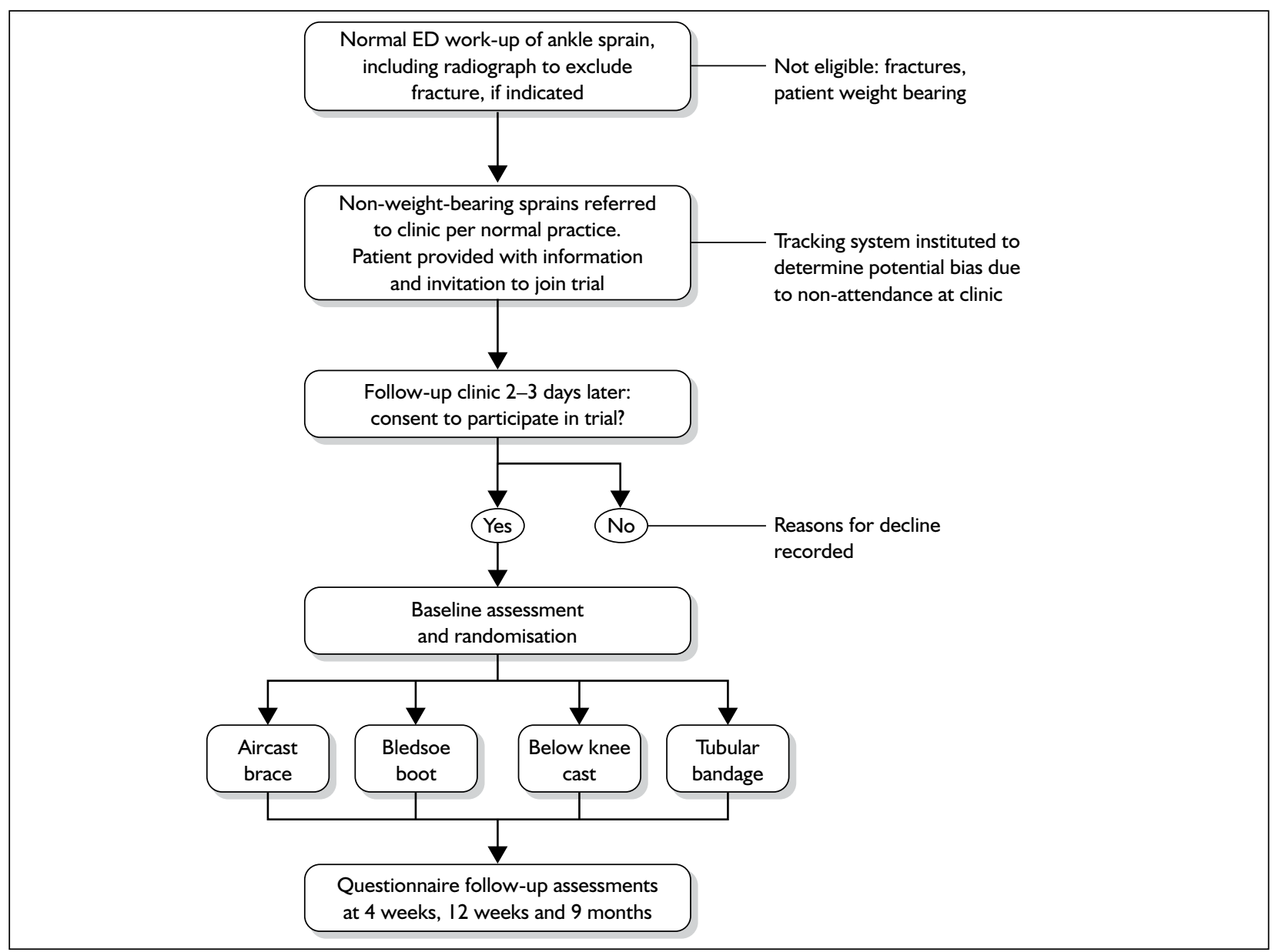

FIGURE 4 Flow chart of participant progress. ED, emergency department.

trial have been reported elsewhere (see Appendix

9). Techniques included:

- teaching sessions for emergency department medical staff, emergency nurse practitioners and nurses

- $\quad$ posters within the emergency department

- trial logo screensavers

- regular contact between recruitment physiotherapists and emergency department staff

- $\quad$ audits of recruitment (Appendix 10).

\section{Randomisation}

Simple randomisation was used, stratified by centre. This was provided by the Cancer Trials Unit at the University of Birmingham via telephone. Allocation concealment was ensured by using a remote computer-generated randomisation system independently administered and quality controlled.
Sealed envelope randomisation was employed over bank holiday periods.

\section{Blinding}

A research assistant, independent of all recruitment and randomisation procedures, was responsible for mailing questionnaires and entering responses into the computerised database (Microsoft Access). Blinding of the intervention was maintained until the final analysis of the data was completed.

\section{Interventions Experimental treatments}

The health technologies being assessed were three different methods of mechanical support for ankle sprains. The interventions were applied in the emergency department follow-up clinic by an appropriately trained health professional. Responsibility for application of braces varied 
between hospitals, being undertaken by a plaster technician, physiotherapist or nurse; all staff were provided with a standardised training package as part of the trial. Each participant had their Bledsoe boot, Aircast splint, below knee cast or tubular bandage fitted individually to ensure comfort and correct fit. If participants refused the treatment to which they were randomised the default strategy was to give them tubular bandage instead. Participants were provided with standardised written and verbal instructions (Appendix 11) that included continuing reduction of swelling, when to remove the brace, encouragement of normal walking within limits of tolerance, simple exercise advice, what to do in the event of experiencing difficulties with the device and washing instructions. These protocols were established with reference to the manufacturer's recommendations, the results of the national survey ${ }^{20}$ and current clinical guidelines. Treatments were applied within 7 days of the injury and within a few hours of randomisation.

\section{Other treatments}

The prescription of walking aids, elevation, painrelieving medications and ice were permitted but were defined by a protocol reflecting current national practice. Physical therapy techniques including musculoskeletal assessment, soft-tissue mobilisations, manipulations, massage, gait reeducation, contrast baths, electrotherapy and supervised exercise or exercise classes were not permitted as part of the trial treatment protocol. However, if during or following the trial treatment period participants were considered by the relevant clinician to need physiotherapy, this was permitted but was classed as an outcome.

\section{Follow-up}

\section{Handling withdrawals}

Participants were free to withdraw from the trial at any time. When possible, reasons for withdrawal were ascertained, including any potential dissatisfaction with the treatment proposed or provided.

\section{Loss to follow-up}

Loss to follow-up has been a problem in previous trials of ankle sprain management, particularly when these have involved participants attending follow-up research clinics at the hospital. ${ }^{67}$ Postal questionnaires were used in an attempt to minimise loss to follow-up, and a system of reminder letters and telephone calls (Figure 5) was instituted to follow up those who did not return their questionnaires. Term-time and holiday addresses were obtained from those participants who were students. If, following completion of the measures shown in Figure 5, participants still did not return questionnaires they were telephoned by a researcher and asked to give answers to key questions over the phone. This enabled us to collect core outcome data for analysis.

\section{Questionnaires}

The layout of questionnaires was designed to minimise the possibility of systematic missing responses, for example avoidance of single-sided photocopying and other recommendations for increasing the return rate. ${ }^{68}$

\section{Resource use}

For data relating to resource use and complications we obtained consent at the beginning of the study to access participant records. This enabled additional information to be gained when participants were lost to follow-up and was used to assess whether data were missing at random and to model the effects of missing data.

\section{Outcome measures}

All measures were taken at baseline and at 4 weeks, 12 weeks and 9 months after the injury (Table 3 ). At 12 weeks and 9 months the questionnaire included use of resources.

\section{Primary outcomes}

1. Foot and Ankle Outcome Score (FAOS) ${ }^{69}$ This questionnaire evaluates symptoms and functional limitations related to ankle injuries and has been validated against objective tests of ankle function..$^{69}$ There are five subscales: pain, other symptoms, function in activities of daily living (ADL), function in sport and recreation, and foot- and ankle-related quality of life (QoL). A normalised score (100 indicating no symptoms and 0 indicating extreme symptoms) is calculated for each subscale. The subscales are not summed and, to guide interpretation of the trial, we identified ankle-related quality of life as providing the best overall assessment of quality of recovery of ankle function.

2. The Functional Limitations Profile (FLP) is the British version of the Sickness Impact Profile..$^{70}$ The ambulatory subscale was used to provide detailed information on the impact of the injury and treatment. This included information on adaptations that occur after the injury, for example participants returning 


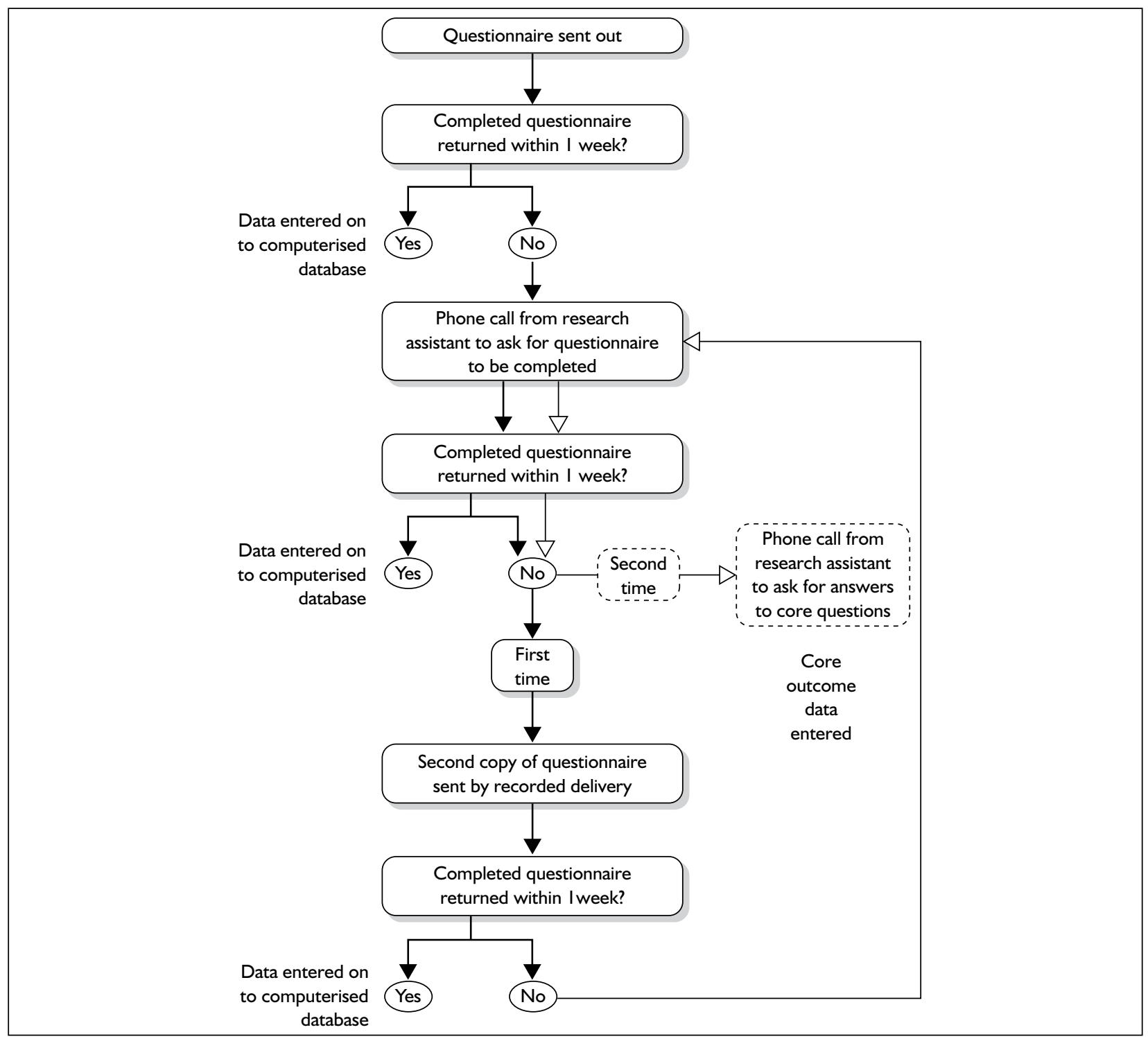

FIGURE 5 Flow chart of method used to maximise questionnaire return for CAST.

to a different type of job or to the same job but with reduced function compared with their pre-injury role. Scoring is from 0 to 100 , with a lower score meaning a better result. This profile has been used for past injury assessment and has been validated in this environment but it has not been used specifically in ankle injuries.

\section{Secondary outcomes}

1. The short form questionnaire with 12 items (SF-12) version $1^{71}$ was used to quantify the recovery of normal occupation and mobility and the broader impact of the treatments on health-related quality of life (HRQoL). The SF-12 was chosen over the the short form questionnaire with 36 items (SF-36) following the pilot study, to reduce the risk of 'questionnaire fatigue'.

2. The EQ-5D $\mathrm{D}^{66}$ measures health on five dimensions and includes a tariff for deriving a single utility score based on time tradeoff utility scores. It was used to conduct an economic evaluation.

3. Visual analogue scale (VAS). Participants were asked to mark a vertical point on a $10-\mathrm{cm}$ horizontal line to show how much pain they 
TABLE 3 Primary and secondary outcome measures

\begin{tabular}{lll}
\hline Outcome & Domain & Measures \\
\hline Primary & Return to function & $\begin{array}{l}\text { Foot and Ankle Outcome Score (FAOS), Functional } \\
\text { Limitations Profile (FLP) ambulatory assessment }\end{array}$ \\
Secondary & $\begin{array}{l}\text { Return to mobility and occupation, health-related } \\
\text { quality of life (HRQoL) measures }\end{array}$ & $\begin{array}{l}\text { Time to return to occupation, time to return to } \\
\text { leisure/sports activities, EQ-5D/SF-12 }\end{array}$ \\
Secondary & Resource use & Resource use questionnaire
\end{tabular}

had in their ankle at rest and when weight bearing, with $0=$ no pain and $100=$ the worst pain imaginable.

4. Benefit scale. Participants were asked to rate the benefit that they had received from their treatment at 12 weeks and 9 months on a scale from 0 to 10 , where $0=$ no benefit and $10=$ maximum benefit .

5. Return to normal occupation and leisure activities. The date that people returned to work and normal activities was recorded.

6. Resource use. At 12 weeks and 9 months an additional questionnaire was completed (see Appendix 12) to determine any additional treatments that had been used for the ankle injury. It identified whether any such treatment was obtained through the NHS or privately and, if privately, whether this had been paid for by the individual or by a private healthcare provider. Participants were asked about the number and types of medications and treatments that they had purchased, including pain-relieving medications, gels or other topical agents, bandages, braces or footwear. Participants were asked to distinguish between prescription and out-of-pocket expenses. Hospital notes and records were audited for information on service use. Primary care records were not retrieved.

7. Pre-injury abilities. Participants were asked to provide information on type of occupation and sports and leisure activities in the month before the injury.

\section{Statistical methods Sample size calculation}

This was based on a standard sample size calculation for a two-sample $t$-test with equal variances and a significance level of 0.05 , using the mean and variance estimates from the literature and confirmed by the pilot study. For the FAOS a difference of $8-10 \%$ was specified as the minimal clinically important difference (MCID). Sample size estimates were calculated using standard methods. ${ }^{72}$
A target of 643 participants was sufficient to provide more than $90 \%$ power to detect differences of $10 \%$ in the primary outcomes and $80 \%$ power to detect differences in a range of secondary outcomes at 4 and 12 weeks assuming a $20 \%$ loss to follow-up. This sample size was independently calculated after 6 months of the trial by the Data Monitoring And Ethics Committee (DMEC).

\section{Statistical analysis}

Appropriate numerical and graphical summaries of all the data were compiled, including a detailed description of missing data at the clinic visit and the questionnaire and individual level.

The analysis was performed on an intention to treat basis. All participants were analysed in the groups to which they were randomised, regardless of the treatment that they received. An analysis of all people who completed the trial was undertaken and a sensitivity analysis performed to assess the range of potential biases that could result from loss to follow-up or withdrawal.

Analysis was also performed for groups defined by their acceptance of the treatment to which they were randomised.

\section{Calculation of effect sizes}

The differences from tubular bandage were transformed into effect sizes (onto a scale of standard deviations) by dividing by the relevant residual standard error.

\section{Recovery}

Recovery at each of the time points was monitored with reference to the baseline assessment. Linear regression models were used to provide estimates of the recovery and the prevalence of residual symptoms, with $95 \%$ confidence intervals.

\section{Comparison of different treatments}

The first comparison was that of each of the three alternative treatments with tubular bandage. Those treatments found to be more effective than tubular bandage were then compared with each other. The 
regression modelling allowed an assessment of factors that might indicate the appropriate choice of treatment. As these analyses were prespecified, issues of multiple comparisons are minimal.

The sensitivity of the above analyses to missing data at case level was assessed and quantified using multiple imputation methods. Where data were missing, linear regression was used to fit a model describing the 4-week, 12-week or 9-month outcome in terms of baseline variables (age, sex, pain at rest VAS score and the relevant baseline score). Five draws were then made from the predicted distribution of 4-week scores for each outcome to produce five complete data sets on which the main analyses were repeated. Estimates from these five analyses were combined ${ }^{73}$ using the 'mifit' command developed for the statistical analysis software package Stata

(StataCorp, College Station, TX). This provided an estimate of effect that incorporated uncertainty due to the missing data.

\section{Economic analysis Estimates of cost consequences}

This analysis sought to estimate the differences in the costs of the resources used by participants in the four arms of the trial, allowing comparisons to be made between different types of ankle support and enabling costs and consequences to be compared from a health-care perspective. Additionally, a wider analysis was conducted that looked at health-care costs plus costs to society as a result of sick leave.

The costs of each ankle support were determined to include staff time, overheads and equipment, and the costs of all subsequent NHS care related to treatment of the severe ankle sprain to include follow-up visits to hospital, GP surgeries, physiotherapists, etc. Other cost consequences for participants in terms of time off work, personal expenditure on aids or private practitioner input were obtained from resource use questions included in the follow-up outcome questionnaires as already described.

Cumulative costs over time associated with each treatment were collated for each of the four groups. The assumption was made that average costs reasonably reflected the long-run marginal costs of provision of services. Primary and hospital services use was costed from a variety of sources, including national sources. ${ }^{74}$
An analysis of the sensitivity of any observed cost differences between areas was undertaken for key cost drivers.

\section{Comparison of costs and consequences}

Full economic evaluation was performed based on a comparative assessment of the marginal costs and outcomes of the interventions used.

\section{Cost-effectiveness analysis}

A single outcome measure common to all interventions is required to estimate costeffectiveness. The additional cost per unit improvement can be measured in terms of clinical outcomes such as recovery time or increases in ambulatory scores to estimate incremental cost per unit of improvement.

\section{Cost-utility analysis}

The EQ-5D instrument generates time trade-off utility scores ${ }^{75}$ and allows determination of the incremental cost of the benefit gained in terms of the cost per quality-adjusted life-year (QALY) gained. Cumulative costs for changes in the health status index measured over the 9 months were calculated for individuals; this was presented in summary form in terms of incremental costeffectiveness ratios (ICERs). Techniques to deal with missing data in economic analysis were considered ${ }^{76-78}$ however, we adopted a conservative approach such that missing outcome values were imputed only in cases in which EQ-5D data were available for other time points. We chose primarily to analyse complete cases to maintain consistency with the clinical analysis presented in Chapter 3 . To ensure the generalisability of any findings we compared the baseline characteristics of the sample used for economic analysis with the sample excluded. For cost data items a non-response was equated to zero resource use only in cases that had reported outcome data. In the cost-utility analysis, uncertainties in the cost and outcomes data were incorporated into a sensitivity analysis.

\section{Study conduct}

A Trial Management Committee was set up to monitor the day-to-day running of the trial. It consisted of the chief investigators, statistical team and project co-ordinator. It met monthly for the duration of the project. This was supplemented by weekly meetings of the chief investigators, trial coordinator and recruitment physiotherapists. 
A Trial Steering Committee (TSC) was set up to: (1) monitor and supervise the progress of the trial towards its interim and overall objectives; (2) review at regular intervals relevant information from other sources; (3) consider the recommendations of the DMEC; and (4) inform the funding body on the progress of the trial. Members of the TSC were Professor Bill Gillespie, Dean, Hull York Medical School (Chair, independent); Professor Sallie Lamb, University of Warwick/University of Oxford (chief investigator); Professor Matthew Cooke, University of Warwick (chief investigator); Professor Jane Hutton, University of Warwick; Dr Jennifer Marsh, University of Warwick; Professor Ala Szczepura, University of Warwick; Professor Jeremy Dale, University of Warwick; Dr Sue Wilson, University of Birmingham; and Vicky Staples (independent lay representative). The committee met at 6-monthly intervals either face-to-face or via teleconference.

A DMEC was set up to: (1) determine if additional interim analyses of trial data should be undertaken; (2) consider data from interim analyses, unblinded if considered appropriate, plus any additional safety issues for the trial and relevant information from elsewhere; (3) ensure that ethical considerations were of prime importance and report to the TSC and recommend on continuation of the trial; (4) consider any requests for the release of interim trial data and to inform the TSC on the advisability of this; and (5) advise on funding issues. Members of the DMEC were Professor Janet Dunn, University of Birmingham (Chair); Professor Damian Griffin, University of Warwick; and Patricia Overton-Brown, University Hospitals Coventry and Warwickshire. The DMEC met 14 and 19 months after recruitment commenced.

\section{Ethical issues}

The study was approved by the Northern and Yorkshire Multicentre Research Ethics Committee and all relevant local research ethics committees. Research governance approval was obtained from all NHS trusts involved in recruiting participants.

Informed consent to the trial and access to records was taken from all participants. Participants between the ages of 16 and 18 gave assent to participate in the trial and parents were asked to provide consent.

\section{Pilot study}

\section{Rationale}

To enable methodological refinement of the study proposal, a pilot study was undertaken. This allowed us to test the methods of collecting costs and outcomes, eliminate redundancy in the outcome measures, identify and overcome any obstacles to participant recruitment and refine the sample size and estimation of project costs.

\section{Methods}

A total of 24 participants were recruited from Coventry and Warwickshire Hospital, Coventry, over an 8-week period. The pilot study was conducted according to the methods given earlier in this chapter, with the exception of two questionnaires completed by the participants following randomisation. At the start of the pilot study the Ankle Performance Scale (APS) ${ }^{79}$ was used as the best available disease-specific instrument. However, during the pilot study a new measure, based on the APS and by the same authors, was published (the FAOS) and this was phased in to replace the APS. The SF-36 rather than the SF-12 was used throughout the pilot study.

\section{Results}

When possible the results from the pilot study participants are included in the final analysis. The first few participants $(n=17)$ in the pilot study only completed the APS at baseline and not the FAOS and the same was true of three participants at 4 weeks. It was therefore not possible to calculate a score for the FAOS for these participants and so they have been excluded from the analyses that use the FAOS but included in all other analyses.

\section{Methodological changes for the main trial}

Several minor methodological alterations were made following the pilot study:

1. refinement of the outcome measure package to use the FAOS instead of the APS, and use of the SF-12 instead of the SF-36 to reduce participant questionnaire burden

2. stratification by trial centre

3. refinement of exclusion criteria, including contraindication to any of the four arms of the trial. 


\section{Chapter 3 \\ Results}

B etween 7 April 2003 and 1 July 2005, 1522 potentially eligible participants were referred to the trial clinics at eight centres in the UK. Trial clinics were held 2-3 days following the initial presentation of the participant at the emergency department with severe ankle sprain. Random audits at centres showed that $15-100 \%$ of potential patients were referred to the clinics (see Appendix 10). A total of 330 patients who were referred did not attend the clinic; 1192 attended the trial clinic of whom $512(43 \%)$ were ineligible and 584 (49\%) were eligible and willing to take part and were randomised to one of the four treatment arms. A small proportion of eligible patients ( $n=79,7 \%$ of eligible patients attending the clinic) were unwilling to join the trial. The main reason for ineligibility was that the patient was already weight bearing by the time of the trial clinic and thus was deemed to have an ankle sprain less severe than grade II or III. Figure 6 describes the numbers of participants approached to participate in the trial, randomised and allocated to various treatments and the numbers of withdrawals and losses to follow-up. Figure 7 shows the numbers of participants recruited from each of the eight centres.

Patients excluded from the analysis were all pilot study participants who initially completed the APS at baseline or 4 weeks rather than the FAOS. These exclusions affected only the analyses using the FAOS scores; all other analyses included all patients. In total, 17 pilot study participants have been excluded from the baseline FAOS analysis and three pilot study participants have been excluded from the 4-week FAOS analysis (one each from the below knee cast, Aircast and Bledsoe groups).

\section{Sample characteristics}

The baseline characteristics of the sample are shown in Table 9. As anticipated from previous studies there was a greater proportion of men $(58 \%)$ than women $(42 \%)$. The mean age of participants was 30 years (SD 10.8, median 27, range 16-72). The majority of the sample was of Caucasian ethnic status (94\%), with $68 \%$ having O levels/General Certificates of Secondary Education (GCSEs) or A levels as their highest educational qualification, $80 \%$ employed for over 25 hours per week and $82 \%$ spending greater than 4 hours per day on their feet.

The mean height of participants was $1.7 \mathrm{~m}$ (SD $0.1 \mathrm{~m}$ ) and the mean weight was $78.6 \mathrm{~kg}(\mathrm{SD}$ $15.4 \mathrm{~kg})$, resulting in a mean BMI of $26.3 \mathrm{~kg} / \mathrm{m}^{2}(\mathrm{SD}$ $\left.5.2 \mathrm{~kg} / \mathrm{m}^{2}\right)$.

Almost half of the participants (49\%) had experienced an ankle injury previously and $9 \%$ of the sample reported recurrent sprain (defined as a previous sprain on three or more occasions, with the most recent incident being within the last year). Pre-existing injuries were generally only of mild to moderate severity and symptoms were intermittent.

\section{Randomisation}

Randomisation groups were generally well matched in terms of age, sex, educational level and baseline symptom profile and injury characteristics. There was a slightly larger number of males in the below knee cast group. All analyses have been adjusted for age, sex and baseline score. The median duration between time of injury and application of treatment was 3 days (interquartile range 2 ), with no differences between the groups.

\section{Baseline injury characteristics}

At baseline FAOS ranges indicated that nearly all participants were unable to participate in sports activities, experiencing significant loss of confidence in the ankle, had at least moderate or very frequent pain, and were experiencing at least moderately severe or frequent symptoms including swelling, bruising, instability and inability to weight bear (Table 10). Over $75 \%$ of participants had scores of less than 50 points for the pain, symptoms, sport and QoL subscales.

Nearly all participants reported at least some difficulty or frequent problems in a range of basic self-care activities of daily living. Mobility, as quantified by both the FLP and FAOS, was significantly impaired. In total, $75 \%$ of participants 


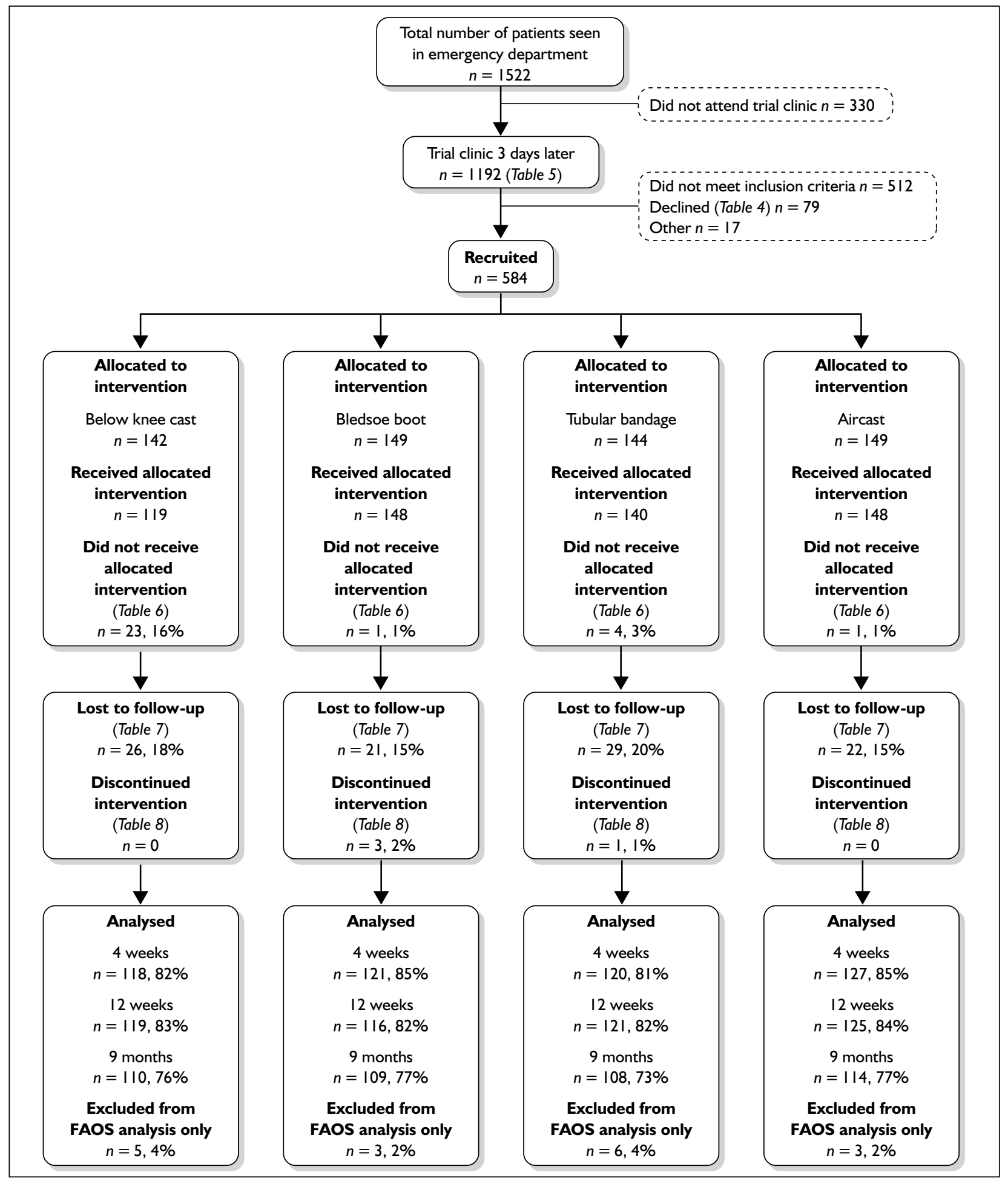

FIGURE 6 Participant progress through the trial. FAOS, Foot and Ankle Outcome Score. 
TABLE 4 Delay from injury to randomisation and application of randomised treatment

\begin{tabular}{|c|c|c|c|c|c|}
\hline & Tubular bandage & Below knee cast & Aircast brace & Bledsoe boot & Total \\
\hline$n$ & 137 & 135 & $|4|$ & 138 & 551 \\
\hline Mean delay (days) & 3.14 & 3.19 & 3.01 & 3.09 & 3.1 \\
\hline SD & 1.33 & 1.58 & 1.3 & 1.4 & 1.4 \\
\hline Minimum & I & I & I & 1 & 1 \\
\hline Ist quartile & 2 & 2 & 2 & 2 & 2 \\
\hline Median & 3 & 3 & 3 & 3 & 3 \\
\hline $3 r d$ quartile & 4 & 4 & 4 & 4 & 4 \\
\hline Maximum & 7 & 8 & 7 & 8 & 8 \\
\hline
\end{tabular}

TABLE 5 Reasons given by 79 participants for declining to take part in the trial

\begin{tabular}{ll} 
Reason for decline & Number \\
\hline Participant unwilling to accept one or more treatment options & 57; tubular bandage 4 (7\%), below knee cast 46 (81\%), \\
& Aircast brace 2 (4\%), Bledsoe boot 9 (16\%) \\
Did not want to fill in questionnaires & 3 \\
Not happy to be part of a research project & 6 \\
Felt that the trial would interfere too much with daily life & 22 \\
Other unstated reason & 26 \\
Total & 114 \\
\hline Note: Participants were free to give more than one reason. &
\end{tabular}

TABLE 6 Reasons for not receiving allocated intervention

\begin{tabular}{lll}
\hline Randomisation group & Reason for not receiving allocated intervention & Number \\
\hline $\begin{array}{l}\text { Tubular bandage } \\
(n=4,3 \%)\end{array}$ & $\begin{array}{l}\text { Participant already wearing tubular bandage on arrival at trial clinic and wanting } \\
\text { something more effective } \\
\text { No tubular bandage available and given Aircast brace }\end{array}$ & 1 \\
& Reason unknown & 2 \\
$\begin{array}{l}\text { Below knee cast } \\
(n=23,16 \%)\end{array}$ & Participant refused below knee cast after randomisation & 8 \\
& Plaster room closed or technician unavailable & 3 \\
& Unable to return for below knee cast removal & 1 \\
Aircast brace & Clinical decision following randomisation & 2 \\
$\begin{array}{l}n=1,1 \%) \\
\text { Bledsoe boot }(n=1,1 \%)\end{array}$ & $\begin{array}{l}\text { Reason unknown } \\
\text { Participant had problems with Aircast brace, physiotherapist decided to use }\end{array}$ & 9 \\
\hline
\end{tabular}


TABLE 7 Reasons for loss to follow-up or withdrawal after randomisation

Randomisation group

Number

Reason for loss to follow-up

Tubular bandage

Loss to follow-up was defined as those participants not sending back their questionnaires and for whom we were unable to obtain core outcomes over the phone. Reasons for this are unknown but include participants moving house or

Below knee cast changing phone numbers

26

Bledsoe boot

\section{Reason for withdrawal}

Tubular bandage

Below knee cast

Participant too busy to fill in questionnaires by 12 weeks

I

Participant too busy to fill in questionnaires by 12 weeks

Participant refused below knee cast after randomisation and withdrew from trial

Reason unknown

Aircast brace

Reason unknown at 9 months

TABLE 8 Reasons for unplanned discontinuation of intervention

\begin{tabular}{|llc|}
\hline Randomisation group & Reason for discontinuation & Number \\
\hline Below knee cast & Two participants removed cast themselves at 9 and 5 days respectively & 2 \\
& $\begin{array}{l}\text { Participant returned after I day with discomfort and was given tubular bandage } \\
\text { instead }\end{array}$ & I \\
Aircast brace & Reason unknown & I
\end{tabular}

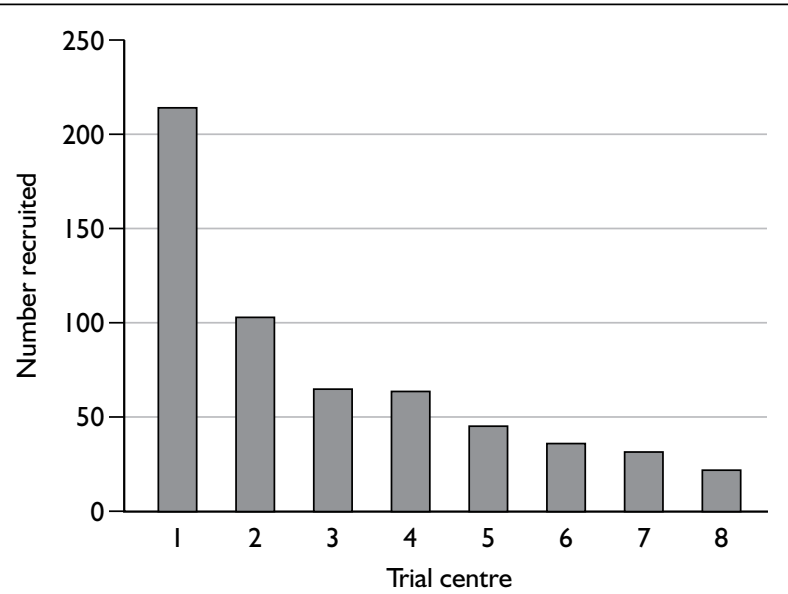

FIGURE 7 Recruitment by trial centre. Recruitment periods and sizes of centres varied. 
TABLE 9 Baseline characteristics table

\begin{tabular}{|c|c|c|c|c|c|}
\hline & \multicolumn{5}{|c|}{ Randomisation group } \\
\hline & Tubular bandage & Below knee cast & Aircast brace & Bledsoe boot & Total \\
\hline$n$ (\% of sample) & $144(25)$ & $142(24)$ & $149(26)$ & $149(26)$ & 584 \\
\hline Age (years), mean (SD) & $31(11.2)$ & $30(10.5)$ & $29(10.7)$ & $30(10.7)$ & $30(10.8)$ \\
\hline \multicolumn{6}{|l|}{ Gender, n (\%) } \\
\hline Female & $64(44)$ & $54(38)$ & $65(44)$ & $64(43)$ & $247(42)$ \\
\hline Male & $80(56)$ & $88(62)$ & $84(56)$ & $85(57)$ & $337(58)$ \\
\hline \multicolumn{6}{|l|}{ Ethnic group, n (\%) } \\
\hline White & $135(94)$ & $133(94)$ & $140(94)$ & $|4|(95)$ & $549(94)$ \\
\hline Non-white & $9(6)$ & $9(6)$ & $9(6)$ & $8(5)$ & $35(6)$ \\
\hline \multicolumn{6}{|l|}{ Education, n (\%) } \\
\hline CSE & $9(6)$ & $10(7)$ & $8(6)$ & II (8) & $38(7)$ \\
\hline O-level/GCSE & $59(42)$ & $57(4 I)$ & $67(48)$ & $66(46)$ & $249(44)$ \\
\hline A-level & $33(24)$ & $33(24)$ & $33(23)$ & $34(23)$ & $133(24)$ \\
\hline Degree & $16(11)$ & $18(13)$ & II (8) & $19(13)$ & $64(11)$ \\
\hline Higher degree & $9(6)$ & $7(5)$ & $7(5)$ & $5(3)$ & $28(5)$ \\
\hline Other & $14(10)$ & $13(9)$ & $15(11)$ & $10(7)$ & $52(9)$ \\
\hline \multicolumn{6}{|l|}{ Employment status, n (\%) } \\
\hline Employed & $114(79)$ & $107(75)$ & $117(79)$ & $114(77)$ & $45 I(77)$ \\
\hline Unemployed & $30(2 I)$ & $35(25)$ & $32(22)$ & $35(24)$ & $133(23)$ \\
\hline \multicolumn{6}{|l|}{ Hours employed per week } \\
\hline Less than 10 hours & $4(3)$ & $4(3)$ & $5(3)$ & $12(8)$ & $25(6)$ \\
\hline $10-25$ hours & $14(10)$ & $14(10)$ & $17(11)$ & $17(11)$ & $62(14)$ \\
\hline $25-40$ hours & $56(39)$ & $56(39)$ & $59(40)$ & $45(30)$ & $216(48)$ \\
\hline More than 40 hours & $39(27)$ & $33(23)$ & $34(23)$ & $37(23)$ & $143(32)$ \\
\hline \multicolumn{6}{|l|}{ Length of day on feet } \\
\hline Most of day & $97(67)$ & $73(6 I)$ & $90(60)$ & $94(63)$ & $354(6 \mathrm{I})$ \\
\hline More than 4 hours & $24(17)$ & $36(25)$ & $36(24)$ & $28(19)$ & $124(2 I)$ \\
\hline Less than 4 hours & $9(6)$ & $20(14)$ & $15(10)$ & $19(13)$ & $63(11)$ \\
\hline Mostly sitting & $14(10)$ & $12(9)$ & $8(5)$ & $8(5)$ & $42(7)$ \\
\hline \multicolumn{6}{|l|}{ Length of time driving } \\
\hline Most of day & $8(6)$ & $6(4)$ & $5(3)$ & $4(3)$ & $23(4)$ \\
\hline More than 4 hours & $6(4)$ & $9(6)$ & $13(9)$ & $4(3)$ & $32(25)$ \\
\hline Less than 4 hours & $41(29)$ & $29(20)$ & $40(27)$ & $38(26)$ & $148(25)$ \\
\hline Just commuting & $35(24)$ & $35(25)$ & $32(2 I)$ & $44(30)$ & $146(25)$ \\
\hline Don't drive & $54(38)$ & $62(44)$ & $59(40)$ & $58(39)$ & $233(40)$ \\
\hline BMI $\left(\mathrm{kg} / \mathrm{m}^{2}\right)$, mean $(\mathrm{SD})$ & $26.5(5)$ & $27.0(5)$ & $26.1(6)$ & $25.8(5)$ & $26.3(5)$ \\
\hline
\end{tabular}


TABLE 9 Baseline characteristics table

\begin{tabular}{|c|c|c|c|c|c|}
\hline & \multicolumn{5}{|c|}{ Randomisation group } \\
\hline & Tubular bandage & Below knee cast & Aircast brace & Bledsoe boot & Total \\
\hline \multicolumn{6}{|c|}{ Previous instability, n (\%) } \\
\hline Yes & $30(21)$ & $23(16)$ & $26(17)$ & $3 I(2 I)$ & $110(19)$ \\
\hline No & $106(74)$ & III (78) & $116(78)$ & $112(75)$ & $445(76)$ \\
\hline No answer & $8(6)$ & $8(6)$ & $7(5)$ & $6(4)$ & $29(5)$ \\
\hline \multicolumn{6}{|c|}{ Previous ankle injury, n (\%) } \\
\hline Yes & $70(49)$ & $7 \mid(50)$ & $76(5 \mathrm{I})$ & $66(44)$ & $283(49)$ \\
\hline No & $74(5 \mathrm{I})$ & $69(49)$ & $73(49)$ & $82(55)$ & $298(5 \mathrm{I})$ \\
\hline No answer & $0(0)$ & $2(1)$ & $0(0)$ & I (I) & $3(1)$ \\
\hline \multicolumn{6}{|c|}{ Previous recurrent sprain, $\mathrm{n}(\%)$} \\
\hline Yes & $12(8)$ & $14(10)$ & $12(8)$ & $17(1 \mathrm{I})$ & $55(9)$ \\
\hline No & $73(5 \mathrm{I})$ & $65(46)$ & $77(52)$ & $63(42)$ & $278(48)$ \\
\hline No answer & $59(4 I)$ & $63(44)$ & $60(40)$ & $69(46)$ & $25 I(43)$ \\
\hline
\end{tabular}

reported scores of 30 points or higher on the FLP ambulatory scale, and nearly all participants (97\%) reported at least some problems in getting about.

In comparison with population norms, SF-12 physical performance scores indicated significant impairment. Mental health scores were consistent with age- and sex-adjusted population means. VAS pain scores in all four groups were very similar, with more pain present on weight bearing than at rest. Over $75 \%$ of participants had scores well below the population norm as defined by the EQ-5D measure of general health.

\section{Data collection and completeness of follow-up \\ Loss to follow-up Case level}

Follow-up at individual time points was good: $486(83 \%)$ participants returned a 4-week questionnaire, $481(82 \%)$ returned a 12 -week questionnaire and $441(76 \%)$ returned a 9-month questionnaire. There were no differences in followup between the four groups (Table 11).

\section{Item level}

In addition to case-level missing data (no questionnaire returned at all) there were also cases in which, although a questionnaire was returned, it standard algorithms to calculate a score. Missing items were was usually of the order of $2-3 \%$.

In general, questionnaires were well completed for the FAOS pain, symptoms and QoL subscales at all points and less well completed for the FAOS ADL and sport subscales and the SF-12 and EQ$5 \mathrm{D}$ scores. Questionnaires were generally better completed at the earlier follow-up points.

\section{Patterns of missing data}

There were no differences between randomisation groups with respect to loss to follow-up or patterns of response.

The majority of responses followed a monotonic pattern: once a participant failed to respond at a follow-up point they did not usually respond at any further follow-up point(s). A small proportion of participants responded in a non-monotonic way: having failed to return information at a particular time point(s) they subsequently provided information at later point(s). All available data were incorporated into the analyses for each time point.

\section{Acceptance and receipt of randomised treatment}

Acceptance and receipt of randomised treatment was generally high, with only $5 \%$ of participants not accepting the treatment to which they were 
TABLE 10 Baseline injury characteristics by randomisation group

\begin{tabular}{|c|c|c|c|c|c|c|}
\hline \multirow[b]{2}{*}{ Score } & & \multicolumn{5}{|c|}{ Randomisation group } \\
\hline & & Tubular bandage & Below knee cast & Aircast & Bledsoe & Total \\
\hline \multirow[t]{3}{*}{ FAOS, pain } & Mean & 40.2 & 40.1 & 37.6 & 39.0 & 39.2 \\
\hline & Median & 38.9 & 41.7 & 39.0 & 39.0 & 38.9 \\
\hline & (Quartiles) & $(33.3-50.0)$ & $(25.00-52.8)$ & $(25.0-47.2)$ & $(27.8-50.0)$ & $(27.8-50.0)$ \\
\hline \multirow{3}{*}{$\begin{array}{l}\text { FAOS, } \\
\text { symptoms }\end{array}$} & Mean & 40.2 & 42.0 & 38.7 & 41.0 & 40.5 \\
\hline & Median & 39.3 & 39.3 & 39.3 & 39.3 & 39.3 \\
\hline & (Quartiles) & $(28.6-50.0)$ & $(32.1-50.0)$ & $(28.6-46.4)$ & $(32.1-50.0)$ & $(28.6-50.0)$ \\
\hline \multirow[t]{3}{*}{ FAOS, ADL } & Mean & 61.5 & 59.0 & 57.2 & 58.6 & 59.1 \\
\hline & Median & 61.8 & 60.3 & 57.4 & 58.8 & 60.3 \\
\hline & (Quartiles) & $(54.4-69.1)$ & $(51.5-66.2)$ & $(50.0-63.2)$ & $(50.0-67.7)$ & $(5 \mid .5-66.2)$ \\
\hline \multirow{3}{*}{$\begin{array}{l}\text { FAOS, } \\
\text { sport }\end{array}$} & Mean & 16.8 & 14.4 & 12.3 & 14.4 & 14.5 \\
\hline & Median & 10.0 & 5.0 & 5.0 & 10.0 & 10.0 \\
\hline & (Quartiles) & $(0.0-25.0)$ & $(0.0-25.0)$ & $(0.0-15.0)$ & $(0.0-20.0)$ & $(0.0-20.0)$ \\
\hline \multirow[t]{3}{*}{ FAOS, QoL } & Mean & 28.0 & 20.8 & 21.3 & 24.4 & 23.6 \\
\hline & Median & 25.0 & 18.8 & 18.8 & 18.8 & 18.8 \\
\hline & (Quartiles) & $(12.5-43.8)$ & $(6.3-25.0)$ & $(6.3-3 \mid .3)$ & $(6.3-37.5)$ & $(6.3-37.5)$ \\
\hline \multirow{3}{*}{$\begin{array}{l}\text { FLP, } \\
\text { ambulatory }\end{array}$} & Mean & 35.4 & 36.3 & 37.0 & 34.0 & 35.7 \\
\hline & Median & 36.4 & 37.0 & 36.6 & 33.1 & 36.3 \\
\hline & (Quartiles) & $(28.3-4 I . I)$ & $(30.2-45.6)$ & $(30.2-45.5)$ & $(26.3-40.4)$ & $(28.8-42.7)$ \\
\hline \multirow{3}{*}{$\begin{array}{l}\text { SF-12, } \\
\text { physical }\end{array}$} & Mean & 35.8 & 36.0 & 34.0 & 35.7 & 35.4 \\
\hline & Median & 35.8 & 37.7 & 32.3 & 34.2 & 34.6 \\
\hline & (Quartiles) & $(27.0-43.3)$ & $(28.9-43.1)$ & $(27.5-41.3)$ & $(27.4-43.4)$ & $(27.6-43.0)$ \\
\hline \multirow{3}{*}{$\begin{array}{l}\text { SF-I2, } \\
\text { mental }\end{array}$} & Mean & 51.5 & 52.0 & 49.5 & 51.4 & 51.1 \\
\hline & Median & 53.3 & 54.3 & 51.7 & 54.2 & 53.3 \\
\hline & (Quartiles) & $(43.8-60.6)$ & $(45.8-60.1)$ & $(40.2-58.7)$ & $(43.5-6 I .5)$ & $(42.8-60.3)$ \\
\hline \multirow[t]{3}{*}{ EQ-5D } & Mean & 0.4 & 0.3 & 0.3 & 0.3 & 0.3 \\
\hline & Median & 0.4 & 0.3 & 0.3 & 0.4 & 0.3 \\
\hline & (Quartiles) & $(0.1-0.7)$ & $(0.1-0.6)$ & $(0.03-0.6)$ & $(0.1-0.6)$ & $(0.1-0.6)$ \\
\hline \multirow{3}{*}{$\begin{array}{l}\text { VAS, pain at } \\
\text { rest }\end{array}$} & Mean & 37.4 & 37.8 & 39.4 & 36.5 & 37.8 \\
\hline & Median & 32.0 & 38.5 & 40.0 & 32.0 & 36.0 \\
\hline & (Quartiles) & $(18.0-55.0)$ & $(|9.5-5| .5)$ & $(21.5-55.0)$ & $(18.0-54.5)$ & $(19.0-53.5)$ \\
\hline \multirow{3}{*}{$\begin{array}{l}\text { VAS, pain } \\
\text { weight } \\
\text { bearing }\end{array}$} & Mean & 74.8 & 74.9 & 78.4 & 73.5 & 75.4 \\
\hline & Median & 78.0 & 77.0 & 80.0 & 77.0 & 78.0 \\
\hline & (Quartiles) & $(65.0-90.0)$ & $(67.0-93.0)$ & $(71.0-90.0)$ & $(61.0-90.0)$ & $(66.0-90.0)$ \\
\hline \multicolumn{7}{|c|}{$\begin{array}{l}\text { ADL, activities of daily living; QoL, quality of life; VAS, visual analogue scale. } \\
\text { The FAOS uses a scale of } 0-100(0=\text { extreme symptoms, } 100=\text { no symptoms). The FLP ambulatory subsection uses a } \\
\text { score of } 0-100 \text {, with a lower score being better. The SF- } 12 \text { score ranges from } 0 \text { to } 100 \text {, with a higher score being better. } \\
\text { The EQ-5D uses a score from I for full health to - } 0.594 \text { for problems with all five dimensions covered. Baseline VAS scores } \\
\text { of pain at rest and on weight bearing are scored from } 0 \text { (no pain) to } 100 \text { (worst pain imaginable). }\end{array}$} \\
\hline
\end{tabular}


TABLE I I Missing data proportions: case-level missing data by randomisation group

\begin{tabular}{|c|c|c|c|c|c|c|c|c|c|c|c|}
\hline & & \multicolumn{2}{|c|}{ Tubular bandage } & \multicolumn{2}{|c|}{ Below knee cast } & \multicolumn{2}{|c|}{ Aircast } & \multicolumn{2}{|c|}{ Bledsoe } & \multicolumn{2}{|c|}{ Total } \\
\hline & & $n$ & $\%$ & $n$ & $\%$ & $n$ & $\%$ & $n$ & $\%$ & $n$ & $\%$ \\
\hline \multirow[t]{2}{*}{4 weeks } & Response & 118 & 82 & 121 & 85 & 120 & 81 & 127 & 85 & 486 & 83 \\
\hline & Missing & 26 & 18 & 21 & 15 & 29 & 20 & 22 & 15 & 98 & 17 \\
\hline \multirow[t]{2}{*}{12 weeks } & Response & 119 & 83 & 116 & 82 & 121 & 81 & 125 & 84 & 481 & 82 \\
\hline & Missing & 25 & 17 & 26 & 18 & 28 & 19 & 24 & 16 & 103 & 18 \\
\hline \multirow[t]{2}{*}{9 months } & Response & 110 & 76 & 109 & 77 & 108 & 73 & 114 & 77 & 441 & 76 \\
\hline & Missing & 34 & 24 & 33 & 23 & 41 & 28 & 35 & 24 & 143 & 25 \\
\hline
\end{tabular}

randomised. Reasons for refusal of randomised treatment were given previously in Table 4. There were differences between randomisation groups in the level of acceptance: the Aircast brace and Bledsoe boot had almost total acceptance, with only one participant (1\%) in each group refusing the treatment, whereas tubular bandage had a slightly higher rate of non-acceptance with four participants (3\%) refusing it. The below knee cast was the least acceptable treatment. The main reason for refusal, when one was given, was an unwillingness to be put in a below knee cast ( 8 of 23 refusals, 35\%), although there were also practical reasons such as not being able to return for cast removal (1 of 23 refusals, 4\%). Randomised treatment was not given because of non-availability of the plaster technician on three occasions (3 of 23 refusals, 13\%). Two participants were not given a below knee cast for clinical reasons (9\%) and nine others $(39 \%)$ refused for unknown reasons.

The trial protocol stated that participants refusing a randomised treatment should be offered tubular bandage, but for eight out of the 29 participants $(28 \%)$ who did not receive their randomised treatment a different treatment was applied. Levels of acceptance of randomised treatment, and treatments given in cases of non-acceptance of randomised treatment, are given in Table 12, with reasons, when known, previously outlined in Table 4.

\section{Withdrawal}

Five (1\%) participants withdrew their consent for follow-up during the 9-month follow-up period. The reasons for withdrawal are listed in Table 7.

\section{Adverse events and serious adverse events}

There were seven adverse events in total, of which two were non-serious and five were serious. The two non-serious adverse events were both cases of cellulitis treated with antibiotics, one each in the Aircast brace and Bledsoe boot groups. The five serious adverse events were all either suspected/confirmed deep vein thrombosis (DVT) or pulmonary embolism. These events are not unexpected in this injury and following immobilisation of any type. There were two each in the tubular bandage and Aircast arms and one in the below knee cast arm. Of these, three were possibly related to the trial treatment, one was unrelated and one was of unknown relatedness (the participant had a previous history of recurrent DVT and was taking warfarin but was classified as eligible for the trial and randomised in error). Table 13 gives full details of the individual cases.

\section{Recovery and estimates of treatment effectiveness}

Figures 8 and 9 illustrate recovery (unadjusted medians) by randomisation group for the primary and secondary outcomes. Descriptive statistics are given in Appendix 13.

With the exception of mental health, recovery was incremental over time and most rapid in the first 4 weeks. However, at 9 months nearly $20 \%$ of individuals reported persisting difficulties getting around and $50 \%$ of participants scored less than $10-20 \%$ of the maximum score range on the FAOS subscales. Overall, mental health declined 
TABLE I2 Uptake of treatment by randomisation group

\begin{tabular}{|c|c|c|c|c|c|}
\hline & \multicolumn{5}{|c|}{ Randomisation group } \\
\hline & Tubular bandage & Below knee cast & Aircast & Bledsoe & Total \\
\hline $\begin{array}{l}\text { Total number of participants } \\
\text { randomised }\end{array}$ & 144 & 142 & 149 & 149 & 584 \\
\hline Treatment as intended & 140 & 119 & 148 & 148 & 556 \\
\hline Alternative treatment & 4 & 23 & I & 1 & 29 \\
\hline \multicolumn{6}{|l|}{ Alternative treatment given } \\
\hline Tubular bandage & - & 20 & - & 1 & - \\
\hline Below knee cast & - & - & 1 & - & - \\
\hline Aircast & 4 & 2 & - & - & - \\
\hline Nothing & - & 1 & - & - & - \\
\hline$\%$ given alternative treatment & 3 & 16 & 1 & 1 & 5 \\
\hline
\end{tabular}

significantly at 4 weeks in comparison with baseline but had recovered by 12 weeks.

Age was a significant determinant of recovery, which was substantially slower as age increased and less complete by 9 months for all outcomes. Gender was also significant in recovery, particularly at the earlier time points, with men reporting better scores than women on average across all scores. Baseline score was positively related to recovery, with a better score at the outset being associated with better scores later on for all outcomes. No interactions between sex, age or randomisation group were observed.

\section{Estimates of treatment effectiveness - intention to treat analysis}

Analysis was controlled for age (centred at 30 years), sex and baseline score (centred at the approximate median of each score). For the FAOS analyses we excluded the 17 pilot study participants who did not complete the FAOS at baseline.

TABLE 13 Serious adverse events

\begin{tabular}{|c|c|c|c|c|c|c|}
\hline $\begin{array}{l}\text { Participant } \\
\text { ID }\end{array}$ & $\begin{array}{l}\text { Treatment } \\
\text { arm }\end{array}$ & Diagnosis & Age & Sex & $\begin{array}{l}\text { Length of time } \\
\text { support worn }\end{array}$ & Related to trial treatment \\
\hline 1060 & $\begin{array}{l}\text { Tubular } \\
\text { bandage }\end{array}$ & $\begin{array}{l}\text { Suspected } \\
\text { deep vein } \\
\text { thrombosis } \\
\text { (DVT) }\end{array}$ & 72 & $\mathrm{~F}$ & $\begin{array}{l}\text { I-2 weeks (full } \\
\text { questionnaire follow- } \\
\text { up returned) }\end{array}$ & Possibly \\
\hline 1183 & $\begin{array}{l}\text { Below knee } \\
\text { cast }\end{array}$ & $\begin{array}{l}\text { Post-partum } \\
\text { pulmonary } \\
\text { embolism } \\
(\mathrm{PE})\end{array}$ & 21 & $\mathrm{~F}$ & $\begin{array}{l}\text { Less than I week (no } \\
\text { response to 9-month } \\
\text { questionnaire) }\end{array}$ & Unrelated \\
\hline 2007 & Aircast & DVT & 28 & $\mathrm{~F}$ & $\begin{array}{l}\text { Less than I week (full } \\
\text { questionnaire follow- } \\
\text { up returned) }\end{array}$ & Possibly \\
\hline 2049 & $\begin{array}{l}\text { Tubular } \\
\text { bandage }\end{array}$ & PE & 51 & $\mathrm{~F}$ & $\begin{array}{l}\text { I-2 weeks (full } \\
\text { questionnaire follow- } \\
\text { up returned) }\end{array}$ & $\begin{array}{l}\text { Unknown. Proforma stated } \\
\text { that participant had a history of } \\
\text { recurrent DVT and was taking } \\
\text { warfarin, but participant was } \\
\text { classified as appropriate for the } \\
\text { trial and randomised in error }\end{array}$ \\
\hline 3032 & Aircast & DVT & 20 & $M$ & $\begin{array}{l}\text { Unknown, as no } \\
\text { questionnaires } \\
\text { returned }\end{array}$ & Possibly \\
\hline
\end{tabular}



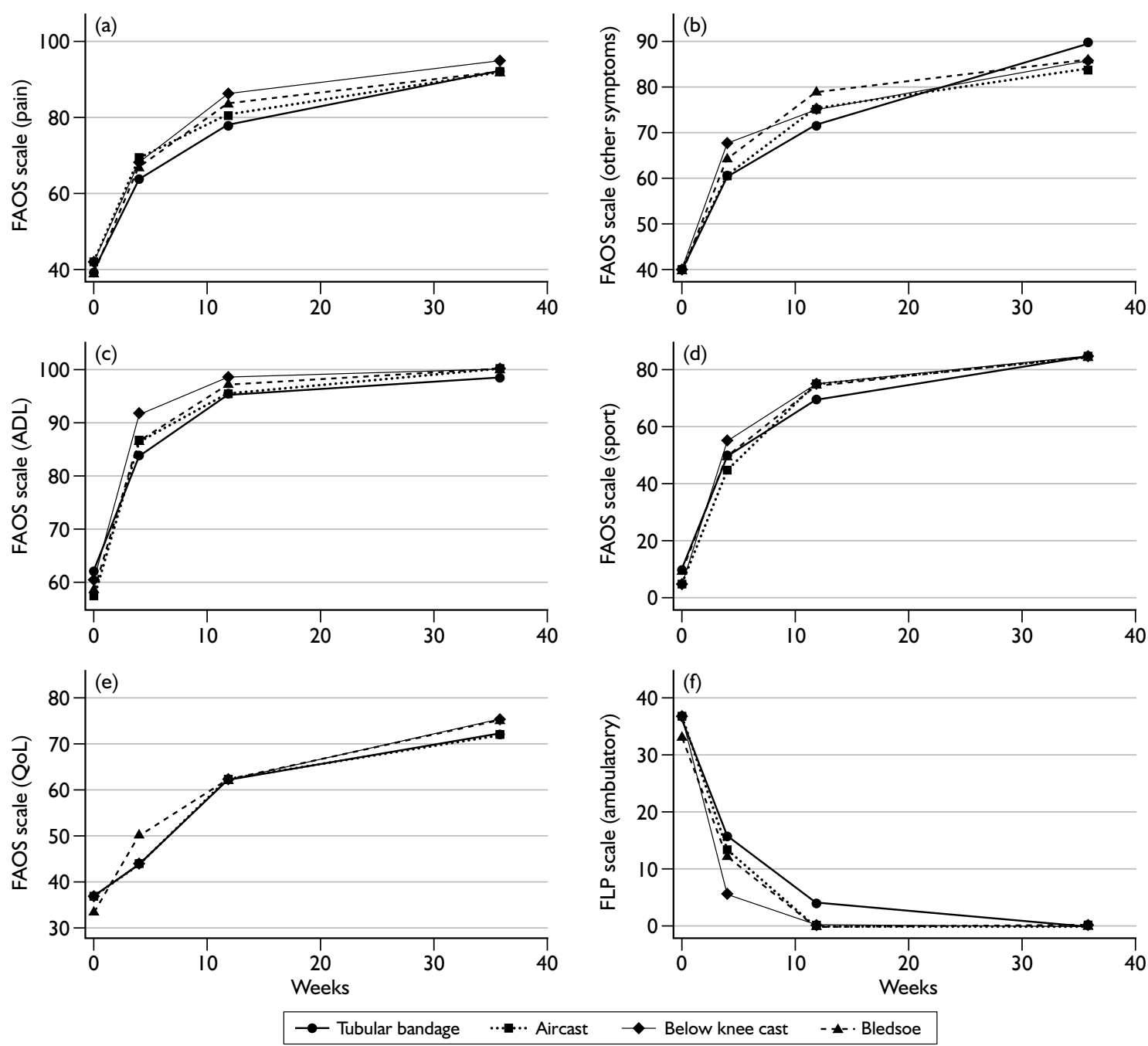

FIGURE 8 Primary outcome recovery curves for the full 9-month follow-up period. Graphs (a)-(e) show the five FAOS subscales - pain, other symptoms, activities of daily living ( $A D L)$, sport and recreation and quality of life $(Q \circ L)$ respectively - and graph (f) shows the FLP ambulatory scale. Figures are unadjusted medians. The FAOS uses a scale of $0-100$, in which $0=$ extreme symptoms and $100=$ no symptoms, whereas the FLP ambulatory subsection uses a score of $0-100$, with a lower score being better. (Tables of means, medians and quartiles are given in Appendix 13.)

Estimates of treatment effectiveness for the primary outcome are presented in Table 14 on the basis of comparison with tubular bandage.

At 4 weeks the below knee cast was the most effective treatment in the early stages of recovery, its difference compared with tubular bandage being significantly non-zero for the pain and QoL subscales. In terms of clinical significance these differences were small effects. Neither the Aircast brace nor the Bledsoe boot conferred a significant advantage over tubular bandage at 4 weeks.

By 12 weeks the below knee cast was statistically significantly better than tubular bandage on four of the five subscales of the FAOS - pain, ADL, sports and QoL. The differences for the sports scale, QoL scale and ADL scale were moderate, whereas differences in pain were small. The Aircast brace was also significantly more effective than tubular bandage in improving the FAOS QoL subscale, but effects on the other domain scores of the FAOS were not statistically significant. The Bledsoe boot conferred no significant advantage over tubular bandage.

Results of the secondary outcomes are presented in Table 15 on the basis of comparison with tubular bandage. At 4 weeks the below knee cast was significantly better than tubular bandage for return 

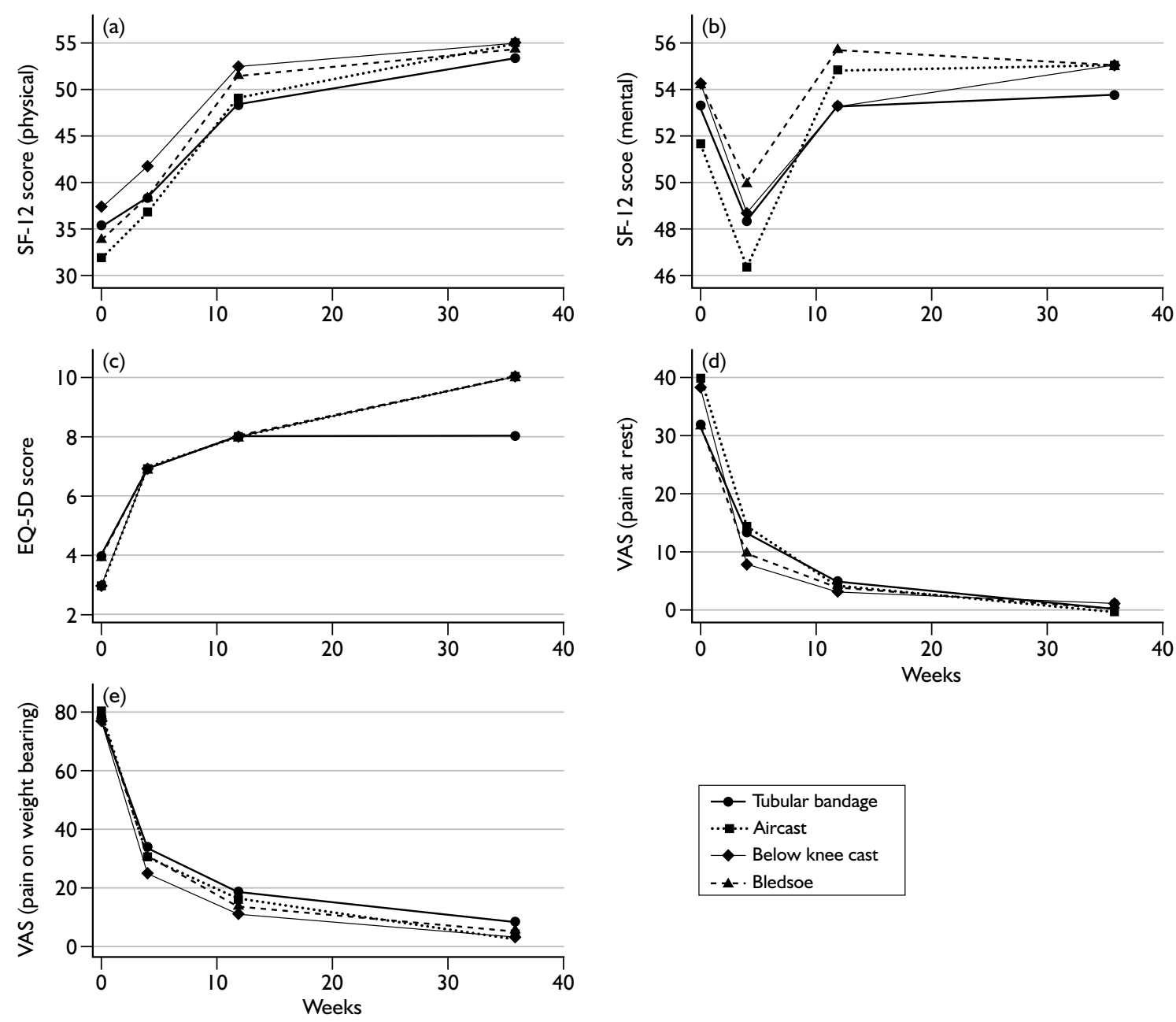

FIGURE 9 Secondary outcome recovery curves for the full 9-month follow-up period. SF- I 2 physical (a) and mental (b) component scores (each scale 0-100 with population norm of 50). (c) The EQ-5D (scale -0.594 to I.0, where a higher score is better). Visual analogue scale (VAS) scores (scale of $0-100$ expressed in millimetres, where $0=$ no pain and $100=$ worst pain imaginable) for pain at rest (d) and pain when weight bearing (e). Figures are unadjusted medians. (Tables of means, medians and quartiles are given in Appendix 13.)

to physical function (SF-12 physical component), with a small effect size. Mental well-being had decreased in all four groups compared with baseline scores.

By 12 weeks the Aircast brace was significantly better than tubular bandage for return to mental health (SF-12 mental component), with a moderate effect size, with the below knee cast being slightly worse than tubular bandage. On the EQ-5D there was a statistically significant benefit for the below knee cast at both 4 and 12 weeks compared with tubular bandage, with a small to moderate effect size.

Pain at rest, as measured on a VAS, was slightly better with the below knee cast at 4 weeks, and pain when weight bearing was also better with the below knee cast at 12 weeks, compared with tubular bandage.

By 9 months there were no statistically significant differences between the groups on any of the primary or secondary outcome measures.

\section{Self-reported benefit}

Participants were asked to rate the benefit that they had received from their treatment at 12 weeks and 9 months on a scale of $0-10$. Those in the tubular bandage arm felt that they had received the least benefit of the four groups at both time points, with half of participants reporting a benefit of less than 5 out of 10; the benefit of the other three supports 


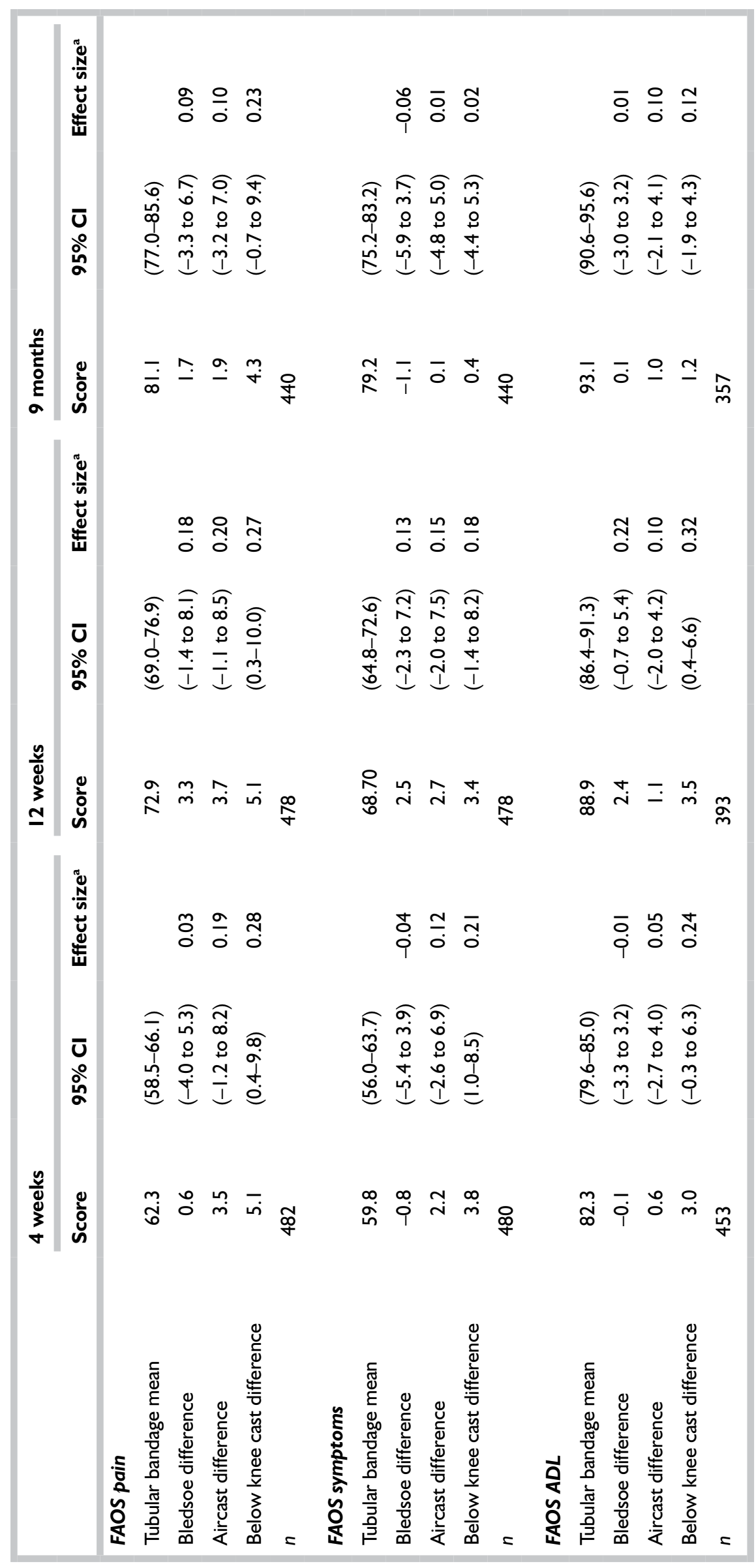




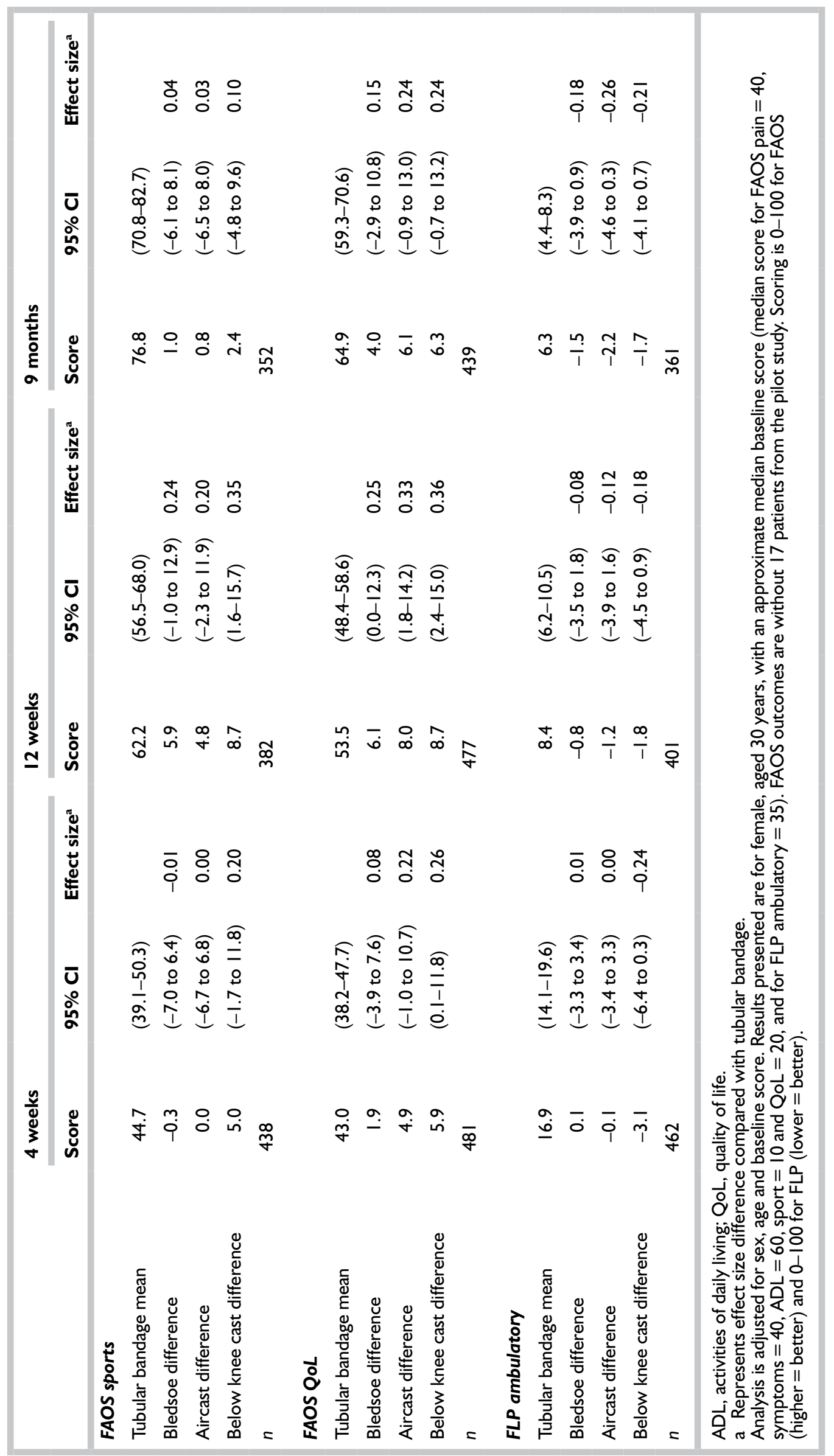




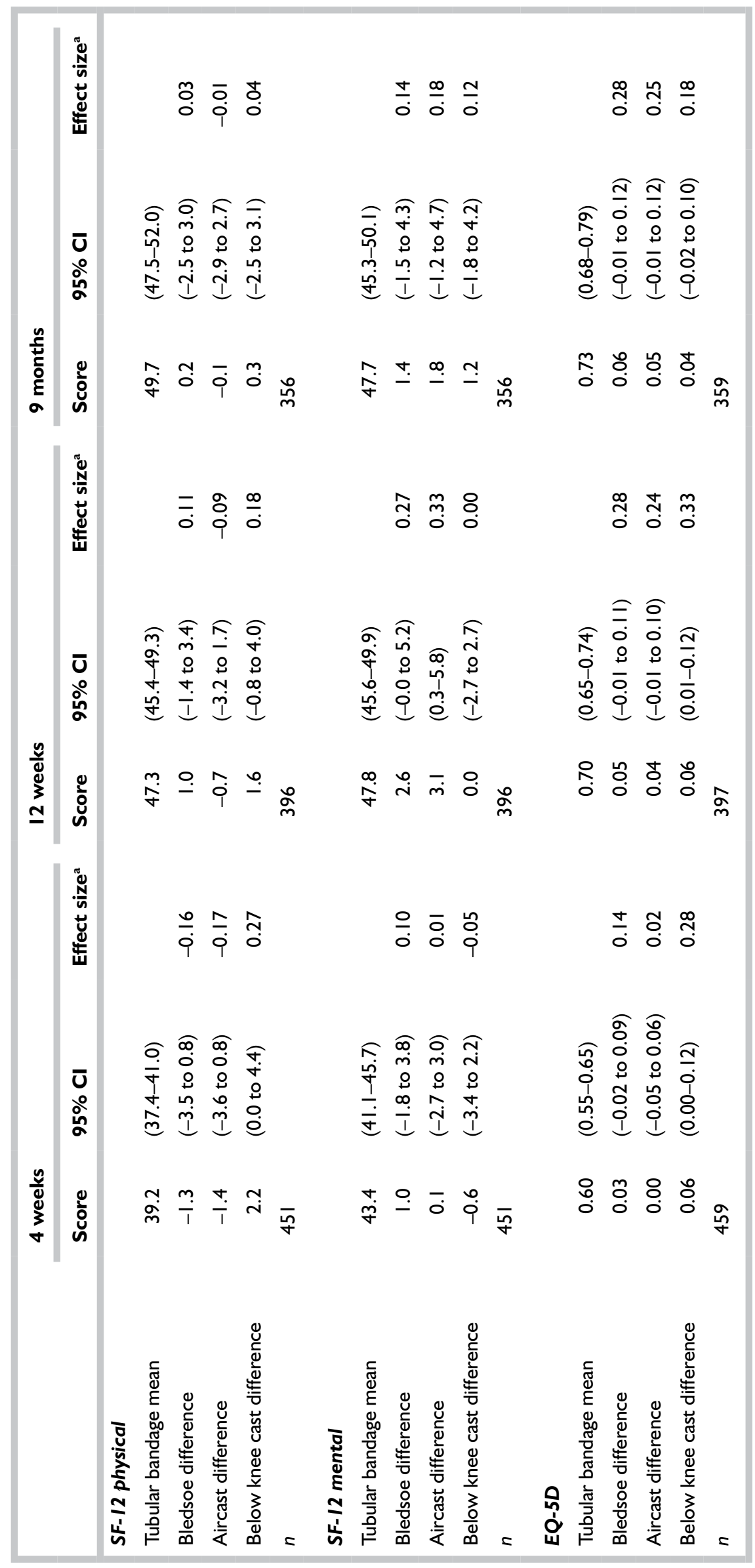




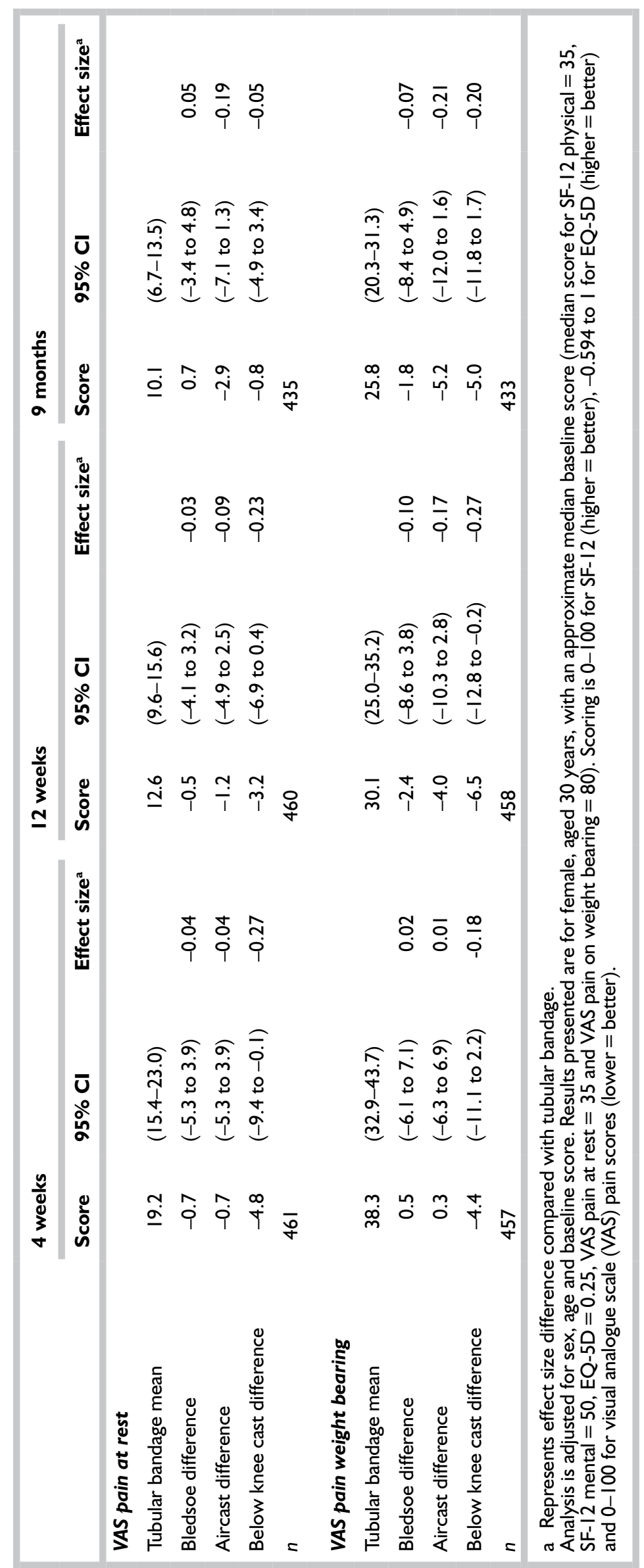


was rated about equally at between 7 and 8 out of 10 (Table 16, Figures 10 and 11).

\section{Analysis of treatment uptake}

Uptake was measured in terms of the numbers of participants who received the application of the treatment to which they were randomised. The analysis was repeated for groups defined by their uptake: that is those who were randomised to a treatment and received it and those who rejected randomisation group treatment. There were no differences between the two groups with respect to sex, age or baseline scores for primary or secondary outcomes (Table 17). Overall, the results were consistent with the results of the intention to treat analysis.

TABLE I6 Self-reported benefit score by randomisation group at 12 weeks and 9 months.

\begin{tabular}{|c|c|c|c|c|c|}
\hline & & \multicolumn{4}{|c|}{ Randomisation group } \\
\hline & & Tubular bandage & Below knee cast & Aircast & Bledsoe \\
\hline \multirow[t]{4}{*}{ Benefit score (12 weeks) $)^{\mathrm{a}}$} & Mean & 4.5 & 6.6 & 6.7 & 6.9 \\
\hline & Median & 5 & 7 & 7 & 8 \\
\hline & (Quartiles) & $(2-7)$ & $(5-9)$ & $(6-8)$ & $(5-9)$ \\
\hline & $n$ & 116 & 113 & 119 & 120 \\
\hline \multirow[t]{4}{*}{ Benefit score ( 9 months) ${ }^{a}$} & Mean & 5.0 & 6.9 & 7.0 & 7.3 \\
\hline & Median & 5 & 8 & 8 & 8 \\
\hline & (Quartiles) & $(2-8)$ & $(5-9)$ & $(5-9)$ & $(7-9)$ \\
\hline & $n$ & 109 & 106 & 106 & III \\
\hline
\end{tabular}

a Participants reported benefit of the treatment on a scale of $0-10(0=$ no benefit, $10=$ maximum benefit $)$.

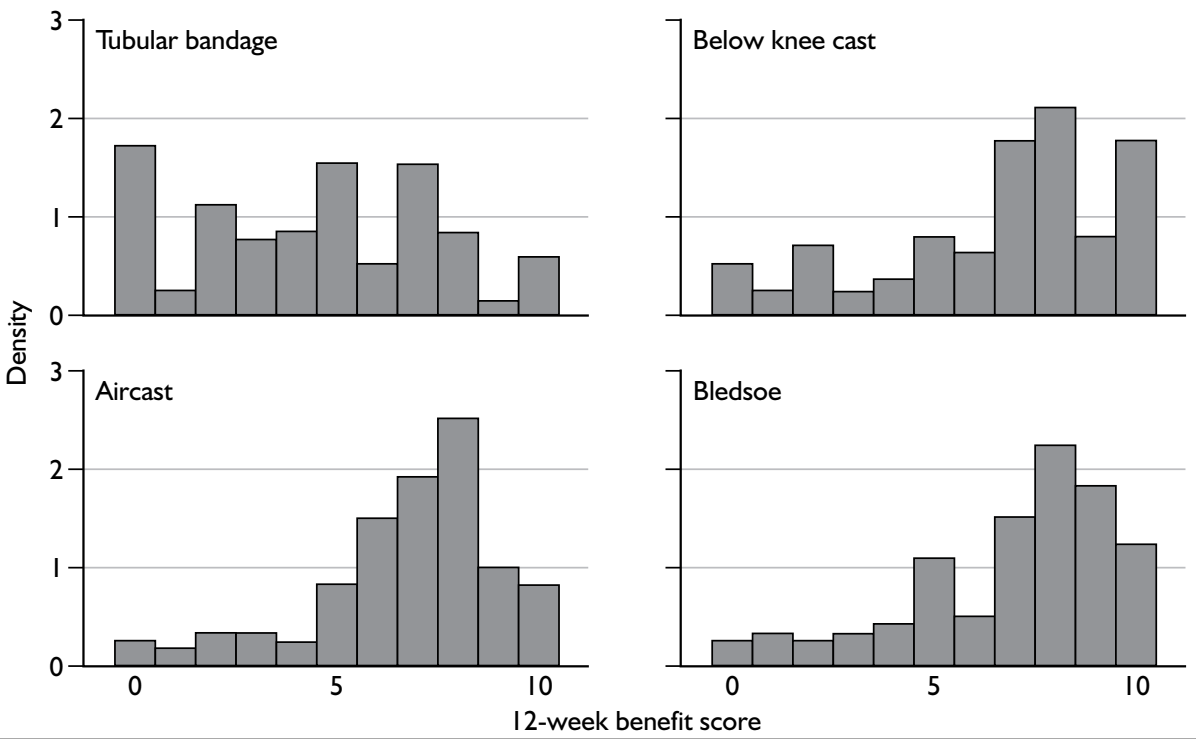

FIGURE 10 Self-reported benefit of treatment at 12 weeks. Benefit is measured on a scale of $0-10$, where $0=$ no benefit and $10=$ maximum benefit (density $=$ proportion). 


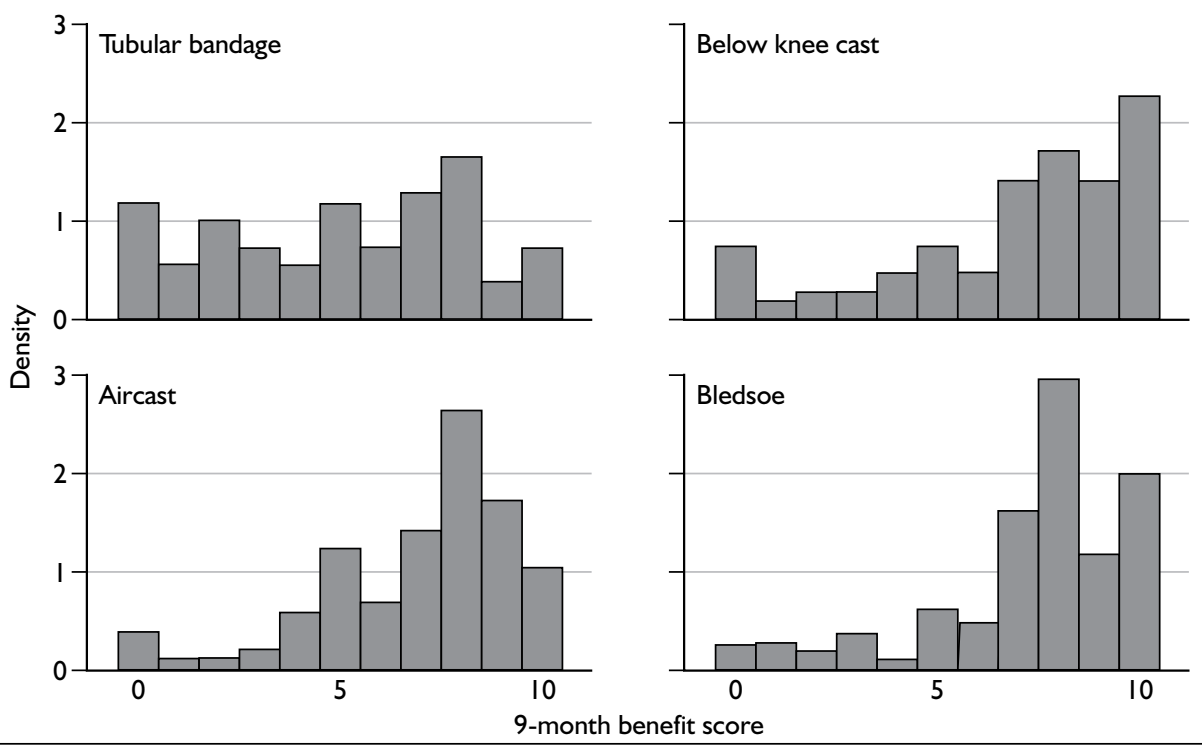

FIGURE II Self-reported benefit of treatment at 9 months. Benefit is measured on a scale of $0-10$, where $0=$ no benefit and $10=$ maximum benefit (density $=$ proportion).

TABLE I7 Baseline characteristics of participants who accepted or rejected their randomisation group treatment

\begin{tabular}{|c|c|c|c|}
\hline & & $\begin{array}{l}\text { Rejected randomisation group } \\
\text { treatment }\end{array}$ & $\begin{array}{l}\text { Accepted randomisation group } \\
\text { treatment }\end{array}$ \\
\hline \multicolumn{4}{|l|}{ Gender } \\
\hline Female, $n(\%)$ & & $12(4 I)$ & $235(42)$ \\
\hline Male, $n(\%)$ & & $17(59)$ & $320(58)$ \\
\hline \multirow[t]{3}{*}{ Age (years) } & Mean & 33 & 30 \\
\hline & Median & 28 & 27 \\
\hline & (Quartiles) & $(23-4 I)$ & $(2 \mathrm{I}-37)$ \\
\hline \multirow[t]{3}{*}{ FAOS, pain } & Mean & 43.0 & 38.1 \\
\hline & Median & 45.8 & 39.0 \\
\hline & (Quartiles) & $(33.3-55.6)$ & $(25.0-94.4)$ \\
\hline \multirow[t]{3}{*}{ FAOS, symptoms } & Mean & 45.5 & 39.2 \\
\hline & Median & 42.9 & 39.3 \\
\hline & (Quartiles) & $(32.1-64.3)$ & $(28.6-50.0)$ \\
\hline \multirow[t]{3}{*}{ FAOS, ADL } & Mean & 62.6 & 57.4 \\
\hline & Median & 64.7 & 58.8 \\
\hline & (Quartiles) & $(52.9-72.1)$ & $(50.0-66.2)$ \\
\hline \multirow[t]{3}{*}{ FAOS, sport } & Mean & 13.8 & 14.0 \\
\hline & Median & 7.5 & 10.0 \\
\hline & (Quartiles) & $(0.0-17.5)$ & $(0.0-20.0)$ \\
\hline \multirow[t]{4}{*}{ FAOS, QoL } & Mean & 18.3 & 23.4 \\
\hline & Median & 12.5 & 18.8 \\
\hline & (Quartiles) & $(0.0-34.4)$ & $(6.3-37.5)$ \\
\hline & & & cont \\
\hline
\end{tabular}


TABLE I7 Baseline characteristics of participants who accepted or rejected their randomisation group treatment (continued)

\begin{tabular}{|c|c|c|c|}
\hline & & $\begin{array}{l}\text { Rejected randomisation group } \\
\text { treatment }\end{array}$ & $\begin{array}{l}\text { Accepted randomisation group } \\
\text { treatment }\end{array}$ \\
\hline \multirow[t]{3}{*}{ FLP, ambulatory } & Mean & 35.2 & 35.7 \\
\hline & Median & 36.6 & 36.3 \\
\hline & (Quartiles) & $(28.8-45.3)$ & $(28.8-42.7)$ \\
\hline \multirow[t]{3}{*}{ SF-12, physical } & Mean & 35.7 & 35.4 \\
\hline & Median & 35.8 & 34.3 \\
\hline & (Quartiles) & $(26.3-43.1)$ & $(27.7-42.9)$ \\
\hline \multirow[t]{3}{*}{ SF-I2, mental } & Mean & 50.0 & 51.1 \\
\hline & Median & 50.5 & 53.4 \\
\hline & (Quartiles) & $(45.6-58.6)$ & $(42.7-60.4)$ \\
\hline \multirow[t]{3}{*}{ EQ-5D } & Mean & 0.38 & 0.33 \\
\hline & Median & 0.36 & 0.29 \\
\hline & (Quartiles) & $(0.16-0.62)$ & $(0.05-0.62)$ \\
\hline \multirow[t]{3}{*}{ VAS, pain at rest } & Mean & 34.9 & 37.9 \\
\hline & Median & 37.5 & 36.0 \\
\hline & (Quartiles) & $(11.0-50.0)$ & $(20.0-54.0)$ \\
\hline \multirow{3}{*}{$\begin{array}{l}\text { VAS, pain on weight } \\
\text { bearing }\end{array}$} & Mean & 67.4 & 75.8 \\
\hline & Median & 72.0 & 79.0 \\
\hline & (Quartiles) & $(49.0-80.0)$ & $(67.0-90.0)$ \\
\hline
\end{tabular}

\section{Sensitivity analysis}

Multiple imputation was used to assess the impact of (complete-case) missing data on the analyses. Conclusions from this were not substantially different from those based on the complete-case analysis presented here, and the findings were, as far as can be ascertained, relatively insensitive to missing data. 


\section{Chapter 4 \\ Economic evaluation}

\section{Introduction}

To inform decision-making on the optimum intervention for severe ankle sprain it is necessary to consider not only the measurable benefits or clinical effectiveness of different treatments but also their costs.

Severe ankle sprains can have a range of direct and indirect health-care cost consequences. These include the cost of initial treatment and any subsequent costs incurred in primary and secondary care during the recovery period. Different treatment arms may result in different direct health-care costs and differences in the date at which people return to work, days off work or 'sick leave'.

The most appropriate economic evaluation technique for a clinical trial will depend on the results, and it is recognised that a well-designed economic study should allow for different eventualities. ${ }^{80}$ The simplest eventuality would be when the cheaper intervention is found to be better on at least one outcome measure and no worse on any other, in which case it is preferred. Another eventuality is when two interventions have the same outcomes, in which case the economic evaluation required is a cost-minimisation analysis focusing only on costs. When there is the possibility that better outcomes are achieved at a higher cost, or vice versa, or when more than two interventions are being considered, a full economic evaluation is required.

This chapter presents an economic evaluation of the three interventions (below knee cast, Aircast brace and Bledsoe boot) versus tubular bandage as the comparator group. The evaluation explores costs and cost-effectiveness of these three approaches, and the factors influencing this, and is presented in several sections: (1) analysis of healthcare costs alone; (2) impact of including indirect costs (sick leave); (3) cost-effectiveness analysis; (4) cost-utility analyses with and without sick leave costs; and (5) sensitivity analyses.

\section{Methods}

The primary analysis adopted an NHS perspective as that is of most interest to NHS decision-makers. A societal perspective, including the impact on productivity costs (i.e. time off work), was included in a secondary analysis. Sensitivity analysis was used to examine the impact of uncertainty on the expected cost-effectiveness of each intervention.

\section{Assessment of costs}

We considered both the costs of providing each intervention and the costs of all subsequent care related to treatment of the severe ankle sprain, for example pain medication, follow-up visits to the hospital, GP surgery visits, associated investigations, further therapist treatments, hospitalisation, use of gels and other topical agents, and use of bandages, braces or footwear.

A combination of a primary costing approach and cost modelling was used to estimate a total cost for each participant in each group. The resource use associated with fitting each support was obtained through a microcosting study in the emergency department, considering staff time for fitting the item and the materials used. NHS list prices were used for materials (including VAT); bulk buy prices were also obtained from manufacturers for the Bledsoe boot and Aircast brace. Non-health-care costs associated with fitting, such as participant travel costs to the emergency department, were excluded.

Subsequent direct care costs and indirect costs (i.e. time off work) were estimated from responses to resource use questions included in the followup questionnaires at 12 weeks and 9 months (see Appendix 12).

Table 18 provides an overview of the resource use recorded, sources of data and means of valuation. More details are provided in Appendix 14.

To estimate subsequent health-care costs and indirect costs, questionnaire responses were 
TABLE I8 Measurement and valuation of resources used

\begin{tabular}{|llll}
\hline Resource & Measure & Source of data & Valuation \\
\hline Intervention & $\begin{array}{l}\text { Resources per person } \\
\text { fitted }\end{array}$ & Trial sites & National average unit costs \\
$\begin{array}{l}\text { Post intervention: ambulatory care } \\
\text { (outpatients, GP contacts, therapist } \\
\text { contacts, investigations, medication) }\end{array}$ & $\begin{array}{l}\text { Number and type } \\
\begin{array}{l}\text { Post intervention: inpatient care } \\
\text { (ward stay) }\end{array}\end{array}$ & $\begin{array}{l}\text { Number and length of } \\
\text { stay }\end{array}$ & Participant questionnaire \\
Sick leave & Number of days off work & Participant questionnaire & National average unit costs \\
\hline
\end{tabular}

combined to provide information on resource use for the full follow-up period. Unit costs for healthcare resources were derived from local and national sources and performed in line with best practice. ${ }^{81}$ Full details are in Appendix 14.

The total cost for each individual participant was estimated as the sum of:

1. the cost of the ankle support material plus the time required to fit multiplied by the cost per minute of a mid-scale grade $\mathrm{E}$ nurse

2. the number of consultant, GP, physiotherapy, osteopath and chiropractor consultations multiplied by the reported cost or average cost per attendance for professional specified, as appropriate

3. the number of scans [radiography, ultrasound, magnetic resonance imaging (MRI), computerised tomography (CT)] multiplied by the reported cost or average price per scan

4. the length of hospital stay multiplied by the cost per participant day

5. specified medications, creams/gels and aids multiplied by the British National Formulary (BNF) prices, or participant self-reported prices.

Cases were limited to participants for whom resource use and economic outcome data (EQ5D) were available or could be imputed over the 9-month period, following established practice. ${ }^{82}$

Costs were summed to provide a total cost estimate for individuals in the three treatment arms and the mean comparative cost was compared with that for tubular bandage participants. Data were analysed separately for direct health-care costs and for direct plus indirect costs. Costs were standardised to 2005-6 prices when possible (see Appendix 14).

\section{Cost-effectiveness analysis}

Time to recovery of mobility or increases in ambulatory score had been identified at the outset of the study as an appropriate measure of clinical effectiveness for this purpose. In the event, the time to recovery outcome measure was rejected because the quality of data obtained in questionnaire responses was judged too poor to enable an accurate analysis; participants tended to provide inconsistent responses at consecutive time points, or no response at all. Ambulatory scores examined were the FLP and the FAOS. To assess cost-effectiveness, comparison was made between baseline and 9-month data and, as is established practice, we estimated ICERs comparing interventions with the control group. ${ }^{83}$

\section{Cost-utility analysis}

Cost-utility analysis measures the cost of an intervention and expresses its benefit quantitatively, in terms of QALYs. QALYs are calculated by estimating the total life-years gained from a treatment, then weighting each year gained with a quality of life score (from 0, representing worst health, to 1 , indicating perfect health). The differences between the costs and effects of two interventions (as measured by QALYs) are expressed as a ratio, the ICER.

The primary outcome measure for the economic evaluation was the EQ-5D. This is a multidimensional measure of HRQoL that can be used to provide a valuation of utilities, or strength of preference of being in a particular health state. The single index figure produced can be used to record HRQoL over time and assess value for money. Changes in EQ-5D scores over the study period were calculated in terms of the area under the curve, assuming linear movement between 
four time points, to generate QALYs. ${ }^{84}$ For the cost-utility analysis the comparison made was undertaken from baseline to 9 months and only participants for whom we had or could impute figures for EQ-5D were included. However, an analysis of baseline characteristics (EQ-5D index, FLP, age, gender, height, weight), comparing included and excluded cases, indicated no significant differences (95\% CI), confirming that the sample used for the economic analyses is representative. Because there are no substantial upfront costs, nor are costs or benefits being tracked over a long period, ${ }^{85}$ we did not discount either costs or benefits.

Given that outcomes for the three intervention groups (measured using EQ-5D) looked broadly equivalent, the application of cost-minimisation analysis might appear attractive in the interests of keeping the economic analysis simple. However, there are major shortcomings with this approach, ${ }^{85}$ which means that it should not generally be applied except in exceptional circumstances. ${ }^{76}$ This supported the case for the use of cost-utility analysis.

\section{Results}

Results given in Chapter 3 showed that at 4 weeks the below knee cast was the most effective treatment with respect to reduction of pain and QoL measures but that by 9 months there were no statistically significant differences observed between groups. These observed early differences appear to be clinically significant.

\section{Health-care costs}

Mean direct health-care costs per participant are shown for all four groups in Table 19. Comparison of the main intervention costs indicated that the Bledsoe boot was the most expensive form of ankle support (£215 including fitting), with tubular bandage the least expensive (£1.44). Of the remaining two interventions the Aircast brace was more than twice as expensive as the below knee cast. For Bledsoe boot participants the intervention cost was the main cost driver overall, accounting for $59 \%$ of the total cost. For the other three arms subsequent treatments for ankle sprains were the major cost driver accounting for between $63 \%$ and $80 \%$ of health-care resources used.

Summing all of the health-care costs in Table 19 to produce a total health-care cost gave similar results: Bledsoe was the most expensive (£365.01) and tubular bandage the least expensive (£135.09) treatment, whereas the total costs for the below knee cast and the Aircast brace were now comparable. The mean total health-care cost for the Bledsoe boot was higher than that for the tubular bandage group; overall costs associated with the below knee cast and the Aircast brace participants were not significantly different from those associated with tubular bandage participants.

TABLE 19 Direct health-care costs by resource category

\begin{tabular}{|c|c|c|c|c|}
\hline \multirow[b]{2}{*}{ Category } & \multicolumn{4}{|c|}{ Mean participant cost $(t)$ (\% of total direct health-care cost) } \\
\hline & Tubular bandage & Below knee cast & Aircast & Bledsoe \\
\hline Intervention cost (including fitting) & $\mathrm{I} .44(\mathrm{I})$ & $16.46(10)$ & $39.23(24)$ & $215.03(59)$ \\
\hline Incremental treatment cost & - & +15.02 & +37.79 & +213.59 \\
\hline Subsequent consultation cost for ankle injury & $95.33(7 \mathrm{I})$ & $137.25(80)$ & $104.46(63)$ & I $18.77(33)$ \\
\hline Subsequent imaging cost & $18.87(14)$ & $2.02(I)$ & $2.91(2)$ & $16.05(4)$ \\
\hline Subsequent hospital admissions cost & $4.84(4)$ & $0(0)$ & $10.73(6)$ & $4.56(1)$ \\
\hline Subsequent prescribed medication cost & $7.03(5)$ & $4.17(2)$ & $3.84(2)$ & $3.84(I)$ \\
\hline Subsequent purchased medication cost & $7.58(6)$ & $10.64(6)$ & $5.35(3)$ & $6.75(2)$ \\
\hline Total direct health-care cost & $135.09(100)$ & $170.54(100)$ & $166.52(100)$ & $365.01(100)^{2}$ \\
\hline Incremental total cost & - & +35.45 & +31.43 & +229.92 \\
\hline Number of cases (imputed) & $81(5)$ & $78(2)$ & $73(1)$ & $86(3)$ \\
\hline
\end{tabular}


The figures in Table 19 are based on cases for which we either had complete EQ-5D outcome data over the 9-month period or had sufficient data points to enable us to estimate cumulative utility so that costs could be related to outcomes in the form of ICERs for the main economic analysis (see Chapter 2 and Cost-utility analyses, below).

\section{Impact of incorporating indirect costs}

Indirect costs (i.e. sick leave) were estimated based on the number of days a participant reported being absent from work multiplied by a daily cost figure (£119.70) derived from the mean gross annual UK pay in 2004, assuming 230 working days per year, inflated to 2005 prices. ${ }^{86}$ Table 20 shows that approximately three-quarters of participants were in employment, the remainder being students, retired or unemployed. Of those who were employed an average of $19 \%$ worked part-time.

If indirect costs were incorporated the total costs for each of the four arms were raised substantially (Table 20). Sick leave costs accounted for between $69 \%$ and $87 \%$ of the total cost for each group. Because inclusion of indirect costs may not meet the needs of NHS decision-makers and their valuation is contentious, ${ }^{87,88}$ the main economic analysis focused on direct health-care costs.

A more detailed breakdown of the pattern of resource use, both direct and indirect items, is shown in Table 21, and the resulting estimated costs are listed in Table 22. It is widely recognised that clinical trial-related cost data exhibit skewed distributions ${ }^{90}$ and so we have presented the median and interquartile range for the total average costs for each of the four arms of the trial.

\section{Cost-effectiveness analysis}

The incremental cost per unit improvement in FLP ambulatory score and FAOS score were estimated. The preliminary analysis did not yield conclusive results. Moreover, as we lacked information on how much society (or clinicians) would be willing to pay for a one-unit improvement in these scores it was not possible to draw any conclusions from findings in terms of value for money for the NHS. For this reason, and in the interests of clarity, the only economic analysis results presented in this report are for the cost-utility analyses.

\section{Cost-utility analyses}

Table 23 presents the cost-utility analysis findings of the incremental cost per QALY gained for the three interventions relative to tubular bandage. To produce these ICERs we used bootstrapping techniques to generate 1000 replications of actual cost and effect data. Table 23 presents the point estimates for cost per QALY; more detailed outputs are reported in Appendix 15.

The Aircast brace and below knee cast had similar ICER values, whereas the Bledsoe boot had a much higher figure (over $£ 2000$ per QALY gained). Although there is debate about the exact amount society should be willing to pay for a QALY, the National Institute for Health and Clinical Excellence (NICE) employs a threshold of approximately $£ 20,000-£ 30,000$ per QALY when considering new technologies. ${ }^{89}$ Table 23 shows that, considering direct health-care costs only, all three intervention groups were associated with a cost per QALY gained that is well within this range. The most cost-effective means of achieving a QALY was the Aircast brace, although this intervention was only marginally more cost-effective than the below knee cast.

TABLE 20 Direct health-care and indirect sick leave costs by resource category

\begin{tabular}{|c|c|c|c|c|}
\hline \multirow[b]{2}{*}{ Category } & \multicolumn{4}{|c|}{ Mean participant cost $(t)$ (\% of sample) } \\
\hline & Tubular bandage & Below knee cast & Aircast & Bledsoe \\
\hline Indirect sick leave cost at $£ \mid$ I 9.70 per diem & $805.39(86)$ & $915.40(84)$ & II47.8I (87) & $822.59(69)$ \\
\hline Direct health-care cost & $135.09(14)$ & $170.54(16)$ & $166.52(13)$ & $365.01(31)$ \\
\hline Total cost including sick leave & $940.48(100)$ & $1085.94(100)$ & $1314.33(100)$ & $1187.60(100)$ \\
\hline$\%$ in group employed & 79 & 75 & 78 & 76 \\
\hline $\begin{array}{l}\% \text { employed who work part-time } \\
(<25 \text { hour per week })\end{array}$ & 16 & 17 & 19 & 25 \\
\hline Mean number of days off work & 6.9 & 7.7 & 9.6 & 6.9 \\
\hline
\end{tabular}


TABLE 2 I Breakdown of resource use

\begin{tabular}{|c|c|c|c|c|}
\hline \multirow[b]{2}{*}{ Resource item } & \multicolumn{4}{|c|}{ Number recorded ( $\%$ of patients not using this resource) } \\
\hline & Tubular bandage & Below knee cast & Aircast & Bledsoe \\
\hline Number of participants & 81 & 78 & 73 & 86 \\
\hline Interventions requiring fitting & 81 & 78 & 73 & 86 \\
\hline \multicolumn{5}{|l|}{ Consultations } \\
\hline Emergency department staff (plaster technician) & 2 & 9 & 7 & 3 \\
\hline NHS consultant & 0 & 2 & 19 & 7 \\
\hline Private consultant & 7 & 8 & 8 & 8 \\
\hline GP & 52 & 35 & 44 & 66 \\
\hline Osteopathy & 0 & 0 & 0 & 0 \\
\hline Chiropractor & 2 & I & 0 & 0 \\
\hline NHS physiotherapy & 44 & 47 & 53 & 68 \\
\hline Private physiotherapy & 113 & 107 & 60 & 110 \\
\hline Other & 0 & 3 & 4 & 1 \\
\hline Mean number per participant & $2.7(60)$ & $2.7(60)$ & $2.7(63)$ & $3.1(65)$ \\
\hline \multicolumn{5}{|l|}{ Imaging } \\
\hline Radiography & 5 & 4 & 3 & 6 \\
\hline Magnetic resonance imaging & 0 & 0 & 0 & 2 \\
\hline Ultrasound & 1 & 1 & 2 & 1 \\
\hline Private imaging & 3 & 0 & 1 & 1 \\
\hline Mean number per participant & $0.1(93)$ & $0.1(94)$ & $0.1(94)$ & $0.1(90)$ \\
\hline \multicolumn{5}{|l|}{ Inpatient episodes } \\
\hline Inpatient days & 1 & 0 & 2 & 1 \\
\hline Mean number per participant & $0.0(99)$ & $0(100)$ & $0.0(99)$ & $0.0(99)$ \\
\hline \multicolumn{5}{|l|}{ Prescribed medication } \\
\hline Painkillers & 22 & 9 & 12 & 7 \\
\hline Anti-inflammatories & 7 & 5 & 7 & 6 \\
\hline Creams/gels & 1 & 0 & 0 & 2 \\
\hline Aids/braces/strapping & 1 & 3 & 4 & $\mathrm{I}$ \\
\hline Injection & 0 & 0 & 0 & 0 \\
\hline Other & 3 & 2 & 2 & 3 \\
\hline Mean number per participant & $0.4(74)$ & $0.2(83)$ & $0.3(79)$ & $0.2(86)$ \\
\hline \multicolumn{5}{|l|}{ Bought medicines } \\
\hline Painkillers & 25 & 19 & 23 & 16 \\
\hline Anti-inflammatories & II & 14 & 13 & 8 \\
\hline Creams/gels & 12 & 8 & 9 & 8 \\
\hline Aids/braces/strapping & 17 & 34 & 8 & 25 \\
\hline Herbal remedies & 1 & 3 & 1 & 3 \\
\hline Other & 2 & 3 & 1 & 3 \\
\hline Mean number per participant & $0.9(60)$ & $1.0(45)$ & $0.8(56)$ & $0.7(58)$ \\
\hline \multicolumn{5}{|l|}{ Sick leave } \\
\hline Days off work & 555 & 596.5 & 700 & 591 \\
\hline Mean number per participant & $6.9(65)$ & $7.7(60)$ & $10.0(59)$ & $6.9(63)$ \\
\hline
\end{tabular}

(C) 2009 Queen's Printer and Controller of HMSO. All rights reserved. 
TABLE 22 Breakdown of costs

\begin{tabular}{|c|c|c|c|c|}
\hline \multirow[b]{2}{*}{ Resource item } & \multicolumn{4}{|c|}{$\begin{array}{l}\text { Cost per participant }(\epsilon) \text { (total cost for group) } \\
{[\% \text { of participants not using this resource] }}\end{array}$} \\
\hline & Tubular bandage & Below knee cast & Aircast & Bledsoe \\
\hline $\begin{array}{l}\text { Number of participants } \\
\text { Interventions }\end{array}$ & 81 & 78 & 73 & 86 \\
\hline Ankle support intervention & $0.34(27.54)$ & $12.80(998.40)$ & $38.19(2787.87)$ & $212.68(18,290.48)$ \\
\hline Cost of fitting the intervention & $1.10(89.10)$ & $3.66(285.48)$ & $\mathrm{I} .04(75.92)$ & $2.35(202.10)$ \\
\hline Average cost per participant & 1.44 & 16.46 & 39.23 & 215.03 \\
\hline \multicolumn{5}{|l|}{ Consultations } \\
\hline $\begin{array}{l}\text { Emergency department staff } \\
\text { (plaster technician) }\end{array}$ & $0.09(7.32)$ & $0.42(32.94)$ & $0.35(25.62)$ & $0.13(10.98)$ \\
\hline NHS consultant & $0(0)$ & I.87 (I 46.00$)$ & $19.00(1387.00)$ & $5.94(511.00)$ \\
\hline Private consultant & $10.37(840.00)$ & $|2.3|(960.00)$ & $13.15(960.00)$ & $22.86(1965.60)$ \\
\hline GP & $33.77(2735.20)$ & $23.60(1841.00)$ & $31.70(2314.40)$ & $40.37(3471.60)$ \\
\hline Osteopathy & $0(0)$ & $0(0)$ & $0(0)$ & $0(0)$ \\
\hline Chiropractor & $0.62(50.00)$ & $0.52(40.52)$ & $0(0)$ & $0(0)$ \\
\hline NHS physiotherapy & $4.38(354.64)$ & $4.86(378.82)$ & $5.85(427.18)$ & $6.37(548.08)$ \\
\hline Private physiotherapy & $46.11(3734.58)$ & $49.75(3880.75)$ & $28.92(2111.34)$ & $42.76(3677.30)$ \\
\hline Other & $0(0)$ & $43.92(3425.50)$ & $5.48(399.99)$ & $0.35(30.00)$ \\
\hline Average cost per participant & $95.33[60]$ & $137.25[60]$ & $104.46[63]$ & II8.77 [65] \\
\hline Total costs for this category & 7722 & 10,706 & 7626 & 10,215 \\
\hline \multicolumn{5}{|l|}{ Imaging } \\
\hline Radiography & $1.40(113.60)$ & $1.17(90.88)$ & $0.93(68.16)$ & $1.59(136.32)$ \\
\hline Magnetic resonance imaging & $0(0)$ & $0(0)$ & $0(0)$ & $7.28(626.00)$ \\
\hline Ultrasound & $0.83(67.00)$ & $0.86(67.00)$ & $1.84(134.00)$ & $0.78(67.00)$ \\
\hline Private imaging & $16.64(1348.00)$ & $0(0)$ & $0.14(10.00)$ & $6.41(551.00)$ \\
\hline Average cost per participant & I8.87 [93] & $2.02[94]$ & $2.91[94]$ & $16.05[90]$ \\
\hline Total costs for this category & 1529 & 158 & 212 & 1380 \\
\hline \multicolumn{5}{|l|}{ Inpatient episodes } \\
\hline Inpatient days & $4.84(391.81)$ & $0(0)$ & $10.73(783.62)$ & $4.56(391.81)$ \\
\hline Average cost per participant & 4.84 [99] & $0[100]$ & $10.73[99]$ & 4.56 [99] \\
\hline Total costs for this category & 392 & 0 & 784 & 392 \\
\hline \multicolumn{5}{|l|}{ Prescribed medication } \\
\hline Painkillers & $5.46(442.58)$ & $2.36(184.40)$ & $2.48(180.92)$ & $2.20(189.46)$ \\
\hline Anti-inflammatories & $0.78(63.00)$ & $0.99(77.40)$ & $0.75(54.56)$ & $0.65(56.20)$ \\
\hline Creams/gels & $0.10(8.00)$ & $0(0)$ & $0(0)$ & $0.22(18.60)$ \\
\hline Aids/braces/strapping & $0.12(9.99)$ & $0.4 \mathrm{I}(32.04)$ & $0.13(9.68)$ & $0.07(6.35)$ \\
\hline Injection & $0(0)$ & $0(0)$ & $0(0)$ & $0(0)$ \\
\hline Other & $0.57(45.96)$ & $0.40(31.08)$ & $0.48(35.00)$ & $0.70(60.00)$ \\
\hline Average cost per participant & $7.03[74]$ & $4.17[83]$ & $3.84[79]$ & $3.84[86]$ \\
\hline Total costs for this category & 570 & 325 & 280 & 331 \\
\hline
\end{tabular}


TABLE 22 Breakdown of costs

\begin{tabular}{|c|c|c|c|c|}
\hline \multirow[b]{2}{*}{ Resource item } & \multicolumn{4}{|c|}{$\begin{array}{l}\text { Cost per participant }(t) \text { (total cost for group) } \\
{[\% \text { of participants not using this resource] }}\end{array}$} \\
\hline & Tubular bandage & Below knee cast & Aircast & Bledsoe \\
\hline \multicolumn{5}{|l|}{ Bought medicines } \\
\hline Painkillers & $3.51(284.17)$ & $2.12(165.28)$ & $\mathrm{I} .70(123.86)$ & $\mathrm{I} .76(151.00)$ \\
\hline Anti-inflammatories & $0.68(54.79)$ & $\mathrm{I} .33(103.42)$ & I.7I (124.69) & $0.5 \mathrm{I}(43.67)$ \\
\hline Creams/gels & $0.90(72.54)$ & $\mathrm{I} .07(83.46)$ & $0.88(64.05)$ & $0.44(37.44)$ \\
\hline Aids/braces/strapping & $2.03(164.59)$ & $5.56(433.64)$ & $0.89(64.96)$ & $3.52(302.61)$ \\
\hline Herbal remedies & $0.04(3.00)$ & $0.32(25.05)$ & $0.11(8.00)$ & $0.4 I(35.0 I)$ \\
\hline Other & $0.43(35.00)$ & $0.24(19.00)$ & $0.07(5.00)$ & $0.13(10.99)$ \\
\hline Average cost per participant & $7.58[60]$ & $10.64[45]$ & $5.35[56]$ & $6.75[58]$ \\
\hline Total costs for this category & 614 & 830 & 391 & 581 \\
\hline \multicolumn{5}{|l|}{ Sick leave } \\
\hline Average cost per participant & $805.39[65]$ & $915.40[60]$ & II47.8I [59] & $822.59[63]$ \\
\hline Total costs for this category & 65,236 & 71,401 & 83,790 & 70,743 \\
\hline \multicolumn{5}{|l|}{ Average cost per participant } \\
\hline Mean & 940.48 & 1085.94 & 1314.99 & 1187.60 \\
\hline Median & 123 & 113.48 & 124.07 & 257.45 \\
\hline (Interquartile range) & $(1.44-88 I .87)$ & $(16.46-960.68)$ & $(39.23-1697.33)$ & $(2 \mid 5.03-1518.20)$ \\
\hline Total costs for this category & 76,179 & 84,703 & 95,946 & 102,133 \\
\hline
\end{tabular}

TABLE 23 Cost-utility analysis: incremental cost-effectiveness ratios (ICERs), direct health-care costs only

\begin{tabular}{lcccc|} 
& Tubular bandage & Below knee cast & Aircast & Bledsoe \\
\hline Number of participants & 81 & 78 & 73 & 86 \\
ICER (direct health-care costs only) & - & $£ 339^{\mathrm{a}}$ & $£ 30 \mathrm{I}$ & $£ 2116$ \\
\hline a Simulation output (I000 trials) ICERs. & & & &
\end{tabular}

There are some methodological problems associated with the application of ICERs, ${ }^{91}$ and summarising clinical trial results in terms of ICERs can be misleading when there are more than two comparators. A particular arm may have the most favourable cost per QALY gained but a lower level of effectiveness than other intervention(s). In these circumstances an alternative intervention that is more effective but also associated with a higher cost may actually represent a more favourable option if the effectiveness gain justifies the additional marginal cost.
In such a situation, and to summarise uncertainty around ICER estimates, the use of costeffectiveness acceptability curves (CEACs) is becoming increasingly accepted within clinical trials to assess different options. ${ }^{92}$ CEACs have the advantage that the curves convey information from which inferences can be made about the statistical significance or otherwise of cost-effectiveness results. ${ }^{93}$ For multiple comparators one can attempt to rank the options by cost and then remove the options by simple and extended dominance. ${ }^{94}$ However, to do this discernible differences must 
exist in effectiveness between comparators. In this instance, the differences in average effects between intervention groups (as measured using EQ-5D) are so small that they are not statistically significant. Therefore, although we could assume that the control group was not a cost-effective option (because of the relatively small incremental cost per QALY associated with all of the intervention groups relative to the control group) we lacked a basis to rank interventions using either simple or extended dominance. Thus, we considered the cost-effectiveness of all options relative to the control group.

A CEAC curve (Figure 12) indicates the probability (on the vertical axis) that an intervention is costeffective relative to the comparator group for a range of possible societal valuations of a QALY (on the horizontal axis). If, for any given valuation of a QALY, the CEAC reaches or exceeds a $95 \%$ probability then it is possible to conclude (at the $5 \%$ significance level) that this intervention is cost-effective relative to the control group. Several interventions can be displayed on the same graph and thus CEACs can shed light upon costeffectiveness in more complex decision-making contexts.

The CEAC curves in Figure 12 demonstrate that there is a high probability that all three interventions are more cost-effective than the control (tubular bandage) for most reasonable cost per QALY thresholds. Both the below knee cast and the Aircast brace were virtually the same, indicating that these two interventions had a comparable costeffectiveness. The Bledsoe boot curve lay below these two, indicative of lower cost-effectiveness.

Appendix 16 provides scattergrams illustrating cost-effectiveness for the 1000 simulations under the different treatment regimes for direct care costs only (Figures 14-16). Similar benefits accrued on use of the Bledsoe boot as a treatment for greater health-care costs than for Aircast or below knee cast in almost all simulations.

\section{Impact of indirect costs on ICERs}

To take the costs associated with absence from work into account we could use either a friction cost or a human capital approach. Although the friction cost approach has its advocates, ${ }^{95,96}$ it lacks a foundation in economic theory. ${ }^{97,98}$ Therefore, in the interests of simplicity we used a human capital approach.

When the costs of days off work because of illness were included, a different picture emerged (Table 24). The Aircast brace was now the least cost-effective intervention and the below knee cast remained the best in terms of value for money.

The CEACs shown in Figure 13 suggest that, once costs arising through sick leave were included, the Aircast brace was the least cost-effective option and that, once society values a QALY at around $£ 7500$, both the Bledsoe boot and below knee cast appeared to be equally cost-effective. All three interventions were cost-effective compared with the control group (tubular bandage) assuming a costeffectiveness threshold of $£ 20,000$ per QALY.

FIGUE 12 Simulation output (1000 trials) cost-effectiveness acceptability curves (CEACs). Graph showing the probability of an intervention being cost-effective relative to tubular bandage at different levels of willingness to pay for an additional quality-adjusted lifeyear (QALY) (direct health-care costs only; excludes sick leave costs). 
TABLE 24 Cost-utility analysis: incremental cost-effectiveness ratios (ICERs), direct health-care and indirect sick leave costs

\begin{tabular}{|c|c|c|c|c|}
\hline & Tubular bandage & Below knee cast & Aircast & Bledsoe \\
\hline Number of participants & 81 & 78 & 73 & 86 \\
\hline $\begin{array}{l}\text { ICER (direct health-care and indirect } \\
\text { sick leave costs) }\end{array}$ & - & $E 1393^{\mathrm{a}}$ & $£ 3585$ & $£ 2275$ \\
\hline
\end{tabular}

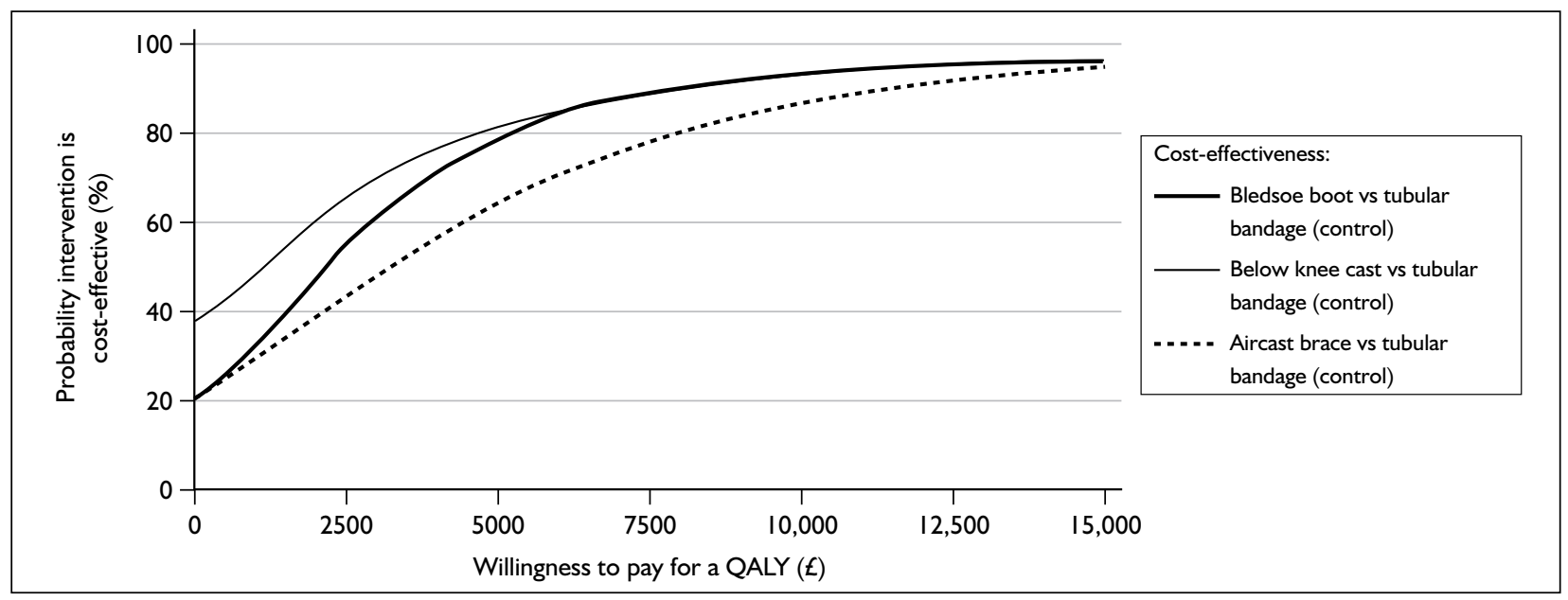

FIGURE I3 Simulation output (1000 trials), cost-effectiveness acceptability curves (CEACs). Graph showing the probability of an intervention being cost-effective relative to tubular bandage at different levels of willingness to pay for an additional quality-adjusted lifeyear (QALY) (direct health-care and indirect sick leave costs).

Appendix 16 provides scattergrams illustrating cost-effectiveness for the different ankle support regimes including indirect costs (Figures 17-19), showing that, if sick leave costs were included, there was little to discriminate between the three interventions in terms of costs or benefits accrued.

\section{Sensitivity analyses}

There will be uncertainties in many of the estimates above and in some of the assumptions made (e.g. the average cost per day off work). In addition to the bootstrapped probabilistic sensitivity analysis described above, one-way sensitivity analyses for a range of input parameters were used to examine the uncertainty in any conclusions drawn on relative cost-effectiveness. ${ }^{99}$ Analyses considered key cost drivers and factors that might affect the outcomes measured.

In terms of costs the main health system cost driver was the cost of the interventions themselves (from
$34 p$ for tubular bandage to $£ 212.68$ for Bledsoe boots). Staff costs for fitting interventions were not key drivers ( $£ 1.10$ and $£ 2.35$ per participant for these same supports respectively). For intervention costs, prices were not adjusted to make any allowance for bulk discounts because this would require very large orders, which it was judged that individual NHS trusts were unlikely to be able to sustain. However, for the purpose of sensitivity analysis we established with manufacturers how costs might be affected if NHS trusts could obtain either Aircast braces or Bledsoe boots at a bulk buy discount (e.g. through some centralised purchasing arrangement via NHS supplies). For Aircast braces the suppliers offered a bulk buy price of $£ 22.56$ (list price £38.19 including VAT) but only for bulk orders of 500 braces on a 3-year contract. For Bledsoe boots bulk buy costs would be $£ 58.75$ (list price £212.68 including VAT) for orders of over 100 per year. Bulk purchase was not appropriate for either tubular bandage (cost too low at 34p) or below knee casts (relatively inexpensive at $£ 12$.80 
and available from a variety of suppliers so prices are competitive).

The main uncertainty in the measures of benefit used was the use of imputation for missing EQ-5D data, although the number of cases involved was very small (1-3\% depending upon treatment arm).

\section{Health-care cost perspective}

The following one-way sensitivity analyses were undertaken.

\section{Impact on health-care cost of removal of imputed cases}

Removal of participants for whom imputed values had been used had no effect on the ranking of the three interventions (Table 25).

\section{Impact on health-care cost of assuming bulk buy prices}

Table 25 shows that bulk buy of the Bledsoe boot or the Aircast brace reduced the respective ICER value. However, the Bledsoe boot still ranked as the least cost-effective intervention, whereas the Aircast brace became substantially more favourable than the below knee cast.

\section{Societal cost perspective}

The inclusion of sick leave costs meant that it was no longer possible to draw clear conclusions regarding the cost-effectiveness of the comparator arms and so sensitivity of the analysis to various assumptions about sick leave was explored rigorously.

\section{Impact on societal cost of varying assumptions on sick leave cost}

Sick leave was clearly a major cost driver, accounting for between $69 \%$ and $87 \%$ of the overall societal costs. There are a number of sources of uncertainty associated with this cost estimate.

\section{Reported days off work and their cost}

Estimation of sick leave cost raised two principal concerns. First, the cost of a day off work may have been overvalued. In cases in which some of the population is unemployed or when individuals can 'catch up' on missed work or other staff can provide cover, the real value to society of the cost of time off work may be less than that based on the value of a day off work ${ }^{87}$ Second, when respondents specified a given number of days or weeks off work it was sometimes unclear whether they had adjusted this figure to account for the part-time nature of their work, and thus the total number of days off work may have been overestimated. An average of $19 \%$ of working trial participants reported that they were employed part-time. We assumed in a one-way sensitivity analysis that the actual cost of a reported day off work was half the value used in the earlier analysis (£59.85). Table 26 shows that if this lower cost for reported days off work is assumed, the below knee cast performed best, with the Aircast brace next best and the Bledsoe boot performing the worst. The cost per QALY improved and the Bledsoe boot fell from second to third in rank order, with the below knee cast and the Aircast brace remaining unchanged.

\section{Sick leave outliers}

In all groups there were a small number of people who reported a large number of weeks off work (up to 9 months). Clinical opinion was sought on how best to interpret these observations. Incapacity requiring time off work greater than 6 weeks (30 days) was thought by clinicians to be highly unusual. Recovery data from the trial were generally consistent with time to recovery not

TABLE 25 Sensitivity analysis (incremental cost effectiveness ratios): direct health-care costs only

\begin{tabular}{|c|c|c|c|c|}
\hline & \multicolumn{4}{|c|}{ Cost per participant ${ }^{a}$} \\
\hline & Tubular bandage & Below knee cast & Aircast brace & Bledsoe boot \\
\hline ICER (baseline) & - & $£ 339^{\mathrm{b}}(2)$ & $£ 301(1)$ & $£ 2116(3)$ \\
\hline ICER (imputed cases removed) & - & $£ 392(2)$ & $£ 323(1)$ & $£ 2184(3)$ \\
\hline Number of participants with imputed data & $5 / 81(6 \%)$ & $2 / 78(3 \%)$ & $1 / 73(1 \%)$ & $3 / 86(3 \%)$ \\
\hline ICER (bulk buy price for Aircast and Bledsoe) & $-^{c}$ & $£ 339^{\mathrm{b}}(2)$ & $E|5|(I)$ & $£ 699(3)$ \\
\hline
\end{tabular}


TABLE 26 Sensitivity analysis (incremental cost effectiveness ratios): direct health-care and indirect sick leave costs

\begin{tabular}{|c|c|c|c|c|}
\hline & \multicolumn{4}{|c|}{ Cost per participant ${ }^{a}$} \\
\hline & Tubular bandage & Below knee cast & Aircast brace & Bledsoe boot \\
\hline $\begin{array}{l}\text { ICER (baseline, sick pay at } £|| 19.70 \\
\text { per diem) }\end{array}$ & - & $£ \mid 393^{\mathrm{b}}(\mathrm{I})$ & $£ 3585(3)$ & $£ 2275(2)$ \\
\hline ICER (sick pay at $£ 59.85$ per diem) & - & $£ 866(1)$ & $f 1943(2)$ & $£ 2195(3)$ \\
\hline $\begin{array}{l}\text { ICER (cap person days off work at } \\
30 \text { days) }\end{array}$ & - & $£ 58(1)$ & $E \mid 746(2)$ & $£ 2596(3)$ \\
\hline Sick leave $>30$ days & $5 / 81(6 \%)$ & $4 / 78(5 \%)$ & $5 / 73(7 \%)$ & $3 / 86(3 \%)$ \\
\hline ICER (imputed cases removed) $^{c}$ (im & - & EI03I (I) & $£ 3024(3)$ & EI $794(2)$ \\
\hline $\begin{array}{l}\text { Number of participants with imputed } \\
\text { data }\end{array}$ & $5 / 81(6 \%)$ & $2 / 78(3 \%)$ & $1 / 73(1 \%)$ & $3 / 86(3 \%)$ \\
\hline $\begin{array}{l}\text { ICER (bulk buy price for Aircast } \\
\text { brace and Bledsoe boot) }\end{array}$ & $-^{\mathrm{d}}$ & $E \mid 393^{\mathrm{d}}(2)$ & $£ 3435$ (3) & f858 (I) \\
\hline \multicolumn{5}{|c|}{$\begin{array}{l}\text { a Cost per participant is ranked from I to } 3 \text {, with I being the most favourable option. } \\
\text { b Incremental cost-effectiveness ratios (ICERs) based on simulation output ( } 1000 \text { trials). } \\
\text { c Sick pay assumption maintained at } f \text { I I } 9.70 \text { per diem. } \\
\text { d No bulk buy price for these items. }\end{array}$} \\
\hline
\end{tabular}

requiring more than 12 weeks. Thus, the effect of introducing a 30-day cap to the number of sick days attributable to ankle injury was explored in a further sensitivity analysis. Table 26 shows that removing these outliers had a similar effect to reducing the value attached to a reported day off work, with a major impact on the below knee cast ICER value (£58), and the Bledsoe boot ICER once again becoming the least favourable (rising to $£ 2596$ per QALY).

\section{Impact on societal cost of removal of imputed cases}

The impact of removing from the analysis any participants for whom imputations were made is also shown in Table 26. This had no effect on the ranking of different interventions relative to tubular bandage.

\section{Impact on societal cost of assuming bulk buy prices}

Table 26 also shows that assuming bulk buy prices were in operation improves significantly the ICER value for the Bledsoe boot, making it the most costeffective intervention. For the Aircast brace there was a small improvement in the ICER value, which was not large enough to change its ranking.

\section{Summary of societal cost perspective}

Table 26 shows that the below knee cast remained the most cost-effective intervention compared with tubular bandage, ranking number one under all conditions except for bulk buy. The Bledsoe boot and Aircast brace gave similar rankings overall, each with two second places and two third places, with the Bledsoe boot ranking first under bulk buy conditions.

\section{Discussion}

From a health-care cost perspective the Aircast brace and below knee cast represented the most cost-effective interventions, with the Bledsoe boot ranked third. The cost-utility analyses also demonstrated that the Bledsoe boot was least costeffective but that all three interventions were highly cost-effective compared with treatments for other types of condition. The cost per QALY figures extended up to a maximum of just above $£ 2000$ per QALY for the Bledsoe boot, which was well below the threshold set by bodies such as NICE of $£ 20,000-£ 30,000$.

To capitalise on any reduced prices associated with bulk buy arrangements some centralised purchasing arrangement would need to be established. For Aircast the suppliers offered a bulk buy price of $£ 22.56$ (list price $£ 38.19$ including VAT), but only for bulk orders of 500 braces on a 3-year contract. The eight trial clinics saw 1522 potentially eligible participants over a period of 
27 months, equating to approximately 85 patients annually per centre; therefore, a throughput of 500 braces per annum would only be feasible at a fivecentre level. The transaction, storage and transport costs involved in a centralised supply chain would then need to be balanced against any cost savings. The feasibility of such an arrangement is doubtful.

\section{Conclusion}

When considered from a health-care perspective alone the below knee cast and Aircast brace are the most cost-effective options for the management of severe ankle sprains. If purchased under bulk buy conditions the Aircast brace is more cost-effective than the below knee cast; however, the feasibility of a bulk buy system is doubtful. If the decision- maker's main concern is to maximise effectiveness relative to total health-care costs then the Aircast brace may have a marginal cost-effectiveness advantage over the below knee cast. The lack of a clear front-runner in terms of cost-effectiveness reinforces the case for giving patients an informed choice.

When considering societal costs as well, the below knee cast is the most cost-effective treatment for severe ankle sprains. This finding persists throughout analyses using a range of assumptions about sick leave.

The sensitivity of rank order to changes in the assumptions made about sick leave means that results from this wider cost perspective should be treated with some caution. 


\section{Chapter 5}

\section{Acceptability of a deposit system}

\section{Introduction}

A component of the original brief commissioned by the National Coordinating Centre for Health Technology Assessment (NCCHTA) was to explore the feasibility of a deposit system to promote return of the mechanical supports and reuse. The manufacturers of the Bledsoe boot and Aircast brace do not recommend reuse, although both allow washing of the device.

In the context of a clinical trial it was felt that, given the manufacturer's recommendations, and the many barriers that already exist to recruitment into trials, implementing a deposit system was impractical. It was agreed with NCCHTA that a small series of interviews would be undertaken as a preliminary exploration of the topic. We undertook a small qualitative study to examine participants' opinions of the viability of a refundable deposit system for expensive items such as the Bledsoe boot.

\section{Method}

A total of 19 CAST trial participants (10 males and 9 females) undertook semistructured interviews. They were conducted by a single researcher (RN). Participants were asked four questions:

1. How would you have felt if we had asked for a refundable deposit on the boot/brace to encourage you to return it?

2. How big a deposit would encourage you to return the boot/brace? $£ 0-5, £ 5-10, £ 10-15$, $£ 15-20$, more than $£ 20$ ?

3. Would you have been willing to pay this amount if asked?
4. If you had been asked to pay a deposit, do you think this would have affected your willingness to take part in the trial? Please explain.

All interviews were audio tape recorded with the participant's consent and later transcribed verbatim. The key questions were designed to give yes/no responses but a subsequent explanation of the answer was open. Thematic analysis of these responses was undertaken.

\section{Participants}

The mean age of participants was 34 (range 1662). Eight participants were non-drivers. The level of sporting activity of participants ranged from no participation in sport to regular participation in three or more sporting activities. The majority of participants $(12,63 \%)$ had injured their ankle between 3 and 6 months before the qualitative study. Four participants were randomised to tubular bandage, four received a below knee cast, six received a Bledsoe boot and five received an Aircast brace. Analysis was performed using the approach of framework analysis. ${ }^{100}$

\section{Results}

The idea of a refundable deposit to encourage return of the boots was explained to the participants and they were then asked whether they would have been willing to pay (Table 27).

The majority of participants had no problem with the idea of paying a deposit. Some participants had previous experience of shortages of hospital equipment and were willing to participate in a

TABLE 27 Frequencies of those willing or not to pay a deposit

\begin{tabular}{|c|c|c|c|c|c|c|}
\hline & \multicolumn{2}{|c|}{ Yes } & \multicolumn{2}{|c|}{ No } & \multicolumn{2}{|c|}{ Not sure } \\
\hline & $n$ & $\%$ & $n$ & $\%$ & $n$ & $\%$ \\
\hline Willing to pay deposit & 16 & 73 & 1 & 5 & 2 & 9 \\
\hline
\end{tabular}


scheme to help prevent this. Two participants were unsure and expressed expectations of 'free' health care. Having to pay a deposit (even if refundable) went against these expectations. One participant was flatly against the deposit system, stating that paying a deposit 'goes against the grain'. Two of the participants suggested that they felt a social obligation to return hospital equipment and that they felt a deposit would not make any difference to them. Most participants $(n=14,64 \%)$ felt that a deposit of between $£ 15$ and $£ 20$ would be fair considering the cost of the Bledsoe boot. Although most participants would be willing to pay they were then asked whether they would have had sufficient funds on them at the time of their emergency department attendance. About half of the participants felt that they would not have had enough cash to pay such a deposit, although many would have had either a cheque book or credit/ debit cards.

\section{Conclusion}

This is a small study that aims only to give an initial exploration of the acceptability of a deposit system. Participants were generally happy with the concept of paying a deposit for a device like the Bledsoe boot. However, the mechanical integrity of the devices over prolonged periods of use and different cleaning regimes is unknown and would have to be established before reuse could be recommended. If the device had proven a more clinically effective option, a deposit and reuse system may have reduced the overall cost. No further modelling was undertaken given the results of the trial. The costs of implementing a deposit system for the Aircast brace are likely to outweigh any benefits if the device was reusable. Neither the tubular bandage nor below knee casts are fit for reuse.

Further research is required to determine the effects of deposits in clinical trials. 


\section{Chapter 6 Discussion}

\section{Main findings of the trial}

This is the first large RCT of three types of mechanical support for ankle sprains of sufficient severity to prevent weight bearing. Results showed a clinically and statistically significant advantage for the use of a below knee cast compared with tubular bandage in relation to symptom resolution and return of normal activity and function in the first 3 months. Benefits were maximal in the first 3 months of recovery. The differences between tubular bandage and the Aircast ankle brace and the Bledsoe boot had less clear clinical relevance, although the Aircast brace gave significantly better results for mental well-being in the early stages. The economic evaluation indicates that from a health-care perspective the Aircast brace and below knee cast perform similarly in terms of costeffectiveness. The Bledsoe boot is the least costeffective (relative to tubular bandage).

\section{External validity and generalisability of the findings}

This multicentred trial recruited from eight centres ranging from teaching hospitals to district hospitals, with a range of sizes of emergency departments, in a variety of metropolitan, urban and semirural environments. The services available in these hospitals reflected the normal services in UK hospitals, with none having specific specialist services applicable to this type of injury. The level of training in application of braces was consistent with what would be expected in routine clinical practice, with some being applied by plaster technicians but most being applied by other clinical staff, as is normal practice for these units. No special instructions regarding the type of below knee casts were given, but all sites used synthetic casts.

The interventions before application of the tubular bandage or mechanical support were standardised to ensure equality between treatment arms. This minimised risk, including compartment syndrome associated with excessive swelling, and ensured that injuries were of sufficient severity to meet the case definition. Injury severity is particularly difficult to ascertain until time has passed and swelling has had a chance to resolve. Audit has demonstrated that there was variable referral into the trial by clinicians, with between $15 \%$ and $100 \%$ of potential participants being referred to the clinic for consideration of recruitment. It was not possible to collect detailed information about these potential participants. We have no reason to believe that there was a systematic bias in those approached. Of those unable to weight bear at the time of presentation who were given a clinic appointment, 512 (43\%) had symptom resolution by the time of clinic attendance and were therefore not eligible for the trial. In practice, it is possible that the tubular bandage, Bledsoe boot or Aircast brace could be applied at the time of emergency department presentation. However, this is highly unlikely to affect the results that we obtained. Larger numbers of less severe self-limiting injuries would have been included. A study of current practice ${ }^{20}$ showed low usage of mechanical supports at initial presentation, and it is believed that current practice in emergency medicine is for delayed application.

Loss to follow-up was minimal for the first 3 months of the trial and the internal validity of the study was not compromised. Slightly higher losses occurred by the 9-month follow-up; however, the main purpose for continuing follow-up until 9 months was not to detect differences between treatment but to ensure that, overall, no one treatment was associated with a consistently poor profile. Otherwise, internal validity of the study was good (see comments in the section on limitations of the study).

Overall, we believe that the generalisability of this trial is good, with valid representation of severe injury (represented by the inability to weight bear as a proxy for grade II and III injuries), a wide range of hospitals and substantial numbers of participants. It is not known whether the spectrum of patients presenting to emergency departments is similar to those presenting to minor injury units, primary care or sports injury facilities. However, the number of patients with the severity of injury 
studied here who are treated at these facilities is likely to be small, as all of these patients require radiography.$^{65}$ It is believed that the results of this trial should be applicable to all patients conforming to the inclusion/exclusion criteria of the trial.

It is important to note that this trial is related to the subgroup of patients who presented to emergency departments with an ankle sprain of such severity that they were unable to weight bear on that leg at the time of presentation and were still unable to weight bear at a review clinic a few days later. The population in this study had a slightly higher proportion of males than females, similar to previous studies, but average age was slightly higher than in previous studies because of the inclusion criteria (no upper age limit and all types of injuries). All participants received advice to elevate the limb, use ice, rest and undertake gentle non-weight-bearing exercises in the days between emergency department attendance and the clinic appointment. This initial period of 2-3 days may be important for the subsequent outcome, as it results in reduced swelling and also promotes early movement. The reduction in swelling is important both to speed up the healing process and to reduce pain, and also to allow proper fitting of any external support devices. The Aircast brace can be applied in the presence of oedema and gradually adjusted as swelling reduces, but the Bledsoe boot and tubular bandage may be oversized if applied early in the presence of swelling. A cast that can be weight bearing is contraindicated in the first few days because of the risk of compartment syndrome.

\section{Internal validity and limitations of the trial}

The trial groups were comparable for age, sex, educational status, baseline symptoms and injury characteristics and we do not believe that there has been any bias in allocation to the four treatment groups. Overall, the trial group was comparable to the English population for sex, height, BMI, employment, educational status and ethnicity, based on 2001 census data and data from the 2004 Health Survey for England. Comparative data for previous ankle injuries and symptoms are not available.

Uptake of treatment varied between groups. The below knee cast is the only treatment that participants cannot remove themselves. The majority of those who declined the trial because they did not want a particular treatment cited plaster as their reason for declining (46 out of 57 participants, $81 \%$ ) (see Table 4). Insignificant numbers did not receive the allocated intervention for other reasons, were lost to follow-up or discontinued their treatment. The compliance rate over the following 2 weeks is not known; participants in the non-cast group could remove their splints either intermittently or permanently after leaving the clinic.

The follow-up rates in the study were high compared with similar clinical trials, with follow-up rates of $83 \%, 82 \%$ and $76 \%$ for the 4 -week, 12 -week and 9-month questionnaires respectively.

At the time of randomisation (a few days after injury), most participants were abstaining from sport, were not confident in walking, had moderate or frequent pain and had moderately severe symptoms. Nearly all participants reported some difficulty in basic self-care and mobility. In comparison with age- and sex-adjusted population norms, the participants had significantly impaired mobility but similar mental health scores.

We confirm the findings of other investigators in smaller studies that ankle sprains presenting with the inability to weight bear do not recover quickly; many participants still had limited mobility and function resulting from their injuries at 9 months. Patients with ankle sprains who initially present with an inability to weight bear should be given a cautious prognosis and warned of potential long-term effects on their mobility and activities. Recovery is slower and less complete with increasing age. At all follow-up points and across all randomisation groups the scores of men were better than those of women on all primary outcome measures.

Three participants in the study developed DVT and two suffered pulmonary emboli (although one was probably related to pregnancy rather than the injury and the other had a past history of thromboembolic disease and was taking warfarin and was randomised in error). These adverse events were not associated with any particular treatment arm. Thromboembolic events are a recognised but unquantified event after ankle injury. Our study suggested a rate of 1\% (4/584) of ankle injuries having a clinically apparent thromboembolic event within 9 months of injury. Numbers were too small to give differential rates 
by treatment. The risks/benefits of the use of prophylactic anticoagulation in lower limb injury are uncertain ${ }^{101}$ and could usefully be investigated in future studies.

\section{Clinical findings}

The differences observed between treatments were broadly consistent across all physical measures and their subscales.

Mental health status at 4 weeks fell to below the norm for all treatment groups, suggesting that this injury has an adverse effect on mental well-being regardless of the support method used. For mental health the results suggest that the removable supports may give better results than either tubular bandage or the fixed below knee cast. By 9 months only the tubular bandage group had mental health scores below the population norm. Psychological issues will result from a combination of the effects of the injury, the recovery and the treatment. Although the below knee cast resulted in quicker recovery it did not give the best mental health scores early on; however, by 9 months the scores were comparable for all groups except for tubular bandage. It is possible that the inability to remove the boot, for either comfort or hygiene purposes, may be responsible for this effect.

Trials that use disability and HRQoL outcomes face significant challenges in interpreting the clinical meaningfulness of the observations made. There are some benchmarks against which we can assess the clinical importance of the differences between treatments. Changes in scores of between 2.5 and 4.0 points on the SF12 are generally considered clinically meaningful in terms of the individual. ${ }^{102}$ Studies of the use of visual analogue scales for pain severity in the emergency care setting indicate that a change of $13 \mathrm{~mm}$ is the accepted level for indicating a clinically significant change. ${ }^{103,104}$ There is little evidence to determine clinically significant changes in the FAOS, although the authors have suggested that an 8- to10-point difference, as used in the Knee injury and Osteoarthritis Outcome Score, is clinically significant. ${ }^{105}$ These guidelines suggest that differences between the treatments observed on the FAOS scores were small at baseline and of moderate size at 12 weeks. Differences between tubular bandage and the below knee cast were commensurate with a clinically significant change.
An alternative method is to express the differences between groups in relation to the standard deviation. ${ }^{106}$ Effect sizes of 0.25 are considered small but may be of clinical relevance, and those of $0.25-0.5$ are considered moderate but are likely to be of clinical relevance. Overall, our interpretation of findings of the CAST study are that the benefits afforded by below knee casts in relation to tubular bandage are clinically small at 4 weeks, but clinically more substantial by 12 weeks, affording greater recovery of mobility, comfort and confidence in the ankle.

Present medical opinion has suggested the importance of early mobilisation and the role of early return of proprioceptive stimulation as key determinants of recovery in ankle sprains. Results from our study contradict this theory by demonstrating that the treatments producing most immobilisation resulted in quicker recovery, without any longer-term disadvantage. However, although we used a below knee cast, it was for a relatively short period compared with that in many studies. There are various pathophysiological mechanisms that could explain our findings that a period of immobilisation may be beneficial, including a decreased risk of further reinjury and rebleeding even at the microscopic level, an early decrease in pain encouraging better mobilisation once the cast is removed, short-term abolition of pain reducing plastic changes in the central nervous system that can lead to increased vigilance of the ankle and the development of centrally sensitised pain, decreased swelling because of increased elevation of the cast compared with other patients, a better proprioceptive response when the cast is removed because of decreased swelling and loss of abnormal stimulus that may occur in the early recovery phase, and a decreased inflammatory response with decreased abnormal fibrosis and a recovery period allowing return of tensile strength of ligaments before mobilisation. The initial 2-day period may be important in dispersing initial haematomata that could lead to a fibrotic response.

It is possible that long-term instability (becoming apparent after 9 months) occurs, but this would not be detected in this study. It is well recognised that a period of initial movement can prevent stiffness in joints that are subsequently immobilised. We do not know how much exercise people undertook when in each form of splint or how much/when they removed the device. If a period of relative immobility is the reason for the improved outcome 
then it is possible that the other groups performed less well because they could remove the splint and therefore moved the ankle more. It would only be possible to determine this by trials of varying regimes of usage of the various splints, to inform any instructions on splint usage. The below knee cast completely immobilises, and therefore gives better analgesia during its use, but this benefit persists at 4 weeks (over 2 weeks after removal). Early diminution of pain may have important consequences for encouraging recovery and could potentially be duplicated by better analgesia. The below knee cast is the only device for which the period of support is guaranteed and which cannot be varied by the patient or by the clinician's instructions. It may also have other reasons for improved outcome that could be independently manipulated, such as indirectly encouraging more elevation, less dependency and less use of the whole limb, being more likely to be elevated at night and providing better analgesia.

With no benefit in outcome and with worse mental health scores this study does not recommend the use of tubular bandage in severe ankle sprains. It is unlikely that severe injuries would be appropriately treated by the widely used RICE (rest, ice compression, elevation) regime.

\section{Cost and economic analysis}

Mean direct health-care costs per participant indicated that the Bledsoe boot was the most expensive form of ankle support, with tubular bandage the least expensive.

Cost-utility analysis, comparing incremental costs with differential impact on HRQoL over 9 months, demonstrated that from a health-care perspective the Aircast brace (£301 per QALY) and below knee cast ( $£ 339$ per QALY) were more cost-effective than the Bledsoe boot (£2116 per QALY). Simulations generated CEACs, which were indistinguishable for the Aircast brace and below knee cast, indicating that these two interventions had comparable cost-effectiveness; the Bledsoe boot was least costeffective.

Cost-utility analysis was necessarily based on the sample of patients for whom we had cumulative outcome data over the study period or for whom we had a sound basis for imputation for missing utility data. We used imputation techniques in a small number of cases in which we considered we could reliably make predictions about utility changes, despite some missing data. A conservative approach using average values was adopted as more sophisticated approaches are recognised to lead to varying predictions. ${ }^{77,78}$ We assume that attrition of the sample is unlikely to have affected final estimates of relative cost-utility in any systematic manner as analysis of baseline characteristics indicated no significant differences. This was confirmed by analysis of sample characteristics such as baseline utility measures. Other uncertainty around ICER estimates was addressed by the use of CEACs and sensitivity analysis.

Although the Aircast brace and below knee cast could not be differentiated in terms of costeffectiveness, they differed in terms of participant preference. Differential compliance rates suggested that the below knee cast was the least popular intervention. In a non-trial population, participants' responses to the offer of this treatment could be even less favourable unless the benefits are explained carefully. Bearing in mind that both types of support were similarly cost-effective, decision-makers may favour the Aircast brace over the below knee cast for routine implementation. We did not formally assess preference or acceptability and so these suggestions should be interpreted with caution. The results of this trial may give participants a greater amount of information with which to make a choice. The cost of a fitted below knee cast was less than half of that for the Aircast brace; however, total health-care costs (including subsequent care costs) did not differ significantly between the two treatment groups and so the below knee cast lost its cost advantage.

If the Aircast brace was acquired at a discount price through bulk purchase it had half the ICER value of the below knee cast. Centralised purchasing arrangements would have to be established to enable this price advantage to be realised; storage and transport costs would need to be added to the intervention cost, although these are unlikely to eliminate purchase cost savings.

From a societal perspective the inclusion of indirect costs associated with sick leave indicated that there was little to discriminate between the three interventions in terms of costs or benefits accrued (CEACs). Because the valuation of indirect costs was contentious, sensitivity analyses were undertaken to include varying the assumed cost of a single day off work and capping reported sick 
leave attributable to ankle injury at 30 working days. The sensitivity of the economic evaluation conclusions to the assumptions made about sick leave means that the results from this wider cost perspective should be treated with some caution.

Overall, the economic evaluation results of this trial indicated that, if the decision-maker's main concern is to maximise effectiveness relative to total health-care costs, the Aircast brace and below knee cast perform similarly. The Aircast brace may also be the optimal pragmatic option in terms of universal use unless patients can be offered the two treatment options. 



\section{Chapter 7 Conclusions}

\begin{abstract}
$\mathrm{A}^{\mathrm{n}}$ nkle sprains with an inability to weight bear have a prolonged recovery. Older people have slower and less complete recovery. Prognosis should be cautious, explaining that the injury, independent of treatment, has a significant risk of some disability in the form of symptoms, mobility or limitation of activities at 9 months.

Such patients, initially treated with 2-3 days of elevation, ice and non-weight bearing exercise, had more rapid resolution of symptoms and return to normal activities in the first 3 months when treated with a below knee cast for 10 days than with tubular bandage. By 9 months all treatments were equally effective. Mental health deteriorated in the early stages of recovery but returned to normal by 12 weeks. This study suggests that choice of treatment may affect speed of recovery but not long-term outcome. The below knee cast was not universally popular from the patient's perspective
\end{abstract}

and, therefore, the clinician and patient need to have an informed discussion to determine the best treatment for each individual.

\section{Implications for health care}

This study demonstrates that severe ankle sprains, as defined by an inability to weight bear 2-3 days following injury, have long-term effects that can be influenced by treatment. Current treatment could be improved by the use of mechanical supports.

This study recommends the use of either a shortterm below knee cast or an Aircast brace, following an initial period of several days to allow swelling reduction and non-weight-bearing exercise, for the treatment of severe ankle sprains. The choice between the two depends on a balance of clinical effectiveness, patient acceptability and cost. 



\section{Chapter 8}

\section{Recommendations for future research}

$\mathrm{T}$

The role of physiotherapy is not known in in in relatively active people it is important to be aware of an appropriate regime of exercise and physiotherapy during and after the period of functional support.

There are still no adequately powered studies of less severe ankle sprains.
In the UK, anticoagulants are not routinely used in lower limb injury, whereas this is standard practice in most of mainland Europe. More research is needed to determine the risk-benefit of such strategies.

The timing of interventions and the role of an initial period of relative rest, elevation and ice application have not been considered by this research and require further investigation. 



\section{Acknowledgements}

\section{The CAST trial group}

We are indebted to the consultants, nurses, physiotherapists and plaster technicians at the collaborating centres for their assistance in participant recruitment and data collection and for application of the ankle supports: Jason Kendall, Sue Kemspon and Caroline Pearce and team, Frenchay Hospital, Bristol; Magdy Sakr, Conor Kelly, Rachel Nakash, Esther Williamson, Mark Williams, Vivien Nichols, Cheryl Ritchie, Gill Doughty, Diane Mooney, Marie Stead, Chris Wootton, Sue Soden, Kim Wilding, Ann McLean and Rona Dixon, University Hospital Coventry and Warwickshire, Coventry; Aidan MacNamara, Raj Patel, Geraldine Saunders, Jo Walker, Saraj Mohammed and Kathy Stretton, Birmingham Heartlands Hospital, Birmingham; David Skinner, Sally Bateman, Jo Sale, Fiona Hooker, Kathryn Lewis, Claire Granville, Sue Norton, Lin Lyzba and Pam Osborne, John Radcliffe Hospital, Oxford; Matthew Cooke and John Hopson, Solihull Hospital, Solihull; Graham O’Byrne, Susan Slater and Tammy Mills-Chester, Alexandra Hospital, Redditch; Jo Williams, Hospital of St Cross, Rugby; Matthew Dunn, Nicky Parker, Esther Noakes, Nic Vaux, Rob Smith and Sheila Poulton, Warwick Hospital, Warwick.

\section{Contribution of authors}

Matthew Cooke, Professor of Emergency Medicine, participated in the design of the original experiment, had input into the original grant application, networking to establish clinical sites and supervision of clinical sites, and was the lead author for the final report.

Jennifer Marsh, Lecturer in Medical Statistics and Health Informatics, was involved in the design of the study, discussions on the pilot study, analysis of data from the pilot study, changes in the light of analysis of the pilot study data, discussions on data collection, data cleaning and management for the main study, implementation of data cleaning and management, analysis of data and discussions on analysis and interpretation, discussions on the statistics sections write-up, and undertaking the write-up. Also made a major contribution to the preparation of DMEC reports and attended TSC meetings, DMEC meetings and management and other meetings.

Michael Clark, Senior Research Fellow in Health Economics, undertook the economic components of the study, including having input into the design of data collection tools and the microcosting study, attended regular study meetings, was responsible for economic data analysis and interpretation, and undertook the final economic analysis and economic write-up.

Rachel Nakash, Research Fellow, was trial coordinator for the planning and set-up phase and to the end point of recruitment and led on the qualitative study and analysis.

Rose Jarvis was the clinical trials co-ordinator for the final stages of the study and was involved in data cleaning and management, analysis and coordination of report writing.

Jane Hutton, Professor of Medical Statistics, was involved in the design of the study, discussions on the pilot study, collection of data for the pilot study, changes in the light of analysis of pilot study data, discussions with statistician on data collection, cleaning and management, discussions with statistician and others on data analysis and interpretation, and writing of the results chapter. Also attended TSC meetings and some management and other meetings.

Ala Szczepura, Professor of Health Services Research, wrote the economics section of the original application, attended TSC and other management meetings and was responsible for the economic analysis and the writing of the economics elements in the report.

Sue Wilson, Professor of Clinical Epidemiology, had input into the original grant application and provided comments on the final draft of the report.

Sallie Lamb, Professor of Rehabilitation, led the design of the original experiment, had responsibility for writing the original grant 
application, gathered comments from other applicants and integrated them into the grant application, set up the trial, appointed and supervised the trial co-ordinator and administrator, supervised the trial on a day-to-day basis in close liaison with Matthew Cooke, participated in analysis and participated in the writing of reports.

\section{Other roles fulfilled}

Bill Gillespie, Chairman of TSC; Sue Wilson, member of TSC; Vicky Staples, member of TSC;
Jeremy Dale, member of TSC; Janet Dunn, Chairman of DMEC; Damian Griffin, member of DMEC; Pat Overton-Brown, member of DMEC; Gulnaz Begum and team, randomisation; Emma Withers, trial administrator; Lisa Craven, followup; Chris McCabe, advice on economic evaluation; Simon Gates, reviewer for systematic review. 


\section{References}

1. Trundle H. Physiotherapy: the contribution. In Skinner D, Swain A, Peyton R, Robertson C, editors. Cambridge textbook of accident and emergency medicine. Cambridge: Cambridge University Press; 1997.

2. Pijnenburg AC, Van Dijk CN, Bossuyt PM, Marti RK. Treatment of ruptures of the lateral ankle ligaments: a meta-analysis. J Bone Joint Surg Am 2000;82:761-73.

3. Struijs P, Kerkhoffs G. Ankle sprain. Clin Evid 2002;7:945-53.

4. Keeman JN. Commentaar Enkelspecial. Reuma en Trauma 1990;1:34-5.

5. Anandacoomarasamy A, Barnsley L. Long term outcomes of inversion ankle injuries. Br J Sports Med 2005;39:e14.

6. Konradsen L, Bech L, Ehrenbjerg M, Nickelsen T. Seven years follow-up after ankle inversion trauma. Scand J Med Sci Sports 2002;12:129-35.

7. Crichton K, Fricker P, Purdam C, Watson A. Injuries to the pelvis and lower limb. In Bloomfield $\mathrm{J}$, Fricher PA, Fitch K, editors. Science and medicine in sport. 2nd edn. Victoria, Australia: Blackwell Science Pty; 1995.

8. Eiff MP, Smith AT, Smith GE. Early mobilization versus immobilization in the treatment of lateral ankle sprains. Am J Sports Med 1994;22:83-8.

9. Kaikkonen A, Kannus P, Jarvinen M. Surgery versus functional treatment in ankle ligament tears. A prospective study. Clin Orthop Relat Res 1996;326:194-202.

10. Gronmark T, Johnsen O, Kogstad O. Rupture of the lateral ligaments of the ankle: a controlled clinical trial. Injury 1980;11:215-18.

11. Evans GA, Hardcastle P, Frenyo AD. Acute rupture of the lateral ligament of the ankle. To suture or not to suture? J Bone Joint Surg Br 1984;66:209-12.

12. Niedermann B, Andersen A, Andersen SB, Funder V, Jorgensen JP, Lindholmer E, et al. Rupture of the lateral ligaments of the ankle: operation or plaster cast? A propective study. Acta Orthop Scand 1981;52:579-87.
13. Sommer HM, Arza D. Functional treatment of recent ruptures of the fibular ligament of the ankle. Int Orthop 1989;13:157-60.

14. Moller-Larsen F, Wethelund JO, Jurik AG, de Carvalho A, Lucht U. Comparison of three different treatments for ruptured lateral ankle ligaments. Acta Orthop Scand 1988;59:564-6.

15. Cetti R, Christensen SE, Corfitzen MT. Ruptured fibular ankle ligament: plaster or Pliton brace? $\mathrm{Br} J$ Sports Med 1984;18:104-9.

16. Konradsen L, Holmer P, Sondergaard L. Early mobilizing treatment for grade III ankle ligament injuries. Foot Ankle 1991;12:69-73.

17. Zwipp H, Hoffmann R, Thermann H, Wippermann BW. Rupture of the ankle ligaments. Int Orthop 1991;15:245-9.

18. Frey C, Bell J, Teresi L, Kerr R, Feder K. A comparison of MRI and clinical examination of acute lateral ankle sprains. Foot Ankle Int 1996;17:533-7.

19. Swain A, Robertson C, Peton JW. Cambridge textbook of accident and emergency medicine. Cambridge University Press: Cambridge; 1997.

20. Cooke MW, Lamb SE, Marsh J, Dale J. A survey of current consultant practice of treatment of severe ankle sprains in emergency departments in the United Kingdom. Emerg Med J 2003;20:505-7.

21. Kerkhoffs GMMJ, Handoll HHG, de Bie R, Rowe $\mathrm{BH}$, Struijs PAA. Surgical versus conservative treatment for acute injuries of the lateral ligament complex of the ankle in adults. Cochrane Database Syst Rev 2007;2:CD000380.

22. Coughlin MJ, Schenck RC, Jr, Grebing BR, Treme G. Comprehensive reconstruction of the lateral ankle for chronic instability using a free gracilis graft. Foot Ankle Int 2004;25:231-41.

23. Baltopoulos P, Tzagarakis GP, Kaseta MA. Midterm results of a modified evans repair for chronic lateral ankle instability. Clin Orthop Relat Res 2004;422:180-5. 
24. Schmidt R, Benesch S, Friemert B, Herbst A, Claes L, Gerngross H. Anatomical repair of lateral ligaments in patients with chronic ankle instability. Knee Surg Sports Traumatol Arthrosc 2005;13:231-7.

25. Gould N, Seligson D, Gassman J. Early and late repair of lateral ligament of the ankle. Foot Ankle 1980;1:84-9.

26. Cass JR, Morrey BF, Katoh Y, Chao EY. Ankle instability: comparison of primary repair and delayed reconstruction after long-term follow-up study. Clin Orthop Relat Res 1985;198:110-7.

27. Ahlgren O, Larsson S. Reconstruction for lateral ligament injuries of the ankle. J Bone Joint Surg Br 1989;71:300-3.

28. Kerkhoffs G, Rowe B, Assendelft W, Kelly K, Struijs P, van Dijk C. Immobilisation and functional treatment for acute lateral ankle ligament injuries in adults [Review]. Cochrane Database Syst Rev 2002;3:CD003762.

29. Kerkhoffs GM, Struijs, PA, Marti RK, Assendelft WJ Blankevoort L, van Dijk CN. Different functional treatment strategies for acute lateral ankle ligament injuries in adults. Cochrane Database Syst Rev 2002;3:CD002938.

30. Kerkhoffs GM, Rowe BH, Assendelft WJ, Kelly $\mathrm{KD}$, Struijs PA, van Dijk CN. Immobilisation for acute ankle sprain. A systematic review. Arch Orthop Trauma Surg 2001;121:462-71.

31. Ardevol J, Bolibar I, Belda V, Argilaga S. Treatment of complete rupture of the lateral ligaments of the ankle: a randomized clinical trial comparing cast immobilization with functional treatment. Knee Surg Sports Traumatol Arthrosc 2002;10:371-7.

32. Kerkhoffs GM, Struijs PA, Marti RK, Blankevoort L, Assendelft WJ, van Dijk CN. Functional treatments for acute ruptures of the lateral ankle ligament: a systematic review. Acta Orthop Scand 2003;74:69-77.

33. Karlsson J, Eriksson BI, Sward L. Early functional treatment for acute ligament injuries of the ankle joint. Scand J Med Sci Sports 1996;6:341-5.

34. Boyce SH, Quigley MA, Campbell S. Management of ankle sprains: a randomised controlled trial of the treatment of inversion injuries using an elastic support bandage or an Aircast ${ }^{\circledR}$ ankle brace. $\mathrm{BrJ}$ Sports Med 2005;39:91-6.

35. Struijs P, Kerkhoffs G. Ankle sprain. In Godlee F, editor. Clinical evidence. London: BMJ; 2004.

36. Clinical evidence. London: BMJ. URL: www. clinicalevidence.com/ceweb/conditions/ msd/1115/1115_I5.jsp. Accessed 3 April 2006.
37. Neilsen HV. Arterial pressure-blood flow relationships during limb elevation in man. Acta Physiol Scand 1983;118:405-13.

38. van Os AG, Bierma-Zeinstra SM, Verhagen AP, de Bie RA, Luijsterburg PA, Koes BW. Comparison of conventional treatment and supervised rehabilitation for treatment of acute lateral ankle sprains: a systematic review of the literature. J Orthop Sports Phys Ther 2005;35:95-105.

39. Clinical evidence. London: BMJ. URL: www. clinicalevidence.com/ceweb/conditions/ msd/1115/1115_I6.jsp. Accessed 3 April 2006.

40. Van der Windt DAWM, Van der Heijden GJMG, Van den Berg SGM, Ter Riet G, De Winter AF, Bouter LM. Therapeutic ultrasound for acute ankle sprains. Cochrane Database Syst Rev 2002;1:CD001250.

41. de Bie RA, de Vet HC, Lenssen TF, van den Wildenberg FA, Kootstra G, Knipschild PG. Lowlevel laser therapy in ankle sprains: a randomized clinical trial. Arch Phys Med Rehabil 1998;79:141520.

42. Jadad AR, Moore RA, Carroll D, Jenkinson C, Reynolds DJ, Gavaghan DJ, et al. Assessing the quality of reports of randomized clinical trials: is blinding necessary? Control Clin Trials 1996;17:1-12.

43. Brakenbury PH, Kotowski J. A comparative study of the management of ankle sprains. Br J Clin Pract $1983 ; 37: 181-5$

44. Brooks SC, Potter BT, Rainey JB. Treatment for partial tears of the lateral ligament of the ankle: a prospective trial. BMJ 1981;282:606-7.

45. Korkala O, Rusanen M, Jokipii P, Kytomaa J, Avikainen V. A prospective study of the treatment of severe tears of the lateral ligament of the ankle. Int Orthop 1987;11:13-17.

46. Munk B, Holm-Christensen K, Lind T. Long-term outcome after ruptured lateral ankle ligaments. A prospective study of three different treatments in 79 patients with 11-year follow-up. Acta Orthop Scand 1995;66:452-4.

47. Dettori JR, Pearson BD, Basmania CJ, Lednar WM. Early ankle mobilization, Part II: a one-year followup of acute, lateral ankle sprains (a randomized clinical trial). Mil Med 1994;159:20-4.

48. Klein J, Rixen D, Albring T, Tiling T. Funktionelle versus Gipsbehandlung bei der frischen Aussenbandruptur des oberen Sprunggelenks. Eine randomisierte klinische Studie. Der Unfallchirurg 1991;94:99-104. 
49. Milford PI, Dunleavy PJ. A pilot trial of treatment of acute inversion sprains to the ankle by ankle supports. J R Nav Med Serv 1990;76:97-100.

50. Regis D, Montanari M, Magnan B, Spagnol S, Bragantini A. Dynamic orthopaedic brace in the treatment of ankle sprains. Foot Ankle Int 1995;16:422-6.

51. Sommer HM, Schreiber H. Early functional conservative therapy of a fresh fibular rupture of the capsular ligament from a socioeconomical viewpoint. Sportverletz Sportschaden 1993;7:40-6.

52. Broström L. Sprained ankles. V. Treatment and prognosis in recent ligament ruptures. Acta Chir Scand 1966;132:537-50.

53. Lind T. Konservativ behandling af laterale ligamentrupturer i fodleddet. Prospektiv sammenligning af to konservative behandlingsmetoder. Ugeskr laeger 1984;146:401719.

54. Caro D, Craft I, Howells J, Shaw P. Diagnosis and treatment of injury of the lateral ligament of the ankle joint. Lancet 1964;171:720-3.

55. Freeman MA. Treatment of ruptures of the lateral ligament of the ankle.J Bone Joint Surg 1965;47:661-8.

56. Hedges JR, Anwar RA. Management of ankle sprains. Ann Emerg Med 1980;9:298-302.

57. Roycroft S, Mantgani AB. Treatment of inversion injuries of the ankle by early active management. Physiotherapy 1983;69:355-6.

58. Twellaar M VJ, Verstappen FT. Ankle sprains. Comparison of the long-term results of functional treatment methods with adhesive tape and bandage ('brace') and stability measurement [Das Knochelinversionstrauma. Vergleich der Langzeitergebnisse funktioneller Behandlungsmethoden mit Klebeverband und Bandage ('Brace') und die Eignung der Stabilometrie]. Unfallchirurg 1993;96:477-82.

59. Allen MJ, McShane M. Inversion injuries to the lateral ligament of the ankle joint. A pilot study of treatment. Br J Clin Pract 1985;39:282-6.

60. Jongen SJM, Dunki PJ, Jacobs PB. Treatment of the sprained ankle. Geneesk Sport 1992;25:98-101.

61. Leanderson J, Wredmark T. Treatment of acute ankle sprain. Comparison of a semi-rigid ankle brace and compression bandage in 73 patients. Acta Orthop Scand 1995;66:529-31.
62. Pasila M Visuri T, Sundholm A. Treatment of ankle and foot sprains with Tensoplast and elastic bandage [Tensoplast- ja ideaaliside nilkan ja jalan ven_hdysten hoidossa]. Suomen Lõ̃oñilehti $1975 ; 7: 40-6$.

63. Zeegers A. Supination injury of the ankle joint [Het supinatieletsel van de enkel]. PhD thesis. Utrecht: University of Utrecht, the Netherlands; 1995.

64. Wilson S, Cooke M. Double bandaging of sprained ankles. BMJ 1998;317:1722-3.

65. Stiell I, Wells G, Laupacis A, Brison R, Verbeek $\mathrm{R}$, Vandemheen $\mathrm{K}$, et al. A multicentre trial to introduce clinical decision rules for the use of radiography in acute ankle injuries. $B M J$ 1995;311:594-7.

66. EuroQol Group. EuroQol - a new facility for the measurement of health-related quality of life. Health Policy 1990;16:199-208.

67. McCulloch PG Holden P, Robson DJ, Rowley DI, Norris SH. The value of mobilisation and non-steroidal anti-inflammatory analgesia in the management of inversion injuries of the ankle. $\mathrm{BrJ}$ Clin Pract 1985;39:69-72.

68. Nakash RA, Hutton JL, Jorstad-Stein EC, Gates $\mathrm{S}$, Lamb SE. Maximising response to postal questionnaires - a systematic review of randomised trials in health research. BMC Med Res Methodol 2006;6:2.

69. Roos E, Brandsson S, Karlsson J. Validation of the foot and ankle outcome score for ankle ligament reconstruction. Foot Ankle Int 2001;22:788-94.

70. Bergner M, Bobbitt RA, Kressel S, Pollard WE, Gilson BS, Morris JR. The sickness impact profile: conceptual formulation and methodology for the development of a health status measure. Int J Health Serv 1976;6:393-415.

71. Ware JJ, Kosinski M, Keller SD. A 12-item shortform health survey: construction of scales and preliminary tests of reliability and validity. Med Care 1996;34:220-33.

72. Machin D, Campbell M, Fayers P, Pinol A. Sample size tables for clinical studies. 2nd edn. Oxford: Blackwell Science; 1997.

73. Rubin DB. Multiple imputation for nonresponse in surveys. New York: Wiley; 1987.

74. Netten A, Dennett J. Unit costs of health and social care 1996. Canterbury: Personal Social Services Research Unit, University of Kent at Canterbury; 1996. 
75. Drummond MF, O'Brien BJ, Stoddart GL, Torrance GW. Methods for the economic evaluation of health care programmes. Oxford: Oxford University Press; 1990.

76. Briggs AH, O'Brien B. The death of costminimisation analysis? Health Econ 2001;10:179-84.

77. Oostenbrink JB, Al MJ, Rutten-van Molken MPMH. Methods to analyse cost data of patients who withdraw in a clinical trial setting. Pharmacoeconomics 2003; 21:1103-12.

78. Manca A, Palmer S. Handling missing data in patient-level cost-effectiveness analysis alongside randomised clinical trials. Appl Health Econ Health Policy 2005;4:65-75.

79. Karlsson J, Peterson L. Evaluation of ankle joint function: the use of a scoring scale. Foot 1991;1:1519.

80. Drummond MF, Jefferson TO. Guidelines for authors and peer reviewers of economic submissions to the BMJ. The BMJ Economic Evaluation Working Party. BMJ 1996;313:275-83.

81. Graves N, Walker D, Raine R, Hutchings A, Roberts JA. Cost data for individual patients included in clinical studies: no amount of statistical analysis can compensate for inadequate costing methods. Health Econ 2002;11:735-9.

82. Briggs A, Clark T, Wolstenholme J, Clarke P. Missing - presumed at random: cost-analysis of incomplete data. Health Econ 2003;12:377-92.

83. Drummond MF, O'Brien, BJ, Stoddart GL, Torrance GW. Methods for the economic evaluation of health care programmes. Oxford: Oxford University Press; 1997.

84. Richardson G, Manca A. Calculation of quality adjusted life years in the published literature: a review of methodology and transparency. Health Econ 2004;13:1203-10.

85. Altman DG, Bland MJ. Statistics notes: absence of evidence is not evidence of absence. $B M J$ 1995;311:485.

86. Dobbs C. Patterns of pay: results of the annual survey of hours and earnings 1998-2004. London: Employment, Earnings and Productivity Division, Office for National Statistics; 2005.

87. Pritchard C, Sculpher M. Productivity costs: principles and practice in economics. London: Office of Health Economics; 2000.

88. NICE. Guide to methods of health technology appraisal. London: NICE; 2004
89. Towse A, Pritchard C, Devlin N. Cost-effectiveness thresholds. London: OHE/King's Fund; 2002.

90. O’Hagan A, Stevens JW. Assessing and comparing costs: how robust are the bootstrap and methods based on asymptotic normality? Health Econ 2003;12:33-49.

91. Willan A. Analysing cost-effectiveness trials: net benefits. In Briggs A, editor. Statistical methods for cost-effectiveness research: a guide to current issues and future developments. London: Office of Health Economics; 2003.

92. Fenwick E, O'Brien BJ, Briggs A. Cost-effectiveness acceptability curves - facts, fallacies and frequently asked questions. Health Econ 2004;13:405-15.

93. Van Hout BA, Al MJ, Gordon GS, Rutten FF. Costs, effects and C/E-ratios alongside a clinical trial. Health Econ 1994;3:309-19.

94. Drummond MF, Sculpher MJ, Torrance GW, O'Brien BJ, Stoddart GL. Methods for the economic evaluation of health care programmes. 3rd edn. Oxford: Oxford University Press; 2005.

95. Brouwer WBF, Koopmanschap MA. The frictioncost method. Replacement for nothing and leisure for free. Pharmacoeconomics 2005;23:105-11.

96. Hutubessy RCW, van Tulder MW, Vondeling H, Bouter LM. Indirect costs of back pain in the Netherlands: a comparison of the human capital method with the friction cost method. Pain 1999;80:201-7.

97. Johannesson M, Karlsson G. The friction cost method: a comment. J Health Econ 1997;16:249-55.

98. Liljas B. How to calculate indirect costs in economic evaluations. Pharmacoeconomics 1998;13:1-7.

99. Briggs AH. Handling uncertainty in costeffectiveness models. Pharmacoeconomics 2000; 17:479-500.

100. Ritchie J, Spencer L. Qualitative data analysis for applied policy research. In Bryman A, Burgess R, editors. Analysing qualitative data. London: Routledge; 1994. pp. 173-94.

101. Batra S Kurup H, Gul A, Andrew JG. Thromboprophylaxis following cast immobilisation for lower limb injuries - survey of current practice in United Kingdom. Injury 2006;37:813-7.

102. Hurst NP, Ruta DA, Kind P. Comparison of the MOS short form-12 (SF12) health status questionnaire with the SF36 in patients with rheumatoid arthritis. Br J Rheumatol 1998;37:862-9. 
103. Gallagher E, Liebman M, Bijur PE. Prospective validation of clinically important changes in pain severity measured on a visual analog scale. Ann Emerg Med 2001;38:633-8.

104. Todd K, Funk, KG, Funk, JP, Bonacci R. Clinical significance of reported changes in pain severity. Ann Emerg Med 1996;27:485-9.
105. Roos EM, Lohmander LS. The Knee Injury and Osteoarthritis Outcome Score (KOOS): from joint injury to osteoarthritis. Health Qual Life Outcomes 2003;1:64.

106. Cohen J. Statistical power analysis for the behavioural sciences. New York: Academy Press; 1977. 



\section{Appendix I \\ Search strategy for literature reviews}

T

he search strategy used in the relevant

Cochrane reviews ${ }^{28,29}$ was replicated but limited to the years $2000-5$ to identify new studies. The databases searched were MEDLINE, EMBASE and the Cochrane Central Register of Controlled Trials (CENTRAL). The National Research Register and the International Standard Randomised Controlled Trial Number register were searched to identify relevant research projects.

The following subject-specific search was used in MEDLINE:

1. Ankle Injuries/

2. Ligaments, Articular/

3. "Sprains and Strains"/
4. or/1-3

5. ankle\$.tw.

6. ligament $\$ . t w$.

7. and $/ 5-6$

8. (sprain\$or strain\$or injur\$or rupture\$or tear or torn).tw

9. and $/ 7-8$

10. and $/ 4,9$

11. Lateral Ligament, Ankle/

12. or/10-11

The reference lists of identified trials and reviews were also searched. The BioMail MEDLINE search service (http://biomail.sourceforge.net/biomail) was used with the search terms of 'ankle AND (injur* OR sprain*)' to alert for new trials. 



\section{Appendix 2}

\section{Ankle injury proforma}




\section{Ankle injury}

(age 16 years or over)

History

Mechanism of injury

Date and time of injury

Location of pain

Ability to walk:

Previous injuries

Any pain or injury elsewhere

\begin{tabular}{l}
\hline \\
\hline unable/with pain/ \\
minimal pain/no pain \\
$\mathrm{Y} / \mathrm{N}$ \\
$\mathrm{Y} / \mathrm{N}$
\end{tabular}

Attach patient sticker

\section{PMH}

Drugs

\section{Allergies}

Contraindications to NSAIDs

\begin{tabular}{|c|c|}
\hline $\begin{array}{l}\text { Examination } \\
\text { Ror } \mathrm{L} \\
\text { Talar tilt test: positive/painful/negative } \\
\text { Proximal fibula tender: } \mathrm{Y} / \mathrm{N}\end{array}$ & $\begin{array}{l}\text { Achilles tendon intact: } Y / N \\
\text { Circulation: } \\
\text { Cap refill time }= \\
\text { Sensation in foot }= \\
\text { Weight bearing/partial weight bearing/non-weight bearing }\end{array}$ \\
\hline $\begin{array}{l}\text { Investigation } \\
\text { Radiography of ankle/foot: } \mathrm{Y} / \mathrm{N} \\
\text { Indication of radiography if not as in adjacent box: }\end{array}$ & $\begin{array}{l}\text { Indicators for radiography: } \\
\text { Tenderness at posterior or tip of either malleolus } \\
\text { Unable to weight bear (at evaluation and at time of accident) } \\
\text { Tender } 5 \text { th metatarsal } \\
\text { Tender navicular } \\
\text { Age over } 60 \text { years and pain }\end{array}$ \\
\hline $\begin{array}{l}\text { Management (Radiograph normal or fragment } \leq 2 \mathrm{~mm} \text { ) } \\
\square \text { Relative rest for } 2 \text { days } \\
\square \text { Ice } \\
\square \text { Elevation } \\
\square \text { Advice leaflet } \\
\square \text { Exercises explained } \\
\square \text { Analgesia (specify) } \\
\square \text { Other (specify) } \\
\text { If non-weight bearing } \\
\text { or minimal bearing } \\
\text { Chronic instability and weight bearing } \rightarrow \text { Physiotherapy } \\
\text { referral }\end{array}$ & $\begin{array}{l}\text { Management if radiograph abnormal } \\
\text { (note: exclude \# fragments }<2 \mathrm{~mm} \text { ) } \\
\text { Consult local guidelines } \\
\square \text { POP } \\
\square \text { Fracture clinic } \\
\square \text { On call orthopaedic team } \\
\text { Other reason for orthopaedic referral: }\end{array}$ \\
\hline
\end{tabular}

Diagnosis

*Appropriate for ankle trial? $\quad$ Yes $\square \quad$ No $\square \quad$ If 'Yes', trial information and invite given? $\quad$ Yes $\square \quad$ No $\square$ (Check inclusion/exclusion criteria)

Record reasons here if patient declines ankle trial: 


\section{Appendix 3 \\ Invitation letter}

\section{Trial of treatment of severe ankle sprains}

This hospital is taking part in a study to determine the best treatment of ankle sprains. We would like to invite you to participate in this trial.

The trial is looking at four different treatments, which are explained in the accompanying leaflet. People taking part would be allocated randomly to these four treatments.

The doctor who sees you today will explain about the trial. Treatment today will not be affected by the trial, as it is the same for everyone, whether participating in the trial or not. You will also be given a leaflet. Please read this leaflet carefully.

If you are prepared to take part in the trial we would arrange to see you in 2-3 days' time. A physiotherapist would then explain the trial in more detail and you would have the opportunity to ask more questions. If you agree, the physiotherapist would then start your treatment.

Your treatment will not be affected if you do not wish to participate in the trial.

Thank you for considering taking part.

A\&E Consultant 



\section{Appendix 4 \\ Patient information sheet}

\section{Study title: study of four ways of treating severe ankle sprains}

You are being invited to take part in a research study. Before you decide it is important for you to understand why the research is being done and what it will involve. Please take time to read the following information carefully and discuss it with others if you wish. Ask us if there is anything that is not clear or if you would like more information. Take time to decide whether or not you wish to take part.

Thank you for reading this.

\section{What is the purpose of the study?}

This study aims to determine the best treatment for severe ankle injuries. We are comparing four treatments - a simple elastic bandage as is commonly used at present, a plaster of Paris cast, a plastic splint and a boot-like support.

\section{Why have I been chosen?}

All patients attending this hospital, and several others, with your type of injury are being invited to take part in this trial. Eventually 600 patients will be taking part.

\section{Do I have to take part?}

It is up to you to decide whether or not to take part. If you do decide to take part you will be given this information sheet to keep and asked to return to a clinic in 2-3 days' time. At that clinic you will be given a further explanation of the trial and have an opportunity to ask questions. If you agree to participate in the trial you will be asked to sign a consent form. If you decide to take part you are still free to withdraw at any time and without giving a reason. A decision to withdraw at any time, or a decision not to take part, will not affect the standard of care you receive. If you decide not to take part the researcher may ask you why, but you do not have to answer this question.

\section{What will happen to me if I take part?}

When you attend the clinic you will be given the opportunity to ask further questions before deciding whether you want to take part in this trial. If you decide to participate you will be allocated to one of the four treatments and given appropriate instructions and advice. We do not know which way of treating patients is best; that is why we need to make comparisons. People will be put into groups and then compared. A computer using an approach similar to tossing a coin selects the groups. Patients in each group then have a different treatment and these are compared.

At the clinic appointment a short examination of your ankle will be performed and you will be asked to complete a short questionnaire with the help of the research physiotherapist. This will take about 30-45 minutes. Your further treatment will then be explained.

At about 4 weeks and 12 weeks after injury we will send you another copy of the questionnaire by post and would like you to complete this and post it back to us (we pay the postage). This will then be repeated 9 months after your injury. The researcher may contact you by phone soon after you receive the questionnaire to see if you need help completing it. 


\section{What do I have to do?}

We will give you advice on what exercise you can undertake whilst in the trial. If you still have problems after 6 weeks we will arrange further treatment for you, although this will not be part of the trial. This will be standard treatment by the NHS. During the trial we will ask you to make note of certain events such as when you return to work or to playing sport.

\section{What is the treatment that is being tested?}

The four different treatments are:

- an elastic bandage worn during the day

- a plaster of Paris cast, like that used when people break a bone

- a plastic splint that supports the side of the ankle

- a boot that looks like a ski boot that supports the ankle.

\section{What are the side effects of any treatment received when taking part?}

We do not know of any side effects from these treatments. Anybody with an ankle injury can develop severe swelling, and occasionally this can affect the circulation in the leg. By the time you receive one of the trial treatments the swelling should be going down. There is a small risk that the swelling could worsen or cause problems when the treatment is applied. If the pain worsens after your treatment is started or your foot becomes numb then you should contact the A\&E department immediately.

\section{What are the possible disadvantages and risks of taking part?}

We do not know which of these treatments gives the best results. The only risk that we know of is the swelling mentioned above.

\section{What are the possible benefits of taking part?}

We hope that the treatments will help you. However, this cannot be guaranteed. The information we get from this study may help us to treat future patients with severe ankle sprains.

\section{What if new information becomes available?}

Sometimes during the course of a research project, new information becomes available about the treatment that is being studied. If this happens your research physiotherapist will tell you about it and discuss with you whether you want to continue in the study. If you decide to withdraw your physiotherapist will make arrangements for your care to continue. If you decide to continue in the study you will be asked to sign an updated consent form. Also, on receiving new information the research physiotherapist might consider it to be in your best interests to withdraw you from the study. He/she will explain the reasons and arrange for your care to continue.

\section{What happens when the research study stops?}

You will be continuing with the treatment for 6 weeks. If you are still having problems at this time we will arrange for you to have an appointment with an appropriate specialist to continue your care.

\section{What if something goes wrong?}

If taking part in this research project harms you there are no special compensation arrangements. If you are harmed because of someone's negligence then you may have grounds for a legal action but you may have to pay for it. Regardless of this, if you wish to complain, or have any concerns about any aspect of the way you have been approached or treated during the course of this study, the normal NHS complaints mechanism is available to you. 


\section{Will my taking part in this study be kept confidential?}

All information that is collected about you during the course of the research will be kept strictly confidential. Any clinical information about you that leaves the hospital will have your name and address removed so that you cannot be recognised from it. We would like to inform your general practitioner of your involvement in this trial so that he or she is fully aware of your situation. We will confirm that you are prepared for us to do this when you see the physiotherapist in the clinic.

\section{What will happen to the results of the research study?}

This study is expected to last 3 years. At the end of the study we will publish the findings in medical journals and at medical conferences. We will also put the results on the trial website at www.warwick.ac.uk/ go/ankle. No individual patient will be identifiable in any results.

\section{Who is organising and funding the research?}

The NHS funds this study. The research team will receive salaries from the grant but these do not depend on the recruitment of patients or on the results that are produced. The study is being organised by the Universities of Warwick and Birmingham.

\section{What will happen if I decide not to participate in the research study?}

If you decide not to participate in the research study you will be treated using the standard treatment used at your hospital, that is elastic bandaging and provision of a pair of crutches with follow-up arranged by the A\&E department.

\section{Who has reviewed the study?}

Your local research ethics committee has reviewed this study. If you have any concerns you may contact them on [to be inserted]

\section{Contacts for further information}

If you would like further information please contact the local researcher, Rachel Nakash, on telephone number 02476000000 . Alternatively, you can speak to Dr Cooke, who is leading the project, by telephoning 02476000000.

Please keep this information sheet for your future use. If you join the study you will also be given a copy of your consent form. 



\section{Appendix 5 \\ Advice to participants prior to trial clinic}

1. Elevate to reduce swelling, keeping your foot well up above the level of your bottom. In bed, rest it on a couple of pillows.

2. Apply ice to ease pain, swelling and bruising. Method: Use frozen peas or crushed ice in a damp towel. Place around elevated ankle for 10 minutes. Repeat 4-6 times a day. Caution: Ice can cause a burn. Protect sensitive skin. Follow instructions.

3. Exercise every $\mathbf{2}$ hours for 10 minutes, especially after ice treatment, if it is not too painful. If you hold your ankle stiff in an awkward position it will become more difficult to move it from that position, i.e. it will stiffen up. Do what exercises you can manage but if it is too painful, stop and try again later. Point foot up towards you and point it down again. Circle ankle keeping knee straight. Keep feet together. Turn soles of feet towards and away from each other.

Bandages can make your ankle go stiff. Most people should not use a bandage on an injured ankle - this allows you to do your exercises better.

Take simple painkillers for the first few days, e.g. paracetamol or ibuprofen, if you feel you need help with the pain. These are available from the chemist.

Walking - You may try to walk if it is not too painful. Try to walk with even strides (heel first, then toe). Put as much weight through the foot as pain allows. Use stick/crutches as advised to help you walk.

If pain increases or swelling gets worse, contact your GP.

Sports - You may benefit from ankle strapping whilst playing sport, for a few weeks after the injury. Remove the strapping at the end of the game.

\section{IMPORTANT}

Sometimes the swelling in the ankle can cause problems with the circulation. This is rare but needs urgent treatment.

If you get increasing pain despite following the instructions above or your foot goes blue, or it becomes numb, then contact either NHS Direct on 03454647 or your local A\&E department IMMEDIATELY. 



\section{Appendix 6 \\ Consent form}

\section{Trial centre:}

\section{Patient's centre ID:}

Title of project: A randomised controlled trial to estimate the clinical and cost-effectiveness of four different methods of mechanical support in severe ankle sprains.

Name of researchers: Professor Sallie Lamb, University of Warwick and

Dr Matthew Cooke, University of Warwick

\section{Please initial box}

I. I confirm that I have read and understand the information leaflet dated I7//2/03 version 3 for the above study and have had the opportunity to ask questions.

2. I understand that my participation is voluntary and that I am free to withdraw at any time, without giving any reason, without my medical care or legal rights being affected.

3. I understand that sections of any of my medical notes relating to the trial may be looked at by responsible individuals from the University of Warwick.

4. I give permission for these individuals to have access to my records, which will be dealt with in a confidential manner.

5. I agree to take part in the above study.

6. As part of the study a sample of patients will be given a 'trial calendar'* to help with questionnaire completion and also a very small number of people will be asked to be interviewed by a member of the research team. I give my consent for this.

Name of patient

Name of person taking consent

Name of researcher
Date

Date

Date
Signature

Signature

Signature

One for patient; one for researcher; one to be kept with hospital notes.

*The calendar was part of an embedded methodology trial that will be reported separately. 



\section{Appendix 7 \\ Pre-randomisation eligibility form}

\section{Patient's centre ID:}

Research physiotherapist name:

\section{Patient details}

Name:

Date of birth:

Home address:

Patient contact number(s):

$\mathrm{H}$ :

W:

Mob:

E-mail:

\section{Trial centre:}

Hospital number:

Sex:

Other address (e.g. student):

GP name and surgery details:

\section{Eligibility checklist}

I. Patient aged 16 years or over

2. Patient non-weight bearing/or weight bearing with aid

3. One week or less since injury

4. No contraindications to any of the four arms of the trial

5. No fracture or other significant injuries present

6. Written informed consent gained

Trial Number

(Given by Randomisation Centre)

Telephone 0800000000 or 0800000000 for randomisation onto the CAST trial 



\section{Appendix 8 \\ Background information}

QI. Age: $\square \square$ Years

Q2. Sex: $\square$ Male $\square$ Female

Q3. Ethnic group: (Please tick one box)

I. White

2. Black-Caribbean

3. Black-African

4. Black-Other

5. Indian

6. Pakistani

7. Bangladeshi

8. Chinese

9. Other (Please specify)

Q4. What is your first language? (Please tick one box)

I. English

2. Other European

3. Gujarati

4. Hindi

5. Punjabi

6. Urdu

7. Bengali

8. Other (please specify)

Will you be able to fill in questionnaires in English?
Yes/No

\section{Q5. Employment status:}

An important part of the study is to determine how much your ankle injury has affected you in terms of days off work. This is why the next question asks about your employment.

5.I Are you currently employed? (If you are a full-time student but also work, complete this section and also tick question 5.6 on page 4 )

Yes - part time

Yes - full time

$\square$

No (go to 5.2 on page 4 )

(a) Is this employment:

Paid

Unpaid 
(b) How many hours a week do you work?

Less then 10

$10-25$

25-40

More than 40

(c) Which of the following categories do you think best describes your employment?

Unskilled manual

Skilled manual

Unskilled non-manual

Skilled non-manual

Professional

Other

Decline to answer

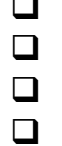

If you are not currently employed which of the following applies to you:

5.2. Retired

5.3. At home and not looking for paid employment (e.g. looking after home, family or others)

5.4. Unable to work because of illness or disability

5.5. Unemployed and looking for work

5.6. In full-time education

5.7. Other (please specify):

\section{Q6. What is the highest qualification you have achieved?}

CSE (or equivalent)

O-level/GCSE (or equivalent)

A-level (or equivalent)

Degree (or equivalent)

Higher degree (or equivalent)

Other (Please specify):

Q7. During your usual daily routine (e.g. work, caring for others, daily activities) approximately how much time do you spend:

(a) On your feet?

Most of the day

More than 4 hours a day

Less than 4 hours a day

Not much time - mostly sitting

(b) Driving?

Most of the day

More than 4 hours a day

Less than 4 hours a day

Usually just to/from work

Don't drive 
Q8. Are you currently taking any medication for pain or inflammation?

Only since ankle injury

Prior to injury for a separate condition

No

Did not answer

Q9. Which of the following activities do you participate in: (before injuring your ankle)

$$
\begin{array}{ll}
\text { More than } & \text { Less than } \\
\text { once weekly } & \text { once weekly Never }
\end{array}
$$

\section{Swimming}

Weight training

Aerobics/keep-fit

Cycling

Jogging/running

Team sport

(e.g. football, rugby, hockey, netball)

Racquet sport

(e.g. tennis, squash, badminton)

Yoga

Athletics

Walking

(2 miles or more)

Heavy DIY, housework, gardening

Other sports or exercise (please specify):

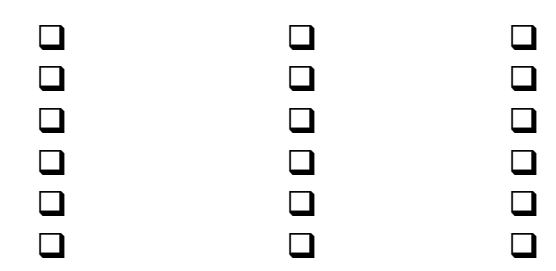

QI0. How tall are you?

QI I. How much do you weigh?

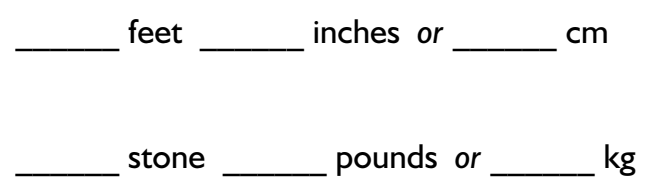

$\mathrm{kg}$

\section{Q12. Pain:}

On a scale of $0-10$, where 0 is no pain and 10 is the worst pain you can imagine, how painful is your ankle now? (please circle)

At rest:

$$
0-1-2-3-4-5-6-7-8-9-10
$$

Weight bearing: $0-1-2-3-4-5-6-7-8-9-10$

\section{Q13. Previous injuries:}

Apart from your current injury, have you sprained or twisted your ankle in the last 3 months?<smiles>[13CH3][13CH3]</smiles>

If 'Yes', did you need to attend A\&E for this injury?

Yes $\square \quad$ No $\square$ 


\section{Q14. Weight bearing:}

Using the weighing scales, whilst sitting in a chair, how much weight are you able to put through your ankle at the moment? 


\section{Appendix 9 \\ Challenges of recruitment}

Abstract from Faculty of Accident and Emergency Medicine meeting, London, 2003.

\begin{tabular}{l} 
Authors(s): Nakash R, Lamb S, Cooke MW, on behalf of the CAST project team \\
\hline ADDRESS: \\
\hline BODY OF ABSTRACT: \\
\hline Title: Conducting clinical trials in ED - a pilot study highlights recruitment challenges. \\
Introduction \\
Conducting clinical research in the ED environment poses particular challenges. The pilot study of a randomised controlled \\
trial of mechanical supports following severe ankle sprains was used to gauge the difficulties of recruitment. \\
Methods \\
ED physicians and emergency nurse practitioners were asked to identify patients with severe ankle sprains using pre-specified \\
inclusion criteria and refer these patients to a 'trial clinic'. These clinics were run by research physiotherapists $2-3$ days later \\
where consent and randomisation was undertaken. An assessment proforma was designed to assist with assessment and act as \\
a tracking instrument and 'aide-mémoire' for staff to refer appropriate patients to the trial clinic.
\end{tabular}

\section{Results}

During the 5 -week pilot phase, 85 patients were referred to the trial clinic as fulfilling the criteria at the time of initial examination. 29 patients (34\%) were recruited onto the study, 29 patients $(34 \%)$ either failed to attend or cancelled their trial clinic appointment, 19 patients $(22 \%)$ attended the trial clinic but were excluded from the study due to significant improvement in symptoms and 8 patients $(9 \%)$ declined to return to the trial clinic.

The high rate of exclusion at the trial clinic was due to the 'severe' sprains diagnosed in ED turning out to be less serious injuries when the patient returned. This could also explain the high rate of trial clinic non-attendance.

\section{Discussion}

The assessment proforma has been well received and has proved a useful tool for tracking recruitment.

Recruiting patients in ED may overestimate the severity of soft tissue injuries and a 2- to 3-day period before recruitment can ensure patients fulfil clinical criteria of severe injury. One-third of patients failed to return to the clinic; mechanisms for encouraging patients to return need to be employed.

ED, emergency department. 



\section{Appendix 10 Audits}

$\mathrm{T}$ he nature of the recruitment process for this trial meant that we were reliant upon emergency department staff to identify potentially appropriate patients and then refer them to the trial recruitment clinics. Considerable time and effort were invested by the trial team to encourage emergency department staff to co-operate with the trial procedures, but it was apparent that some difficulties with recruitment were partly due to potentially appropriate patients attending emergency departments but not being referred to the recruitment clinics, meaning that the patients were then lost to the trial.

To gauge how well individual members of the emergency department team understood the trial and co-operated with trial procedures, audits were carried out of patients' emergency department notes. On days selected at random, and with the help of emergency department reception staff, lists were obtained of patients coded as 'ankle injury' throughout the 24-hour period. Each patient's notes were then retrieved and evaluated for whether the patient was potentially appropriate for the trial. The results of these audits are summarised in the table below.
As the audit process was a time-consuming activity, the local trial centres received more attention than the remote centres. Members of the trial team were able to conduct the local audits whereas at the more distal centres we relied on the help of the collaborating clinicians.

Although the audits were not systematically conducted they gave us a valuable insight into the approach used by emergency department clinicians. We were able to establish reasons why patients with ankle sprains were not referred to the recruitment clinics. The most useful outcome was that we were able to identify individual emergency department staff who appeared to be unaware of the trial procedures and who failed to refer appropriate patients to the recruitment clinics. It was then possible to approach these staff members personally and remind them of the trial. The trial team endeavoured to conduct a training session at each trial centre following senior house officer rotations, but the audit process was particularly useful following such rotations, to identify new emergency department staff who required training in the trial procedures.

\section{Details of audits undertaken}

\begin{tabular}{|c|c|c|c|c|c|c|}
\hline $\begin{array}{l}\text { Trial } \\
\text { centre }\end{array}$ & $\begin{array}{l}\text { Days } \\
\text { audited }\end{array}$ & $\begin{array}{l}\text { Total adult } \\
\text { ankle injuries }\end{array}$ & $\begin{array}{l}\text { Not } \\
\text { appropriate }^{a}\end{array}$ & $\begin{array}{l}\text { Potentially } \\
\text { appropriate }\end{array}$ & $\begin{array}{l}\text { Potentially appropriate and } \\
\text { referred to CAST, } n(\%)\end{array}$ & Other $^{b}$ \\
\hline I & 64 & 380 & 233 & 98 & $29(30)$ & 49 \\
\hline 2 & 103 & 404 & 242 & 94 & $23(24)$ & 68 \\
\hline 3 & 62 & 165 & 108 & 31 & $8(26)$ & 26 \\
\hline 4 & 209 & 539 & 377 & 81 & 48 (59) & 81 \\
\hline 5 & 75 & 359 & 186 & 95 & $14(15)$ & 78 \\
\hline 6 & 11 & 67 & 29 & 21 & 4 (19) & 17 \\
\hline 7 & 9 & 32 & 23 & 2 & I (I00) & 7 \\
\hline 8 & 0 & - & - & - & - & - \\
\hline $\begin{array}{l}\text { a 'Not } \\
\text { the er } \\
\text { medic } \\
\text { b 'Othe } \\
\text { inforn }\end{array}$ & $\begin{array}{l}\text { propriate' } \\
\text { ergency de } \\
\text { I history th } \\
\text { includes n } \\
\text { tion about }\end{array}$ & $\begin{array}{l}\text { ludes those patie } \\
\text { tment, who had } \\
\text { nade them inelig } \\
\text { otes or insufficie } \\
\text { e trial in the eme }\end{array}$ & $\begin{array}{l}\text { who were fully } \\
\text { ion-acute ankle } \\
\text { information avail } \\
\text { ency department }\end{array}$ & $\begin{array}{l}\text { ight bearing, w } \\
\text { ry or a fracture } \\
\text { e for the audit, }\end{array}$ & $\begin{array}{l}\text { vere wrongly categorised on arri } \\
\text { kle or other bone, or who had ot } \\
\text { rred elsewhere for treatment, or }\end{array}$ & $\begin{array}{l}\text { lat at } \\
\text { der past } \\
\text { declined }\end{array}$ \\
\hline
\end{tabular}





\section{Appendix I I \\ Ankle support instructions to participants}

\section{Tubular bandage advice sheet}

The research physiotherapist will show you how to apply your tubular bandage whilst you are in the Ankle Trial Clinic.

You may want to wear your tubular bandage continuously for the first few days but you can remove it when:

- bathing

- applying ice

- doing the exercises you have been instructed to do.

Remove your tubular bandage at night when you go to bed

The tubular bandage should be hand washed only, using warm water and detergent for delicate fabrics such as Lux soap flakes, then rinsed, squeezed and dried.

Stop using the tubular bandage as soon as your ankle feels comfortable and you feel confident to do so.

If you are having any problems contact: Rachel Nakash, Study Trial Co-ordinator: Tel: 02476574650

\section{Aircast/Air-stirrup advice sheet}

Your physiotherapist will show you how to apply your brace whilst you are in the Ankle Trial Clinic.

If you have any problems, follow the fitting instructions you have been given.

Apply the Air-stirrup brace over an absorbent long sock and wear a laced shoe such as a trainer.

You may want to wear your Air-stirrup brace continuously for the first few days but you can remove it when:

- bathing

- applying ice

- doing the exercises you have been instructed to do.

Remove your Air-stirrup brace at night when you go to bed

When your ankle starts to feel more comfortable, wear the brace only when walking.

Stop using the brace when your ankle feels comfortable and you feel confident to do so.

If you are having any problems contact: Rachel Nakash, Study Trial Co-ordinator: Tel: 02476574650 


\section{Bledsoe boot advice sheet}

The research physiotherapist will show you how to apply your boot whilst you are in the Ankle Trial Clinic.

If you have any problems, follow the fitting instructions you have been given.

Your boot may feel more comfortable if you wear it over an absorbent long sock.

You may want to wear your boot continuously for the first few days but you can remove it when:

- bathing

- applying ice

- doing the exercises you have been instructed to do.

Remove your boot at night when you go to bed

The straps and the foam wrap should be hand washed only, using warm water and detergent for delicate fabrics such as Lux soap flakes, then rinsed, squeezed and line dried.

Stop using the boot when your ankle feels comfortable and you feel confident to do so.

If you are having any problems contact: Rachel Nakash, Study Trial Co-ordinator: Tel: 02476574650

\section{Below knee cast advice sheet}

Each participant was given the standard advice sheet from the plaster room at the relevant hospital. 


\section{Appendix 12}

\section{Resource use questionnaire}

QI. Is your ankle better, just the same or worse after the treatment you received 9 months ago?

Better $\square \quad$ Same $\square \quad$ Worse $\square$

On a scale of $0-10$, how much benefit do you think you have gained from the treatment?

Circle your answer $(0=$ no benefit, $10=$ maximum benefit).

$\begin{array}{lllllllllll}0 & 1 & 2 & 3 & 4 & 5 & 6 & 7 & 8 & 9 & 10\end{array}$

Q2. During the past 6 months, have you consulted a doctor or therapist or received any further treatment for your ankle (apart from the treatment you received as part of the trial)?

Yes $\square \quad$ No $\square$

If 'Yes', please specify which treatment by placing a tick in the appropriate box:

\begin{tabular}{lcl} 
A\&E staff, e.g. plaster technician & $\square$ & How many times? \\
NHS consultant & $\square$ & How many times? \\
Private consultant & $\square$ & How many times? \\
GP & $\square$ & How many times? \\
Osteopathy & $\square$ & How many times? \\
Chiropractic & $\square$ & How many times? \\
NHS physiotherapy & $\square$ & How many times? \\
Private physiotherapy & $\square$ & How many times? \\
Other (please specify): & & \\
\hline
\end{tabular}

Did you pay for this treatment? $\quad$ Yes $\square \quad$ No $\square$

If 'Yes', was payment made by yourself or a private insurance company?

Self $\square \quad$ Insurance company $\square$

How much did it cost?

Q3. Over the past 6 months have you had any scans or radiographs because of your ankle?

Yes $\square \quad$ No $\square$

If 'Yes', what type of radiograph or scan? (Tick more than one box if needed)

Normal radiograph

MRI scan

Ultrasound scan

Did you pay for this/these scan(s)? $\quad$ Yes $\square \quad$ No $\square$

If 'Yes', was payment made by yourself or a private insurance company? Self $\square$ Insurance company $\square$

How much did it cost? 
Q4. Over the past 6 months have you been admitted to hospital because of your ankle?

Yes $\quad$ No $\quad$ a

If 'Yes', how many days did you spend in hospital?

Q5. Has your doctor prescribed any medicines, creams or other treatments (e.g. brace/strapping) for your ankle over the past 6 months? (Do not include the brace/support you wore as part of the trial)

Prescribed medicines/creams:

\begin{tabular}{|l|l|l|}
\hline Item description & $\begin{array}{l}\text { Name of item } \\
\text { (e.g. ibuprofen) }\end{array}$ & $\begin{array}{l}\text { Cost to you } \\
\text { (e.g. prescription charge or other cost) }\end{array}$ \\
\hline Painkillers & & $€$ \\
\hline Anti-inflammatories & & $£$ \\
\hline Creams/gels & & $£$ \\
\hline Aids/braces/strapping & & $£$ \\
\hline Injection & & $£$ \\
\hline Other & & $€$ \\
\hline
\end{tabular}

Q6. Over the past 6 months, have you bought any medicines, creams or other treatment (e.g. brace) for your ankle?

Medicines/creams bought without prescription:

\begin{tabular}{|l|l|l|}
\hline Item description & Name of item & Cost to you \\
\hline Painkillers & & $€$ \\
\hline Anti-inflammatories & & $€$ \\
\hline Creams/gels & $£$ \\
\hline Aids/braces/strapping & $£$ \\
\hline Herbal remedies & $£$ \\
\hline Other & $£$ \\
\hline
\end{tabular}

Q7. Over the past 6 months have you had to take any sick leave from work because of your ankle?

$$
\text { Yes } \square \text { No } \square \quad \text { Not applicable }
$$

If 'Yes', how many sick days did you take? 
Q8. Have you been involved in any exercise/sport over the last 6 months?

Yes $\square \quad$ No $\square$

If 'Yes', which ones? (Please tick all boxes that apply).

Swimming

Weight training

Aerobics/keep-fit

Cycling

Jogging/running

Team sport

(e.g. football, rugby, hockey, netball)

Racquet sport

(e.g. tennis, squash, badminton)

Yoga

Athletics

Walks of 2 miles or more

Heavy housework/DIY/gardening

Other sports or exercise (please specify):

Approximately how many times in the last 6 months have you done any of these activities?

Less than once a month

Once a month

Once a fortnight

$\square$
$\square$
$\square$

Once a week

Twice a week

More than twice a week 



\section{Appendix 13 \\ Results tables}

\section{Primary outcomes}

Data are summary statistics and exclude the 17 pilot study patients for the FAOS analyses only.

\section{Four weeks}

\begin{tabular}{|c|c|c|c|c|c|}
\hline \multirow[b]{2}{*}{ Score } & & \multicolumn{4}{|c|}{ Randomisation group } \\
\hline & & Tubular bandage & Below knee cast & Aircast brace & Bledsoe boot \\
\hline \multirow[t]{3}{*}{ FAOS, pain } & Mean & 63.6 & 66.9 & 67.1 & 65.5 \\
\hline & Median & 63.9 & 67.9 & 69.4 & 66.7 \\
\hline & (Quartiles) & $(47.2-80.6)$ & $(51.8-82.1)$ & $(50.0-83.3)$ & $(50.0-83.3)$ \\
\hline \multirow[t]{3}{*}{ FAOS, symptoms } & Mean & 61.0 & 66.9 & 63.0 & 61.6 \\
\hline & Median & 60.7 & 67.9 & 60.7 & 64.3 \\
\hline & (Quartiles) & $(46.4-75.0)$ & $(51.8-82.1)$ & $(46.4-78.6)$ & $(46.4-82.1)$ \\
\hline \multirow[t]{3}{*}{ FAOS, ADL } & Mean & 83.0 & 87.0 & 83.4 & 83.7 \\
\hline & Median & 83.8 & 91.9 & 86.8 & 86.8 \\
\hline & (Quartiles) & $(72.1-97.1)$ & $(79.4-98.5)$ & $(75.0-95.6)$ & $(73.5-95.6)$ \\
\hline \multirow[t]{3}{*}{ FAOS, sport } & Mean & 48.9 & 55.2 & 48.5 & 48.8 \\
\hline & Median & 50.0 & 55.0 & 45.0 & 50.0 \\
\hline & (Quartiles) & $(30.0-70.0)$ & $(30.0-75.0)$ & $(30.0-70.0)$ & $(25.0-75.0)$ \\
\hline \multirow[t]{3}{*}{ FAOS, QoL } & Mean & 44.3 & 49.5 & 48.6 & 46.4 \\
\hline & Median & 43.8 & 43.8 & 43.8 & 50.0 \\
\hline & (Quartiles) & $(25.0-62.5)$ & $(31.3-68.8)$ & $(31.3-62.5)$ & $(25.0-62.5)$ \\
\hline \multirow[t]{3}{*}{ FLP, ambulatory } & Mean & 16.0 & 11.7 & 15.3 & 14.7 \\
\hline & Median & 15.6 & 5.9 & 13.4 & 12.6 \\
\hline & (Quartiles) & (3.9-24.5) & $(0.0-22.5)$ & $(0.0-24.1)$ & $(0.0-22.7)$ \\
\hline
\end{tabular}


Twelve weeks

\begin{tabular}{|c|c|c|c|c|c|}
\hline \multirow[b]{2}{*}{ Score } & & \multicolumn{4}{|c|}{ Randomisation group } \\
\hline & & Tubular bandage & Below knee cast & Aircast brace & Bledsoe boot \\
\hline \multirow[t]{3}{*}{ FAOS, symptoms } & Mean & 70.6 & 75.6 & 73.9 & 74.6 \\
\hline & Median & 71.4 & 75.0 & 75.0 & 78.6 \\
\hline & (Quartiles) & $(57.1-85.7)$ & $(60.7-92.9)$ & $(58.9-92.9)$ & $(60.7-92.9)$ \\
\hline \multirow[t]{3}{*}{ FAOS, pain } & Mean & 74.2 & 79.8 & 77.7 & 78.0 \\
\hline & Median & 77.8 & 86.1 & 80.6 & 83.3 \\
\hline & (Quartiles) & $(55.6-94.4)$ & $(69.4-97.2)$ & $(63.9-94.4)$ & $(66.7-91.7)$ \\
\hline \multirow[t]{3}{*}{ FAOS, ADL } & Mean & 89.3 & 92.8 & 90.6 & 92.1 \\
\hline & Median & 95.6 & 98.5 & 95.6 & 97.1 \\
\hline & (Quartiles) & $(80.9-100.0)$ & $(89.7-100.0)$ & $(85.3-100.0)$ & $(88.2-100.0)$ \\
\hline \multirow[t]{3}{*}{ FAOS, sport } & Mean & 63.5 & 72.8 & 68.7 & 69.3 \\
\hline & Median & 70.0 & 75.0 & 75.0 & 75.0 \\
\hline & (Quartiles) & $(45.0-85.0)$ & $(60.0-95.0)$ & $(55.0-85.0)$ & $(55.0-90.0)$ \\
\hline \multirow[t]{3}{*}{ FAOS, QoL } & Mean & 55.5 & 63.5 & 63.5 & 61.8 \\
\hline & Median & 62.5 & 62.5 & 62.5 & 62.5 \\
\hline & (Quartiles) & $(37.5-75.0)$ & $(50.0-81.3)$ & $(43.8-81.3)$ & $(43.8-75.0)$ \\
\hline \multirow[t]{3}{*}{ FLP, ambulatory } & Mean & 8.1 & 5.7 & 6.3 & 5.9 \\
\hline & Median & 3.88 & 0.0 & 0.0 & 0.0 \\
\hline & (Quartiles) & $(0.0-14.3)$ & $(0.0-6.2)$ & $(0.0-8.2)$ & $(0.0-9.2)$ \\
\hline
\end{tabular}

\section{Nine months}

\begin{tabular}{|c|c|c|c|c|c|}
\hline \multirow[b]{2}{*}{ Score } & & \multicolumn{4}{|c|}{ Randomisation group } \\
\hline & & Tubular bandage & Below knee cast & Aircast brace & Bledsoe boot \\
\hline \multirow[t]{3}{*}{ FAOS, symptoms } & Mean & 80.7 & 82.6 & 80.9 & 81.0 \\
\hline & Median & 89.3 & 85.7 & 83.9 & 85.7 \\
\hline & (Quartiles) & $(64.3-100.0)$ & $(75.0-96.4)$ & $(69.6-100.0)$ & (7I.4-96.4) \\
\hline \multirow[t]{3}{*}{ FAOS, pain } & Mean & 82.1 & 87.0 & 83.6 & 84.2 \\
\hline & Median & 91.7 & 94.4 & 91.7 & 91.7 \\
\hline & (Quartiles) & $(69.4-100.0)$ & $(80.6-100.0)$ & $(75.0-100.0)$ & $(75.0-100.0)$ \\
\hline \multirow[t]{3}{*}{ FAOS, ADL } & Mean & 93.2 & 95.1 & 94.4 & 94.2 \\
\hline & Median & 98.5 & 100.0 & 100.0 & 100.0 \\
\hline & (Quartiles) & $(92.7-100.0)$ & $(95.6-100.0)$ & $(95.6-100.0)$ & $(92.7-100.0)$ \\
\hline \multirow[t]{3}{*}{ FAOS, sport } & Mean & 77.5 & 80.8 & 78.9 & 79.1 \\
\hline & Median & 85.0 & 85.0 & 85.0 & 85.0 \\
\hline & (Quartiles) & $(67.5-100.0)$ & $(75.0-100.0)$ & $(70.0-100.0)$ & $(70.0-100)$. \\
\hline \multirow[t]{3}{*}{ FAOS, QoL } & Mean & 67.0 & 72.8 & 72.8 & 71.2 \\
\hline & Median & 71.9 & 75.0 & 75.0 & 75.0 \\
\hline & (Quartiles) & $(50.0-93.8)$ & $(56.3-100.0)$ & $(50.0-100.0)$ & $(50.0-93.8)$ \\
\hline \multirow[t]{3}{*}{ FLP, ambulatory } & Mean & 6.0 & 3.7 & 3.3 & 3.4 \\
\hline & Median & 0.0 & 0.0 & 0.0 & 0.0 \\
\hline & (Quartiles) & $(0.0-7.1)$ & $(0.0-0.0)$ & $(0.0-0.0)$ & $(0.0-0.0)$ \\
\hline
\end{tabular}




\section{Secondary outcomes}

Data are summary statistics.

\section{Four weeks}

\begin{tabular}{|c|c|c|c|c|c|}
\hline \multirow[b]{2}{*}{ Score } & & \multicolumn{4}{|c|}{ Randomisation group } \\
\hline & & Tubular bandage & Below knee cast & Aircast brace & Bledsoe boot \\
\hline \multirow[t]{3}{*}{ SF-12, physical } & Mean & 39.5 & 42.5 & 38.4 & 38.9 \\
\hline & Median & 38.6 & 42.0 & 37.2 & 38.8 \\
\hline & (Quartiles) & $(32.6-46.7)$ & $(34.5-49.7)$ & $(32.5-43.4)$ & $(32.1-44.8)$ \\
\hline \multirow[t]{3}{*}{ SF-I2, mental } & Mean & 45.6 & 45.7 & 45.1 & 47.3 \\
\hline & Median & 48.4 & 48.7 & 46.4 & 50.0 \\
\hline & (Quartiles) & $(35.7-55.0)$ & $(37.2-55.7)$ & $(38.3-54.0)$ & $(39.1-56.7)$ \\
\hline \multirow[t]{3}{*}{ EQ-5D } & Mean & 0.6 & 0.7 & 0.7 & 0.7 \\
\hline & Median & 0.7 & 0.7 & 0.7 & 0.7 \\
\hline & (Quartiles) & $(0.6-0.8)$ & $(0.6-0.8)$ & $(0.6-0.8)$ & $(0.6-0.8)$ \\
\hline \multirow[t]{3}{*}{ VAS, pain at rest } & Mean & 20.4 & 15.1 & 19.6 & 18.1 \\
\hline & Median & 13.5 & 8.0 & 14.5 & 10.0 \\
\hline & (Quartiles) & $(2.0-32.5)$ & $(0.0-23.0)$ & $(3.0-29.0)$ & $(2.0-25.0)$ \\
\hline \multirow{3}{*}{$\begin{array}{l}\text { VAS, pain weight } \\
\text { bearing }\end{array}$} & Mean & 37.2 & 31.7 & 37.6 & 35.1 \\
\hline & Median & 33.0 & 25.0 & 30.5 & 30.5 \\
\hline & (Quartiles) & $(\mid 2.5-60.0)$ & $(6.0-50.0)$ & $(14.5-62.0)$ & $(9.0-60.0)$ \\
\hline
\end{tabular}

EQ-5D, EuroQol 5 dimensions; SF-12, short form questionnaire with I 2 items; VAS, visual analogue scale.

\section{Twelve weeks}

\begin{tabular}{|c|c|c|c|c|c|}
\hline \multirow[b]{2}{*}{ Score } & & \multicolumn{4}{|c|}{ Randomisation group } \\
\hline & & Tubular bandage & Below knee cast & Aircast brace & Bledsoe boot \\
\hline \multirow[t]{3}{*}{ SF-12, physical } & Mean & 47.0 & 49.1 & 46.5 & 48.7 \\
\hline & Median & 48.7 & 52.5 & 49.2 & 51.7 \\
\hline & (Quartiles) & $(41.5-55.2)$ & $(42.2-56.4)$ & $(38.6-54.5)$ & $(43.5-56.5)$ \\
\hline \multirow[t]{3}{*}{ SF-12, mental } & Mean & 49.5 & 49.8 & 52.2 & 52.5 \\
\hline & Median & 53.3 & 53.3 & 54.9 & 55.7 \\
\hline & (Quartiles) & $(42.3-57.7)$ & $(44.1-57.7)$ & $(47.3-58.6)$ & $(49.4-58.6)$ \\
\hline \multirow[t]{3}{*}{ EQ-5D } & Mean & 0.7 & 0.8 & 0.8 & 0.8 \\
\hline & Median & 0.8 & 0.8 & 0.8 & 0.8 \\
\hline & (Quartiles) & $(0.6-1.0)$ & $(0.7-1.0)$ & $(0.7-1.0)$ & $(0.7-1.0)$ \\
\hline \multirow[t]{3}{*}{ VAS, pain at rest } & Mean & 12.7 & 9.0 & 10.8 & 10.6 \\
\hline & Median & 5.0 & 3.5 & 4.0 & 4.0 \\
\hline & (Quartiles) & $(0.0-20.0)$ & $(0.0-\mid I .0)$ & $(0.0-16.0)$ & $(0.0-15.0)$ \\
\hline \multirow{3}{*}{$\begin{array}{l}\text { VAS, pain weight } \\
\text { bearing }\end{array}$} & Mean & 27.9 & 20.3 & 23.9 & 23.3 \\
\hline & Median & 18.5 & 11.0 & 16.0 & 13.5 \\
\hline & (Quartiles) & $(3.0-49.5)$ & $(1.0-30.0)$ & $(3.0-35.0)$ & $(2.0-40.0)$ \\
\hline
\end{tabular}

EQ-5D, EuroQol 5 dimensions; SF-12, short form questionnaire with 12 items; VAS, visual analogue scale. 
Nine months

\begin{tabular}{|c|c|c|c|c|c|}
\hline \multirow[b]{2}{*}{ Score } & & \multicolumn{4}{|c|}{ Randomisation group } \\
\hline & & Tubular bandage & Below knee cast & Aircast brace & Bledsoe boot \\
\hline \multirow[t]{3}{*}{ SF-12, physical } & Mean & 49.9 & 50.8 & 50.1 & 50.9 \\
\hline & Median & 53.5 & 55.1 & 54.9 & 54.5 \\
\hline & (Quartiles) & $(44.6-57.0)$ & $(47.1-57.7)$ & $(44.5-57.0)$ & $(50.0-57.0)$ \\
\hline \multirow[t]{3}{*}{ SF-12, mental } & Mean & 49.4 & 51.2 & 51.2 & 51.6 \\
\hline & Median & 53.8 & 55.1 & 55.0 & 55.1 \\
\hline & (Quartiles) & $(44.3-57.7)$ & $(46.9-58.6)$ & $(47.1-57.7)$ & $(49.1-58.4)$ \\
\hline \multirow[t]{3}{*}{ EQ-5D } & Mean & 0.8 & 0.8 & 0.8 & 0.9 \\
\hline & Median & 0.8 & 1.0 & 1.0 & 1.0 \\
\hline & (Quartiles) & $(0.7-1.0)$ & $(0.7-1.0)$ & $(0.7-1.0)$ & $(0.8-1.0)$ \\
\hline \multirow[t]{3}{*}{ VAS, pain at rest } & Mean & 9.9 & 8.7 & 6.5 & 9.8 \\
\hline & Median & 1.0 & 1.0 & 0.0 & 1.0 \\
\hline & (Quartiles) & $(0.0-9.0)$ & $(0.0-8.5)$ & $(0.0-6.0)$ & $(0.0-8.0)$ \\
\hline \multirow{3}{*}{$\begin{array}{l}\text { VAS, pain weight } \\
\text { bearing }\end{array}$} & Mean & 23.5 & 16.9 & 18.2 & 19.3 \\
\hline & Median & 8.0 & 3.5 & 4.0 & 5.0 \\
\hline & (Quartiles) & $(0.0-45.0)$ & $(0.0-29.0)$ & $(0.0-29.0)$ & $(0.0-25.0)$ \\
\hline
\end{tabular}

Analyses of covariance (ANCOVAS) of primary outcomes, intention to treat analysis, all participants, showing the influence of age, sex and baseline score

Four weeks

\begin{tabular}{|c|c|c|c|c|c|c|c|c|}
\hline & & $\begin{array}{l}\text { Tubular } \\
\text { bandage }\end{array}$ & $\begin{array}{l}\text { Below } \\
\text { knee cast }\end{array}$ & $\begin{array}{l}\text { Aircast } \\
\text { brace }\end{array}$ & $\begin{array}{l}\text { Bledsoe } \\
\text { boot }\end{array}$ & Male & Age & $\begin{array}{l}\text { Baseline } \\
\text { score }\end{array}$ \\
\hline \multirow[t]{2}{*}{ FAOS, pain } & Coefficient & 62.23 & 5.03 & 3.64 & 0.69 & 5.04 & -0.55 & 0.37 \\
\hline & SE & 1.93 & 2.38 & 2.38 & 2.34 & 1.71 & 0.07 & 0.05 \\
\hline \multirow{2}{*}{$\begin{array}{l}\text { FAOS, } \\
\text { symptoms }\end{array}$} & Coefficient & 59.52 & 3.28 & 2.46 & -0.99 & 4.21 & -0.33 & 0.40 \\
\hline & SE & 1.97 & 2.43 & 2.43 & 2.39 & 1.74 & 0.07 & 0.05 \\
\hline \multirow[t]{2}{*}{ FAOS, ADL } & Coefficient & 82.32 & 2.96 & 0.27 & 0.02 & 2.88 & -0.40 & 0.24 \\
\hline & SE & 1.40 & 1.73 & 1.74 & 1.70 & 1.23 & 0.05 & 0.04 \\
\hline \multirow[t]{2}{*}{ FAOS, sport } & Coefficient & 44.59 & 4.78 & -0.37 & -0.20 & 5.27 & -0.66 & 0.34 \\
\hline & SE & 2.84 & 3.44 & 3.45 & 3.42 & 2.47 & 0.11 & 0.07 \\
\hline \multirow[t]{2}{*}{ FAOS, QoL } & Coefficient & 42.67 & 5.52 & 5.06 & 1.74 & 0.97 & -0.45 & 0.28 \\
\hline & SE & 2.40 & 2.97 & 2.96 & 2.90 & 2.13 & 0.09 & 0.04 \\
\hline \multirow[t]{2}{*}{ FLP } & Coefficient & 16.86 & -3.06 & -0.06 & 0.06 & -3.39 & 0.39 & 0.14 \\
\hline & SE & 1.38 & I.7I & 1.71 & 1.68 & 1.23 & 0.05 & 0.05 \\
\hline
\end{tabular}


Twelve weeks

\begin{tabular}{|c|c|c|c|c|c|c|c|c|}
\hline & & $\begin{array}{l}\text { Tubular } \\
\text { bandage }\end{array}$ & $\begin{array}{l}\text { Below } \\
\text { knee cast }\end{array}$ & $\begin{array}{l}\text { Aircast } \\
\text { brace }\end{array}$ & $\begin{array}{l}\text { Bledsoe } \\
\text { boot }\end{array}$ & Male & Age & $\begin{array}{l}\text { Baseline } \\
\text { score }\end{array}$ \\
\hline \multirow[t]{2}{*}{ FAOS, pain } & Coefficient & 72.93 & 5.13 & 3.70 & 3.33 & 3.51 & -0.33 & 0.31 \\
\hline & SE & 2.00 & 2.46 & 2.42 & 2.40 & I.77 & 0.07 & 0.05 \\
\hline \multirow{2}{*}{$\begin{array}{l}\text { FAOS, } \\
\text { symptoms }\end{array}$} & Coefficient & 68.70 & 3.38 & 2.74 & 2.46 & 5.32 & -0.35 & 0.31 \\
\hline & SE & 1.98 & 2.44 & 2.42 & 2.40 & 1.76 & 0.07 & 0.05 \\
\hline \multirow[t]{2}{*}{ FAOS, ADL } & Coefficient & 88.86 & 3.48 & 1.09 & 2.35 & 1.95 & -0.26 & 0.17 \\
\hline & SE & 1.25 & 1.57 & 1.58 & 1.53 & 1.12 & 0.05 & 0.04 \\
\hline \multirow[t]{2}{*}{ FAOS, sport } & Coefficient & 62.24 & 8.68 & 4.78 & 5.94 & I.7I & -0.61 & 0.12 \\
\hline & SE & 2.91 & 3.59 & 3.61 & 3.51 & 2.56 & 0.12 & 0.08 \\
\hline \multirow[t]{2}{*}{ FAOS, QoL } & Coefficient & 53.48 & 8.68 & 8.01 & 6.11 & 2.40 & -0.43 & 0.18 \\
\hline & SE & 2.59 & 3.19 & 3.15 & 3.12 & 2.30 & 0.10 & 0.05 \\
\hline \multirow[t]{2}{*}{ FLP } & Coefficient & 8.36 & -1.76 & -1.16 & -0.81 & -2.02 & 0.30 & 0.14 \\
\hline & SE & 1.10 & 1.37 & 1.39 & 1.34 & 0.98 & 0.04 & 0.04 \\
\hline
\end{tabular}

ADL, activities of daily living; FAOS, Foot and Ankle Outcome Score; FLP, Functional Limitations Profile; QoL, quality of life.

\section{Nine months}

\begin{tabular}{|c|c|c|c|c|c|c|c|c|}
\hline & & $\begin{array}{l}\text { Tubular } \\
\text { bandage }\end{array}$ & $\begin{array}{l}\text { Below } \\
\text { knee cast }\end{array}$ & $\begin{array}{l}\text { Aircast } \\
\text { brace }\end{array}$ & $\begin{array}{l}\text { Bledsoe } \\
\text { boot }\end{array}$ & Male & Age & $\begin{array}{l}\text { Baseline } \\
\text { score }\end{array}$ \\
\hline \multirow[t]{2}{*}{ FAOS, pain } & Coefficient & 81.11 & 4.33 & 1.91 & 1.71 & 2.91 & -0.29 & 0.27 \\
\hline & SE & 2.09 & 2.56 & 2.58 & 2.53 & 1.87 & 0.08 & 0.05 \\
\hline \multirow{2}{*}{$\begin{array}{l}\text { FAOS, } \\
\text { symptoms }\end{array}$} & Coefficient & 79.19 & 0.42 & 0.10 & -1.08 & 4.52 & -0.24 & 0.28 \\
\hline & SE & 2.01 & 2.47 & 2.48 & 2.44 & 1.80 & 0.08 & 0.05 \\
\hline \multirow[t]{2}{*}{ FAOS, ADL } & Coefficient & 93.14 & 1.20 & 0.99 & 0.09 & 2.00 & -0.17 & 0.13 \\
\hline & SE & 1.27 & 1.58 & 1.59 & 1.55 & 1.13 & 0.05 & 0.03 \\
\hline \multirow[t]{2}{*}{ FAOS, sport } & Coefficient & 76.77 & 2.39 & 0.78 & 0.97 & 2.25 & -0.31 & 0.16 \\
\hline & SE & 3.01 & 3.68 & 3.69 & 3.61 & 2.63 & 0.11 & 0.08 \\
\hline \multirow[t]{2}{*}{ FAOS, QoL } & Coefficient & 64.92 & 6.26 & 6.07 & 3.95 & 2.89 & -0.28 & 0.20 \\
\hline & SE & 2.88 & 3.54 & 3.54 & 3.47 & 2.57 & 0.11 & 0.05 \\
\hline \multirow[t]{2}{*}{ FLP } & Coefficient & 6.32 & -1.68 & -2.15 & -1.49 & -2.26 & 0.21 & 0.09 \\
\hline & SE & 0.99 & 1.23 & 1.23 & 1.21 & 0.88 & 0.03 & 0.03 \\
\hline
\end{tabular}

ADL, activities of daily living; FAOS, Foot and Ankle Outcome Score; FLP, Functional Limitations Profile; QoL, quality of life. 
ANCOVAs of primary outcomes, intention to treat analysis, excluding pilot study participants who did not complete the FAOS at baseline, showing the influence of age, sex and baseline score

Four weeks

\begin{tabular}{|c|c|c|c|c|c|c|c|c|}
\hline & & $\begin{array}{l}\text { Tubular } \\
\text { bandage }\end{array}$ & $\begin{array}{l}\text { Below } \\
\text { knee cast }\end{array}$ & $\begin{array}{l}\text { Aircast } \\
\text { brace }\end{array}$ & $\begin{array}{l}\text { Bledsoe } \\
\text { boot }\end{array}$ & Male & Age & $\begin{array}{l}\text { Baseline } \\
\text { score }\end{array}$ \\
\hline \multirow[t]{2}{*}{ FAOS, pain } & Coefficient & 62.28 & 5.12 & 3.53 & 0.62 & 3.68 & -0.33 & 0.38 \\
\hline & SE & 1.94 & 2.38 & 2.39 & 2.35 & 1.73 & 0.07 & 0.05 \\
\hline \multirow{2}{*}{$\begin{array}{l}\text { FAOS, } \\
\text { symptoms }\end{array}$} & Coefficient & 59.80 & 3.78 & 2.18 & -0.75 & 4.95 & -0.55 & 0.38 \\
\hline & SE & 1.95 & 2.41 & 2.41 & 2.37 & 1.72 & 0.07 & 0.05 \\
\hline \multirow[t]{2}{*}{ FAOS, ADL } & Coefficient & 82.26 & 3.02 & 0.63 & -0.07 & 3.01 & -0.42 & 0.21 \\
\hline & SE & 1.36 & 1.68 & 1.69 & 1.65 & 1.21 & 0.05 & 0.04 \\
\hline \multirow[t]{2}{*}{ FAOS, sport } & Coefficient & 44.69 & 5.02 & 0.04 & -0.26 & 5.22 & -0.68 & 0.33 \\
\hline & SE & 2.83 & 3.43 & 3.44 & 3.41 & 2.47 & 0.11 & 0.07 \\
\hline \multirow[t]{2}{*}{ FAOS, QoL } & Coefficient & 42.95 & 5.91 & 4.86 & 1.85 & 0.53 & -0.46 & 0.28 \\
\hline & SE & 2.40 & 2.96 & 2.96 & 2.90 & 2.13 & 0.09 & 0.04 \\
\hline \multirow[t]{2}{*}{ FLP } & Coefficient & 16.86 & -3.06 & -0.06 & 0.06 & -3.39 & 0.39 & 0.14 \\
\hline & SE & 1.38 & 1.71 & I.7I & 1.68 & 1.23 & 0.05 & 0.05 \\
\hline
\end{tabular}

Twelve weeks

\begin{tabular}{|c|c|c|c|c|c|c|c|c|}
\hline & & $\begin{array}{l}\text { Tubular } \\
\text { bandage }\end{array}$ & $\begin{array}{l}\text { Below } \\
\text { knee cast }\end{array}$ & $\begin{array}{l}\text { Aircast } \\
\text { brace }\end{array}$ & $\begin{array}{l}\text { Bledsoe } \\
\text { boot }\end{array}$ & Male & Age & $\begin{array}{l}\text { Baseline } \\
\text { score }\end{array}$ \\
\hline \multirow[t]{2}{*}{ FAOS, pain } & Coefficient & 72.93 & 5.13 & 3.70 & 3.33 & 3.51 & -0.33 & 0.31 \\
\hline & SE & 2.00 & 2.46 & 2.42 & 2.40 & 1.77 & 0.07 & 0.05 \\
\hline \multirow{2}{*}{$\begin{array}{l}\text { FAOS, } \\
\text { symptoms }\end{array}$} & Coefficient & 68.70 & 3.38 & 2.74 & 2.46 & 5.32 & -0.35 & 0.31 \\
\hline & SE & 1.98 & 2.44 & 2.42 & 2.40 & 1.76 & 0.07 & 0.05 \\
\hline \multirow[t]{2}{*}{ FAOS, ADL } & Coefficient & 88.86 & 3.48 & 1.09 & 2.35 & 1.95 & -0.26 & 0.17 \\
\hline & SE & 1.25 & 1.57 & 1.58 & 1.53 & 1.12 & 0.05 & 0.04 \\
\hline \multirow[t]{2}{*}{ FAOS, sport } & Coefficient & 62.24 & 8.68 & 4.78 & 5.94 & 1.71 & -0.61 & 0.12 \\
\hline & SE & 2.91 & 3.59 & 3.61 & 3.51 & 2.56 & 0.12 & 0.08 \\
\hline \multirow[t]{2}{*}{ FAOS, QoL } & Coefficient & 53.48 & 8.68 & 8.01 & 6.11 & 2.40 & -0.43 & 0.18 \\
\hline & SE & 2.59 & 3.19 & 3.15 & 3.12 & 2.30 & 0.10 & 0.05 \\
\hline \multirow[t]{2}{*}{ FLP } & Coefficient & 8.36 & -1.76 & -1.16 & -0.81 & -2.02 & 0.30 & 0.14 \\
\hline & SE & 1.10 & 1.37 & 1.39 & 1.34 & 0.98 & 0.04 & 0.04 \\
\hline
\end{tabular}


Nine months

\begin{tabular}{|c|c|c|c|c|c|c|c|c|}
\hline & & $\begin{array}{l}\text { Tubular } \\
\text { bandage }\end{array}$ & $\begin{array}{l}\text { Below } \\
\text { knee cast }\end{array}$ & $\begin{array}{l}\text { Aircast } \\
\text { brace }\end{array}$ & $\begin{array}{l}\text { Bledsoe } \\
\text { boot }\end{array}$ & Male & Age & $\begin{array}{l}\text { Baseline } \\
\text { score }\end{array}$ \\
\hline \multirow[t]{2}{*}{ FAOS, pain } & Coefficient & 81.11 & 4.33 & 1.91 & I.7I & 2.91 & -0.29 & 0.27 \\
\hline & SE & 2.09 & 2.56 & 2.58 & 2.53 & 1.87 & 0.08 & 0.05 \\
\hline \multirow{2}{*}{$\begin{array}{l}\text { FAOS, } \\
\text { symptoms }\end{array}$} & Coefficient & 79.19 & 0.42 & 0.10 & -1.08 & 4.52 & -0.24 & 0.28 \\
\hline & SE & 2.01 & 2.47 & 2.48 & 2.44 & 1.80 & 0.08 & 0.05 \\
\hline \multirow[t]{2}{*}{ FAOS, ADL } & Coefficient & 93.14 & 1.20 & 0.99 & 0.09 & 2.00 & -0.17 & 0.13 \\
\hline & SE & 1.27 & 1.58 & 1.59 & 1.55 & 1.13 & 0.05 & 0.03 \\
\hline \multirow[t]{2}{*}{ FAOS, sport } & Coefficient & 76.77 & 2.39 & 0.78 & 0.97 & 2.25 & -0.31 & 0.16 \\
\hline & SE & 3.01 & 3.68 & 3.69 & 3.61 & 2.63 & 0.11 & 0.08 \\
\hline \multirow[t]{2}{*}{ FAOS, QoL } & Coefficient & 64.92 & 6.26 & 6.07 & 3.95 & 2.89 & -0.28 & 0.20 \\
\hline & SE & 2.88 & 3.54 & 3.54 & 3.47 & 2.57 & 0.11 & 0.05 \\
\hline \multirow[t]{2}{*}{ FLP } & Coefficient & 6.32 & -1.68 & -2.15 & -1.49 & -2.26 & 0.21 & 0.09 \\
\hline & SE & 0.99 & 1.23 & 1.23 & 1.21 & 0.88 & 0.03 & 0.03 \\
\hline
\end{tabular}

ADL, activities of daily living; FAOS, Foot and Ankle Outcome Score; FLP, Functional Limitations Profile; QoL, quality of life.

ANCOVAs of primary outcomes, compliance analysis, all participants, showing the influence of age, sex and baseline score

\section{Four weeks}

$\begin{array}{llrrrrrrr} & & \begin{array}{c}\text { Tubular } \\ \text { bandage }\end{array} & \begin{array}{l}\text { Below } \\ \text { knee cast }\end{array} & \begin{array}{l}\text { Aircast } \\ \text { brace }\end{array} & \begin{array}{l}\text { Bledsoe } \\ \text { boot }\end{array} & \text { Male } & \text { Age } & \begin{array}{l}\text { Baseline } \\ \text { score }\end{array} \\ \text { FAOS, pain } & \text { Coefficient } & 62.36 & 3.80 & 3.40 & 0.15 & 5.40 & -0.56 & 0.34 \\ & \text { SE } & 1.97 & 2.51 & 3.41 & 2.37 & 1.76 & 0.08 & 0.05 \\ \text { FAOS, } & \text { Coefficient } & 59.44 & 2.86 & 2.38 & -1.33 & 4.62 & -0.33 & 0.38 \\ \text { symptoms } & \text { SE } & 2.00 & 2.55 & 2.46 & 2.42 & 1.79 & 0.08 & 0.05 \\ \text { FAOS, ADL } & \text { Coefficient } & 82.37 & 1.98 & 0.18 & -0.30 & 3.07 & -0.41 & 0.23 \\ & \text { SE } & 1.42 & 1.83 & 1.76 & 1.72 & 1.28 & 0.06 & 0.04 \\ \text { FAOS, sport } & \text { Coefficient } & 44.34 & 3.32 & -0.35 & -0.53 & 6.29 & -0.64 & 0.33 \\ & \text { SE } & 2.85 & 3.59 & 3.46 & 3.42 & 2.53 & 0.12 & 0.07 \\ \text { FAOS, QoL } & \text { Coefficient } & 42.98 & 4.56 & 4.50 & 1.01 & 1.26 & -0.45 & 0.28 \\ & \text { SE } & 2.44 & 3.13 & 2.99 & 2.94 & 2.20 & 0.10 & 0.04 \\ \text { FLP } & \text { Coefficient } & 16.61 & -1.66 & 0.20 & 0.55 & -3.56 & 0.38 & 0.12 \\ & \text { SE } & 1.40 & 1.80 & 1.73 & 1.70 & 1.26 & 0.05 & 0.05\end{array}$


Twelve weeks

\begin{tabular}{|c|c|c|c|c|c|c|c|c|}
\hline & & $\begin{array}{l}\text { Tubular } \\
\text { bandage }\end{array}$ & $\begin{array}{l}\text { Below } \\
\text { knee cast }\end{array}$ & $\begin{array}{l}\text { Aircast } \\
\text { brace }\end{array}$ & $\begin{array}{l}\text { Bledsoe } \\
\text { boot }\end{array}$ & Male & Age & $\begin{array}{l}\text { Baseline } \\
\text { score }\end{array}$ \\
\hline \multirow[t]{2}{*}{ FAOS, pain } & Coefficient & 72.78 & 4.35 & 3.53 & 3.21 & 3.69 & -0.32 & 0.29 \\
\hline & SE & 2.05 & 2.64 & 2.47 & 2.45 & 1.84 & 0.08 & 0.05 \\
\hline \multirow{2}{*}{$\begin{array}{l}\text { FAOS, } \\
\text { symptoms }\end{array}$} & Coefficient & 68.84 & 3.08 & 2.80 & 2.39 & 4.86 & -0.38 & 0.30 \\
\hline & SE & 2.02 & 2.58 & 2.45 & 2.43 & 1.81 & 0.08 & 0.05 \\
\hline \multirow[t]{2}{*}{ FAOS, ADL } & Coefficient & 88.89 & 2.69 & 0.75 & 2.11 & 2.23 & -0.26 & 0.14 \\
\hline & SE & 1.28 & 1.68 & 1.61 & 1.55 & 1.17 & 0.05 & 0.04 \\
\hline \multirow[t]{2}{*}{ FAOS, sport } & Coefficient & 62.23 & 7.65 & 4.11 & 5.56 & 2.50 & -0.58 & 0.10 \\
\hline & SE & 2.94 & 3.78 & 3.63 & 3.53 & 2.64 & 0.12 & 0.08 \\
\hline \multirow[t]{2}{*}{ FAOS, QOL } & Coefficient & 53.57 & 8.84 & 7.44 & 5.48 & 2.86 & -0.42 & 0.16 \\
\hline & SE & 2.64 & 3.40 & 3.20 & 3.17 & 2.38 & 0.10 & 0.05 \\
\hline \multirow[t]{2}{*}{ FLP } & Coefficient & 7.90 & -0.50 & -0.55 & -0.31 & -2.18 & 0.03 & 0.12 \\
\hline & SE & 1.10 & 1.42 & 1.38 & 1.33 & 1.00 & 0.04 & 0.04 \\
\hline
\end{tabular}

Nine months

\begin{tabular}{llrrrrrrr} 
& & $\begin{array}{c}\text { Tubular } \\
\text { bandage }\end{array}$ & $\begin{array}{l}\text { Below } \\
\text { knee cast }\end{array}$ & $\begin{array}{l}\text { Aircast } \\
\text { brace }\end{array}$ & $\begin{array}{l}\text { Bledsoe } \\
\text { boot }\end{array}$ & Male & Age & $\begin{array}{l}\text { Baseline } \\
\text { score }\end{array}$ \\
\hline FAOS, pain & Coefficient & 81.69 & 2.93 & 1.67 & 1.38 & 2.31 & -0.30 & 0.27 \\
& SE & 2.14 & 2.73 & 2.63 & 2.58 & 1.93 & 0.08 & 0.05 \\
FAOS, & Coefficient & 79.51 & -0.64 & 0.05 & -1.38 & 4.28 & -0.26 & 0.27 \\
symptoms & SE & 2.06 & 2.63 & 2.53 & 2.49 & 1.86 & 0.08 & 0.05 \\
FAOS, ADL & Coefficient & 93.20 & 0.72 & 0.97 & 0.05 & 1.85 & -0.18 & 0.13 \\
& SE & 1.30 & 1.70 & 1.63 & 1.59 & 1.18 & 0.05 & 0.04 \\
FAOS, sport & Coefficient & 77.58 & -0.39 & 0.32 & 0.17 & 1.67 & -0.36 & 0.16 \\
& SE & 3.06 & 3.90 & 3.74 & 3.67 & 2.72 & 0.12 & 0.08 \\
FAOS, QoL & Coefficient & 65.93 & 3.43 & 5.58 & 3.15 & 2.00 & -0.30 & 0.20 \\
& SE & 2.92 & 3.72 & 3.58 & 3.51 & 2.64 & 0.12 & 0.06 \\
FLP & Coefficient & 5.94 & -0.69 & -1.80 & -1.07 & -2.29 & 0.20 & 0.07 \\
& SE & 1.00 & 1.30 & 1.24 & 1.22 & 0.91 & 0.04 & 0.04
\end{tabular}




\section{ANCOVAs of primary outcomes, compliance analysis, excluding pilot study participants who did not complete the FAOS at baseline, showing the influence of age, sex and baseline score}

\section{Four weeks}

\begin{tabular}{|c|c|c|c|c|c|c|c|c|}
\hline & & $\begin{array}{l}\text { Tubular } \\
\text { bandage }\end{array}$ & $\begin{array}{l}\text { Below } \\
\text { knee cast }\end{array}$ & $\begin{array}{l}\text { Aircast } \\
\text { brace }\end{array}$ & $\begin{array}{l}\text { Bledsoe } \\
\text { boot }\end{array}$ & Male & Age & $\begin{array}{l}\text { Baseline } \\
\text { score }\end{array}$ \\
\hline \multirow[t]{2}{*}{ FAOS, pain } & Coefficient & 62.41 & 3.91 & 3.30 & 0.09 & 5.31 & -0.56 & 0.35 \\
\hline & SE & 1.97 & 2.52 & 2.42 & 2.38 & 1.77 & 0.08 & 0.05 \\
\hline \multirow{2}{*}{$\begin{array}{l}\text { FAOS, } \\
\text { symptoms }\end{array}$} & Coefficient & 59.74 & 3.41 & 2.10 & -1.11 & 4.07 & -0.33 & 0.37 \\
\hline & SE & 1.98 & 2.54 & 2.44 & 2.40 & 1.78 & 0.08 & 0.05 \\
\hline \multirow[t]{2}{*}{ FAOS, ADL } & Coefficient & 82.31 & 2.02 & 0.53 & -0.43 & 3.22 & -0.43 & 0.19 \\
\hline & SE & 1.38 & 1.79 & I.7I & 1.67 & 1.25 & 0.05 & 0.04 \\
\hline \multirow[t]{2}{*}{ FAOS, sport } & Coefficient & 44.44 & 3.61 & 0.07 & -0.58 & 6.26 & -0.66 & 0.32 \\
\hline & SE & 2.83 & 3.58 & 3.45 & 3.40 & 2.52 & 0.12 & 0.07 \\
\hline \multirow[t]{2}{*}{ FAOS, QoL } & Coefficient & 43.26 & 5.03 & 4.30 & 1.12 & 0.81 & -0.46 & 0.27 \\
\hline & SE & 2.43 & 3.13 & 2.99 & 2.93 & 2.20 & 0.10 & 0.04 \\
\hline \multirow[t]{2}{*}{ FLP } & Coefficient & 16.61 & -1.66 & 0.20 & 0.55 & -3.56 & 0.38 & 0.12 \\
\hline & SE & 1.40 & 1.80 & 1.73 & 1.70 & 1.26 & 0.05 & 0.05 \\
\hline
\end{tabular}

\section{Twelve weeks}

\begin{tabular}{|c|c|c|c|c|c|c|c|c|}
\hline & & $\begin{array}{l}\text { Tubular } \\
\text { bandage }\end{array}$ & $\begin{array}{l}\text { Below } \\
\text { knee cast }\end{array}$ & $\begin{array}{l}\text { Aircast } \\
\text { brace }\end{array}$ & $\begin{array}{l}\text { Bledsoe } \\
\text { boot }\end{array}$ & Male & Age & $\begin{array}{l}\text { Baseline } \\
\text { score }\end{array}$ \\
\hline \multirow[t]{2}{*}{ FAOS, pain } & Coefficient & 72.78 & 4.35 & 3.53 & 3.21 & 3.69 & -0.32 & 0.29 \\
\hline & SE & 2.05 & 2.64 & 2.47 & 2.45 & 1.84 & 0.08 & 0.05 \\
\hline \multirow{2}{*}{$\begin{array}{l}\text { FAOS, } \\
\text { symptoms }\end{array}$} & Coefficient & 68.84 & 3.08 & 2.80 & 2.39 & 4.86 & -0.38 & 0.30 \\
\hline & SE & 2.02 & 2.58 & 2.45 & 2.43 & 1.81 & 0.08 & 0.05 \\
\hline \multirow[t]{2}{*}{ FAOS, ADL } & Coefficient & 88.89 & 2.69 & 0.75 & 2.11 & 2.23 & -0.26 & 0.14 \\
\hline & SE & 1.28 & 1.68 & 1.61 & 1.55 & 1.17 & 0.05 & 0.04 \\
\hline \multirow[t]{2}{*}{ FAOS, sport } & Coefficient & 62.23 & 7.65 & 4.11 & 5.56 & 2.50 & -0.58 & 0.10 \\
\hline & SE & 2.94 & 3.78 & 3.63 & 3.53 & 2.64 & 0.12 & 0.08 \\
\hline \multirow[t]{2}{*}{ FAOS, QoL } & Coefficient & 53.57 & 8.84 & 7.44 & 5.48 & 2.86 & -0.42 & 0.16 \\
\hline & SE & 2.64 & 3.40 & 3.20 & 3.17 & 2.38 & 0.10 & 0.05 \\
\hline \multirow[t]{2}{*}{ FLP } & Coefficient & 7.90 & -0.50 & -0.55 & -0.31 & -2.18 & 0.03 & 0.12 \\
\hline & SE & 1.10 & 1.42 & 1.38 & 1.33 & 1.00 & 0.04 & 0.04 \\
\hline
\end{tabular}




\section{Nine months}

\begin{tabular}{|c|c|c|c|c|c|c|c|c|}
\hline & & $\begin{array}{l}\text { Tubular } \\
\text { bandage }\end{array}$ & $\begin{array}{l}\text { Below } \\
\text { knee cast }\end{array}$ & $\begin{array}{l}\text { Aircast } \\
\text { brace }\end{array}$ & $\begin{array}{l}\text { Bledsoe } \\
\text { boot }\end{array}$ & Male & Age & $\begin{array}{l}\text { Baseline } \\
\text { score }\end{array}$ \\
\hline \multirow[t]{2}{*}{ FAOS, pain } & Coefficient & 81.69 & 2.93 & 1.67 & 1.38 & 2.31 & -0.30 & 0.27 \\
\hline & SE & 2.14 & 2.73 & 2.63 & 2.58 & 1.93 & 0.08 & 0.05 \\
\hline \multirow{2}{*}{$\begin{array}{l}\text { FAOS, } \\
\text { symptoms }\end{array}$} & Coefficient & 79.51 & -0.64 & 0.05 & -1.38 & 4.28 & -0.26 & 0.27 \\
\hline & SE & 2.06 & 2.63 & 2.53 & 2.49 & 1.86 & 0.08 & 0.05 \\
\hline \multirow[t]{2}{*}{ FAOS, ADL } & Coefficient & 93.20 & 0.72 & 0.97 & 0.05 & 1.85 & -0.18 & 0.13 \\
\hline & SE & 1.30 & 1.70 & 1.63 & 1.59 & 1.18 & 0.05 & 0.04 \\
\hline \multirow[t]{2}{*}{ FAOS, sport } & Coefficient & 77.58 & -0.39 & 0.32 & 0.17 & 1.67 & -0.36 & 0.16 \\
\hline & SE & 3.06 & 3.90 & 3.74 & 3.67 & 2.72 & 0.12 & 0.08 \\
\hline \multirow[t]{2}{*}{ FAOS, QoL } & Coefficient & 65.93 & 3.43 & 5.58 & 3.15 & 2.00 & -0.30 & 0.20 \\
\hline & SE & 2.92 & 3.72 & 3.58 & 3.51 & 2.64 & 0.12 & 0.06 \\
\hline \multirow[t]{2}{*}{ FLP } & Coefficient & 5.94 & -0.69 & -1.80 & -1.07 & -2.29 & 0.20 & 0.07 \\
\hline & SE & 1.00 & 1.30 & 1.24 & 1.22 & 0.91 & 0.04 & 0.04 \\
\hline
\end{tabular}

ADL, activities of daily living; FAOS, Foot and Ankle Outcome Score; FLP, Functional Limitations Profile; QoL, quality of life. 


\section{Appendix 14 \\ Methods of derivation of individual costs}

\section{Unit resource costs between baseline and 9 months}

\begin{tabular}{|c|c|c|c|}
\hline $\begin{array}{l}\text { Health-care } \\
\text { resource }\end{array}$ & Unit & $\begin{array}{l}\text { Actual cost given if not in } 2005-6 \\
\text { prices (for date see footnotes) }\end{array}$ & $\begin{array}{l}\text { Actual cost inflated to } 2005-6 \\
\text { prices (if applicable) }\end{array}$ \\
\hline \multirow[t]{2}{*}{ Aircast braces } & Per brace & & $\begin{array}{l}\text { List price to NHS: } \\
£ 32.50+\mathrm{VAT}=£ 38.19\end{array}$ \\
\hline & & & $\begin{array}{l}\text { Bulk buy price: } \\
£ 19.20+\text { VAT }=£ 22.56 \text { for orders } \\
\text { of } 500 \text { braces a year on a 3-year } \\
\text { contract }^{\mathrm{b}}\end{array}$ \\
\hline \multirow[t]{2}{*}{ Bledsoe boots } & Per boot & & $\begin{array}{l}\text { List price to NHS }=£ 212.68 \\
\text { including VAT }\end{array}$ \\
\hline & & & $\begin{array}{l}\text { Bulk buy price of } £ 58.75 \text { including } \\
\text { VAT for large orders (over } 100 \text { per } \\
\text { year) }{ }^{c}\end{array}$ \\
\hline $\begin{array}{l}\text { Elasticated stockings } \\
\text { (tubular bandage) }\end{array}$ & $\begin{array}{l}\text { Per elasticated } \\
\text { stocking }\end{array}$ & & NHS price: $34 p^{d}$ \\
\hline Below knee cast & $\begin{array}{l}\text { Per participant: two } \\
\text { rolls of polyresin } \\
\text { casting tape required }\end{array}$ & & NHS price: $€ 12.80^{f}$ \\
\hline \multicolumn{4}{|l|}{ Cost of fitting } \\
\hline Aircast braces & Fitting a brace & & $f 1.04^{\mathrm{g}}$ \\
\hline Bledsoe boots & Fitting a boot & & $£ 2.35^{\mathrm{h}}$ \\
\hline $\begin{array}{l}\text { Elasticated stockings } \\
\text { (tubular bandage) }\end{array}$ & $\begin{array}{l}\text { Fitting elasticated } \\
\text { stockings }\end{array}$ & & $E I .10^{i}$ \\
\hline Below knee cast & $\begin{array}{l}\text { Cost of applying } \\
\text { polyresin casting tape }\end{array}$ & & $E 3.66^{i}$ \\
\hline \multicolumn{4}{|l|}{ Staff costs (NHS) } \\
\hline NHS consultant & Consultation & & $\begin{array}{l}£ 73.00 \\
\text { (quartile range } £ 63.00-£ 89.00)^{k}\end{array}$ \\
\hline GP & Consultation & $£ 49$ (quartile range $£ 31-£ 44)^{\prime}$ & $\begin{array}{l}£ 52.60 \\
\text { (quartile range } £ 33.28-£ 47.23)^{m}\end{array}$ \\
\hline Osteopath & Session & $£ 40.29^{n}$ & $£ 43.25^{\circ}$ \\
\hline Chiropractor & Session & $£ 37.75^{\mathrm{p}}$ & $£ 40.52^{q}$ \\
\hline NHS physiotherapy & Consultation & & $£ 8.06^{r}$ \\
\hline $\begin{array}{l}\text { Other: attendances } \\
\text { at deep vein } \\
\text { thrombosis clinic }\end{array}$ & Consultation & & $£ \mid 89$ (quartile range $£ \mid 30-£ 242)^{\mathrm{s}}$ \\
\hline \multicolumn{4}{|l|}{ Staff costs (private) ${ }^{t}$} \\
\hline Private consultant & Consultation & & $E 120^{u}$ \\
\hline Osteopathy & Session & $£ 40.29^{v}$ & $£ 43.25^{w}$ \\
\hline Chiropractor & Session & $£ 37.75^{x}$ & $£ 40.52^{y}$ \\
\hline Private physiotherapy & Session & $£ 33.86^{z}$ & $£ 36.35^{\mathrm{aa}}$ \\
\hline
\end{tabular}




\begin{tabular}{|c|c|c|c|}
\hline $\begin{array}{l}\text { Health-care } \\
\text { resource }\end{array}$ & Unit & $\begin{array}{l}\text { Actual cost given if not in } 2005 / 6 \\
\text { prices (for date see footnotes) }\end{array}$ & $\begin{array}{l}\text { Actual cost inflated to } 2005 / 6 \\
\text { prices (if applicable) }\end{array}$ \\
\hline \multicolumn{4}{|c|}{ Imaging because of ankle injury (NHS) } \\
\hline Normal radiograph & Scan & $£ 22.57^{\text {bb }}$ & $£ 22.72^{\mathrm{cc}}$ \\
\hline MRI scan & Scan & & $£ 3 \mid 3$ (quartile range $£ \mid 87-£ 527$ ) dd \\
\hline Ultrasound scan & Scan & & $£ 67$ (quartile range $£ 51-£ 89$ ) ${ }^{\mathrm{ee}}$ \\
\hline CT scan & Scan & & $£ \mid 60$ (quartile range $£|07-£| 95)^{\mathrm{ff}}$ \\
\hline \multicolumn{4}{|c|}{ Imaging because of ankle injury (private) ${ }^{t}$} \\
\hline Normal radiograph & Scan & & $£ 74.50 \mathrm{gg}$ \\
\hline MRI scan & Scan & & $£ 556.20^{\text {hh }}$ \\
\hline Ultrasound scan & Scan & & $£ 212.50^{i i}$ \\
\hline CT scan & Scan & & $£ 518.75 i$ \\
\hline \multicolumn{4}{|l|}{ Hospital admissions } \\
\hline $\begin{array}{l}\text { Cost of days } \\
\text { hospital admission } \\
\text { (orthopaedics) }\end{array}$ & $\begin{array}{l}\text { Inpatient day in } \\
\text { orthopaedic care: } \\
\text { regular day/night } \\
\text { admissions }\end{array}$ & $£ 365^{\mathrm{kk}}$ & $€ 391.81^{11}$ \\
\hline \multicolumn{4}{|l|}{ Prescribed medicine } \\
\hline $\begin{array}{l}\text { Various prescribed } \\
\text { medicine }\end{array}$ & & & $\begin{array}{l}\text { Prices sourced from the British } \\
\text { National Formulary (BNF) website }\end{array}$ \\
\hline
\end{tabular}

Privately purchased medicine

Prices self-reported by patients ${ }^{\text {nn }}$

Sick leave due to ankle injury

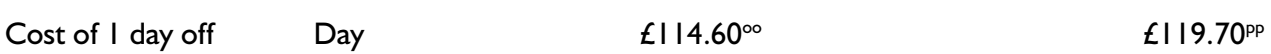

work (based on

national average

wage)

a If unit costs not already in $2005 / 6$ prices.

b For the equivalent product (i.e. trial version no longer available), which has the advantage over the existing one in that it fits both legs but is otherwise comparable. Supplied by Aircast Ltd Partnership, Brant House, Scragglethorpe, Lincs, LN5 0QZ, February 2006.

c Up-to-date costs (list and bulk buying prices) supplied by Bhraum Medical, Thorncliffe Park, Sheffield, S35 2PW.

d Cost provided relates to prevailing costs of elasticated stockings supplied to Coventry and Warwickshire hospital (part of UHCW NHS Trust)

e Information confirmed by Coventry and Warwickshire hospital plastering department in 2006.

f Cost information provided by Coventry and Warwickshire hospital plastering department in 2006 for two rolls.

$\mathrm{g}$ Average total time to apply 4 minutes [standard deviation $=0.97$ : using the formula for Cls for difference between the means comparing the control group (elasticated stockings) with Aircast braces gives 4.5 minutes vs 4.0 minutes, a difference between means of 0.5 minutes $(\mathrm{Cl}-\mathrm{I} .35$ minutes to $2.4 \mathrm{I}$ minutes)], assuming 3 minutes of a Senior II physiotherapist's time [mid-scale (average of points 3 and 4 salaries for 2004/5 with on-costs at $9.3 \%$ for employers national insurance and $14 \%$ for superannuation)]. Nurse time taken as E-grade nurse on point 4 of 7 , with on-costs for 2005/6.

h Average total time to apply 9 minutes [standard deviation $=5.0$ : using the formula for $\mathrm{Cl}$ for difference between the means comparing the control group (elasticated stockings) with Bledsoe boots gives 4.5 minutes vs 9 minutes, a difference between means of -4.6 minutes $(\mathrm{Cl}-\mathrm{I} .66$ to -7.56$)$ ], assuming 5 minutes of physiotherapist time and 4 minutes of nursing time. Grades and costing procedures as for Aircast braces.

i Average total time to apply 4.5 minutes (standard deviation $=4.17$ ), assuming a mid-scale E-grade nurse on an average of points 3 or 4 of 6 for 2005/6, with on-cost percentages as for Aircast brace and elasticated stockings. 
j Average total time to apply 15 minutes [standard deviation $=7.34$ : using the formula for $\mathrm{Cl}$ for difference between the means comparing the control group (elasticated stockings) with below knee cast gives 4.5 minutes vs 15 minutes, a difference in means of -10.5 minutes $(\mathrm{Cl}-6.80$ minutes to -14.20 minutes)], assuming a mid-scale $\mathrm{E}$-grade nurse on the average of points 3 or 4 of 6 for 2005/6, with on-cost percentages as for Aircast brace and elasticated stockings.

k National schedule of reference costs - NHS trusts and primary care trusts - Outpatient follow-up attendance data. Reference costs 2005. Figure taken for Trauma and Orthopaedics: Trauma.

I National schedule of reference costs - Primary care trusts - Outpatient follow-up attendance data. Reference costs 2004 (published March 2005).

m Based on National schedule of reference costs - Primary care trusts - Outpatient follow-up attendance data. Reference costs 2004 (published March 2005), inflated using an average of the 5-year annual percentage increase in health and community health services inflation factors for pay.

n Lack of information on NHS figures meant that private sector figures were used. The average cost of a session at seven private osteopaths consulted about their 2004 prices. All these osteopaths were selected because they were close to sites involved in the study.

- 2004 costs of osteopathy inflated using an average of the 5-year annual percentage increase in health and community health services inflation factors for pay.

P Approach to costing as for osteopaths but using costs for chiropractors, using eight private chiropractors and 2004 prices.
2004 costs of chiropractors inflated using an average of the 5 -year annual percentage increase in health and community health services inflation factors for pay.

$r \quad$ Using physiotherapy pay scales (2005/6); based on a 30-minute consultation and a 37.5-hour working week for 46 weeks per year, assuming a Senior II physiotherapist on the average of point 3 or 4 out of 6 , costed with on-costs for national insurance and superannuation.

s Based on National schedule of reference costs - NHS trusts - Outpatient first attendance data. Reference costs 2004 (published March 2005).

$\mathrm{t} \quad$ Figures used if respondents did not supply a cost. If a cost was supplied this was used. Such costs were not inflated because of (a) the relatively short time period of the trial; (b) the absence of a readily available cost inflation index applying directly to such private sector services; (c) the fact that use of such services was not a major cost driver.

u Cost for use if patient did not specify cost: Walsgrave Hospital, Coventry; cost in 2006 for a I5-minute consultation with an orthopaedic surgeon.

$\checkmark$ Cost for use if patient did not specify cost: average cost of a session at seven private osteopaths consulted about their 2004 prices.

w Cost for use if patient did not specify cost: 2004 costs of osteopathy inflated using an average of the 5-year annual percentage increase in health and community health services inflation factors for pay.

$x \quad$ Cost for use if patient did not specify cost: average cost of a session at eight private chiropractors using 2004 prices.

y Cost for use if patient did not specify cost: 2004 costs for a chiropractor inflated using an average of the 5-year annual percentage increase in health and community health services inflation factors for pay.

z Cost for use if patient did not specify cost: average cost of a session at seven private physiotherapists using 2004 prices.

aa Cost for use if patient did not specify cost: 2004 costs for private physiotherapy inflated using an average of the 5-year annual percentage increase in health and community health services inflation factors for pay.

bb Based on average of 2004/5 prices for ankle imaging without radiologist support.

CC Based on average of 2004/5 prices for ankle imaging without radiologist support. This figure was then inflated to 2005/6 prices using an average of the 5-year trend for 2000-5 of the price component of the health and community health services pay and price inflation index.

dd National schedule of reference costs - NHS trusts - Direct access: radiology services test data - Banding code RBFI. Reference costs 2005 (published April 2006).

ee National schedule of reference costs - NHS trusts - Direct access: Radiology services test data - Banding code RBC2. Reference costs 2005 (published April 2006).

ff National schedule of reference costs - NHS trusts - Direct access: radiology services test data - Banding code RBDI. Reference costs 2005 (published April 2006).

gg Cost for use if patient did not specify cost: based on the average price of a radiograph in late 2005 with BUPA (Whalley Range, Manchester); MedTel (City of London); BMI Healthcare (nationwide costs); and Alliance Medical (nationwide costs).

hh Cost for use if patient did not specify cost: based on the average price of an MRI in late 2005 with BUPA (Whalley Range, Manchester); MedTel (City of London); MedTel (Cardiff); BMI Healthcare (nationwide costs); and Alliance Medical (nationwide costs).

ii Cost for use if patient did not specify cost: based on the average price of an ultrasound in late 2005 at BUPA (Whalley Range, Manchester) and MedTel (City of London).

jj Cost for use if patient did not specify cost: based on the average price of a CT scan in late 2005 with BUPA (Whalley Range, Manchester); MedTel (City of London); BMI Healthcare (nationwide costs); and Alliance Medical (nationwide costs).

kk National schedule of reference costs - NHS trusts (regular admissions data). Reference costs 2004 (published March 2005).

II 2004 reference cost inflated using an average of the 5-year annual percentage increase in health and community health services inflation factors for pay. 
mm BNF website: www.bnf.org (costs sourced in early 2006).

nn No attempt was made to inflate self-reported costs to 2005/6 prices if items were obtained before this period. This was because, when the trial began in November 2002, the Health Service Cost Index (available from the Resource Planning Acquisition Team at the Department of Health) for drugs was 77.86; in March 2005, just before the 2005/6 financial year for which we wanted to standardise prices, the figure was 76.97. Thus, drug prices were practically static over the period, suggesting inflating or deflating such costs was unnecessary. On occasions, if respondents volunteered information about purchasing an item but failed to indicate a cost then we sometimes assumed a cost figure supplied by another respondent, or used personal knowledge about the retail price of such an item, or obtained a cost from the BNF website.

oo Data sourced from Dobbs. ${ }^{86}$ Using Table 3, Make-up of mean gross weekly pay, United Kingdom, April 1998-2004 column 2004 - implies a weekly wage of $£ 506.90$. This figure was multiplied by 52 and then divided by 230 (allowing for 6 weeks of holidays and assuming 230 working days). This yielded a daily rate of $£|| 4.60$.

pp The 2004 pay data has been inflated to 2005 prices (because of the paucity of data available) using the average percentage increase over the 5-year series 1999-2004 obtained from the same data set (and row) as the actual 2004 pay information. 


\section{Appendix 15}

\section{Cost-utility analysis results}

\section{Cost-utility analysis (ICERs) related to cost per QALY (health-care costs only)}

\begin{tabular}{|c|c|c|c|c|}
\hline & Tubular bandage & Below knee cast & Aircast brace & Bledsoe boot \\
\hline Effect, mean & 0.3254 & 0.4299 & 0.4297 & $0.434 I$ \\
\hline Effect, SD & 0.2678 & 0.2802 & 0.2491 & 0.2902 \\
\hline Effect, SE & 0.0298 & 0.0317 & 0.0292 & 0.0340 \\
\hline Cost, mean & $E \mid 35.09$ & $E \mid 70.54$ & $E \mid 66.52$ & $£ 365.00$ \\
\hline Cost, SD & $£ 371.51$ & $£ 394.51$ & $£ 366.64$ & $£ 381.72$ \\
\hline Cost, SE & $£ 41.28$ & $£ 44.67$ & $€ 42.91$ & $£ 44.68$ \\
\hline Difference (effect), mean & & 0.1044 & 0.1043 & 0.1086 \\
\hline Difference (effect), SE & & 0.0435 & 0.0417 & 0.0452 \\
\hline Difference (effect), lower $95 \% \mathrm{Cl}$ & & 0.0192 & 0.0227 & 0.0201 \\
\hline Difference (effect), upper $95 \% \mathrm{Cl}$ & & 0.1897 & 0.1859 & 0.1971 \\
\hline Difference (cost), mean & & $£ 35.44$ & $£ 31.43$ & $£ 229.91$ \\
\hline Difference (cost), SE & & $£ 60.82$ & $£ 59.54$ & $£ 60.83$ \\
\hline Difference (cost), lower $95 \% \mathrm{Cl}$ & & $-£ 83.76$ & $-£ 85.28$ & $f \mid 10.69$ \\
\hline Difference (cost), upper $95 \% \mathrm{Cl}$ & & $€ 154.65$ & $E \mid 48.13$ & $£ 349.13$ \\
\hline ICER & & $£ 339$ & $£ 301$ & $£ 2116$ \\
\hline
\end{tabular}


Cost-utility analysis (ICERs) related to cost per QALY (health-care costs only) comparing below knee cast with Aircast brace and with Bledsoe boot

\begin{tabular}{|c|c|c|c|}
\hline & Below knee cast & Aircast brace & Bledsoe boo \\
\hline Effect, mean & 0.4299 & 0.4297 & 0.4341 \\
\hline Effect, SD & 0.2802 & 0.2491 & 0.2902 \\
\hline Effect, SE & 0.0317 & 0.0292 & 0.0340 \\
\hline Cost, mean & €170.54 & f147.33 & $£ 365.00$ \\
\hline Cost, SD & $£ 394.51$ & $£ 366.64$ & $£ 381.72$ \\
\hline Cost, SE & $£ 44.67$ & $€ 42.91$ & $£ 44.68$ \\
\hline Difference (effect), mean & & -0.0001 & 0.0042 \\
\hline Difference (effect), SE & & 0.0431 & 0.0465 \\
\hline Difference (effect), lower $95 \% \mathrm{Cl}$ & & -0.0846 & -0.0869 \\
\hline Difference (effect), upper $95 \% \mathrm{Cl}$ & & 0.0843 & 0.0953 \\
\hline Difference (cost), mean & & $-£ 23.21$ & $£ 194.47$ \\
\hline Difference (cost), SE & & 661.94 & $£ 63.18$ \\
\hline Difference (cost), lower 95\% Cl & & $-€|44.6|$ & $£ 70.64$ \\
\hline Difference (cost), upper $95 \% \mathrm{Cl}$ & & $£ 98.20$ & $£ 318.29$ \\
\hline ICER & & $f \mid 59,214$ & $£ 46,324$ \\
\hline
\end{tabular}

\section{Cost-utility analysis (ICERs) related to cost per QALY (health-care costs and} indirect sick leave cost)

\begin{tabular}{|c|c|c|c|c|}
\hline & Tubular bandage & Below knee cast & Aircast brace & Bledsoe boot \\
\hline Effect, mean & 0.3254 & 0.4299 & 0.4297 & $0.434 I$ \\
\hline Effect, SD & 0.2678 & 0.2802 & 0.2491 & 0.2902 \\
\hline Effect, SE & 0.0298 & 0.0317 & 0.0292 & 0.0340 \\
\hline Cost, mean & $£ 940.48$ & $€ 1085.94$ & $f|3| 4.33$ & $£ \mid 187.60$ \\
\hline Cost, SD & f1903.39 & $€ 2842.05$ & $£ 3254.27$ & $€ 1918.34$ \\
\hline Cost, SE & $£ 211.49$ & $£ 321.80$ & $£ 380.88$ & $£ 224.53$ \\
\hline Difference (effect), mean & & 0.1044 & 0.1043 & 0.1086 \\
\hline Difference (effect), SE & & 0.0435 & 0.0417 & 0.0452 \\
\hline Difference (effect), lower $95 \% \mathrm{Cl}$ & & 0.0192 & 0.0227 & 0.0201 \\
\hline Difference (effect), upper $95 \% \mathrm{Cl}$ & & 0.1897 & 0.1859 & 0.1971 \\
\hline Difference (cost), mean & & f145.45 & $€ 373.85$ & $£ 247.11$ \\
\hline Difference (cost), SE & & $£ 385.07$ & $£ 435.66$ & $£ 308.45$ \\
\hline Difference (cost), lower $95 \% \mathrm{Cl}$ & & $-€ 609.28$ & $-£ 480.03$ & $-£ 357.43$ \\
\hline Difference (cost), upper $95 \% \mathrm{Cl}$ & & $£ 900.18$ & $£ \mid 227.72$ & $£ 851.65$ \\
\hline ICER & & $f 1393$ & $£ 3585$ & $£ 2275$ \\
\hline
\end{tabular}




\section{Cost-utility analysis (ICERs) related to cost per QALY (health-care costs and indirect sick leave cost) comparing below knee cast with Aircast brace and with Bledsoe boot}

\begin{tabular}{|c|c|c|c|}
\hline & Below knee cast & Aircast brace & Bledsoe boot \\
\hline Effect, mean & 0.4299 & 0.4297 & 0.4341 \\
\hline Effect, SD & 0.2802 & 0.2491 & 0.2902 \\
\hline Effect, SE & 0.0317 & 0.0292 & 0.0340 \\
\hline Cost, mean & $E 1085.94$ & $£|3| 4.33$ & $E \mid 187.59$ \\
\hline Cost, SD & $£ 2842.05$ & $£ 3254.27$ & $f|9| 8.34$ \\
\hline Cost, SE & $£ 321.80$ & $£ 380.88$ & $£ 224.53$ \\
\hline Difference (effect), mean & & -0.0001 & 0.0042 \\
\hline Difference (effect), SE & & 0.0431 & 0.0465 \\
\hline Difference (effect), lower $95 \% \mathrm{Cl}$ & & -0.0846 & -0.0869 \\
\hline Difference (effect), upper $95 \% \mathrm{Cl}$ & & 0.0843 & 0.0953 \\
\hline Difference (cost), mean & & $£ 228.39$ & $E 101.66$ \\
\hline Difference (cost), SE & & $£ 498.62$ & $£ 392.38$ \\
\hline Difference (cost), lower $95 \% \mathrm{Cl}$ & & $-£ 748.89$ & $-£ 667.40$ \\
\hline Difference (cost), upper $95 \% \mathrm{Cl}$ & & $£ \mid 205.68$ & $£ 870.72$ \\
\hline ICER & & $-£ \mid 566,824$ & $£ 24,216$ \\
\hline
\end{tabular}

\section{Sensitivity analysis: cost-utility analysis (ICERs) related to cost per QALY (health-care costs) excluding cases for which imputation necessary}

\begin{tabular}{|c|c|c|c|c|}
\hline & Tubular bandage & Below knee cast & Aircast brace & Bledsoe boot \\
\hline Effect, mean & 0.3275 & 0.4225 & 0.4320 & 0.4294 \\
\hline Effect, SD & 0.2651 & 0.2798 & 0.2516 & 0.2889 \\
\hline Effect, SE & 0.0304 & 0.0321 & 0.0296 & 0.0317 \\
\hline Cost, mean & $E \mid 36.38$ & $E \mid 73.66$ & $E|70| \mid$. & $£ 358.93$ \\
\hline Cost, SD & $£ 379.31$ & $£ 399.21$ & $£ 371.20$ & $£ 386.66$ \\
\hline Cost, SE & $£ 43.51$ & $£ 45.79$ & $£ 43.75$ & $€ 42.44$ \\
\hline Difference (effect), mean & & 0.0950 & 0.1045 & 0.1019 \\
\hline Difference (effect), SE & & 0.0442 & 0.0419 & 0.0434 \\
\hline Difference (effect), lower $95 \% \mathrm{Cl}$ & & 0.0083 & 0.0223 & 0.0168 \\
\hline Difference (effect), upper $95 \% \mathrm{Cl}$ & & 0.1817 & 0.1866 & 0.01870 \\
\hline Difference (cost), mean & & $£ 37.27$ & $£ 33.72$ & $£ 222.54$ \\
\hline Difference (cost), SE & & $£ 63.17$ & $£ 60.93$ & $£ 60.00$ \\
\hline Difference (cost), lower $95 \% \mathrm{Cl}$ & & $-£ 86.54$ & $-£ 85.70$ & $£ 104.95$ \\
\hline Difference (cost), upper $95 \% \mathrm{Cl}$ & & $E \mid 61.08$ & EI53.14 & $£ 340.14$ \\
\hline ICER & & $£ 392$ & $£ 323$ & $£ 2184$ \\
\hline
\end{tabular}


Sensitivity analysis: cost-utility analysis (ICERs) related to cost per QALY (health-care costs at bulk buy discounted prices) comparing tubular bandage with Aircast brace and with Bledsoe boot

\begin{tabular}{|c|c|c|c|}
\hline & Tubular bandage & $\begin{array}{l}\text { Aircast brace at bulk } \\
\text { buy price }\end{array}$ & $\begin{array}{l}\text { Bledsoe boot at bulk } \\
\text { buy price }\end{array}$ \\
\hline Effect, mean & 0.3254 & 0.4297 & $0.434 I$ \\
\hline Effect, SD & 0.2678 & 0.4291 & 0.2902 \\
\hline Effect, SE & 0.0298 & 0.0292 & 0.0340 \\
\hline Cost, mean & $f 135.09$ & 6150.89 & $£ 211.07$ \\
\hline Cost, SD & $€ 371.51$ & $£ 366.64$ & $£ 381.72$ \\
\hline Cost, SE & $£ 41.28$ & $£ 42.91$ & $£ 44.68$ \\
\hline Difference (effect), mean & & 0.1043 & 0.1086 \\
\hline Difference (effect), SE & & 0.0417 & 0.0452 \\
\hline Difference (effect), lower $95 \% \mathrm{Cl}$ & & 0.0227 & 0.0201 \\
\hline Difference (effect), upper $95 \% \mathrm{Cl}$ & & 0.1859 & 0.1971 \\
\hline Difference (cost), mean & & $£ 15.80$ & $£ 75.98$ \\
\hline Difference (cost), SE & & $£ 59.54$ & $£ 60.83$ \\
\hline Difference (cost), lower $95 \% \mathrm{Cl}$ & & $-f \mid 00.91$ & $-£ 43.24$ \\
\hline Difference (cost), upper $95 \% \mathrm{Cl}$ & & $£ 132.50$ & $£ 195.20$ \\
\hline ICER & & $£|5| .00$ & $£ 699.00$ \\
\hline
\end{tabular}

Sensitivity analysis: cost-utility analysis (ICERs) related to cost per QALY (health-care costs and indirect sick leave cost at $\mathbf{£ 5 9 . 8 5}$ per diem)

\begin{tabular}{|c|c|c|c|c|}
\hline & Tubular bandage & Below knee cast & Aircast brace & Bledsoe boot \\
\hline Effect, mean & 0.3254 & 0.4299 & 0.4297 & $0.434 I$ \\
\hline Effect, SD & 0.2678 & 0.2802 & 0.2491 & 0.2902 \\
\hline Effect, SE & 0.0298 & 0.0317 & 0.0292 & 0.0340 \\
\hline Cost, mean & $£ 537.79$ & $€ 628.24$ & $€ 740.42$ & $£ 776.30$ \\
\hline Cost, SD & $€ 1038.87$ & $€ 1543.73$ & $£ \mid 688.57$ & $f 1103.98$ \\
\hline Cost, SE & fl15.43 & $£ 174.79$ & $f 197.63$ & $f \mid 29.21$ \\
\hline Difference (effect), mean & & 0.1044 & 0.1043 & 0.1086 \\
\hline Difference (effect), SE & & 0.0435 & 0.0417 & 0.0452 \\
\hline Difference (effect), lower $95 \% \mathrm{Cl}$ & & 0.0192 & 0.0227 & 0.0201 \\
\hline Difference (effect), upper $95 \% \mathrm{Cl}$ & & 0.1897 & 0.1859 & 0.1971 \\
\hline Difference (cost), mean & & $£ 90.45$ & $£ 202.64$ & $£ 238.51$ \\
\hline Difference (cost), SE & & $£ 209.47$ & $£ 228.87$ & $f 173.26$ \\
\hline Difference (cost), lower $95 \% \mathrm{Cl}$ & & $-\notin 320.10$ & $-£ 245.95$ & $-\notin 101.07$ \\
\hline Difference (cost), upper $95 \% \mathrm{Cl}$ & & 501.00 & 651.22 & $£ 578.10$ \\
\hline ICER & & $£ 866$ & $€ 1943$ & $£ 2195$ \\
\hline
\end{tabular}




\section{Cost-utility analysis (ICERs) related to cost per QALY (health-care costs and indirect sick leave cost at $\mathbf{E 5 9 . 8 5}$ per diem) comparing below knee cast with Aircast brace}

\begin{tabular}{|c|c|c|}
\hline & Below knee cast & Aircast brace \\
\hline Effect, mean & 0.3351 & 0.4297 \\
\hline Effect, SD & 0.2642 & 0.2491 \\
\hline Effect, SE & 0.0299 & 0.0292 \\
\hline Cost, mean & $£ 628.24$ & $£ 740.42$ \\
\hline Cost, SD & $£ \mid 543.73$ & $f \mid 688.57$ \\
\hline Cost, SE & $£ \mid 74.79$ & $£ 197.63$ \\
\hline Difference (effect), mean & & 0.0946 \\
\hline Difference (effect), SE & & 0.0418 \\
\hline Difference (effect), lower $95 \% \mathrm{Cl}$ & & 0.0127 \\
\hline Difference (effect), upper $95 \% \mathrm{Cl}$ & & 0.1765 \\
\hline Difference (cost), mean & & $f 112.19$ \\
\hline Difference (cost), SE & & $£ 263.84$ \\
\hline Difference (cost), lower $95 \% \mathrm{Cl}$ & & $-£ 404.93$ \\
\hline Difference (cost), upper $95 \% \mathrm{Cl}$ & & $£ 629.30$ \\
\hline ICER & & $E 1186$ \\
\hline
\end{tabular}

\section{Sensitivity analysis: cost-utility analysis (ICERs) related to cost per QALY (health-care costs and indirect sick leave cost capped at 30 days)}

\begin{tabular}{|c|c|c|c|c|}
\hline & Tubular bandage & Below knee cast & Aircast brace & Bledsoe boot \\
\hline Effect, mean & 0.3254 & 0.4299 & 0.4297 & $0.434 I$ \\
\hline Effect, SD & 0.2678 & 0.2802 & 0.2491 & 0.2902 \\
\hline Effect, SE & 0.0298 & 0.0317 & 0.0292 & 0.0340 \\
\hline Cost, mean & $£ 746.89$ & $£ 725.92$ & $£ 928.99$ & $£ 1028.92$ \\
\hline Cost, SD & $E|256.6|$ & $£ 1264.99$ & $£ \mid 326.03$ & $E \mid 279.08$ \\
\hline Cost, SE & $E 139.62$ & $£ \mid 43.23$ & $£ \mid 55.20$ & $£ \mid 49.70$ \\
\hline Difference (effect), mean & & 0.1044 & 0.1043 & 0.1086 \\
\hline Difference (effect), SE & & 0.0435 & 0.0417 & 0.0452 \\
\hline Difference (effect), lower $95 \% \mathrm{Cl}$ & & 0.0192 & 0.0227 & 0.0201 \\
\hline Difference (effect), upper $95 \% \mathrm{Cl}$ & & 0.1897 & 0.1859 & 0.1971 \\
\hline Difference (cost), mean & & $£ 6.03$ & $£ \mid 82.10$ & $£ 282.03$ \\
\hline Difference (cost), SE & & $£ 200.02$ & $£ 208.76$ & $£ 204.71$ \\
\hline Difference (cost), lower $95 \% \mathrm{Cl}$ & & $-£ 386.01$ & $-£ 227.07$ & $-£ \mid 19.20$ \\
\hline Difference (cost), upper $95 \% \mathrm{Cl}$ & & $£ 398.07$ & $£ 591.26$ & $£ 683.25$ \\
\hline ICER & & $£ 58$ & $£ \mid 746$ & $£ 2596$ \\
\hline
\end{tabular}


Sensitivity analysis: cost-utility analysis (ICERs) related to cost per QALY (health-care costs and indirect sick leave cost capped at 30 days) to assess cost-effectiveness of top two performing options

\begin{tabular}{|c|c|c|}
\hline & Below knee cast & Aircast brace \\
\hline Effect, mean & 0.3351 & 0.4297 \\
\hline Effect, SD & 0.2642 & 0.2491 \\
\hline Effect, SE & 0.0299 & 0.0292 \\
\hline Cost, mean & $£ 752.92$ & $£ 928.99$ \\
\hline Cost, SD & $£ 1264.99$ & $f \mid 326.03$ \\
\hline Cost, SE & f143.23 & f155.20 \\
\hline Difference (effect), mean & & 0.0946 \\
\hline Difference (effect), SE & & 0.0418 \\
\hline Difference (effect), lower $95 \% \mathrm{Cl}$ & & 0.0127 \\
\hline Difference (effect), upper $95 \% \mathrm{Cl}$ & & 0.1765 \\
\hline Difference (cost), mean & & $£ 176.06$ \\
\hline Difference (cost), SE & & 6211.19 \\
\hline Difference (cost), lower $95 \% \mathrm{Cl}$ & & $-£ 237.86$ \\
\hline Difference (cost), upper $95 \% \mathrm{Cl}$ & & $£ 590.00$ \\
\hline ICER & & $€|86|$ \\
\hline
\end{tabular}

Sensitivity analysis: cost-utility analysis (ICERs) related to cost per QALY (health-care costs at bulk buy discounted prices and indirect sick leave cost) comparing tubular bandage with Aircast brace and with Bledsoe boot

\begin{tabular}{|c|c|c|c|}
\hline & Tubular bandage & $\begin{array}{l}\text { Aircast brace at bulk } \\
\text { buy price }\end{array}$ & $\begin{array}{l}\text { Bledsoe boot at bulk } \\
\text { buy price }\end{array}$ \\
\hline Effect, mean & 0.3254 & 0.4297 & 0.4341 \\
\hline Effect, SD & 0.2678 & 0.2491 & 0.2902 \\
\hline Effect, SE & 0.0298 & 0.0292 & 0.0340 \\
\hline Cost, mean & $£ 940.48$ & $£ \mid 298.70$ & $£ 1033.66$ \\
\hline Cost, SD & $£ 1903.39$ & $£ 3254.27$ & $f|9| 8.34$ \\
\hline Cost, SE & $£ 211.49$ & $£ 380.88$ & $£ 224.53$ \\
\hline Difference (effect), mean & & 0.1043 & 0.1086 \\
\hline Difference (effect), SE & & 0.0417 & 0.0452 \\
\hline Difference (effect), lower $95 \% \mathrm{Cl}$ & & 0.0227 & 0.0201 \\
\hline Difference (effect), upper $95 \% \mathrm{Cl}$ & & 0.1859 & 0.1971 \\
\hline Difference (cost), mean & & $£ 358.22$ & $€ 93.18$ \\
\hline Difference (cost), SE & & $£ 435.66$ & $£ 308.45$ \\
\hline Difference (cost), lower $95 \% \mathrm{Cl}$ & & $-£ 495.66$ & $-£ 511.36$ \\
\hline Difference (cost), upper $95 \% \mathrm{Cl}$ & & $E 1212.09$ & $£ 697.73$ \\
\hline ICER & & $£ 3435$ & $£ 858$ \\
\hline
\end{tabular}




\section{Sensitivity analysis: cost-utility analysis (ICERs) related to cost per QALY (health-care costs and indirect sick leave cost) excluding cases for which imputation necessary}

\begin{tabular}{|c|c|c|c|c|}
\hline & Tubular bandage & Below knee cast & Aircast brace & Bledsoe boot \\
\hline Effect, mean & 0.3275 & 0.4225 & 0.4320 & 0.4294 \\
\hline Effect, SD & 0.2651 & 0.2798 & 0.2516 & 0.2889 \\
\hline Effect, SE & 0.0304 & 0.0321 & 0.0296 & 0.0317 \\
\hline Cost, mean & $£ 983.73$ & $f \mid 081.64$ & $E \mid 299.67$ & $E|| 66.54$ \\
\hline Cost, SD & $f \mid 955.68$ & $£ 2872.53$ & $£ 3285.24$ & $E 1942.10$ \\
\hline Cost, SE & $£ 224.33$ & $£ 329.50$ & $£ 387.17$ & $£ 227.31$ \\
\hline Difference (effect), mean & & 0.0950 & 0.1045 & 0.1019 \\
\hline Difference (effect), SE & & 0.0442 & 0.0419 & 0.0448 \\
\hline Difference (effect), lower $95 \% \mathrm{Cl}$ & & 0.0083 & 0.0223 & 0.0140 \\
\hline Difference (effect), upper $95 \% \mathrm{Cl}$ & & 0.1817 & 0.1866 & 0.1898 \\
\hline Difference (cost), mean & & $£ 97.91$ & $£ 315.93$ & $E|82.8|$ \\
\hline Difference (cost), SE & & $£ 398.62$ & $£ 444.64$ & $£ 314.46$ \\
\hline Difference (cost), lower $95 \% \mathrm{Cl}$ & & $-£ 683.37$ & $-£ 555.55$ & $-£ 433.53$ \\
\hline Difference (cost), upper $95 \% \mathrm{Cl}$ & & $£ 879.19$ & $E \mid 187.42$ & $£ 799.14$ \\
\hline ICER & & $f|03|$ & $£ 3024$ & $E 1794$ \\
\hline
\end{tabular}





\section{Appendix 16}

\section{Scattergrams}

These illustrate cost-effectiveness for the 1000 trials under the different treatment regimes.

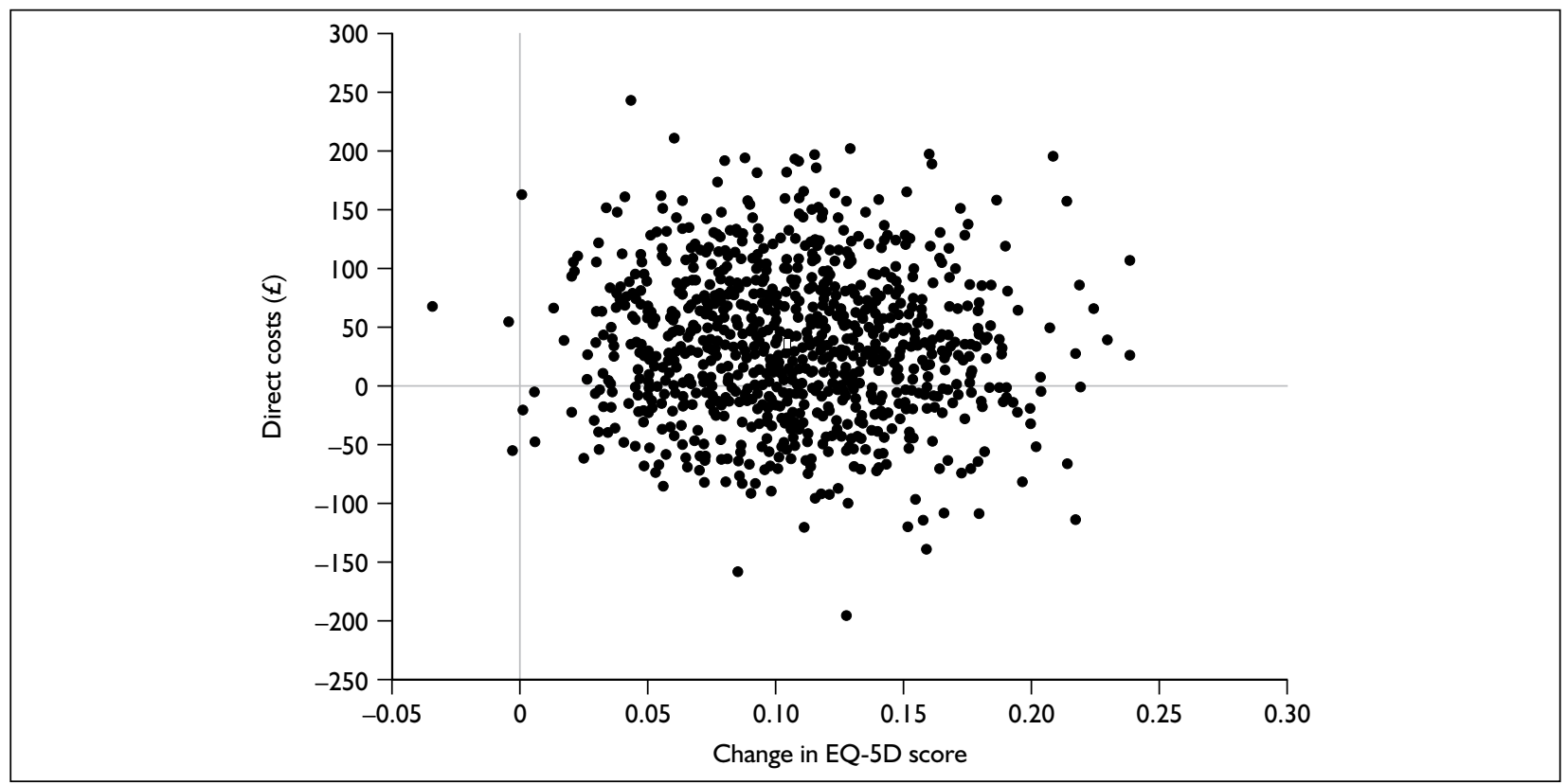

FIGURE I4 Simulation output (1000 trials) showing the cost-effectiveness of the below knee cast relative to tubular bandage (direct health-care costs).

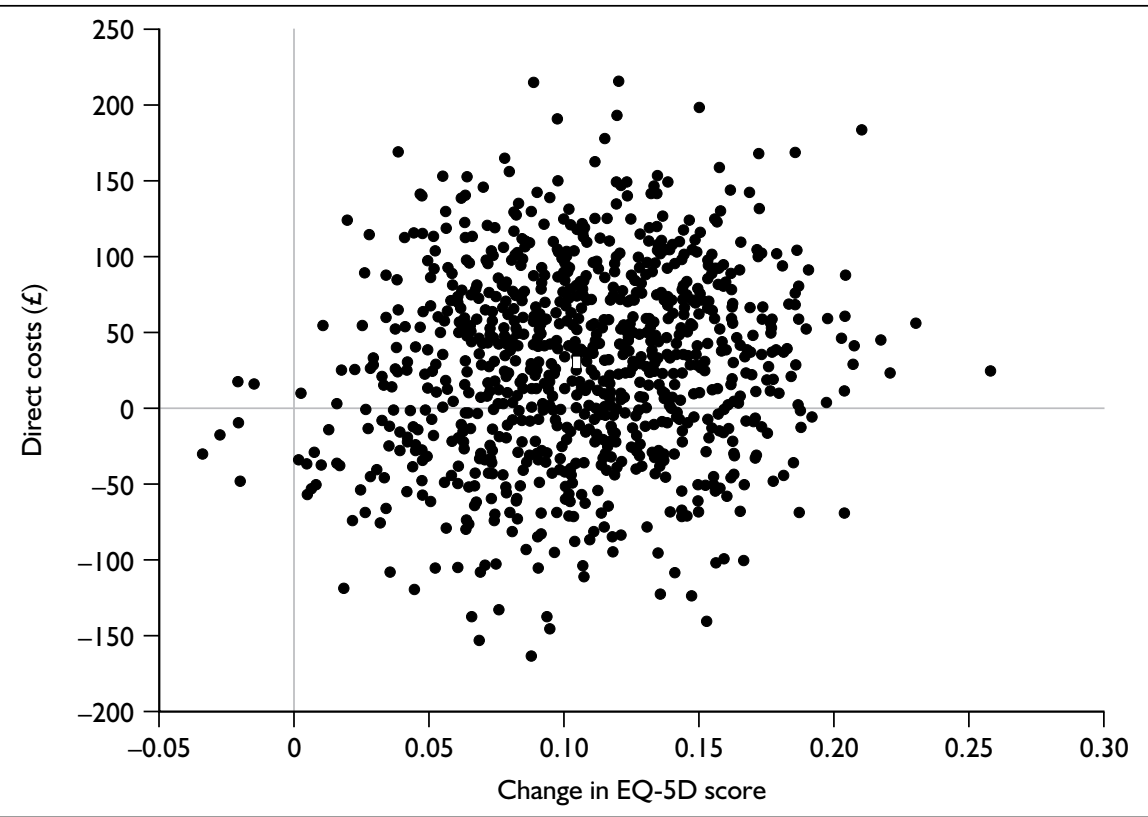

FIGURE I5 Simulation output (1000 trials) showing the cost-effectiveness of the Aircast brace relative to tubular bandage (direct health-care costs). 


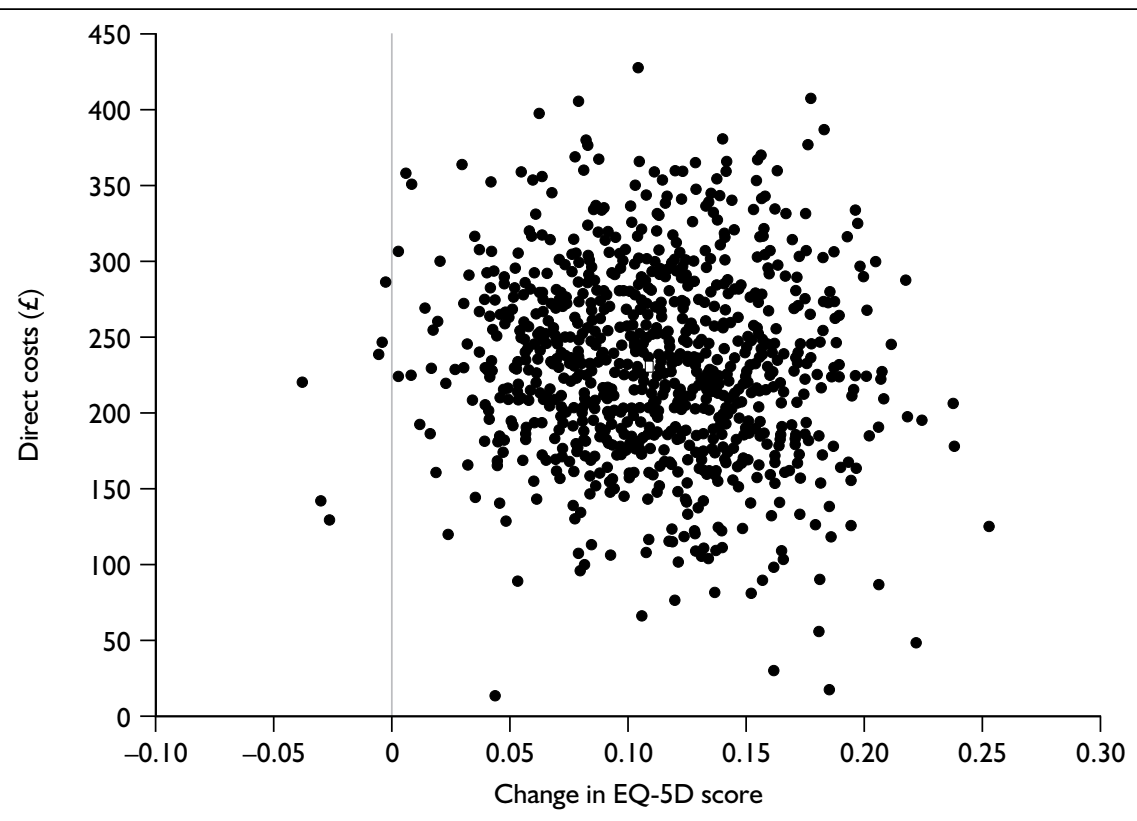

FIGURE I6 Simulation output (1000 trials) showing the cost-effectiveness of the Bledsoe boot relative to tubular bandage (direct health-care costs).

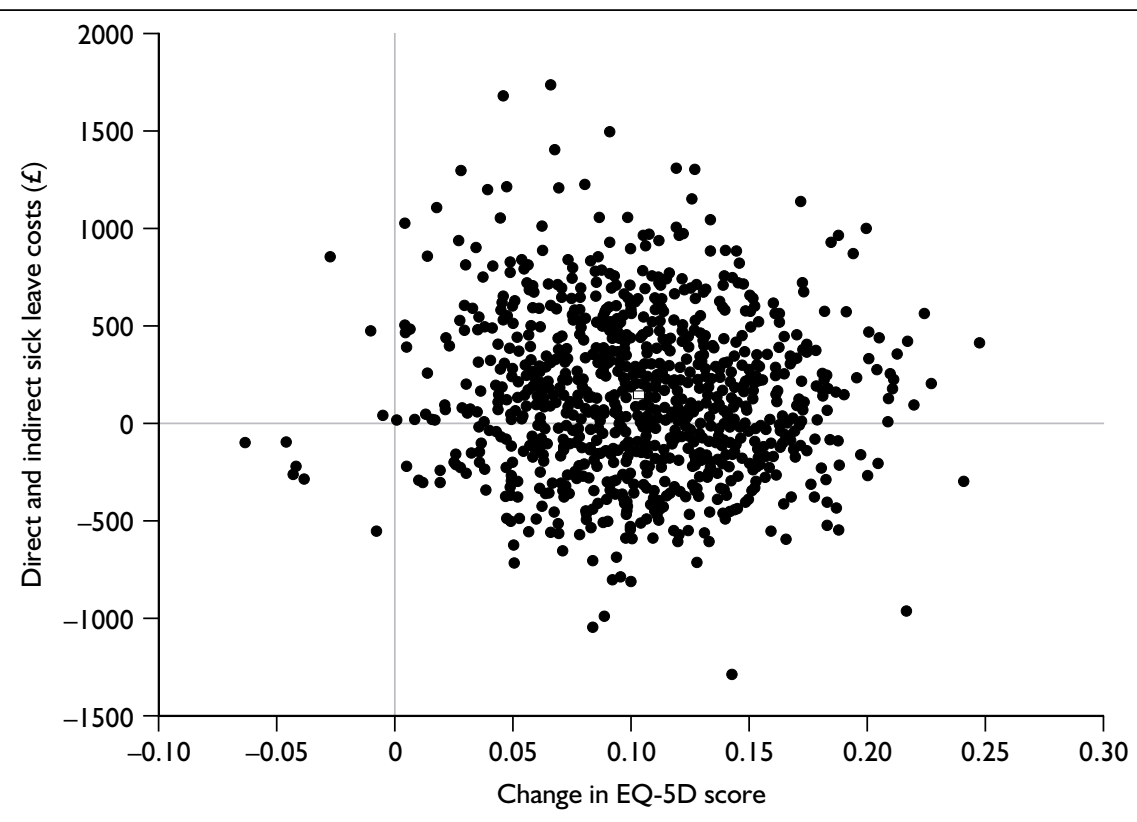

FIGURE I7 Simulation output (1000 trials) showing the cost-effectiveness of the below knee cast relative to tubular bandage (direct health-care and indirect sick leave costs). 


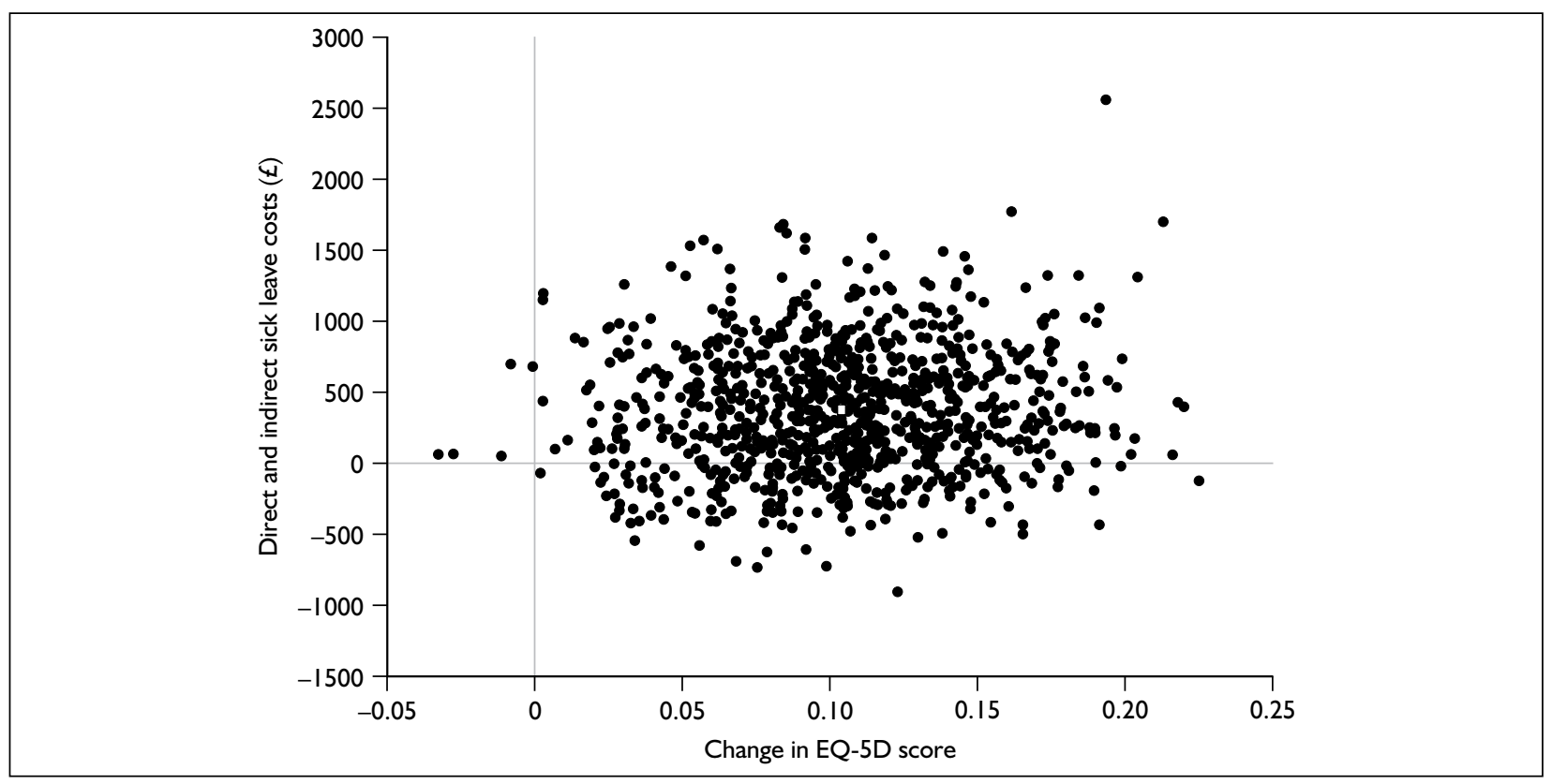

FIGURE I8 Simulation output (1000 trials) showing the cost-effectiveness of the Aircast brace relative to tubular bandage (direct health-care and indirect sick leave costs).

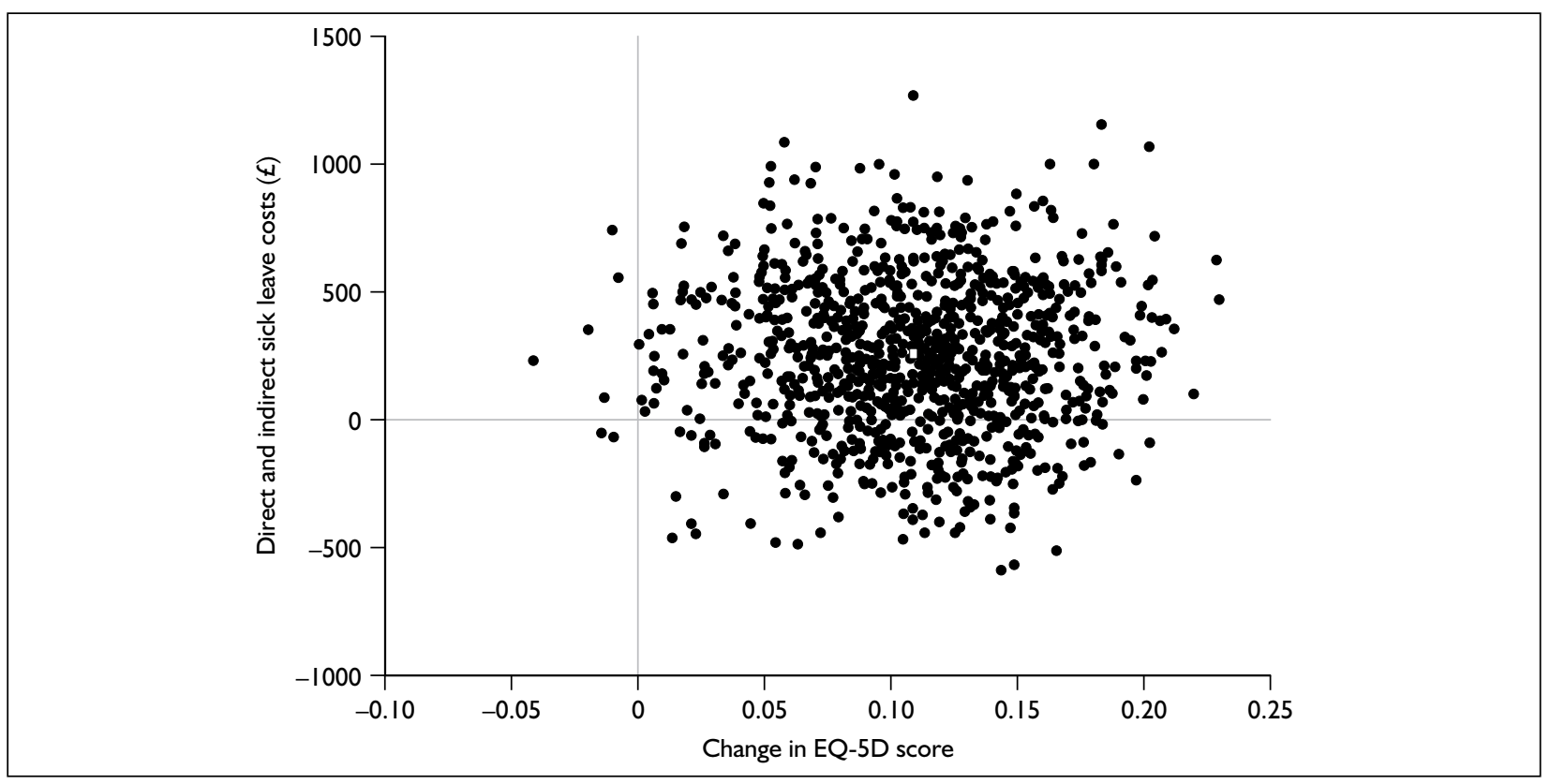

FIGURE 19 Simulation output (1000 trials) showing the cost-effectiveness of the Bledsoe boot relative to tubular bandage (direct health-care and indirect sick leave costs). 



\section{Health Technology Assessment reports published to date}

\section{Volume I, 1997}

No. 1

Home parenteral nutrition: a systematic review.

By Richards DM, Deeks JJ, Sheldon TA, Shaffer JL.

No. 2

Diagnosis, management and screening of early localised prostate cancer.

A review by Selley S, Donovan J, Faulkner A, Coast J, Gillatt D.

No. 3

The diagnosis, management, treatment and costs of prostate cancer in England and Wales.

A review by Chamberlain J, Melia J, Moss S, Brown J.

No. 4

Screening for fragile $\mathrm{X}$ syndrome. A review by Murray J, Cuckle $\mathrm{H}$, Taylor G, Hewison J.

No. 5

A review of near patient testing in primary care

By Hobbs FDR, Delaney BC Fitzmaurice DA, Wilson S, Hyde CJ, Thorpe GH, et al.

No. 6

Systematic review of outpatient services for chronic pain control.

By McQuay HJ, Moore RA, Eccleston

C, Morley S, de C Williams AC.

No. 7

Neonatal screening for inborn errors of metabolism: cost, yield and outcome

A review by Pollitt RJ, Green A,

McCabe CJ, Booth A, Cooper NJ,

Leonard JV, et al.

No. 8

Preschool vision screening.

A review by Snowdon SK,

Stewart-Brown SL.

No. 9

Implications of socio-cultural contexts for the ethics of clinical trials.

A review by Ashcroft RE, Chadwick DW, Clark SRL, Edwards RHT, Frith L, Hutton JL.

No. 10

A critical review of the role of neonatal hearing screening in the detection of congenital hearing impairment.

By Davis A, Bamford J, Wilson I,

Ramkalawan T, Forshaw M, Wright S.
No. 11

Newborn screening for inborn errors of metabolism: a systematic review.

By Seymour CA, Thomason MJ, Chalmers RA, Addison GM, Bain MD, Cockburn F, et al.

No. 12

Routine preoperative testing: a systematic review of the evidence.

By Munro J, Booth A, Nicholl J.

No. 13

Systematic review of the effectiveness of laxatives in the elderly

By Petticrew M, Watt I, Sheldon T.

No. 14

When and how to assess fast-changing technologies: a comparative study of medical applications of four generic technologies.

A review by Mowatt G, Bower DJ, Brebner JA, Cairns JA, Grant AM, McKee L.

\section{Volume 2, 1998}

No. 1

Antenatal screening for Down's syndrome.

A review by Wald NJ, Kennard A, Hackshaw A, McGuire A.

No. 2

Screening for ovarian cancer: a systematic review.

By Bell R, Petticrew M, Luengo S, Sheldon TA.

No. 3

Consensus development methods, and their use in clinical guideline development.

A review by Murphy MK, Black NA, Lamping DL, McKee CM, Sanderson CFB, Askham J, et al.

No. 4

A cost-utility analysis of interferon beta for multiple sclerosis.

By Parkin D, McNamee P, Jacoby A, Miller P, Thomas S, Bates D.

No. 5

Effectiveness and efficiency of methods of dialysis therapy for end-stage renal disease: systematic reviews.

By MacLeod A, Grant A, Donaldson

C, Khan I, Campbell M, Daly C, et al.
No. 6

Effectiveness of hip prostheses in primary total hip replacement: a critical review of evidence and an economic model.

By Faulkner A, Kennedy LG, Baxter K, Donovan J, Wilkinson M, Bevan G.

No. 7

Antimicrobial prophylaxis in colorectal surgery: a systematic review of randomised controlled trials.

By Song F, Glenny AM.

No. 8

Bone marrow and peripheral

blood stem cell transplantation for malignancy.

A review by Johnson PWM,

Simnett SJ, Sweetenham JW, Morgan GJ, Stewart LA.

No. 9

Screening for speech and language delay: a systematic review of the literature.

By Law J, Boyle J, Harris F, Harkness A, Nye C.

No. 10

Resource allocation for chronic stable angina: a systematic review of effectiveness, costs and cost-effectiveness of alternative interventions.

By Sculpher MJ, Petticrew M, Kelland JL, Elliott RA, Holdright DR, Buxton MJ.

No. 11

Detection, adherence and control of hypertension for the prevention of stroke: a systematic review. By Ebrahim S.

No. 12

Postoperative analgesia and vomiting, with special reference to day-case surgery: a systematic review. By McQuay HJ, Moore RA

No. 13

Choosing between randomised and nonrandomised studies: a systematic review.

By Britton A, McKee M, Black N, McPherson K, Sanderson C, Bain C.

No. 14

Evaluating patient-based outcome measures for use in clinical trials.

A review by Fitzpatrick R, Davey C, Buxton MJ, Jones DR. 


\section{No. 15}

Ethical issues in the design and conduct of randomised controlled trials.

A review by Edwards SJL, Lilford RJ, Braunholtz DA, Jackson JC, Hewison J, Thornton J.

\section{No. 16}

Qualitative research methods in health technology assessment: a review of the literature.

By Murphy E, Dingwall R,

Greatbatch D, Parker S, Watson P.

\section{No. 17}

The costs and benefits of paramedic skills in pre-hospital trauma care.

By Nicholl J, Hughes S, Dixon S, Turner J, Yates D.

\section{No. 18}

Systematic review of endoscopic ultrasound in gastro-oesophageal cancer.

By Harris KM, Kelly S, Berry E, Hutton J, Roderick P, Cullingworth J, et al.

\section{No. 19}

Systematic reviews of trials and other studies.

By Sutton AJ, Abrams KR, Jones DR, Sheldon TA, Song F.

\section{No. 20}

Primary total hip replacement surgery: a systematic review of outcomes and modelling of cost-effectiveness associated with different prostheses.

A review by Fitzpatrick R, Shortall E, Sculpher M, Murray D, Morris R, Lodge M, et al.

\section{Volume 3, 1999}

No. 1

Informed decision making: an annotated bibliography and systematic review.

By Bekker H, Thornton JG, Airey CM, Connelly JB, Hewison J, Robinson MB, et al.

No. 2

Handling uncertainty when performing economic evaluation of healthcare interventions.

A review by Briggs AH, Gray AM.

No. 3

The role of expectancies in the placebo effect and their use in the delivery of health care: a systematic review.

By Crow R, Gage H, Hampson S,
No. 4

A randomised controlled trial of different approaches to universal antenatal HIV testing: uptake and acceptability. Annex: Antenatal HIV testing - assessment of a routine voluntary approach.

By Simpson WM, Johnstone FD, Boyd FM, Goldberg DJ, Hart GJ, Gormley SM, et al.

No. 5

Methods for evaluating area-wide and organisation-based interventions in health and health care: a systematic review.

By Ukoumunne OC, Gulliford MC, Chinn S, Sterne JAC, Burney PGJ.

\section{No. 6}

Assessing the costs of healthcare technologies in clinical trials.

A review by Johnston K, Buxton MJ, Jones DR, Fitzpatrick R.

\section{No. 7}

Cooperatives and their primary care emergency centres: organisation and impact.

By Hallam L, Henthorne K.

No. 8

Screening for cystic fibrosis. A review by Murray J, Cuckle $\mathrm{H}$, Taylor G, Littlewood J, Hewison J.

No. 9

A review of the use of health status measures in economic evaluation.

By Brazier J, Deverill M, Green C, Harper R, Booth A.

No. 10

Methods for the analysis of qualityof-life and survival data in health technology assessment.

A review by Billingham LJ,

Abrams KR, Jones DR.

\section{No. 11}

Antenatal and neonatal

haemoglobinopathy screening in the

UK: review and economic analysis. By Zeuner D, Ades AE, Karnon J, Brown J, Dezateux C, Anionwu EN.

\section{No. 12}

Assessing the quality of reports of randomised trials: implications for the conduct of meta-analyses.

A review by Moher D, Cook DJ, Jadad AR, Tugwell P, Moher M, Jones A, et al.

\section{No. 13}

'Early warning systems' for identifying new healthcare technologies.

By Robert G, Stevens A, Gabbay J.

\section{No. 14}

A systematic review of the role of human papillomavirus testing within a cervical screening programme.

By Cuzick J, Sasieni P, Davies P, Adams J, Normand C, Frater A, et al.
No. 15

Near patient testing in diabetes clinics: appraising the costs and outcomes.

By Grieve R, Beech R, Vincent J,

$$
\text { Mazurkiewicz J. }
$$

No. 16

Positron emission tomography: establishing priorities for health technology assessment.

A review by Robert $\mathrm{G}$, Milne $\mathrm{R}$.

No. 17 (Pt 1)

The debridement of chronic wounds: a systematic review.

By Bradley M, Cullum N, Sheldon T.

\section{No. 17 (Pt 2)}

Systematic reviews of wound care management: (2) Dressings and topical agents used in the healing of chronic wounds.

By Bradley M, Cullum N, Nelson EA, Petticrew M, Sheldon T, Torgerson D.

\section{No. 18}

A systematic literature review of spiral and electron beam computed tomography: with particular reference to clinical applications in hepatic lesions, pulmonary embolus and coronary artery disease.

By Berry E, Kelly S, Hutton J, Harris KM, Roderick P, Boyce JC, et al

No. 19

What role for statins? A review and economic model.

By Ebrahim S, Davey Smith G, McCabe C, Payne N, Pickin M, Sheldon TA, et al.

No. 20

Factors that limit the quality, number and progress of randomised controlled trials.

A review by Prescott RJ, Counsell CE, Gillespie WJ, Grant AM, Russell IT, Kiauka S, et al.

No. 21

Antimicrobial prophylaxis in total hip replacement: a systematic review.

By Glenny AM, Song F.

No. 22

Health promoting schools and health promotion in schools: two systematic reviews.

By Lister-Sharp D, Chapman S, Stewart-Brown S, Sowden A

No. 23

Economic evaluation of a primary care-based education programme for patients with osteoarthritis of the knee.

A review by Lord J, Victor $\mathrm{C}$,

Littlejohns P, Ross FM, Axford JS 


\section{Volume 4, 2000}

No. 1

The estimation of marginal time preference in a UK-wide sample (TEMPUS) project.

A review by Cairns JA, van der Pol MM.

\section{No. 2}

Geriatric rehabilitation following fractures in older people: a systematic review.

By Cameron I, Crotty M, Currie C, Finnegan T, Gillespie L, Gillespie W, et al.

No. 3

Screening for sickle cell disease and thalassaemia: a systematic review with supplementary research.

By Davies SC, Cronin E, Gill M, Greengross P, Hickman M, Normand C.

\section{No. 4}

Community provision of hearing aids and related audiology services.

A review by Reeves DJ, Alborz A, Hickson FS, Bamford JM.

No. 5

False-negative results in screening programmes: systematic review of impact and implications.

By Petticrew MP, Sowden AJ, Lister-Sharp D, Wright K.

\section{No. 6}

Costs and benefits of community postnatal support workers: a randomised controlled trial.

By Morrell CJ, Spiby H, Stewart P, Walters S, Morgan A.

\section{No. 7}

Implantable contraceptives (subdermal implants and hormonally impregnated intrauterine systems) versus other forms of reversible contraceptives: two systematic reviews to assess relative effectiveness, acceptability, tolerability and cost-effectiveness.

By French RS, Cowan FM, Mansour DJA, Morris S, Procter T, Hughes D, et al.

No. 8

An introduction to statistical methods for health technology assessment.

A review by White SJ, Ashby D, Brown PJ.

No. 9

Disease-modifying drugs for multiple sclerosis: a rapid and systematic review. By Clegg A, Bryant J, Milne R.

No. 10

Publication and related biases.

A review by Song F, Eastwood AJ, Gilbody S, Duley L, Sutton AJ.

\section{No. 11}

Cost and outcome implications of the organisation of vascular services

By Michaels J, Brazier J,

Palfreyman S, Shackley P, Slack R.

\section{No. 12}

Monitoring blood glucose control in diabetes mellitus: a systematic review. By Coster S, Gulliford MC, Seed PT, Powrie JK, Swaminathan R.

\section{No. 13}

The effectiveness of domiciliary health visiting: a systematic review of international studies and a selective review of the British literature.

By Elkan R, Kendrick D, Hewitt M, Robinson JJA, Tolley K, Blair M, et al.

\section{No. 14}

The determinants of screening uptake and interventions for increasing uptake a systematic review.

By Jepson R, Clegg A, Forbes C, Lewis R, Sowden A, Kleijnen J.

\section{No. 15}

The effectiveness and cost-effectiveness of prophylactic removal of wisdom teeth.

A rapid review by Song F, O'Meara S, Wilson P, Golder S, Kleijnen J.

\section{No. 16}

Ultrasound screening in pregnancy: a systematic review of the clinical effectiveness, cost-effectiveness and women's views.

By Bricker L, Garcia J, Henderson J, Mugford M, Neilson J, Roberts T, et al.

No. 17

A rapid and systematic review of the effectiveness and cost-effectiveness of the taxanes used in the treatment of advanced breast and ovarian cancer.

By Lister-Sharp D, McDonagh MS, Khan KS, Kleijnen J.

\section{No. 18}

Liquid-based cytology in cervical screening: a rapid and systematic review.

By Payne N, Chilcott J, McGoogan E.

\section{No. 19}

Randomised controlled trial of nondirective counselling, cognitivebehaviour therapy and usual general practitioner care in the management of depression as well as mixed anxiety and depression in primary care.

By King M, Sibbald B, Ward E, Bower P, Lloyd M, Gabbay M, et al.

\section{No. 20}

Routine referral for radiography of patients presenting with low back pain: is patients' outcome influenced by GPs' referral for plain radiography?

By Kerry S, Hilton S, Patel S,

Dundas D, Rink E, Lord J.
No. 21

Systematic reviews of wound care management: (3) antimicrobial agents for chronic wounds; (4) diabetic foot ulceration.

By O'Meara S, Cullum N, Majid M, Sheldon T.

\section{No. 22}

Using routine data to complement and enhance the results of randomised controlled trials.

By Lewsey JD, Leyland AH, Murray GD, Boddy FA.

\section{No. 23}

Coronary artery stents in the treatment of ischaemic heart disease: a rapid and systematic review.

By Meads C, Cummins C, Jolly K, Stevens A, Burls A, Hyde C.

\section{No. 24}

Outcome measures for adult critical care: a systematic review.

By Hayes JA, Black NA, Jenkinson C, Young JD, Rowan KM, Daly K, et al.

No. 25

A systematic review to evaluate the effectiveness of interventions to promote the initiation of breastfeeding. By Fairbank L, O'Meara S,

Renfrew MJ, Woolridge M, Sowden AJ, Lister-Sharp D.

No. 26

Implantable cardioverter defibrillators: arrhythmias. A rapid and systematic review.

By Parkes J, Bryant J, Milne R.

\section{No. 27}

Treatments for fatigue in multiple sclerosis: a rapid and systematic review.

By Brañas P, Jordan R, Fry-Smith A, Burls A, Hyde C.

No. 28

Early asthma prophylaxis, natura history, skeletal development and economy (EASE): a pilot randomised controlled trial.

By Baxter-Jones ADG, Helms PJ, Russell G, Grant A, Ross S, Cairns JA et al.

\section{No. 29}

Screening for hypercholesterolaemia versus case finding for familial hypercholesterolaemia: a systematic review and cost-effectiveness analysis.

By Marks D, Wonderling

D, Thorogood M, Lambert H, Humphries SE, Neil HAW.

\section{No. 30}

A rapid and systematic review of the clinical effectiveness and costeffectiveness of glycoprotein IIb/IIIa antagonists in the medical management of unstable angina.

By McDonagh MS, Bachmann LM, Golder S, Kleijnen J, ter Riet G. 


\section{No. 31}

A randomised controlled trial of prehospital intravenous fluid replacement therapy in serious trauma.

By Turner J, Nicholl J, Webber L, Cox H, Dixon S, Yates D.

\section{No. 32}

Intrathecal pumps for giving opioids in chronic pain: a systematic review. By Williams JE, Louw G,

Towlerton G.

\section{No. 33}

Combination therapy (interferon alfa and ribavirin) in the treatment of chronic hepatitis C: a rapid and systematic review.

By Shepherd J, Waugh N,

Hewitson P.

\section{No. 34}

A systematic review of comparisons of effect sizes derived from randomised and non-randomised studies.

By MacLehose RR, Reeves BC, Harvey IM, Sheldon TA, Russell IT, Black AMS.

\section{No. 35}

Intravascular ultrasound-guided interventions in coronary artery disease: a systematic literature review, with decision-analytic modelling, of outcomes and cost-effectiveness.

By Berry E, Kelly S, Hutton J, Lindsay HSJ, Blaxill JM, Evans JA, et al.

No. 36

A randomised controlled trial to evaluate the effectiveness and costeffectiveness of counselling patients with chronic depression.

By Simpson S, Corney R, Fitzgerald P, Beecham J.

\section{No. 37}

Systematic review of treatments for atopic eczema.

By Hoare C, Li Wan Po A,

Williams $\mathrm{H}$.

\section{No. 38}

Bayesian methods in health technology assessment: a review.

By Spiegelhalter DJ, Myles JP, Jones DR, Abrams KR.

\section{No. 39}

The management of dyspepsia: a systematic review.

By Delaney B, Moayyedi P, Deeks J, Innes M, Soo S, Barton P, et al.

\section{No. 40}

A systematic review of treatments for severe psoriasis.

By Griffiths CEM, Clark CM, Chalmers RJG, Li Wan Po A,

\section{Volume 5, 200 I}

\section{No. 1}

Clinical and cost-effectiveness of donepezil, rivastigmine and galantamine for Alzheimer's disease: a rapid and systematic review.

By Clegg A, Bryant J, Nicholson T, McIntyre L, De Broe S, Gerard K, et al.

No. 2

The clinical effectiveness and costeffectiveness of riluzole for motor neurone disease: a rapid and systematic review.

By Stewart A, Sandercock J, Bryan S, Hyde C, Barton PM, Fry-Smith A, et al.

No. 3

Equity and the economic evaluation of healthcare.

By Sassi F, Archard L, Le Grand J.

No. 4

Quality-of-life measures in chronic diseases of childhood.

By Eiser C, Morse R.

No. 5

Eliciting public preferences for healthcare: a systematic review of techniques.

By Ryan M, Scott DA, Reeves C, Bate A, van Teijlingen ER, Russell EM, et al.

\section{No. 6}

General health status measures for people with cognitive impairment: learning disability and acquired brain injury.

By Riemsma RP, Forbes CA, Glanville JM, Eastwood AJ, Kleijnen J.

\section{No. 7}

An assessment of screening strategies for fragile $\mathrm{X}$ syndrome in the UK.

By Pembrey ME, Barnicoat AJ, Carmichael B, Bobrow M, Turner G.

\section{No. 8}

Issues in methodological research: perspectives from researchers and commissioners.

By Lilford RJ, Richardson A, Stevens A, Fitzpatrick R, Edwards S, Rock F, et al.

\section{No. 9}

Systematic reviews of wound care management: (5) beds; (6) compression; (7) laser therapy, therapeutic ultrasound, electrotherapy and electromagnetic therapy.

By Cullum N, Nelson EA, Flemming K, Sheldon T.

\section{No. 10}

Effects of educational and psychosocial interventions for adolescents with diabetes mellitus: a systematic review.

By Hampson SE, Skinner TC, Hart J, Storey L, Gage H, Foxcroft D, et al.
No. 11

Effectiveness of autologous chondrocyte transplantation for hyaline cartilage defects in knees: a rapid and systematic review.

By Jobanputra P, Parry D, Fry-Smith A, Burls A.

No. 12

Statistical assessment of the learning curves of health technologies.

By Ramsay CR, Grant AM, Wallace SA, Garthwaite PH, Monk AF, Russell IT.

No. 13

The effectiveness and cost-effectiveness of temozolomide for the treatment of recurrent malignant glioma: a rapid and systematic review.

By Dinnes J, Cave C, Huang S, Major K, Milne R.

No. 14

A rapid and systematic review of the clinical effectiveness and costeffectiveness of debriding agents in treating surgical wounds healing by secondary intention.

By Lewis R, Whiting P, ter Riet G, O'Meara S, Glanville J.

No. 15

Home treatment for mental health problems: a systematic review.

By Burns T, Knapp M, Catty J, Healey A, Henderson J, Watt $\mathrm{H}$, et al.

No. 16

How to develop cost-conscious guidelines.

By Eccles M, Mason J.

No. 17

The role of specialist nurses in multiple sclerosis: a rapid and systematic review.

By De Broe S, Christopher F, Waugh N.

No. 18

A rapid and systematic review of the clinical effectiveness and cost-effectiveness of orlistat in the management of obesity.

By O'Meara S, Riemsma R, Shirran L, Mather L, ter Riet G.

No. 19

The clinical effectiveness and costeffectiveness of pioglitazone for type 2 diabetes mellitus: a rapid and systematic review.

By Chilcott J, Wight J, Lloyd Jones $\mathrm{M}$, Tappenden P.

No. 20

Extended scope of nursing practice: a multicentre randomised controlled trial of appropriately trained nurses and preregistration house officers in preoperative assessment in elective general surgery.

By Kinley H, Czoski-Murray C, George S, McCabe C, Primrose J, Reilly C, et al. 


\section{No. 21}

Systematic reviews of the effectiveness of day care for people with severe mental disorders: (1) Acute day hospital versus admission; (2) Vocational rehabilitation; (3) Day hospital versus outpatient care.

By Marshall M, Crowther R, Almaraz- Serrano A, Creed F, Sledge W, Kluiter $\mathrm{H}$, et al.

\section{No. 22}

The measurement and monitoring of surgical adverse events.

By Bruce J, Russell EM, Mollison J, Krukowski ZH.

\section{No. 23}

Action research: a systematic review and guidance for assessment

By Waterman H, Tillen D, Dickson R, de Koning $\mathrm{K}$.

\section{No. 24}

A rapid and systematic review of the clinical effectiveness and costeffectiveness of gemcitabine for the treatment of pancreatic cancer.

By Ward S, Morris E, Bansback N, Calvert N, Crellin A, Forman D, et al.

\section{No. 25}

A rapid and systematic review of the evidence for the clinical effectiveness and cost-effectiveness of irinotecan, oxaliplatin and raltitrexed for the treatment of advanced colorectal cancer.

By Lloyd Jones M, Hummel S, Bansback N, Orr B, Seymour M.

\section{No. 26}

Comparison of the effectiveness of inhaler devices in asthma and chronic obstructive airways disease: a systematic review of the literature.

By Brocklebank D, Ram F, Wright J, Barry P, Cates C, Davies L, et al.

\section{No. 27}

The cost-effectiveness of magnetic resonance imaging for investigation of the knee joint.

By Bryan S, Weatherburn G, Bungay H, Hatrick C, Salas C, Parry D, et al.

\section{No. 28}

A rapid and systematic review of the clinical effectiveness and costeffectiveness of topotecan for ovarian cancer.

By Forbes C, Shirran L, Bagnall A-M, Duffy S, ter Riet G.

\section{No. 29}

Superseded by a report published in a later volume.

\section{No. 30}

The role of radiography in primary care patients with low back pain of at least 6 weeks duration: a randomised (unblinded) controlled trial.

By Kendrick D, Fielding K, Bentley E, Miller P, Kerslake R, Pringle M.

\section{No. 31}

Design and use of questionnaires: a review of best practice applicable to surveys of health service staff and patients.

By McColl E, Jacoby A, Thomas L, Soutter J, Bamford C, Steen N, et al.

\section{No. 32}

A rapid and systematic review of the clinical effectiveness and costeffectiveness of paclitaxel, docetaxel, gemcitabine and vinorelbine in nonsmall-cell lung cancer.

By Clegg A, Scott DA, Sidhu M, Hewitson P, Waugh $\mathrm{N}$.

\section{No. 33}

Subgroup analyses in randomised controlled trials: quantifying the risks of false-positives and false-negatives.

By Brookes ST, Whitley E, Peters TJ, Mulheran PA, Egger M, Davey Smith G.

\section{No. 34}

Depot antipsychotic medication in the treatment of patients with schizophrenia: (1) Meta-review; (2) Patient and nurse attitudes.

By David AS, Adams C.

\section{No. 35}

A systematic review of controlled trials of the effectiveness and costeffectiveness of brief psychological treatments for depression.

By Churchill R, Hunot V, Corney R, Knapp M, McGuire H, Tylee A, et al.

\section{No. 36}

Cost analysis of child health surveillance.

By Sanderson D, Wright D, Acton C, Duree D.

\section{Volume 6, 2002}

No. 1

A study of the methods used to select review criteria for clinical audit. By Hearnshaw H, Harker R, Cheater F, Baker R, Grimshaw G.

\section{No. 2}

Fludarabine as second-line therapy for B cell chronic lymphocytic leukaemia: a technology assessment.

By Hyde C, Wake B, Bryan S, Barton P, Fry-Smith A, Davenport C, et al.

No. 3

Rituximab as third-line treatment for refractory or recurrent Stage III or IV follicular non-Hodgkin's lymphoma: a systematic review and economic evaluation.

By Wake B, Hyde C, Bryan S, Barton P, Song F, Fry-Smith A, et al.

No. 4

A systematic review of discharge arrangements for older people.

By Parker SG, Peet SM, McPherson

A, Cannaby AM, Baker R, Wilson A, et al.
No. 5

The clinical effectiveness and costeffectiveness of inhaler devices used in the routine management of chronic asthma in older children: a systematic review and economic evaluation.

By Peters J, Stevenson M, Beverley C, Lim J, Smith S.

No. 6

The clinical effectiveness and costeffectiveness of sibutramine in the management of obesity: a technology assessment.

By O’Meara S, Riemsma R, Shirran L, Mather L, ter Riet G.

No. 7

The cost-effectiveness of magnetic resonance angiography for carotid artery stenosis and peripheral vascular disease: a systematic review.

By Berry E, Kelly S, Westwood ME, Davies LM, Gough MJ, Bamford JM, et al.

No. 8

Promoting physical activity in South Asian Muslim women through 'exercise on prescription'.

By Carroll B, Ali N, Azam N.

No. 9

Zanamivir for the treatment of influenza in adults: a systematic review and economic evaluation.

By Burls A, Clark W, Stewart T, Preston C, Bryan S, Jefferson T, et al.

No. 10

A review of the natural history and epidemiology of multiple sclerosis: implications for resource allocation and health economic models.

By Richards RG, Sampson FC, Beard SM, Tappenden P.

No. 11

Screening for gestational diabetes: a systematic review and economic evaluation.

By Scott DA, Loveman E, McIntyre L, Waugh N.

No. 12

The clinical effectiveness and costeffectiveness of surgery for people with morbid obesity: a systematic review and economic evaluation.

By Clegg AJ, Colquitt J, Sidhu MK, Royle P, Loveman E, Walker A.

No. 13

The clinical effectiveness of trastuzumab for breast cancer: a systematic review.

By Lewis R, Bagnall A-M, Forbes C, Shirran E, Duffy S, Kleijnen J, et al.

No. 14

The clinical effectiveness and costeffectiveness of vinorelbine for breast cancer: a systematic review and economic evaluation.

By Lewis R, Bagnall A-M, King S, Woolacott N, Forbes C, Shirran L, et al. 


\section{No. 15}

A systematic review of the effectiveness and cost-effectiveness of metal-onmetal hip resurfacing arthroplasty for treatment of hip disease.

By Vale L, Wyness L, McCormack K, McKenzie L, Brazzelli M, Stearns SC.

\section{No. 16}

The clinical effectiveness and costeffectiveness of bupropion and nicotine replacement therapy for smoking cessation: a systematic review and economic evaluation.

By Woolacott NF, Jones L, Forbes CA, Mather LC, Sowden AJ, Song FJ, et al.

\section{No. 17}

A systematic review of effectiveness and economic evaluation of new drug treatments for juvenile idiopathic arthritis: etanercept.

By Cummins C, Connock M,

Fry-Smith A, Burls A.

\section{No. 18}

Clinical effectiveness and costeffectiveness of growth hormone in children: a systematic review and economic evaluation.

By Bryant J, Cave C, Mihaylova B, Chase D, McIntyre L, Gerard K, et al.

\section{No. 19}

Clinical effectiveness and costeffectiveness of growth hormone in adults in relation to impact on quality of life: a systematic review and economic evaluation.

By Bryant J, Loveman E, Chase D, Mihaylova B, Cave C, Gerard K, et al.

\section{No. 20}

Clinical medication review by a pharmacist of patients on repeat prescriptions in general practice: a randomised controlled trial.

By Zermansky AG, Petty DR, Raynor DK, Lowe CJ, Freementle N, Vail A.

\section{No. 21}

The effectiveness of infliximab and etanercept for the treatment of rheumatoid arthritis: a systematic review and economic evaluation.

By Jobanputra P, Barton P, Bryan S, Burls A.

\section{No. 22}

A systematic review and economic evaluation of computerised cognitive behaviour therapy for depression and anxiety.

By Kaltenthaler E, Shackley P, Stevens K, Beverley C, Parry G, Chilcott $\mathrm{J}$.

\section{No. 23}

A systematic review and economic evaluation of pegylated liposomal doxorubicin hydrochloride for ovarian cancer.

By Forbes C, Wilby J, Richardson G,
No. 24

A systematic review of the effectiveness of interventions based on a stages-ofchange approach to promote individual behaviour change.

By Riemsma RP, Pattenden J, Bridle C, Sowden AJ, Mather L, Watt IS, et al.

No. 25

A systematic review update of the clinical effectiveness and costeffectiveness of glycoprotein IIb/IIIa antagonists.

By Robinson M, Ginnelly L, Sculpher M, Jones L, Riemsma R, Palmer S, et al.

\section{No. 26}

A systematic review of the effectiveness, cost-effectiveness and barriers to implementation of thrombolytic and neuroprotective therapy for acute ischaemic stroke in the NHS.

By Sandercock P, Berge E, Dennis M, Forbes J, Hand P, Kwan J, et al.

No. 27

A randomised controlled crossover trial of nurse practitioner versus doctor-

led outpatient care in a bronchiectasis clinic.

By Caine N, Sharples LD,

Hollingworth W, French J, Keogan M, Exley A, et al.

\section{No. 28}

Clinical effectiveness and cost consequences of selective serotonin reuptake inhibitors in the treatment of sex offenders.

By Adi Y, Ashcroft D, Browne K, Beech A, Fry-Smith A, Hyde C.

\section{No. 29}

Treatment of established osteoporosis a systematic review and cost-utility analysis.

By Kanis JA, Brazier JE, Stevenson M, Calvert NW, Lloyd Jones M.

No. 30

Which anaesthetic agents are costeffective in day surgery? Literature review, national survey of practice and randomised controlled trial.

By Elliott RA Payne K, Moore JK, Davies LM, Harper NJN, St Leger AS, et al.

\section{No. 31}

Screening for hepatitis C among injecting drug users and in genitourinary medicine clinics: systematic reviews of effectiveness, modelling study and national survey of current practice.

By Stein K, Dalziel K, Walker A McIntyre L, Jenkins B, Horne J, et al.

\section{No. 32}

The measurement of satisfaction with healthcare: implications for practice from a systematic review of the literature.

By Crow R, Gage H, Hampson S, Hart J, Kimber A, Storey L, et al.
No. 33

The effectiveness and cost-effectiveness of imatinib in chronic myeloid leukaemia: a systematic review. By Garside R, Round A, Dalziel K, Stein K, Royle R.

No. 34

A comparative study of hypertonic saline, daily and alternate-day rhDNase in children with cystic fibrosis.

By Suri R, Wallis C, Bush A,

Thompson S, Normand C, Flather M, et al.

No. 35

A systematic review of the costs and effectiveness of different models of paediatric home care.

By Parker G, Bhakta P, Lovett CA Paisley S, Olsen R, Turner D, et al.

\section{Volume 7, 2003}

No. 1

How important are comprehensive literature searches and the assessment of trial quality in systematic reviews?

Empirical study.

By Egger M, Jüni P, Bartlett C, Holenstein F, Sterne J.

No. 2

Systematic review of the effectiveness and cost-effectiveness, and economic evaluation, of home versus hospital or satellite unit haemodialysis for people with end-stage renal failure.

By Mowatt G, Vale L, Perez J, Wyness L, Fraser C, MacLeod A, et al.

No. 3

Systematic review and economic evaluation of the effectiveness of infliximab for the treatment of Crohn's disease.

By Clark W, Raftery J, Barton P, Song F, Fry-Smith A, Burls A.

No. 4

A review of the clinical effectiveness and cost-effectiveness of routine anti-D prophylaxis for pregnant women who are rhesus negative.

By Chilcott J, Lloyd Jones M, Wight J, Forman K, Wray J, Beverley C, et al.

No. 5

Systematic review and evaluation of the use of tumour markers in paediatric oncology: Ewing's sarcoma and neuroblastoma.

By Riley RD, Burchill SA, Abrams KR, Heney D, Lambert PC, Jones DR, et al.

No. 6

The cost-effectiveness of screening for Helicobacter pylori to reduce mortality and morbidity from gastric cancer and peptic ulcer disease: a discrete-event simulation model.

By Roderick P, Davies R, Raftery J, Crabbe D, Pearce R, Bhandari P, et al. 
No. 7

The clinical effectiveness and costeffectiveness of routine dental checks: a systematic review and economic evaluation.

By Davenport C, Elley K, Salas C, Taylor-Weetman CL, Fry-Smith A, Bryan S, et al.

\section{No. 8}

A multicentre randomised controlled trial assessing the costs and benefits of using structured information and analysis of women's preferences in the management of menorrhagia.

By Kennedy ADM, Sculpher MJ, Coulter A, Dwyer N, Rees M, Horsley S, et al.

\section{No. 9}

Clinical effectiveness and cost-utility of photodynamic therapy for wet age-related macular degeneration: a systematic review and economic evaluation.

By Meads C, Salas C, Roberts T, Moore D, Fry-Smith A, Hyde C.

No. 10

Evaluation of molecular tests for prenatal diagnosis of chromosome abnormalities.

By Grimshaw GM, Szczepura A, Hultén M, MacDonald F, Nevin NC, Sutton $\mathrm{F}$, et al.

\section{No. 11}

First and second trimester antenatal screening for Down's syndrome: the results of the Serum, Urine and Ultrasound Screening Study (SURUSS)

By Wald NJ, Rodeck C, Hackshaw AK, Walters J, Chitty L, Mackinson AM.

\section{No. 12}

The effectiveness and cost-effectiveness of ultrasound locating devices for central venous access: a systematic review and economic evaluation.

By Calvert N, Hind D, McWilliams RG, Thomas SM, Beverley C, Davidson A.

\section{No. 13}

A systematic review of atypical antipsychotics in schizophrenia.

By Bagnall A-M, Jones L, Lewis R, Ginnelly L, Glanville J, Torgerson D,

$$
\text { et al. }
$$

No. 14

Prostate Testing for Cancer and Treatment (ProtecT) feasibility study. By Donovan J, Hamdy F, Neal D, Peters T, Oliver S, Brindle L, et al.

\section{No. 15}

Early thrombolysis for the treatment of acute myocardial infarction: a systematic review and economic evaluation.

By Boland A, Dundar Y, Bagust A, Haycox A, Hill R, Mujica Mota R, et al.

\section{No. 16}

Screening for fragile X syndrome: a literature review and modelling.

By Song FJ, Barton P, Sleightholme V, Yao GL, Fry-Smith A.

\section{No. 17}

Systematic review of endoscopic sinus surgery for nasal polyps.

By Dalziel K, Stein K, Round A, Garside R, Royle P.

\section{No. 18}

Towards efficient guidelines: how to monitor guideline use in primary care. By Hutchinson A, McIntosh A, Cox S, Gilbert C.

\section{No. 19}

Effectiveness and cost-effectiveness of acute hospital-based spinal cord injuries services: systematic review.

By Bagnall A-M, Jones L, Richardson G, Duffy S, Riemsma R.

No. 20

Prioritisation of health technology assessment. The PATHS model: methods and case studies.

By Townsend J, Buxton M, Harper G.

\section{No. 21}

Systematic review of the clinical effectiveness and cost-effectiveness of tension-free vaginal tape for treatment of urinary stress incontinence.

By Cody J, Wyness L, Wallace S, Glazener C, Kilonzo M, Stearns S, et al.

\section{No. 22}

The clinical and cost-effectiveness of patient education models for diabetes: a systematic review and economic evaluation.

By Loveman E, Cave C, Green C, Royle P, Dunn N, Waugh N.

\section{No. 23}

The role of modelling in prioritising and planning clinical trials.

By Chilcott J, Brennan A, Booth A Karnon J, Tappenden P.

\section{No. 24}

Cost-benefit evaluation of routine influenza immunisation in people 65-74 years of age.

By Allsup S, Gosney M, Haycox A, Regan M.

\section{No. 25}

The clinical and cost-effectiveness of pulsatile machine perfusion versus cold storage of kidneys for transplantation retrieved from heart-beating and nonheart-beating donors.

By Wight J, Chilcott J, Holmes M, Brewer N

\section{No. 26}

Can randomised trials rely on existing electronic data? A feasibility study to explore the value of routine data in health technology assessment.

By Williams JG, Cheung WY,

Cohen DR, Hutchings HA, Longo MF, Russell IT.

\section{No. 27}

Evaluating non-randomised intervention studies.

By Deeks JJ, Dinnes J, D’Amico R, Sowden AJ, Sakarovitch C, Song F, et al.

No. 28

A randomised controlled trial to assess the impact of a package comprising a patient-orientated, evidence-based selfhelp guidebook and patient-centred consultations on disease management and satisfaction in inflammatory bowel disease.

By Kennedy A, Nelson E, Reeves D, Richardson G, Roberts C, Robinson A, et al.

\section{No. 29}

The effectiveness of diagnostic tests for the assessment of shoulder pain due to soft tissue disorders: a systematic review.

By Dinnes J, Loveman E, McIntyre L, Waugh N.

No. 30

The value of digital imaging in diabetic retinopathy.

By Sharp PF, Olson J, Strachan F, Hipwell J, Ludbrook A, O'Donnell M, et al.

No. 31

Lowering blood pressure to prevent myocardial infarction and stroke: a new preventive strategy.

By Law M, Wald N, Morris J.

No. 32

Clinical and cost-effectiveness of capecitabine and tegafur with uracil for the treatment of metastatic colorectal cancer: systematic review and economic evaluation.

By Ward S, Kaltenthaler E, Cowan J, Brewer N.

No. 33

Clinical and cost-effectiveness of new and emerging technologies for early localised prostate cancer: a systematic review.

By Hummel S, Paisley S, Morgan A, Currie E, Brewer N.

\section{No. 34}

Literature searching for clinical and cost-effectiveness studies used in health technology assessment reports carried out for the National Institute for Clinical Excellence appraisal system. By Royle P, Waugh N. 


\section{No. 35}

Systematic review and economic decision modelling for the prevention and treatment of influenza A and B.

By Turner D, Wailoo A, Nicholson K, Cooper N, Sutton A, Abrams K.

\section{No. 36}

A randomised controlled trial to evaluate the clinical and costeffectiveness of Hickman line insertions in adult cancer patients by nurses.

By Boland A, Haycox A, Bagust A, Fitzsimmons L.

\section{No. 37}

Redesigning postnatal care: a randomised controlled trial of protocolbased midwifery-led care focused on individual women's physical and psychological health needs.

By MacArthur C, Winter HR, Bick DE, Lilford RJ, Lancashire RJ, Knowles H, et al.

\section{No. 38}

Estimating implied rates of discount in healthcare decision-making.

By West RR, McNabb R, Thompson AGH, Sheldon TA, Grimley Evans J.

\section{No. 39}

Systematic review of isolation policies in the hospital management of methicillin-resistant Staphylococcus aureus: a review of the literature with epidemiological and economic modelling.

By Cooper BS, Stone SP, Kibbler CC, Cookson BD, Roberts JA, Medley GF, et al.

\section{No. 40}

Treatments for spasticity and pain in multiple sclerosis: a systematic review.

By Beard S, Hunn A, Wight J.

\section{No. 41}

The inclusion of reports of randomised trials published in languages other than English in systematic reviews.

By Moher D, Pham B, Lawson ML, Klassen TP.

\section{No. 42}

The impact of screening on future health-promoting behaviours and health beliefs: a systematic review.

By Bankhead CR, Brett J, Bukach C, Webster P, Stewart-Brown S, Munafo M, et al.

\section{Volume 8, 2004}

No. 1

What is the best imaging strategy for acute stroke?

By Wardlaw JM, Keir SL, Seymour J, Lewis S, Sandercock PAG, Dennis MS,
No. 2

Systematic review and modelling of the investigation of acute and chronic chest pain presenting in primary care.

By Mant J, McManus RJ, Oakes RAL, Delaney BC, Barton PM, Deeks JJ, et al.

\section{No. 3}

The effectiveness and cost-effectiveness of microwave and thermal balloon endometrial ablation for heavy menstrual bleeding: a systematic review and economic modelling.

By Garside R, Stein K, Wyatt K, Round A, Price A.

\section{No. 4}

A systematic review of the role of bisphosphonates in metastatic disease. By Ross JR, Saunders Y,

Edmonds PM, Patel S, Wonderling D, Normand C, et al.

\section{No. 5}

Systematic review of the clinical effectiveness and cost-effectiveness of capecitabine (Xeloda ${ }^{\circledR}$ for locally advanced and/or metastatic breast cancer.

By Jones L, Hawkins N, Westwood M, Wright K, Richardson G, Riemsma R.

\section{No. 6}

Effectiveness and efficiency of guideline dissemination and implementation strategies.

By Grimshaw JM, Thomas RE, MacLennan G, Fraser C, Ramsay CR, Vale L, et al.

\section{No. 7}

Clinical effectiveness and costs of the Sugarbaker procedure for the treatment of pseudomyxoma peritonei.

By Bryant J, Clegg AJ, Sidhu MK, Brodin H, Royle P, Davidson P.

\section{No. 8}

Psychological treatment for insomnia in the regulation of long-term hypnotic drug use.

By Morgan K, Dixon S, Mathers N, Thompson J, Tomeny M.

\section{No. 9}

Improving the evaluation of therapeutic interventions in multiple sclerosis: development of a patientbased measure of outcome.

By Hobart JC, Riazi A, Lamping DL, Fitzpatrick R, Thompson AJ.

\section{No. 10}

A systematic review and economic evaluation of magnetic resonance cholangiopancreatography compared with diagnostic endoscopic retrograde cholangiopancreatography.

By Kaltenthaler E, Bravo Vergel Y, Chilcott J, Thomas S, Blakeborough T, Walters SJ, et al.

\section{No. 11}

The use of modelling to evaluate new drugs for patients with a chronic condition: the case of antibodies against tumour necrosis factor in rheumatoid arthritis.

By Barton P, Jobanputra P, Wilson J, Bryan S, Burls A.

No. 12

Clinical effectiveness and costeffectiveness of neonatal screening for inborn errors of metabolism using tandem mass spectrometry: a systematic review.

By Pandor A, Eastham J, Beverley C, Chilcott J, Paisley S.

No. 13

Clinical effectiveness and costeffectiveness of pioglitazone and rosiglitazone in the treatment of type 2 diabetes: a systematic review and economic evaluation.

By Czoski-Murray C, Warren E, Chilcott J, Beverley C, Psyllaki MA, Cowan J.

\section{No. 14}

Routine examination of the newborn: the EMREN study. Evaluation of an extension of the midwife role including a randomised controlled trial of appropriately trained midwives and paediatric senior house officers.

By Townsend J, Wolke D, Hayes J, Davé S, Rogers C, Bloomfield L, et al.

No. 15

Involving consumers in research and development agenda setting for the NHS: developing an evidence-based approach.

By Oliver S, Clarke-Jones L, Rees R, Milne R, Buchanan P, Gabbay J, et al.

No. 16

A multi-centre randomised controlled trial of minimally invasive direct coronary bypass grafting versus percutaneous transluminal coronary angioplasty with stenting for proximal stenosis of the left anterior descending coronary artery.

By Reeves BC, Angelini GD, Bryan AJ, Taylor FC, Cripps T, Spyt TJ, et al.

\section{No. 17}

Does early magnetic resonance imaging influence management or improve outcome in patients referred to secondary care with low back pain? A pragmatic randomised controlled trial.

By Gilbert FJ, Grant AM, Gillan MGC, Vale L, Scott NW, Campbell MK, et al.

\section{No. 18}

The clinical and cost-effectiveness of anakinra for the treatment of rheumatoid arthritis in adults: a systematic review and economic analysis.

By Clark W, Jobanputra P, Barton P, Burls A. 
No. 19

A rapid and systematic review and economic evaluation of the clinical and cost-effectiveness of newer drugs for treatment of mania associated with bipolar affective disorder.

By Bridle C, Palmer S, Bagnall A-M, Darba J, Duffy S, Sculpher M, et al.

\section{No. 20}

Liquid-based cytology in cervical screening: an updated rapid and systematic review and economic analysis.

By Karnon J, Peters J, Platt J, Chilcott J, McGoogan E, Brewer N.

\section{No. 21}

Systematic review of the long-term effects and economic consequences of treatments for obesity and implications for health improvement.

By Avenell A, Broom J, Brown TJ, Poobalan A, Aucott L, Stearns SC, et al.

\section{No. 22}

Autoantibody testing in children with newly diagnosed type 1 diabetes mellitus.

By Dretzke J, Cummins C, Sandercock J, Fry-Smith A, Barrett T, Burls A.

No. 23

Clinical effectiveness and costeffectiveness of prehospital intravenous fluids in trauma patients.

By Dretzke J, Sandercock J, Bayliss S, Burls A.

\section{No. 24}

Newer hypnotic drugs for the shortterm management of insomnia: a systematic review and economic evaluation.

By Dündar Y, Boland A, Strobl J, Dodd S, Haycox A, Bagust A, et al.

No. 25

Development and validation of methods for assessing the quality of diagnostic accuracy studies.

By Whiting P, Rutjes AWS, Dinnes J, Reitsma JB, Bossuyt PMM, Kleijnen J.

No. 26

EVALUATE hysterectomy trial: a multicentre randomised trial comparing abdominal, vaginal and laparoscopic methods of hysterectomy. By Garry R, Fountain J, Brown J,

Manca A, Mason S, Sculpher M, et al.

\section{No. 27}

Methods for expected value of information analysis in complex health economic models: developments on the health economics of interferon- $\beta$ and glatiramer acetate for multiple sclerosis.

By Tappenden P, Chilcott JB, Eggington S, Oakley J, McCabe C.

\section{No. 28}

Effectiveness and cost-effectiveness of imatinib for first-line treatment of chronic myeloid leukaemia in chronic phase: a systematic review and economic analysis.

By Dalziel K, Round A, Stein K, Garside R, Price A.

\section{No. 29}

VenUS I: a randomised controlled trial of two types of bandage for treating venous leg ulcers.

By Iglesias C, Nelson EA, Cullum NA, Torgerson DJ, on behalf of the VenUS Team.

\section{No. 30}

Systematic review of the effectiveness and cost-effectiveness, and economic evaluation, of myocardial perfusion scintigraphy for the diagnosis and management of angina and myocardial infarction.

By Mowatt G, Vale L, Brazzelli M, Hernandez R, Murray A, Scott N, et al.

\section{No. 31}

A pilot study on the use of decision theory and value of information analysis as part of the NHS Health Technology Assessment programme.

By Claxton K, Ginnelly L, Sculpher M, Philips Z, Palmer S.

\section{No. 32}

The Social Support and Family Health Study: a randomised controlled trial and economic evaluation of two alternative forms of postnatal support for mothers living in disadvantaged inner-city areas.

By Wiggins M, Oakley A, Roberts I, Turner H, Rajan L, Austerberry H, et al.

\section{No. 33}

Psychosocial aspects of genetic screening of pregnant women and newborns: a systematic review.

By Green JM, Hewison J, Bekker HL, Bryant, Cuckle HS.

\section{No. 34}

Evaluation of abnormal uterine bleeding: comparison of three outpatient procedures within cohorts defined by age and menopausal status.

By Critchley HOD, Warner P, Lee AJ, Brechin S, Guise J, Graham B.

\section{No. 35}

Coronary artery stents: a rapid

systematic review and economic evaluation.

By Hill R, Bagust A, Bakhai A, Dickson R, Dündar Y, Haycox A, et al.

\section{No. 36}

Review of guidelines for good practice in decision-analytic modelling in health technology assessment.

By Philips Z, Ginnelly L, Sculpher M, Claxton K, Golder S, Riemsma R, et al.

\section{No. 37}

Rituximab (MabThera ${ }^{\circledast}$ ) for aggressive non-Hodgkin's lymphoma: systematic review and economic evaluation.

By Knight C, Hind D, Brewer N, Abbott V.

\section{No. 38}

Clinical effectiveness and costeffectiveness of clopidogrel and modified-release dipyridamole in the secondary prevention of occlusive vascular events: a systematic review and economic evaluation.

By Jones L, Griffin S, Palmer S, Main C, Orton V, Sculpher M, et al.

\section{No. 39}

Pegylated interferon $\alpha-2 \mathrm{a}$ and $-2 \mathrm{~b}$ in combination with ribavirin in the treatment of chronic hepatitis C: a systematic review and economic evaluation.

By Shepherd J, Brodin H, Cave C, Waugh N, Price A, Gabbay J.

\section{No. 40}

Clopidogrel used in combination with aspirin compared with aspirin alone in the treatment of non-ST-segmentelevation acute coronary syndromes: a systematic review and economic evaluation.

By Main C, Palmer S, Griffin S, Jones L, Orton V, Sculpher M, et al.

\section{No. 41}

Provision, uptake and cost of cardiac rehabilitation programmes: improving services to under-represented groups.

By Beswick AD, Rees K, Griebsch I, Taylor FC, Burke M, West RR, et al.

No. 42

Involving South Asian patients in clinical trials.

By Hussain-Gambles M, Leese B, Atkin K, Brown J, Mason S, Tovey P.

No. 43

Clinical and cost-effectiveness of continuous subcutaneous insulin infusion for diabetes.

By Colquitt JL, Green C, Sidhu MK, Hartwell D, Waugh N.

\section{No. 44}

Identification and assessment of ongoing trials in health technology assessment reviews.

By Song FJ, Fry-Smith A, Davenport C, Bayliss S, Adi Y, Wilson JS, et al.

\section{No. 45}

Systematic review and economic evaluation of a long-acting insulin analogue, insulin glargine

By Warren E, Weatherley-Jones E, Chilcott J, Beverley C. 


\section{No. 46}

Supplementation of a home-based exercise programme with a classbased programme for people with osteoarthritis of the knees: a randomised controlled trial and health economic analysis.

By McCarthy CJ, Mills PM, Pullen R, Richardson G, Hawkins N, Roberts CR, et al.

\section{No. 47}

Clinical and cost-effectiveness of oncedaily versus more frequent use of same potency topical corticosteroids for atopic eczema: a systematic review and economic evaluation.

By Green C, Colquitt JL, Kirby J, Davidson P, Payne E.

\section{No. 48}

Acupuncture of chronic headache disorders in primary care: randomised controlled trial and economic analysis.

By Vickers AJ, Rees RW, Zollman CE, McCarney R, Smith CM, Ellis N, et al.

\section{No. 49}

Generalisability in economic evaluation studies in healthcare: a review and case studies.

By Sculpher MJ, Pang FS, Manca A, Drummond MF, Golder S, Urdahl H, et al.

\section{No. 50}

Virtual outreach: a randomised controlled trial and economic evaluation of joint teleconferenced medical consultations.

By Wallace P, Barber J, Clayton W, Currell R, Fleming K, Garner P, et al.

\section{Volume 9, 2005}

No. 1

Randomised controlled multiple treatment comparison to provide a costeffectiveness rationale for the selection of antimicrobial therapy in acne.

By Ozolins M, Eady EA, Avery A, Cunliffe WJ, O'Neill C, Simpson NB, et al.

\section{No. 2}

Do the findings of case series studies vary significantly according to methodological characteristics?

By Dalziel K, Round A, Stein K, Garside R, Castelnuovo E, Payne L.

\section{No. 3}

Improving the referral process for familial breast cancer genetic counselling: findings of three randomised controlled trials of two interventions.

By Wilson BJ, Torrance N, Mollison J, Wordsworth S, Gray JR,
No. 4

Randomised evaluation of alternative electrosurgical modalities to treat bladder outflow obstruction in men with benign prostatic hyperplasia.

By Fowler C, McAllister W, Plail R, Karim O, Yang Q.

No. 5

A pragmatic randomised controlled trial of the cost-effectiveness of palliative therapies for patients with inoperable oesophageal cancer.

By Shenfine J, McNamee P, Steen N, Bond J, Griffin SM.

\section{No. 6}

Impact of computer-aided detection prompts on the sensitivity and specificity of screening mammography. By Taylor P, Champness J, GivenWilson R, Johnston K, Potts H.

\section{No. 7}

Issues in data monitoring and interim analysis of trials.

By Grant AM, Altman DG, Babiker $\mathrm{AB}$, Campbell MK, Clemens FJ, Darbyshire JH, et al.

\section{No. 8}

Lay public's understanding of equipoise and randomisation in randomised controlled trials.

By Robinson EJ, Kerr CEP, Stevens AJ, Lilford RJ, Braunholtz DA, Edwards SJ, et al.

\section{No. 9}

Clinical and cost-effectiveness of electroconvulsive therapy for depressive illness, schizophrenia, catatonia and mania: systematic reviews and economic modelling studies.

By Greenhalgh J, Knight C, Hind D, Beverley C, Walters S.

\section{No. 10}

Measurement of health-related quality of life for people with dementia: development of a new instrument (DEMQOL) and an evaluation of current methodology.

By Smith SC, Lamping DL, Banerjee S, Harwood R, Foley B, Smith P, et al.

\section{No. 11}

Clinical effectiveness and costeffectiveness of drotrecogin alfa (activated) (Xigris $\left.{ }^{\star}\right)$ for the treatment of severe sepsis in adults: a systematic review and economic evaluation.

By Green C, Dinnes J, Takeda A, Shepherd J, Hartwell D, Cave C, et al.

\section{No. 12}

A methodological review of how heterogeneity has been examined in systematic reviews of diagnostic test accuracy.

By Dinnes J, Deeks J, Kirby J, Roderick P.
No. 13

Cervical screening programmes: can automation help? Evidence from systematic reviews, an economic analysis and a simulation modelling exercise applied to the UK.

By Willis BH, Barton P, Pearmain P, Bryan S, Hyde C.

\section{No. 14}

Laparoscopic surgery for inguinal hernia repair: systematic review of effectiveness and economic evaluation. By McCormack K, Wake B, Perez J, Fraser C, Cook J, McIntosh E, et al.

\section{No. 15}

Clinical effectiveness, tolerability and cost-effectiveness of newer drugs for epilepsy in adults: a systematic review and economic evaluation.

By Wilby J, Kainth A, Hawkins N, Epstein D, McIntosh H, McDaid C, et al.

No. 16

A randomised controlled trial to compare the cost-effectiveness of tricyclic antidepressants, selective serotonin reuptake inhibitors and lofepramine.

By Peveler R, Kendrick T, Buxton M, Longworth L, Baldwin D, Moore M, et al.

\section{No. 17}

Clinical effectiveness and costeffectiveness of immediate angioplasty for acute myocardial infarction: systematic review and economic evaluation.

By Hartwell D, Colquitt J, Loveman E, Clegg AJ, Brodin H, Waugh N, et al.

\section{No. 18}

A randomised controlled comparison of alternative strategies in stroke care.

By Kalra L, Evans A, Perez I,

Knapp M, Swift C, Donaldson N.

No. 19

The investigation and analysis of critical incidents and adverse events in healthcare.

By Woloshynowych M, Rogers S, Taylor-Adams S, Vincent C.

\section{No. 20}

Potential use of routine databases in health technology assessment.

By Raftery J, Roderick P, Stevens A.

\section{No. 21}

Clinical and cost-effectiveness of newer immunosuppressive regimens in renal transplantation: a systematic review and modelling study.

By Woodroffe R, Yao GL, Meads C, Bayliss S, Ready A, Raftery J, et al.

\section{No. 22}

A systematic review and economic evaluation of alendronate, etidronate, risedronate, raloxifene and teriparatide for the prevention and treatment of postmenopausal osteoporosis.

By Stevenson M, Lloyd Jones M, De Nigris E, Brewer N, Davis S, Oakley J. 
No. 23

A systematic review to examine the impact of psycho-educational interventions on health outcomes and costs in adults and children with difficult asthma.

By Smith JR, Mugford M, Holland R, Candy B, Noble MJ, Harrison BDW, et al.

\section{No. 24}

An evaluation of the costs, effectiveness and quality of renal replacement therapy provision in renal satellite units in England and Wales.

By Roderick P, Nicholson T, Armitage A, Mehta R, Mullee M, Gerard K, et al.

\section{No. 25}

Imatinib for the treatment of patients with unresectable and/or metastatic gastrointestinal stromal tumours: systematic review and economic evaluation.

By Wilson J, Connock M, Song F, Yao G, Fry-Smith A, Raftery J, et al.

\section{No. 26}

Indirect comparisons of competing interventions.

By Glenny AM, Altman DG, Song F, Sakarovitch C, Deeks JJ, D'Amico R, et al.

\section{No. 27}

Cost-effectiveness of alternative strategies for the initial medical management of non-ST elevation acute coronary syndrome: systematic review and decision-analytical modelling.

By Robinson M, Palmer S, Sculpher M, Philips Z, Ginnelly L, Bowens A, et al.

\section{No. 28}

Outcomes of electrically stimulated gracilis neosphincter surgery.

By Tillin T, Chambers M, Feldman R.

\section{No. 29}

The effectiveness and cost-effectiveness of pimecrolimus and tacrolimus for atopic eczema: a systematic review and economic evaluation.

By Garside R, Stein K, Castelnuovo E, Pitt M, Ashcroft D, Dimmock P, et al.

\section{No. 30}

Systematic review on urine albumin testing for early detection of diabetic complications.

By Newman DJ, Mattock MB Dawnay ABS, Kerry S, McGuire A, Yaqoob M, et al.

No. 31

Randomised controlled trial of the costeffectiveness of water-based therapy for lower limb osteoarthritis.

By Cochrane T, Davey RC Matthes Edwards SM.

\section{No. 32}

Longer term clinical and economic benefits of offering acupuncture care to patients with chronic low back pain.

By Thomas KJ, MacPherson

H, Ratcliffe J, Thorpe L, Brazier J, Campbell M, et al.

\section{No. 33}

Cost-effectiveness and safety of epidural steroids in the management of sciatica.

By Price C, Arden N, Coglan L, Rogers P.

\section{No. 34}

The British Rheumatoid Outcome Study Group (BROSG) randomised controlled trial to compare the effectiveness and cost-effectiveness of aggressive versus symptomatic therapy in established rheumatoid arthritis.

By Symmons D, Tricker K, Roberts C, Davies L, Dawes P, Scott DL.

\section{No. 35}

Conceptual framework and systematic review of the effects of participants' and professionals' preferences in randomised controlled trials.

By King M, Nazareth I, Lampe F, Bower P, Chandler M, Morou M, et al.

\section{No. 36}

The clinical and cost-effectiveness of implantable cardioverter defibrillators: a systematic review.

By Bryant J, Brodin H, Loveman E, Payne E, Clegg A

\section{No. 37}

A trial of problem-solving by community mental health nurses for anxiety, depression and life difficulties among general practice patients. The CPN-GP study.

By Kendrick T, Simons L, Mynors-Wallis L, Gray A, Lathlean J, Pickering $\mathrm{R}$, et al.

\section{No. 38}

The causes and effects of sociodemographic exclusions from clinical trials.

By Bartlett C, Doyal L, Ebrahim S, Davey P, Bachmann M, Egger M, et al.

No. 39

Is hydrotherapy cost-effective? A randomised controlled trial of combined hydrotherapy programmes compared with physiotherapy land techniques in children with juvenile idiopathic arthritis.

By Epps H, Ginnelly L, Utley M, Southwood T, Gallivan S, Sculpher M, et al.

\section{No. 40}

A randomised controlled trial and cost-effectiveness study of systematic screening (targeted and total population screening) versus routine practice for the detection of atrial fibrillation in people aged 65 and over. The SAFE study.

By Hobbs FDR, Fitzmaurice DA, Mant J, Murray E, Jowett S, Bryan S, et al.

\section{No. 41}

Displaced intracapsular hip fractures in fit, older people: a randomised comparison of reduction and fixation, bipolar hemiarthroplasty and total hip arthroplasty.

By Keating JF, Grant A, Masson M, Scott NW, Forbes JF.

No. 42

Long-term outcome of cognitive behaviour therapy clinical trials in central Scotland.

By Durham RC, Chambers JA, Power KG, Sharp DM, Macdonald RR, Major KA, et al.

\section{No. 43}

The effectiveness and cost-effectiveness of dual-chamber pacemakers compared with single-chamber pacemakers for bradycardia due to atrioventricular block or sick sinus syndrome: systematic review and economic evaluation.

By Castelnuovo E, Stein K, Pitt M, Garside R, Payne E.

\section{No. 44}

Newborn screening for congenital heart defects: a systematic review and costeffectiveness analysis.

By Knowles R, Griebsch I, Dezateux C, Brown J, Bull C, Wren C.

No. 45

The clinical and cost-effectiveness of left ventricular assist devices for endstage heart failure: a systematic review and economic evaluation.

By Clegg AJ, Scott DA, Loveman E, Colquitt J, Hutchinson J, Royle P, et al.

No. 46

The effectiveness of the Heidelberg Retina Tomograph and laser diagnostic glaucoma scanning system (GDx) in detecting and monitoring glaucoma.

By Kwartz AJ, Henson DB, Harper RA, Spencer AF, McLeod D.

\section{No. 47}

Clinical and cost-effectiveness of autologous chondrocyte implantation for cartilage defects in knee joints: systematic review and economic evaluation.

By Clar C, Cummins E, McIntyre L, Thomas S, Lamb J, Bain L, et al. 


\section{No. 48}

Systematic review of effectiveness of different treatments for childhood retinoblastoma.

By McDaid C, Hartley S, Bagnall A-M, Ritchie G, Light K, Riemsma R.

\section{No. 49}

Towards evidence-based guidelines for the prevention of venous thromboembolism: systematic reviews of mechanical methods, oral anticoagulation, dextran and regional anaesthesia as thromboprophylaxis.

By Roderick P, Ferris G, Wilson K, Halls H, Jackson D, Collins R, et al.

\section{No. 50}

The effectiveness and cost-effectiveness of parent training/education programmes for the treatment of conduct disorder, including oppositional defiant disorder, in children.

By Dretzke J, Frew E, Davenport C, Barlow J, Stewart-Brown S, Sandercock J, et al.

\section{Volume 10, 2006}

No. 1

The clinical and cost-effectiveness of donepezil, rivastigmine, galantamine and memantine for Alzheimer's disease.

By Loveman E, Green C, Kirby J, Takeda A, Picot J, Payne E, et al.

\section{No. 2}

FOOD: a multicentre randomised trial evaluating feeding policies in patients admitted to hospital with a recent stroke.

By Dennis M, Lewis S, Cranswick G, Forbes J.

No. 3

The clinical effectiveness and costeffectiveness of computed tomography screening for lung cancer: systematic reviews.

By Black C, Bagust A, Boland A, Walker S, McLeod C, De Verteuil R, et al.

No. 4

A systematic review of the effectiveness and cost-effectiveness of neuroimaging assessments used to visualise the seizure focus in people with refractory epilepsy being considered for surgery.

By Whiting P, Gupta R, Burch J, Mujica Mota RE, Wright K, Marson A, et al.

No. 5

Comparison of conference abstracts and presentations with full-text articles in the health technology assessments of rapidly evolving technologies.

By Dundar Y, Dodd S, Dickson R,

\section{No. 6}

Systematic review and evaluation of methods of assessing urinary incontinence.

By Martin JL, Williams KS, Abrams KR, Turner DA, Sutton AJ, Chapple C, et al.

No. 7

The clinical effectiveness and costeffectiveness of newer drugs for children with epilepsy. A systematic review.

By Connock M, Frew E, Evans B-W, Bryan S, Cummins C, Fry-Smith A, et al.

No. 8

Surveillance of Barrett's oesophagus: exploring the uncertainty through systematic review, expert workshop and economic modelling.

By Garside R, Pitt M, Somerville M, Stein K, Price A, Gilbert N.

\section{No. 9}

Topotecan, pegylated liposomal doxorubicin hydrochloride and paclitaxel for second-line or subsequent treatment of advanced ovarian cancer: a systematic review and economic evaluation.

By Main C, Bojke L, Griffin S, Norman G, Barbieri M, Mather L, et al.

\section{No. 10}

Evaluation of molecular techniques in prediction and diagnosis of cytomegalovirus disease in immunocompromised patients.

By Szczepura A, Westmoreland D, Vinogradova Y, Fox J, Clark M.

\section{No. 11}

Screening for thrombophilia in highrisk situations: systematic review and cost-effectiveness analysis. The Thrombosis: Risk and Economic Assessment of Thrombophilia Screening (TREATS) study. By Wu O, Robertson L, Twaddle S, Lowe GDO, Clark P, Greaves M, et al.

No. 12

A series of systematic reviews to inform a decision analysis for sampling and treating infected diabetic foot ulcers. By Nelson EA, O'Meara S, Craig D, Iglesias C, Golder S, Dalton J, et al.

\section{No. 13}

Randomised clinical trial, observational study and assessment of costeffectiveness of the treatment of varicose veins (REACTIV trial)

By Michaels JA, Campbell WB, Brazier JE, MacIntyre JB, Palfreyman SJ, Ratcliffe J, et al.

\section{No. 14}

The cost-effectiveness of screening for oral cancer in primary care.

By Speight PM, Palmer S, Moles DR, Downer MC, Smith DH, Henriksson M, et al.

\section{No. 15}

Measurement of the clinical and costeffectiveness of non-invasive diagnostic testing strategies for deep vein thrombosis.

By Goodacre S, Sampson F, Stevenson M, Wailoo A, Sutton A, Thomas $\mathrm{S}$, et al.

No. 16

Systematic review of the effectiveness and cost-effectiveness of HealOzone for the treatment of occlusal pit/fissure caries and root caries.

By Brazzelli M, McKenzie L, Fielding $\mathrm{S}$, Fraser C, Clarkson J, Kilonzo M, et al.

No. 17

Randomised controlled trials of conventional antipsychotic versus new atypical drugs, and new atypical drugs versus clozapine, in people with schizophrenia responding poorly to, or intolerant of, current drug treatment.

By Lewis SW, Davies L, Jones PB, Barnes TRE, Murray RM, Kerwin R, et al.

\section{No. 18}

Diagnostic tests and algorithms used in the investigation of haematuria: systematic reviews and economic evaluation

By Rodgers M, Nixon J, Hempel S, Aho T, Kelly J, Neal D, et al.

No. 19

Cognitive behavioural therapy in addition to antispasmodic therapy for irritable bowel syndrome in primary care: randomised controlled trial.

By Kennedy TM, Chalder T, McCrone P, Darnley S, Knapp M, Jones RH, et al.

No. 20

A systematic review of the clinical effectiveness and costeffectiveness of enzyme replacement therapies for Fabry's disease and mucopolysaccharidosis type 1 .

By Connock M, Juarez-Garcia A, Frew E, Mans A, Dretzke J, Fry-Smith A, et al.

\section{No. 21}

Health benefits of antiviral therapy for mild chronic hepatitis $\mathrm{C}$ : randomised controlled trial and economic evaluation.

By Wright M, Grieve R, Roberts J, Main J, Thomas HC, on behalf of the UK Mild Hepatitis C Trial Investigators.

No. 22

Pressure relieving support surfaces: a randomised evaluation.

By Nixon J, Nelson EA, Cranny G, Iglesias CP, Hawkins K, Cullum NA, et al. 


\section{No. 23}

A systematic review and economic model of the effectiveness and costeffectiveness of methylphenidate, dexamfetamine and atomoxetine for the treatment of attention deficit hyperactivity disorder in children and adolescents.

By King S, Griffin S, Hodges Z, Weatherly H, Asseburg C, Richardson G, et al.

\section{No. 24}

The clinical effectiveness and costeffectiveness of enzyme replacement therapy for Gaucher's disease: a systematic review.

By Connock M, Burls A, Frew E, Fry-Smith A, Juarez-Garcia A, McCabe C, et al.

\section{No. 25}

Effectiveness and cost-effectiveness of salicylic acid and cryotherapy for cutaneous warts. An economic decision model.

By Thomas KS, Keogh-Brown MR, Chalmers JR, Fordham RJ, Holland RC, Armstrong SJ, et al.

\section{No. 26}

A systematic literature review of the effectiveness of non-pharmacological interventions to prevent wandering in dementia and evaluation of the ethical implications and acceptability of their use.

By Robinson L, Hutchings D, Corner L, Beyer F, Dickinson H, Vanoli A, et al.

\section{No. 27}

A review of the evidence on the effects and costs of implantable cardioverter defibrillator therapy in different patient groups, and modelling of costeffectiveness and cost-utility for these groups in a UK context.

By Buxton M, Caine N, Chase D, Connelly D, Grace A, Jackson C, et al.

\section{No. 28}

Adefovir dipivoxil and pegylated interferon alfa-2a for the treatment of chronic hepatitis B: a systematic review and economic evaluation.

By Shepherd J, Jones J, Takeda A, Davidson P, Price A.

No. 29

An evaluation of the clinical and costeffectiveness of pulmonary artery catheters in patient management in intensive care: a systematic review and a randomised controlled trial.

By Harvey S, Stevens K, Harrison D, Young D, Brampton W, McCabe C, et al.

\section{No. 30}

Accurate, practical and cost-effective assessment of carotid stenosis in the UK.

By Wardlaw JM, Chappell FM, Stevenson M, De Nigris E, Thomas S, Gillard J, et al.

\section{No. 31}

Etanercept and infliximab for the treatment of psoriatic arthritis: a systematic review and economic evaluation.

By Woolacott N, Bravo Vergel Y, Hawkins N, Kainth A, Khadjesari Z, Misso K, et al.

\section{No. 32}

The cost-effectiveness of testing for hepatitis $\mathrm{C}$ in former injecting drug users.

By Castelnuovo E, Thompson-Coon J, Pitt M, Cramp M, Siebert U, Price A, et al.

\section{No. 33}

Computerised cognitive behaviour therapy for depression and anxiety update: a systematic review and economic evaluation.

By Kaltenthaler E, Brazier J, De Nigris E, Tumur I, Ferriter M, Beverley C, et al.

No. 34

Cost-effectiveness of using prognostic information to select women with breast cancer for adjuvant systemic therapy.

By Williams C, Brunskill S, Altman D, Briggs A, Campbell H, Clarke M, et al.

\section{No. 35}

Psychological therapies including dialectical behaviour therapy for borderline personality disorder: a systematic review and preliminary economic evaluation.

By Brazier J, Tumur I, Holmes M, Ferriter M, Parry G, Dent-Brown K, et al.

\section{No. 36}

Clinical effectiveness and costeffectiveness of tests for the diagnosis and investigation of urinary tract infection in children: a systematic review and economic model.

By Whiting P, Westwood M, Bojke L, Palmer S, Richardson G, Cooper J, et al.

\section{No. 37}

Cognitive behavioural therapy in chronic fatigue syndrome: a randomised controlled trial of an outpatient group programme.

By O'Dowd H, Gladwell P, Rogers CA, Hollinghurst S, Gregory A.

\section{No. 38}

A comparison of the cost-effectiveness of five strategies for the prevention of nonsteroidal anti-inflammatory drug-induced gastrointestinal toxicity: a systematic review with economic modelling.

By Brown TJ, Hooper L, Elliott RA, Payne K, Webb R, Roberts C, et al

\section{No. 39}

The effectiveness and cost-effectiveness of computed tomography screening for coronary artery disease: systematic review.

By Waugh N, Black C, Walker S, McIntyre L, Cummins E, Hillis G.

\section{No. 40}

What are the clinical outcome and costeffectiveness of endoscopy undertaken by nurses when compared with doctors? A Multi-Institution Nurse Endoscopy Trial (MINuET).

By Williams J, Russell I, Durai D, Cheung W-Y, Farrin A, Bloor K, et al.

\section{No. 41}

The clinical and cost-effectiveness of oxaliplatin and capecitabine for the adjuvant treatment of colon cancer: systematic review and economic evaluation.

By Pandor A, Eggington S, Paisley S, Tappenden P, Sutcliffe P.

No. 42

A systematic review of the effectiveness of adalimumab, etanercept and infliximab for the treatment of rheumatoid arthritis in adults and an economic evaluation of their costeffectiveness.

By Chen Y-F, Jobanputra P, Barton P, Jowett S, Bryan S, Clark W, et al.

No. 43

Telemedicine in dermatology: a randomised controlled trial.

By Bowns IR, Collins K, Walters SJ, McDonagh AJG.

\section{No. 44}

Cost-effectiveness of cell salvage and alternative methods of minimising perioperative allogeneic blood transfusion: a systematic review and economic model.

By Davies L, Brown TJ, Haynes S, Payne K, Elliott RA, McCollum C.

\section{No. 45}

Clinical effectiveness and costeffectiveness of laparoscopic surgery for colorectal cancer: systematic reviews and economic evaluation.

By Murray A, Lourenco T, de Verteuil R, Hernandez R, Fraser C, McKinley A, et al.

\section{No. 46}

Etanercept and efalizumab for the treatment of psoriasis: a systematic review.

By Woolacott N, Hawkins N, Mason A, Kainth A, Khadjesari Z, Bravo Vergel Y, et al.

\section{No. 47}

Systematic reviews of clinical decision tools for acute abdominal pain.

By Liu JLY, Wyatt JC, Deeks JJ, Clamp S, Keen J, Verde P, et al.

\section{No. 48}

Evaluation of the ventricular assist device programme in the UK.

By Sharples L, Buxton M, Caine N, Cafferty F, Demiris N, Dyer M, et al. 


\section{No. 49}

A systematic review and economic model of the clinical and costeffectiveness of immunosuppressive therapy for renal transplantation in children.

By Yao G, Albon E, Adi Y, Milford D, Bayliss S, Ready A, et al.

\section{No. 50}

Amniocentesis results: investigation of anxiety. The ARIA trial.

By Hewison J, Nixon J, Fountain J, Cocks K, Jones C, Mason G, et al.

\section{Volume I I, 2007}

\section{No. 1}

Pemetrexed disodium for the treatment of malignant pleural mesothelioma: a systematic review and economic evaluation.

By Dundar Y, Bagust A, Dickson R, Dodd S, Green J, Haycox A, et al.

\section{No. 2}

A systematic review and economic model of the clinical effectiveness and cost-effectiveness of docetaxel in combination with prednisone or prednisolone for the treatment of hormone-refractory metastatic prostate cancer.

By Collins R, Fenwick E, Trowman R, Perard R, Norman G, Light K, et al.

No. 3

A systematic review of rapid diagnostic tests for the detection of tuberculosis infection.

By Dinnes J, Deeks J, Kunst H, Gibson A, Cummins E, Waugh N, et al.

\section{No. 4}

The clinical effectiveness and costeffectiveness of strontium ranelate for the prevention of osteoporotic fragility fractures in postmenopausal women.

By Stevenson M, Davis S, Lloyd-Jones M, Beverley C.

\section{No. 5}

A systematic review of quantitative and qualitative research on the role and effectiveness of written information available to patients about individual medicines.

By Raynor DK, Blenkinsopp A, Knapp P, Grime J, Nicolson DJ, Pollock K, et al.

No. 6

Oral naltrexone as a treatment for relapse prevention in formerly opioiddependent drug users: a systematic review and economic evaluation.

By Adi Y, Juarez-Garcia A, Wang D,
No. 7

Glucocorticoid-induced osteoporosis: a systematic review and cost-utility analysis.

By Kanis JA, Stevenson M, McCloskey EV, Davis S, Lloyd-Jones M.

No. 8

Epidemiological, social, diagnostic and economic evaluation of population screening for genital chlamydial infection.

By Low N, McCarthy A, Macleod J, Salisbury C, Campbell R, Roberts TE, et al.

\section{No. 9}

Methadone and buprenorphine for the management of opioid dependence: a systematic review and economic evaluation.

By Connock M, Juarez-Garcia A, Jowett S, Frew E, Liu Z, Taylor RJ, et al.

No. 10

Exercise Evaluation Randomised Trial (EXERT): a randomised trial comparing GP referral for leisure centre-based exercise, community-based walking and advice only.

By Isaacs AJ, Critchley JA, See Tai

S, Buckingham K, Westley D, Harridge SDR, et al.

No. 11

Interferon alfa (pegylated and nonpegylated) and ribavirin for the treatment of mild chronic hepatitis C: a systematic review and economic evaluation.

By Shepherd J, Jones J, Hartwell D, Davidson P, Price A, Waugh N.

\section{No. 12}

Systematic review and economic evaluation of bevacizumab and cetuximab for the treatment of metastatic colorectal cancer.

By Tappenden P, Jones R, Paisley S, Carroll C.

No. 13

A systematic review and economic evaluation of epoetin alfa, epoetin beta and darbepoetin alfa in anaemia associated with cancer, especially that attributable to cancer treatment.

By Wilson J, Yao GL, Raftery J, Bohlius J, Brunskill S, Sandercock J, et al.

\section{No. 14}

A systematic review and economic evaluation of statins for the prevention of coronary events.

By Ward S, Lloyd Jones M, Pandor A Holmes M, Ara R, Ryan A, et al.

\section{No. 15}

A systematic review of the effectiveness and cost-effectiveness of different models of community-based respite care for frail older people and their carers.

By Mason A, Weatherly H, Spilsbury $\mathrm{K}$, Arksey H, Golder S, Adamson J, et al.
No. 16

Additional therapy for young children with spastic cerebral palsy: a randomised controlled trial.

By Weindling AM, Cunningham CC, Glenn SM, Edwards RT, Reeves DJ.

No. 17

Screening for type 2 diabetes: literature review and economic modelling.

By Waugh N, Scotland G, McNamee P, Gillett M, Brennan A, Goyder E, et al.

No. 18

The effectiveness and cost-effectiveness of cinacalcet for secondary

hyperparathyroidism in end-stage renal disease patients on dialysis: a systematic review and economic evaluation.

By Garside R, Pitt M, Anderson R, Mealing S, Roome C, Snaith A, et al.

No. 19

The clinical effectiveness and costeffectiveness of gemcitabine for metastatic breast cancer: a systematic review and economic evaluation.

By Takeda AL, Jones J, Loveman E, Tan SC, Clegg AJ.

\section{No. 20}

A systematic review of duplex ultrasound, magnetic resonance angiography and computed tomography angiography for the diagnosis and assessment of symptomatic, lower limb peripheral arterial disease.

By Collins R, Cranny G, Burch J, Aguiar-Ibáñez R, Craig D, Wright K, et al.

No. 21

The clinical effectiveness and costeffectiveness of treatments for children with idiopathic steroid-resistant nephrotic syndrome: a systematic review.

By Colquitt JL, Kirby J, Green C, Cooper K, Trompeter RS.

No. 22

A systematic review of the routine monitoring of growth in children of primary school age to identify growthrelated conditions.

By Fayter D, Nixon J, Hartley S, Rithalia A, Butler G, Rudolf M, et al.

\section{No. 23}

Systematic review of the effectiveness of preventing and treating Staphylococcus aureus carriage in reducing peritoneal catheter-related infections.

By McCormack K, Rabindranath K, Kilonzo M, Vale L, Fraser C, McIntyre L, et al. 


\section{No. 24}

The clinical effectiveness and cost of repetitive transcranial magnetic stimulation versus electroconvulsive therapy in severe depression: a multicentre pragmatic randomised controlled trial and economic analysis.

By McLoughlin DM, Mogg A, Eranti S, Pluck G, Purvis R, Edwards D, et al.

\section{No. 25}

A randomised controlled trial and economic evaluation of direct versus indirect and individual versus group modes of speech and language therapy for children with primary language impairment.

By Boyle J, McCartney E, Forbes J, O'Hare A.

\section{No. 26}

Hormonal therapies for early breast cancer: systematic review and economic evaluation.

By Hind D, Ward S, De Nigris E, Simpson E, Carroll C, Wyld L.

\section{No. 27}

Cardioprotection against the toxic effects of anthracyclines given to children with cancer: a systematic review.

By Bryant J, Picot J, Levitt G, Sullivan I, Baxter L, Clegg A.

\section{No. 28}

Adalimumab, etanercept and infliximab for the treatment of ankylosing spondylitis: a systematic review and economic evaluation.

By McLeod C, Bagust A, Boland A, Dagenais P, Dickson R, Dundar Y, et al.

\section{No. 29}

Prenatal screening and treatment strategies to prevent group B streptococcal and other bacterial infections in early infancy: costeffectiveness and expected value of information analyses.

By Colbourn T, Asseburg C, Bojke L, Philips Z, Claxton K, Ades AE, et al.

\section{No. 30}

Clinical effectiveness and costeffectiveness of bone morphogenetic proteins in the non-healing of fractures and spinal fusion: a systematic review.

By Garrison KR, Donell S, Ryder J, Shemilt I, Mugford M, Harvey I, et al.

\section{No. 31}

A randomised controlled trial of postoperative radiotherapy following breast-conserving surgery in a minimum-risk older population. The PRIME trial.

By Prescott RJ, Kunkler IH, Williams LJ, King CC, Jack W, van der Pol M, et al.

\section{No. 32}

Current practice, accuracy, effectiveness and cost-effectiveness of the school entry hearing screen.

By Bamford J, Fortnum H, Bristow K, Smith J, Vamvakas G, Davies L, et al.

\section{No. 33}

The clinical effectiveness and costeffectiveness of inhaled insulin in diabetes mellitus: a systematic review and economic evaluation.

By Black C, Cummins E, Royle P, Philip S, Waugh N.

\section{No. 34}

Surveillance of cirrhosis for hepatocellular carcinoma: systematic review and economic analysis.

By Thompson Coon J, Rogers G, Hewson P, Wright D, Anderson R, Cramp M, et al.

\section{No. 35}

The Birmingham Rehabilitation Uptake Maximisation Study (BRUM). Homebased compared with hospitalbased cardiac rehabilitation in a multiethnic population: cost-effectiveness and patient adherence.

By Jolly K, Taylor R, Lip GYH, Greenfield S, Raftery J, Mant J, et al.

\section{No. 36}

A systematic review of the clinical, public health and cost-effectiveness of rapid diagnostic tests for the detection and identification of bacterial intestinal pathogens in faeces and food.

By Abubakar I, Irvine L, Aldus CF, Wyatt GM, Fordham R, Schelenz S, et al.

\section{No. 37}

A randomised controlled trial examining the longer-term outcomes of standard versus new antiepileptic drugs. The SANAD trial.

By Marson AG, Appleton R, Baker GA, Chadwick DW, Doughty J, Eaton B, et al.

\section{No. 38}

Clinical effectiveness and cost-

effectiveness of different models of managing long-term oral anticoagulation therapy: a systematic review and economic modelling.

By Connock M, Stevens C, Fry-Smith A, Jowett S, Fitzmaurice D, Moore D, et al.

\section{No. 39}

A systematic review and economic model of the clinical effectiveness and cost-effectiveness of interventions for preventing relapse in people with bipolar disorder.

By Soares-Weiser K, Bravo Vergel Y, Beynon S, Dunn G, Barbieri M, Duffy S, et al.

\section{No. 40}

Taxanes for the adjuvant treatment of early breast cancer: systematic review and economic evaluation.

By Ward S, Simpson E, Davis S, Hind D, Rees A, Wilkinson A.

No. 41

The clinical effectiveness and costeffectiveness of screening for open angle glaucoma: a systematic review and economic evaluation.

By Burr JM, Mowatt G, Hernández R, Siddiqui MAR, Cook J, Lourenco T, et al.

\section{No. 42}

Acceptability, benefit and costs of early screening for hearing disability: a study of potential screening tests and models.

By Davis A, Smith P, Ferguson M, Stephens D, Gianopoulos I.

\section{No. 43}

Contamination in trials of educational interventions

By Keogh-Brown MR, Bachmann MO, Shepstone L, Hewitt C, Howe A, Ramsay CR, et al.

\section{No. 44}

Overview of the clinical effectiveness of positron emission tomography imaging in selected cancers.

By Facey K, Bradbury I, Laking G, Payne E.

\section{No. 45}

The effectiveness and cost-effectiveness of carmustine implants and temozolomide for the treatment of newly diagnosed high-grade glioma: a systematic review and economic evaluation.

By Garside R, Pitt M, Anderson R, Rogers G, Dyer M, Mealing S, et al.

\section{No. 46}

Drug-eluting stents: a systematic review and economic evaluation.

By Hill RA, Boland A, Dickson R, Dündar Y, Haycox A, McLeod C, et al.

\section{No. 47}

The clinical effectiveness and cost-effectiveness of cardiac resynchronisation (biventricular pacing) for heart failure: systematic review and economic model.

By Fox M, Mealing S, Anderson R, Dean J, Stein K, Price A, et al.

\section{No. 48}

Recruitment to randomised trials: strategies for trial enrolment and participation study. The STEPS study.

By Campbell MK, Snowdon C, Francis D, Elbourne D, McDonald AM, Knight R, et al. 


\section{No. 49}

Cost-effectiveness of functional cardiac testing in the diagnosis and management of coronary artery disease: a randomised controlled trial. The CECaT trial.

By Sharples L, Hughes V, Crean A, Dyer M, Buxton M, Goldsmith K, et al.

\section{No. 50}

Evaluation of diagnostic tests when there is no gold standard. A review of methods.

By Rutjes AWS, Reitsma

JB, Coomarasamy A, Khan KS, Bossuyt PMM.

\section{No. 51}

Systematic reviews of the clinical effectiveness and cost-effectiveness of proton pump inhibitors in acute upper gastrointestinal bleeding.

By Leontiadis GI, Sreedharan A, Dorward S, Barton P, Delaney B, Howden CW, et al.

\section{No. 52}

A review and critique of modelling in prioritising and designing screening programmes.

By Karnon J, Goyder E, Tappenden P, McPhie S, Towers I, Brazier J, et al.

\section{No. 53}

An assessment of the impact of the NHS Health Technology Assessment Programme.

By Hanney S, Buxton M, Green C, Coulson D, Raftery J.

\section{Volume 12, 2008}

\section{No. 1}

A systematic review and economic model of switching from

nonglycopeptide to glycopeptide antibiotic prophylaxis for surgery.

By Cranny G, Elliott R, Weatherly H, Chambers D, Hawkins N, Myers L, et al.

\section{No. 2}

'Cut down to quit' with nicotine replacement therapies in smoking cessation: a systematic review of effectiveness and economic analysis.

By Wang D, Connock M, Barton P, Fry-Smith A, Aveyard P, Moore D.

\section{No. 3}

A systematic review of the effectiveness of strategies for reducing fracture risk in children with juvenile idiopathic arthritis with additional data on longterm risk of fracture and cost of disease management.

By Thornton J, Ashcroft D, O'Neill T,

\section{No. 4}

Does befriending by trained lay workers improve psychological well-being and quality of life for carers of people with dementia, and at what cost? A randomised controlled trial.

By Charlesworth G, Shepstone L, Wilson E, Thalanany M, Mugford M, Poland F.

\section{No. 5}

A multi-centre retrospective cohort study comparing the efficacy, safety and cost-effectiveness of hysterectomy and uterine artery embolisation for the treatment of symptomatic uterine fibroids. The HOPEFUL study.

By Hirst A, Dutton S, Wu O, Briggs A, Edwards C, Waldenmaier L, et al.

No. 6

Methods of prediction and prevention of pre-eclampsia: systematic reviews of accuracy and effectiveness literature with economic modelling.

By Meads CA, Cnossen JS, Meher S, Juarez-Garcia A, ter Riet G, Duley L, et al.

\section{No. 7}

The use of economic evaluations in NHS decision-making: a review and empirical investigation.

By Williams I, McIver S, Moore D, Bryan S.

\section{No. 8}

Stapled haemorrhoidectomy (haemorrhoidopexy) for the treatment of haemorrhoids: a systematic review and economic evaluation.

By Burch J, Epstein D, Baba-Akbari A, Weatherly H, Fox D, Golder S, et al.

No. 9

The clinical effectiveness of diabetes education models for Type 2 diabetes: a systematic review.

By Loveman E, Frampton GK, Clegg AJ.

\section{No. 10}

Payment to healthcare professionals for patient recruitment to trials: systematic review and qualitative study.

By Raftery J, Bryant J, Powell J, Kerr C, Hawker S.

\section{No. 11}

Cyclooxygenase-2 selective nonsteroidal anti-inflammatory drugs (etodolac, meloxicam, celecoxib, rofecoxib, etoricoxib, valdecoxib and lumiracoxib) for osteoarthritis and rheumatoid arthritis: a systematic review and economic evaluation.

By Chen Y-F, Jobanputra P, Barton P, Bryan S, Fry-Smith A, Harris G, et al.
No. 12

The clinical effectiveness and costeffectiveness of central venous catheters treated with anti-infective agents in preventing bloodstream infections: a systematic review and economic evaluation.

By Hockenhull JC, Dwan K, Boland A, Smith G, Bagust A, Dundar Y, et al.

No. 13

Stepped treatment of older adults on laxatives. The STOOL trial.

By Mihaylov S, Stark C, McColl E, Steen N, Vanoli A, Rubin G, et al.

No. 14

A randomised controlled trial of cognitive behaviour therapy in adolescents with major depression treated by selective serotonin reuptake inhibitors. The ADAPT trial.

By Goodyer IM, Dubicka B, Wilkinson P, Kelvin R, Roberts C, Byford S, et al.

No. 15

The use of irinotecan, oxaliplatin and raltitrexed for the treatment of advanced colorectal cancer: systematic review and economic evaluation.

By Hind D, Tappenden P, Tumur I, Eggington E, Sutcliffe P, Ryan A.

No. 16

Ranibizumab and pegaptanib for the treatment of age-related macular degeneration: a systematic review and economic evaluation.

By Colquitt JL, Jones J, Tan SC, Takeda A, Clegg AJ, Price A.

No. 17

Systematic review of the clinical effectiveness and cost-effectiveness of 64-slice or higher computed tomography angiography as an alternative to invasive coronary angiography in the investigation of coronary artery disease.

By Mowatt G, Cummins E, Waugh N, Walker S, Cook J, Jia X, et al.

No. 18

Structural neuroimaging in psychosis: a systematic review and economic evaluation.

By Albon E, Tsourapas A, Frew E, Davenport C, Oyebode F, Bayliss S, et al.

No. 19

Systematic review and economic analysis of the comparative effectiveness of different inhaled corticosteroids and their usage with long-acting beta ${ }_{2}$ agonists for the treatment of chronic asthma in adults and children aged 12 years and over.

By Shepherd J, Rogers G, Anderson R, Main C, Thompson-Coon J, Hartwell D, et al. 


\section{No. 20}

Systematic review and economic analysis of the comparative effectiveness of different inhaled corticosteroids and their usage with long-acting beta ${ }_{2}$ agonists for the treatment of chronic asthma in children under the age of 12 years.

By Main C, Shepherd J, Anderson R, Rogers G, Thompson-Coon J, Liu Z, et al.

\section{No. 21}

Ezetimibe for the treatment of hypercholesterolaemia: a systematic review and economic evaluation.

By Ara R, Tumur I, Pandor A, Duenas A, Williams R, Wilkinson A, et al.

No. 22

Topical or oral ibuprofen for chronic knee pain in older people. The TOIB study.

By Underwood M, Ashby D, Carnes D, Castelnuovo E, Cross P, Harding G, et al.

\section{No. 23}

A prospective randomised comparison of minor surgery in primary and secondary care. The MiSTIC trial.

By George S, Pockney P, Primrose J, Smith H, Little P, Kinley H, et al.

\section{No. 24}

A review and critical appraisal of measures of therapist-patient interactions in mental health settings.

By Cahill J, Barkham M, Hardy G, Gilbody S, Richards D, Bower P, et al.

\section{No. 25}

The clinical effectiveness and costeffectiveness of screening programmes for amblyopia and strabismus in children up to the age of $4-5$ years: a systematic review and economic evaluation.

By Carlton J, Karnon J, CzoskiMurray C, Smith KJ, Marr J.

\section{No. 26}

A systematic review of the clinical effectiveness and cost-effectiveness and economic modelling of minimal incision total hip replacement approaches in the management of arthritic disease of the hip.

By de Verteuil R, Imamura M, Zhu S, Glazener C, Fraser C, Munro N, et al.

\section{No. 27}

A preliminary model-based assessment of the cost-utility of a screening programme for early age-related macular degeneration.

By Karnon J, Czoski-Murray C, Smith K, Brand C, Chakravarthy U, Davis S, et al.

\section{No. 28}

Intravenous magnesium sulphate and sotalol for prevention of atrial fibrillation after coronary artery bypass surgery: a systematic review and economic evaluation.

By Shepherd J, Jones J, Frampton GK, Tanajewski L, Turner D, Price A.

\section{No. 29}

Absorbent products for urinary/faecal incontinence: a comparative evaluation of key product categories.

By Fader M, Cottenden A, Getliffe K, Gage H, Clarke-O’Neill S, Jamieson K, et al.

No. 30

A systematic review of repetitive functional task practice with modelling of resource use, costs and effectiveness.

By French B, Leathley M, Sutton C, McAdam J, Thomas L, Forster A, et al.

No. 31

The effectiveness and cost-effectivness of minimal access surgery amongst people with gastro-oesophageal reflux disease - a UK collaborative study. The REFLUX trial.

By Grant A, Wileman S, Ramsay C, Bojke L, Epstein D, Sculpher M, et al.

\section{No. 32}

Time to full publication of studies of anti-cancer medicines for breast cancer and the potential for publication bias: a short systematic review.

By Takeda A, Loveman E, Harris P, Hartwell D, Welch K.

\section{No. 33}

Performance of screening tests for child physical abuse in accident and emergency departments.

By Woodman J, Pitt M, Wentz R, Taylor B, Hodes D, Gilbert RE.

\section{No. 34}

Curative catheter ablation in atrial fibrillation and typical atrial flutter: systematic review and economic evaluation.

By Rodgers M, McKenna C, Palmer S, Chambers D, Van Hout S, Golder S, et al.

No. 35

Systematic review and economic modelling of effectiveness and cost utility of surgical treatments for men with benign prostatic enlargement.

By Lourenco T, Armstrong N, N'Dow J, Nabi G, Deverill M, Pickard R, et al.

\section{No. 36}

Immunoprophylaxis against respiratory syncytial virus (RSV) with palivizumab in children: a systematic review and economic evaluation.

By Wang D, Cummins C, Bayliss S, Sandercock J, Burls A.

\section{Volume 13, 2009}

No. 1

Deferasirox for the treatment of iron overload associated with regular blood transfusions (transfusional haemosiderosis) in patients suffering with chronic anaemia: a systematic review and economic evaluation.

By McLeod C, Fleeman N, Kirkham J, Bagust A, Boland A, Chu P, et al.

No. 2

Thrombophilia testing in people with venous thromboembolism: systematic review and cost-effectiveness analysis. By Simpson EL, Stevenson MD, Rawdin A, Papaioannou D.

No. 3

Surgical procedures and non-surgical devices for the management of nonapnoeic snoring: a systematic review of clinical effects and associated treatment costs.

By Main C, Liu Z, Welch K, Weiner G, Quentin Jones S, Stein K.

No. 4

Continuous positive airway pressure devices for the treatment of obstructive sleep apnoea-hypopnoea syndrome: a systematic review and economic analysis.

By McDaid C, Griffin S, Weatherly H, Durée K, van der Burgt M, van Hout $S$, Akers J, et al.

No. 5

Use of classical and novel biomarkers as prognostic risk factors for localised prostate cancer: a systematic review.

By Sutcliffe P, Hummel S, Simpson E, Young T, Rees A, Wilkinson A, et al.

No. 6

The harmful health effects of recreational ecstasy: a systematic review of observational evidence.

By Rogers G, Elston J, Garside R, Roome C, Taylor R, Younger P, et al.

No. 7

Systematic review of the clinical effectiveness and cost-effectiveness of oesophageal Doppler monitoring in critically ill and high-risk surgical patients.

By Mowatt G, Houston G, Hernández R, de Verteuil R, Fraser C, Cuthbertson $\mathrm{B}$, et al.

No. 8

The use of surrogate outcomes in model-based cost-effectiveness analyses: a survey of UK Health Technology Assessment reports

By Taylor RS, Elston J.

No. 9

Controlling Hypertension and

Hypotension Immediately Post Stroke (CHHIPS) - a randomised controlled trial.

By Potter J, Mistri A, Brodie F, Chernova J, Wilson E, Jagger C, et al. 


\section{No. 10}

Routine antenatal anti-D prophylaxis for RhD-negative women: a systematic review and economic evaluation.

By Pilgrim H, Lloyd-Jones M, Rees A.

\section{No. 11}

Amantadine, oseltamivir and zanamivir for the prophylaxis of influenza

(including a review of existing guidance no. 67): a systematic review and economic evaluation.

By Tappenden P, Jackson R, Cooper

K, Rees A, Simpson E, Read R, et al.
No. 12

Improving the evaluation of

therapeutic interventions in multiple sclerosis: the role of new psychometric methods.

By Hobart J, Cano S. 


\section{Health Technology Assessment Programme}

\author{
Director, \\ Professor Tom Walley, \\ Director, NIHR HTA \\ Programme, Professor of \\ Clinical Pharmacology, \\ University of Liverpoo
}

\author{
Deputy Director, \\ Professor Jon Nicholl, \\ Director, Medical Care Research \\ Unit, University of Sheffield
}

Members

\section{Chair,}

Professor Tom Walley,

Director, NIHR HTA

Programme, Professor of

Clinical Pharmacology,

University of Liverpool

\section{Deputy Chair,}

Professor Jon Nicholl,

Director, Medical Care Research

Unit, University of Sheffield

Dr Bob Coates,

Consultant Advisor, NCCHTA

\section{Prioritisation Strategy Group}

Dr Andrew Cook,

Consultant Advisor, NCCHTA

Dr Peter Davidson,

Director of Science Support,

NCCHTA

Professor Robin E Ferner,

Consultant Physician and Director, West Midlands Centre

for Adverse Drug Reactions,

City Hospital NHS Trust,

Birmingham
Professor Paul Glasziou, Professor of Evidence-Based

Medicine, University of Oxford

Dr Nick Hicks,

Director of NHS Support, NCCHTA

Dr Edmund Jessop,

Medical Adviser, National Specialist, National

Commissioning Group (NCG), Department of Health, London
Ms Lynn Kerridge, Chief Executive Officer, NETSCC and NCCHTA

Dr Ruairidh Milne,

Director of Strategy and Development, NETSCC

Ms Kay Pattison,

Section Head, NHS R\&D

Programme, Department of Health

Ms Pamela Young,

Specialist Programme Manager, NCCHTA

\section{HTA Commissioning Board}

\section{Members}

Programme Director,

Professor Tom Walley,

Director, NIHR HTA

Programme, Professor of

Clinical Pharmacology,

University of Liverpool

Chair,

Professor Jon Nicholl,

Director, Medical Care Research

Unit, University of Sheffield

\section{Deputy Chair,}

Dr Andrew Farmer,

Senior Lecturer in General

Practice, Department of

Primary Health Care,

University of Oxford

Professor Ann Ashburn, Professor of Rehabilitation and Head of Research, Southampton General Hospital
Professor Deborah Ashby, Professor of Medical Statistics, Queen Mary, University of London

Professor John Cairns, Professor of Health Economics, London School of Hygiene and Tropical Medicine

Professor Peter Croft Director of Primary Care Sciences Research Centre, Keele University

Professor Nicky Cullum, Director of Centre for EvidenceBased Nursing, University of York

Professor Jenny Donovan, Professor of Social Medicine, University of Bristol

Professor Steve Halligan, Professor of Gastrointestinal Radiology, University College Hospital, London
Professor Freddie Hamdy, Professor of Urology,

University of Sheffield

Professor Allan House, Professor of Liaison Psychiatry, University of Leeds

Dr Martin J Landray, Reader in Epidemiology, Honorary Consultant Physician, Clinical Trial Service Unit, University of Oxford

Professor Stuart Logan, Director of Health \& Social Care Research, The Peninsula Medical School, Universities of Exeter and Plymouth

Dr Rafael Perera, Lecturer in Medical Statisitics, Department of Primary Health Care, Univeristy of Oxford

Dr Morven Roberts,

Clinical Trials Manager,

Medical Research Council
Professor Ian Roberts, Professor of Epidemiology \& Public Health, London School of Hygiene and Tropical Medicine

Professor Mark Sculpher, Professor of Health Economics, University of York

Professor Helen Smith, Professor of Primary Care, University of Brighton

Professor Kate Thomas, Professor of Complementary \& Alternative Medicine Research, University of Leeds

Professor David John Torgerson,

Director of York Trials Unit, University of York

Professor Hywel Williams, Professor of DermatoEpidemiology, University of Nottingham

Observers

Ms Kay Pattison,

Section Head, NHS R\&D

Programmes, Research and

Development Directorate,

Department of Health 


\section{Diagnostic Technologies \& Screening Panel}

Members

\section{Chair,}

Professor Paul Glasziou,

Professor of Evidence-Based

Medicine, University of Oxford

\section{Deputy Chair,}

\section{Dr David Elliman,}

Consultant Paediatrician and

Honorary Senior Lecturer,

Great Ormond Street Hospital,

London

Professor Judith E Adams,

Consultant Radiologist,

Manchester Royal Infirmary,

Central Manchester \&

Manchester Children's

University Hospitals NHS

Trust, and Professor of

Diagnostic Radiology, Imaging

Science and Biomedical

Engineering, Cancer \&

Imaging Sciences, University of Manchester

Ms Jane Bates,

Consultant Ultrasound

Practitioner, Ultrasound

Department, Leeds Teaching

Hospital NHS Trust
Dr Stephanie Dancer,

Consultant Microbiologist,

Hairmyres Hospital, East

Kilbride

Professor Glyn Elwyn,

Primary Medical Care Research

Group, Swansea Clinical School,

University of Wales

Dr Ron Gray,

Consultant Clinical

Epidemiologist, Department

of Public Health, University of

Oxford

Professor Paul D Griffiths,

Professor of Radiology,

University of Sheffield

Dr Jennifer J Kurinczuk,

Consultant Clinical

Epidemiologist, National

Perinatal Epidemiology Unit,

Oxford

Dr Susanne M Ludgate,

Medical Director, Medicines \&

Healthcare Products Regulatory

Agency, London
Dr Anne Mackie,

Director of Programmes, UK

National Screening Committee

Dr Michael Millar

Consultant Senior Lecturer in

Microbiology, Barts and The

London NHS Trust, Royal

London Hospital

Mr Stephen Pilling,

Director, Centre for Outcomes,

Research \& Effectiveness,

Joint Director, National

Collaborating Centre for

Mental Health, University

College London

Mrs Una Rennard,

Service User Representative

Dr Phil Shackley,

Senior Lecturer in Health

Economics, School of

Population and Health

Sciences, University of

Newcastle upon Tyne
Dr W Stuart A Smellie,

Consultant in Chemical

Pathology, Bishop Auckland

General Hospital

Dr Nicholas Summerton, Consultant Clinical and Public Health Advisor, NICE

Ms Dawn Talbot, Service User Representative

Dr Graham Taylor, Scientific Advisor, Regional DNA Laboratory, St James' University Hospital, Leeds

Professor Lindsay Wilson Turnbull,

Scientific Director of the Centre for Magnetic Resonance Investigations and YCR Professor of Radiology, Hull Royal Infirmary

\section{Observers}

Dr Tim Elliott,

Team Leader, Cancer

Screening, Department of Health
Dr Catherine Moody,

Programme Manager

Neuroscience and Mental

Health Board
Dr Ursula Wells,

Principal Research Officer,

Department of Health

\section{Pharmaceuticals Panel}

Members

Chair,

Professor Robin Ferner,

Consultant Physician and

Director, West Midlands Centre

for Adverse Drug Reactions,

City Hospital NHS Trust,

Birmingham

Deputy Chair,

Professor Imti Choonara,

Professor in Child Health,

University of Nottingham

Mrs Nicola Carey,

Senior Research Fellow,

School of Health and Social

Care, The University of

Reading

Mr John Chapman,

Service User Representative

\section{Dr Peter Elton,}

Director of Public Health,

Bury Primary Care Trust

Dr Ben Goldacre,

Research Fellow, Division of

Psychological Medicine and

Psychiatry, King's College

London

Mrs Barbara Greggains,

Service User Representative

Dr Bill Gutteridge,

Medical Adviser, London

Strategic Health Authority

Dr Dyfrig Hughes,

Reader in Pharmacoeconomics and Deputy Director, Centre for Economics and Policy in

Health, IMSCaR, Bangor

University
Professor Jonathan Ledermann, Professor of Medical Oncology and Director of the Cancer Research UK and University College London Cancer Trials Centre

Dr Yoon K Loke,

Senior Lecturer in Clinical Pharmacology, University of East Anglia

Professor Femi Oyebode, Consultant Psychiatrist and Head of Department, University of Birmingham

Dr Andrew Prentice,

Senior Lecturer and Consultant Obstetrician and Gynaecologist,

The Rosie Hospital, University of Cambridge
Dr Martin Shelly,

General Practitioner, Leeds, and Associate Director, NHS Clinical Governance Support Team, Leicester

Dr Gillian Shepherd,

Director, Health and Clinica Excellence, Merck Serono Ltd

Mrs Katrina Simister,

Assistant Director New

Medicines, National Prescribing Centre, Liverpool

Mr David Symes,

Service User Representative

Dr Lesley Wise,

Unit Manager,

Pharmacoepidemiology

Research Unit, VRMM,

Medicines \& Healthcare

Products Regulatory Agency
Mr Simon Reeve,

Head of Clinical and Cost-

Effectiveness, Medicines,

Pharmacy and Industry Group,

Department of Health
Dr Ursula Wells,

Dr Heike Weber,

Programme Manager,

Medical Research Council

Principal Research Officer,

Department of Health

Programme, Department of 


\section{Therapeutic Procedures Panel}

Members

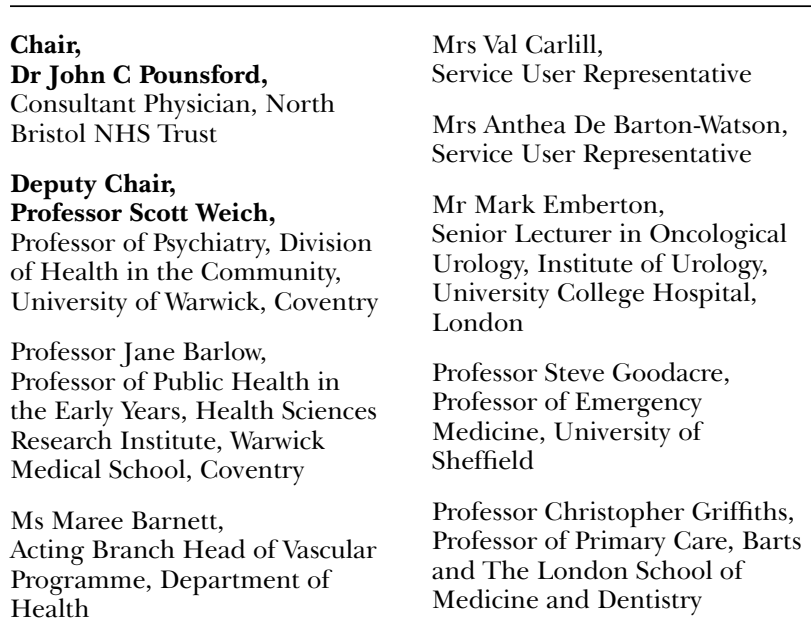

\author{
Mr Paul Hilton, \\ Consultant Gynaecologist \\ and Urogynaecologist, Royal \\ Victoria Infirmary, Newcastle \\ upon Tyne \\ Professor Nicholas James, \\ Professor of Clinical Oncology, \\ University of Birmingham, \\ and Consultant in Clinical \\ Oncology, Queen Elizabeth \\ Hospital \\ Dr Peter Martin, \\ Consultant Neurologist, \\ Addenbrooke's Hospital, \\ Cambridge
}

Dr Kate Radford,

Senior Lecturer (Research),

Clinical Practice Research

Unit, University of Central

Lancashire, Preston

Mr Jim Reece

Service User Representative

Dr Karen Roberts,

Nurse Consultant, Dunston Hill

Hospital Cottages

\section{Observers}

Dr Phillip Leech,

Principal Medical Officer for Primary Care, Department of Health

Ms Kay Pattison,

Section Head, NHS R\&D

Programme, Department of

Health
Dr Morven Roberts,

Clinical Trials Manager,

Medical Research Council
Professor Tom Walley, Director, NIHR HTA Programme, Professor of Clinical Pharmacology, University of Liverpool
Dr Ursula Wells,

Principal Research Officer, Department of Health

\section{Disease Prevention Panel}

Members

\section{Chair,}

Dr Edmund Jessop,

Medical Adviser, National

Specialist, National

Commissioning Group (NCG),

London

Deputy Chair,

Dr David Pencheon,

Director, NHS Sustainable

Development Unit, Cambridge

Dr Elizabeth Fellow-Smith,

Medical Director, West London

Mental Health Trust, Middlesex
Dr John Jackson,

General Practitioner, Parkway

Medical Centre, Newcastle upon Tyne

Professor Mike Kelly,

Director, Centre for Public

Health Excellence, NICE,

London

Dr Chris McCall,

General Practitioner, The

Hadleigh Practice, Corfe

Mullen, Dorset

Ms Jeanett Martin,

Director of Nursing, BarnDoc

Limited, Lewisham Primary

Care Trust
Dr Julie Mytton,

Locum Consultant in Public

Health Medicine, Bristol

Primary Care Trust

Miss Nicky Mullany,

Service User Representative

Professor Ian Roberts,

Professor of Epidemiology and Public Health, London

School of Hygiene \& Tropical

Medicine

Professor Ken Stein,

Senior Clinical Lecturer in

Public Health, University of

Exeter
Dr Kieran Sweeney,

Honorary Clinical Senior

Lecturer, Peninsula College of Medicine and Dentistry,

Universities of Exeter and

Plymouth

Professor Carol Tannahill, Glasgow Centre for Population Health

Professor Margaret Thorogood, Professor of Epidemiology, University of Warwick Medical

School, Coventry

\section{Observers}

Ms Christine McGuire, Research \& Development, Department of Health
Dr Caroline Stone,

Programme Manager, Medical

Research Council 


\section{Expert Advisory Network}

Members

Professor Douglas Altman, Professor of Statistics in Medicine, Centre for Statistics in Medicine, University of Oxford

Professor John Bond, Professor of Social Gerontology \& Health Services Research, University of Newcastle upon Tyne

Professor Andrew Bradbury, Professor of Vascular Surgery, Solihull Hospital, Birmingham

Mr Shaun Brogan, Chief Executive, Ridgeway Primary Care Group, Aylesbury

Mrs Stella Burnside OBE, Chief Executive, Regulation and Improvement Authority, Belfast

Ms Tracy Bury, Project Manager, World Confederation for Physical Therapy, London

Professor Iain T Cameron, Professor of Obstetrics and Gynaecology and Head of the School of Medicine, University of Southampton

Dr Christine Clark, Medical Writer and Consultant Pharmacist, Rossendale

Professor Collette Clifford, Professor of Nursing and Head of Research, The Medical School, University of Birmingham

Professor Barry Cookson, Director, Laboratory of Hospital Infection, Public Health Laboratory Service, London

Dr Carl Counsell,

Clinical Senior Lecturer in Neurology, University of Aberdeen

Professor Howard Cuckle, Professor of Reproductive Epidemiology, Department of Paediatrics, Obstetrics \& Gynaecology, University of Leeds

Dr Katherine Darton,

Information Unit, MIND - The Mental Health Charity, London

Professor Carol Dezateux, Professor of Paediatric

Epidemiology, Institute of Child Health, London

Mr John Dunning, Consultant Cardiothoracic Surgeon, Papworth Hospital NHS Trust, Cambridge
Mr Jonothan Earnshaw,

Consultant Vascular Surgeon,

Gloucestershire Royal Hospital, Gloucester

Professor Martin Eccles,

Professor of Clinical

Effectiveness, Centre for Health

Services Research, University of

Newcastle upon Tyne

Professor Pam Enderby,

Dean of Faculty of Medicine,

Institute of General Practice

and Primary Care, University of Sheffield

Professor Gene Feder,

Professor of Primary Care

Research \& Development,

Centre for Health Sciences,

Barts and The London School

of Medicine and Dentistry

Mr Leonard R Fenwick,

Chief Executive, Freeman

Hospital, Newcastle upon Tyne

Mrs Gillian Fletcher,

Antenatal Teacher and Tutor

and President, National

Childbirth Trust, Henfield

Professor Jayne Franklyn,

Professor of Medicine,

University of Birmingham

Mr Tam Fry,

Honorary Chairman, Child

Growth Foundation, London

Professor Fiona Gilbert,

Consultant Radiologist and

NCRN Member, University of Aberdeen

Professor Paul Gregg,

Professor of Orthopaedic

Surgical Science, South Tees

Hospital NHS Trust

Bec Hanley,

Co-director, TwoCan Associates,

West Sussex

Dr Maryann L Hardy,

Senior Lecturer, University of

Bradford

Mrs Sharon Hart,

Healthcare Management

Consultant, Reading

Professor Robert E Hawkins,

CRC Professor and Director

of Medical Oncology, Christie

CRC Research Centre,

Christie Hospital NHS Trust,

Manchester

Professor Richard Hobbs,

Head of Department of Primary

Care \& General Practice,

University of Birmingham
Professor Alan Horwich, Dean and Section Chairman, The Institute of Cancer

Research, London

Professor Allen Hutchinson, Director of Public Health and Deputy Dean of ScHARR,

University of Sheffield

Professor Peter Jones,

Professor of Psychiatry,

University of Cambridge,

Cambridge

Professor Stan Kaye,

Cancer Research UK Professor

of Medical Oncology, Royal

Marsden Hospital and Institute

of Cancer Research, Surrey

Dr Duncan Keeley,

General Practitioner (Dr Burch

\& Ptnrs), The Health Centre,

Thame

Dr Donna Lamping,

Research Degrees Programme

Director and Reader in

Psychology, Health Services

Research Unit, London School

of Hygiene and Tropical

Medicine, London

Mr George Levvy,

Chief Executive, Motor

Neurone Disease Association,

Northampton

Professor James Lindesay,

Professor of Psychiatry for the

Elderly, University of Leicester

Professor Julian Little,

Professor of Human Genome

Epidemiology, University of

Ottawa

Professor Alistaire McGuire,

Professor of Health Economics, London School of Economics

Professor Rajan Madhok,

Medical Director and Director of Public Health, Directorate

of Clinical Strategy \& Public

Health, North \& East Yorkshire

\& Northern Lincolnshire

Health Authority, York

Professor Alexander Markham, Director, Molecular Medicine

Unit, St James's University

Hospital, Leeds

Dr Peter Moore,

Freelance Science Writer,

Ashtead

Dr Andrew Mortimore,

Public Health Director

Southampton City Primary

Care Trust

Dr Sue Moss,

Associate Director, Cancer

Screening Evaluation Unit,

Institute of Cancer Research,

Sutton
Professor Miranda Mugford, Professor of Health Economics and Group Co-ordinator, University of East Anglia

Professor Jim Neilson,

Head of School of Reproductive \& Developmental Medicine and Professor of Obstetrics and Gynaecology, University of Liverpool

Mrs Julietta Patnick,

National Co-ordinator, NHS

Cancer Screening Programmes, Sheffield

Professor Robert Peveler, Professor of Liaison Psychiatry, Royal South Hants Hospital, Southampton

Professor Chris Price,

Director of Clinical Research,

Bayer Diagnostics Europe,

Stoke Poges

Professor William Rosenberg, Professor of Hepatology and Consultant Physician, University of Southampton

Professor Peter Sandercock, Professor of Medical Neurology, Department of Clinical

Neurosciences, University of Edinburgh

Dr Susan Schonfield, Consultant in Public Health, Hillingdon Primary Care Trust, Middlesex

Dr Eamonn Sheridan, Consultant in Clinical Genetics, St James's University Hospital, Leeds

Dr Margaret Somerville, Director of Public Health Learning, Peninsula Medical School, University of Plymouth

Professor Sarah Stewart-Brown, Professor of Public Health, Division of Health in the Community, University of Warwick, Coventry

Professor Ala Szczepura, Professor of Health Service Research, Centre for Health Services Studies, University of Warwick, Coventry

Mrs Joan Webster

Consumer Member, Southern

Derbyshire Community Health Council

Professor Martin Whittle, Clinical Co-director, National Co-ordinating Centre for Women's and Children's Health, Lymington 



\section{Feedback}

The HTA Programme and the authors would like to know your views about this report.

The Correspondence Page on the HTA website

(www.hta.ac.uk) is a convenient way to publish your comments. If you prefer, you can send your comments

to the address below, telling us whether you would like us to transfer them to the website.

\section{We look forward to hearing from you.}

The NIHR Coordinating Centre for Health Technology Assessment

Alpha House, Enterprise Road

Southampton Science Park

Chilworth

Southampton SOI6 7NS, UK

Email: hta@hta.ac.uk

www.hta.ac.uk 